\title{
Evaluation of Oxygen-Enrichment System for Alternative Fuel Vehicles
}

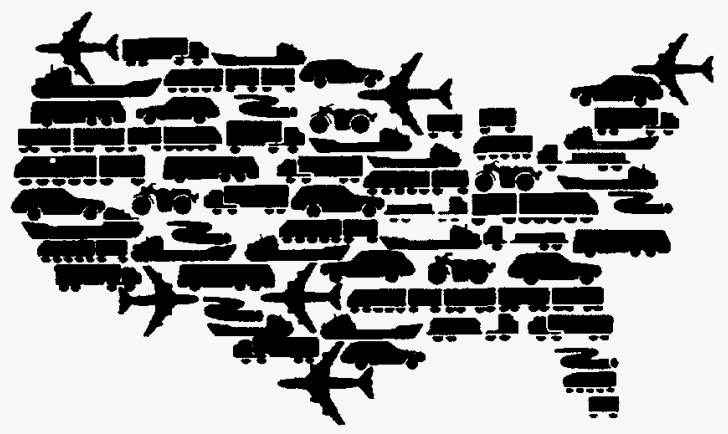

Center for Transportation Research Argonne National Laboratory

Operated by The University of Chicago, under Contract W-31-109-Eng-38, for the

United States Department of Energy 


\section{Argonne National Laboratory}

Argonne National Laboratory, with facilities in the states of Illinois and Idaho, is owned by the United States Government, and operated by the University of Chicago under the provisions of a contract with the Department of Energy

This technical memo is a product of Argonne's Energy Systems (ES) Division. For information on the division's scientific and engineering activities, contact:

Director, Energy Systems Division

Argonne National Laboratory

Argonne, Illinois 60439-4815

Telephone (708) 252-3724

Presented in this technical memo are preliminary results of ongoing work or work that is more limited in scope and depth than that described in formal reports issued by the ES Division.

Publishing support services were provided by Argonne's Information and Publishing Division (for more information, see IPD's home page: http://www.ipd.anl.gov/).

\section{Disclaimer}

This report was prepared as an account of work sponsored by an agency of the United States Government. Neither the United States Government nor any agency thereof, nor any of their employees, makes any warranty, express or implied, or assumes any legal liability or responsibility for the accuracy, completeness, or usefulness of any information, apparatus, product, or process disclosed, or represents that its use would not infringe privately owned rights. Reference herein to any specific commercial product, process, or service by trade name, trademark, manufacturer, or otherwise, does not necessarily constitute or imply its endorsement, recommendation, or favoring by the United States Government or any agency thereof. The views and opinions of authors expressed herein do not necessarily state or reflect those of the United States Government or any agency thereof. 


\section{Evaluation of Oxygen-Enrichment System for Alternative Fuel Vehicles}

by R.B. Poola, R.R. Sekar, and H.K. Ng

Center for Transportation Research, Energy Systems Division,

Argonne National Laboratory, 9700 South Cass Avenue, Argonne, Illinois 60439

December 1995

Work sponsored by United States Department of Energy,

Assistant Secretary for Energy Efficiency and Renewable Energy,

Office of Transportation Technologies, and National Renewable Energy Laboratory

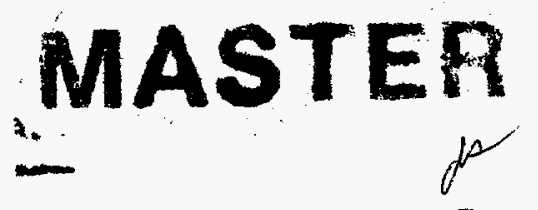




\section{DISCLAIMER}

Portions of this document may be illegible in electronic image products. Images are produced from the best available original document. 


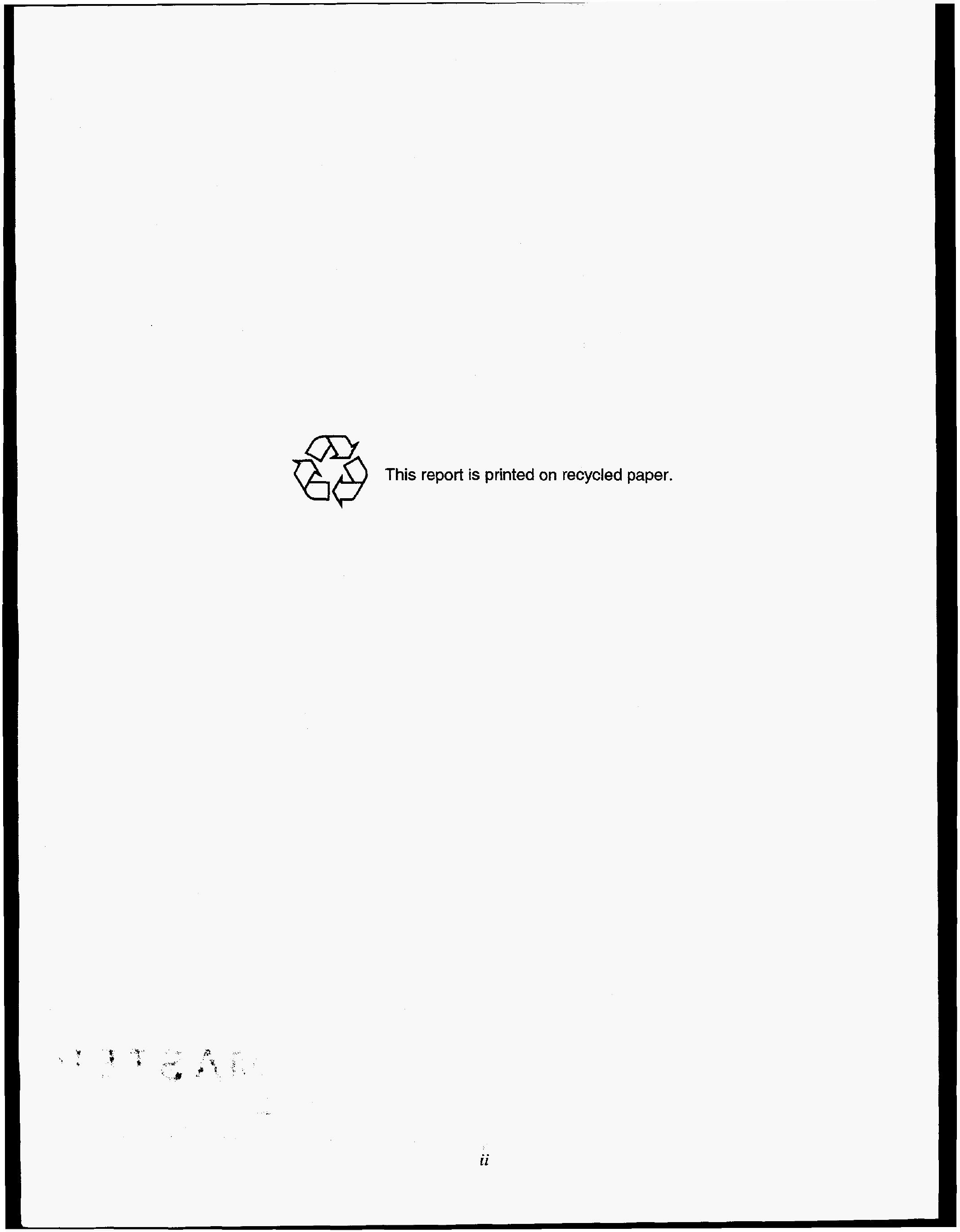




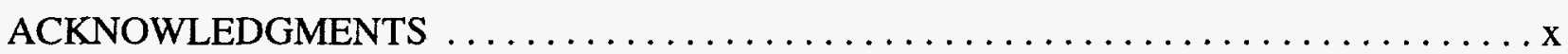

NOMENCLATURE $\ldots \ldots \ldots \ldots \ldots \ldots \ldots \ldots \ldots \ldots \ldots \ldots \ldots \ldots \ldots \ldots \ldots \ldots \ldots \ldots \ldots$

SUMMARY OF PRESENT WORK $\ldots \ldots \ldots \ldots \ldots \ldots \ldots \ldots \ldots \ldots \ldots \ldots \ldots \ldots \ldots \ldots \ldots \ldots \ldots \ldots$

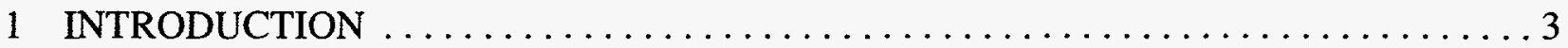

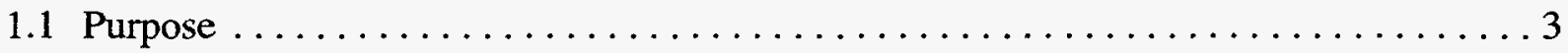

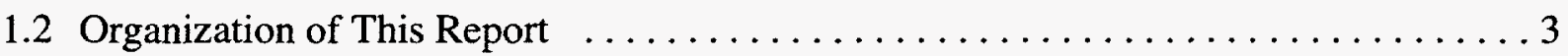

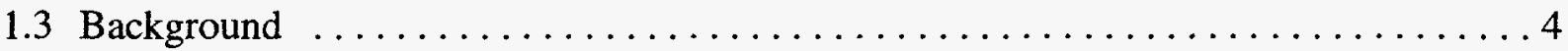

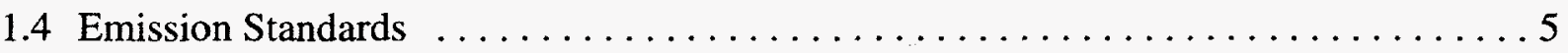

1.5 Cold-Phase Emission Reduction Technologies $\ldots \ldots \ldots \ldots \ldots \ldots \ldots \ldots \ldots$

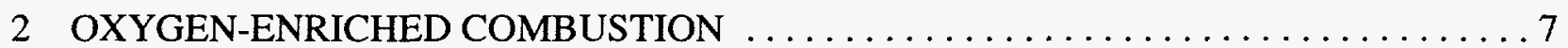

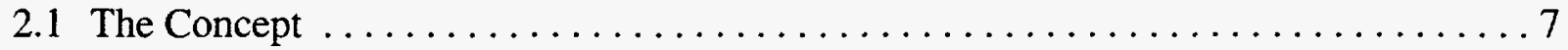

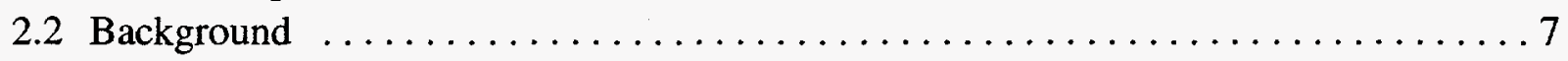

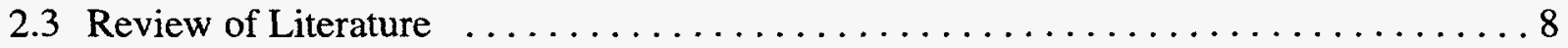

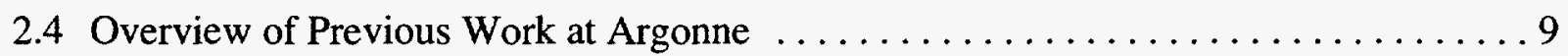

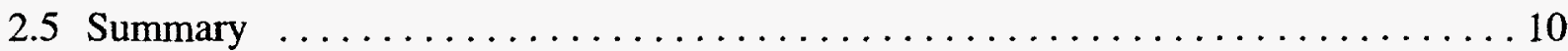

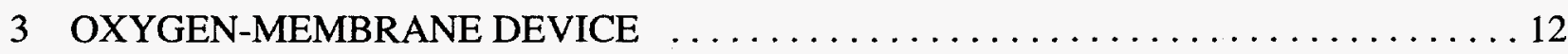

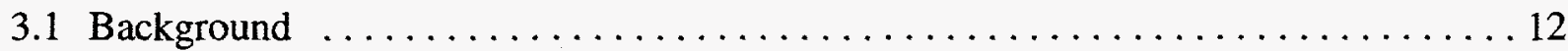

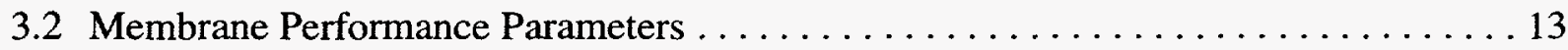

3.3 Membrane Cartridge Options ................................... 14

3.4 Operating Modes of Membrane Oxygen-Enriched Air Systems . . . . . . . . . . 14

3.5 Present Status of Membrane Module Development ................... 16

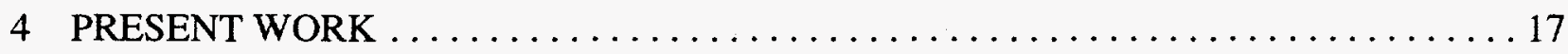

5 EXPERIMENTAL TEST SET-UP AND PROCEDURE $\ldots \ldots \ldots \ldots \ldots \ldots \ldots \ldots$

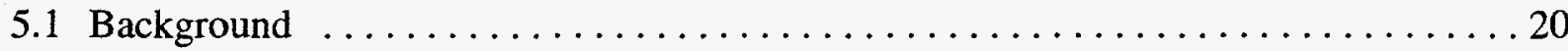

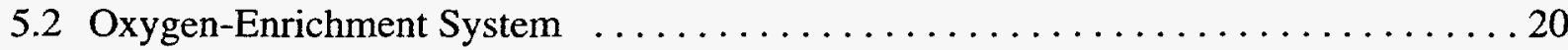

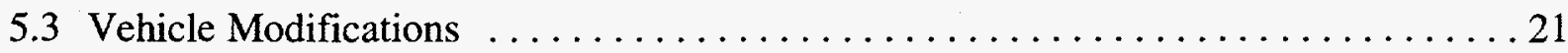

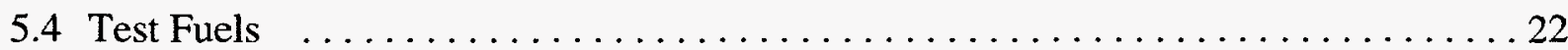

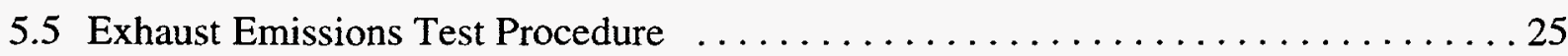




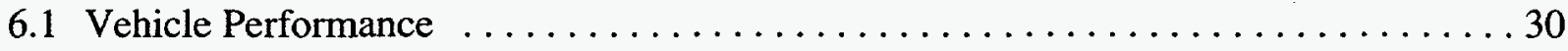

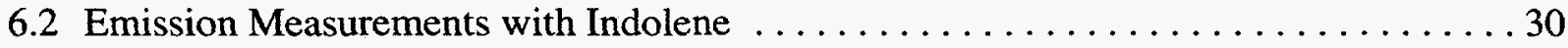

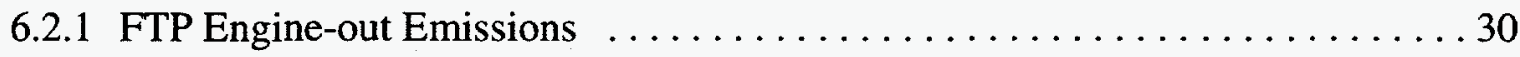

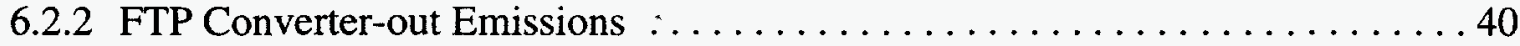

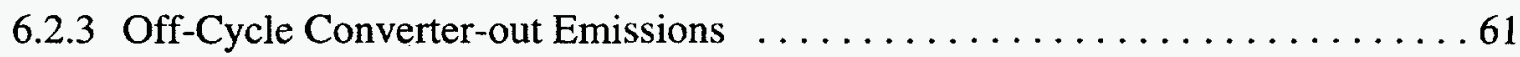

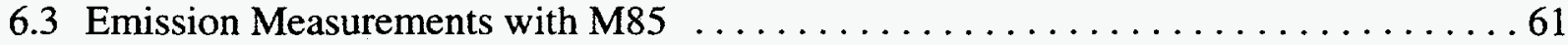

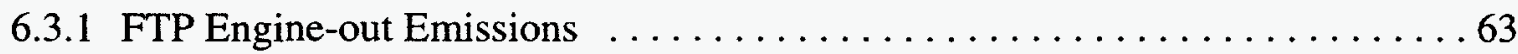

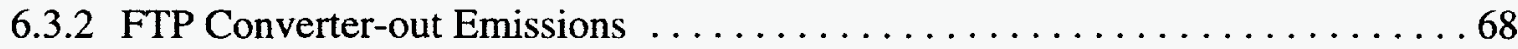

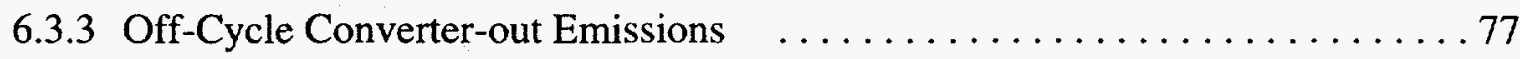

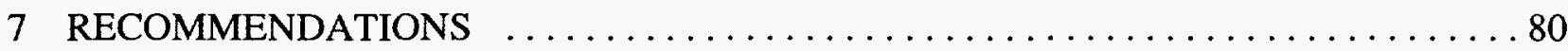

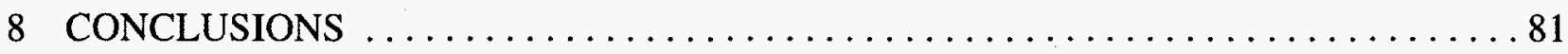

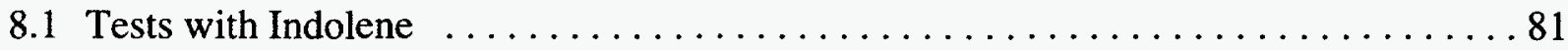

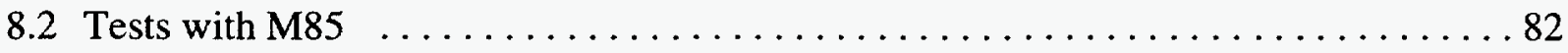

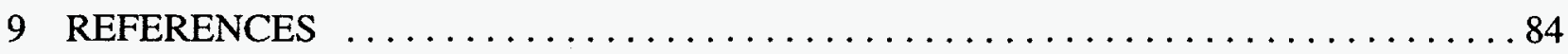

APPENDIX: EQUIPMENT AND DATA $\ldots \ldots \ldots \ldots \ldots \ldots \ldots \ldots \ldots \ldots \ldots \ldots$

\section{TABLES}

4.1 Test Matrix for Dodge Spirit Flexible-Fuel Vehicle $\ldots \ldots \ldots \ldots \ldots \ldots \ldots \ldots$

5.1 Specifications for Test Vehicle and Engine $\ldots \ldots \ldots \ldots \ldots \ldots \ldots \ldots \ldots \ldots$

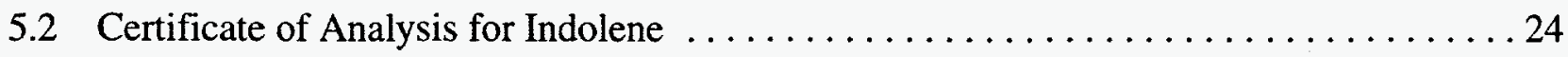

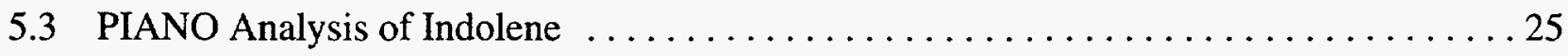




\section{TABLES (Cont.)}

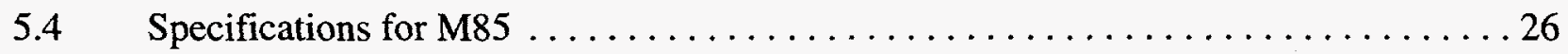

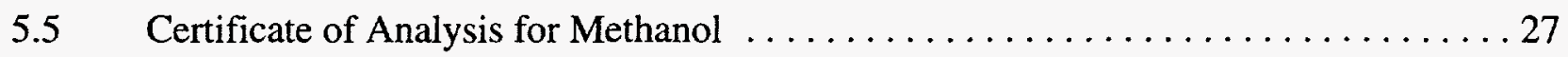

6.1 Converter-out Emissions at Various Levels of Oxygen Enrichment and

Different Emission Standards: FTP with Indolene $\ldots \ldots \ldots \ldots \ldots \ldots \ldots \ldots . \ldots 4$

6.2 Major Engine-out and Converter-out Ozone-Forming Potential of Hydrocarbons: Cold-Phase FTP with Indolene $\ldots \ldots \ldots \ldots \ldots \ldots \ldots \ldots \ldots$

6.3 Averaged Engine-out Hydrocarbon Emissions: FTP with M85 . . . . . . . . 67

6.4 Averaged Engine-out Ozone-Forming Potential and Specific Reactivity:

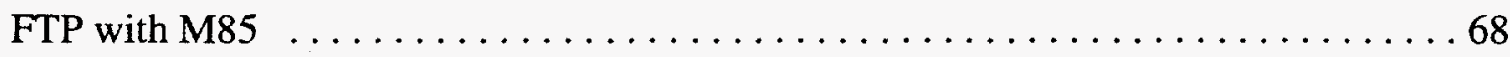

6.5 Averaged Converter-out Hydrocarbon Emissions: FTP with M85 … ........ 74

6.6 Averaged Converter-out Ozone-Forming Potential and Specific Reactivity:

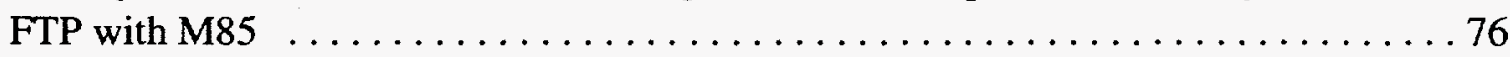

6.7 CARB Reactivity Adjustment Factors and Baseline Specific Reactivities for Different Emission and Clean Fuel Categories . . . . . . . . . . . . . . 77

6.8 Reactivity-Adjusted, Weighted-Average NMOG Emissions: FTP with M85 . . . . 78

A.1 Averaged Engine-out Emissions: FTP with Indolene $\ldots \ldots \ldots \ldots \ldots \ldots \ldots 2$

A.2 Averaged Engine-out Hydrocarbon Emissions: FTP with Indolene $\ldots \ldots \ldots \ldots . . .94$

A.3 Averaged Engine-out Ozone-Forming Potential and Specific Reactivity:

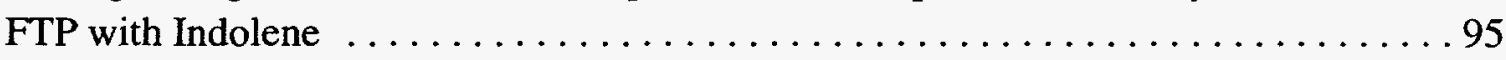

A.4 Converter-out Emissions: FTP with Indolene $\ldots \ldots \ldots \ldots \ldots \ldots \ldots \ldots \ldots$

A.5 Averaged Converter-out Emissions: FTP with Indolene $\ldots \ldots \ldots \ldots \ldots \ldots \ldots$

A.6 Averaged Converter-out Hydrocarbon Emissions: FTP with Indolene . . . . . . . . 99 


\section{TABLES (Cont.)}

A.7 Averaged Converter-out Ozone-Forming Potential and Specific Reactivity:

FTP with Indolene

A.8 Converter-out Emissions: Off-Cycle Test with Indolene $\ldots \ldots \ldots \ldots \ldots \ldots \ldots \ldots$

A.9 Averaged Converter-out Emissions: Off-Cycle Test with Indolene $\ldots \ldots \ldots \ldots \ldots 103$

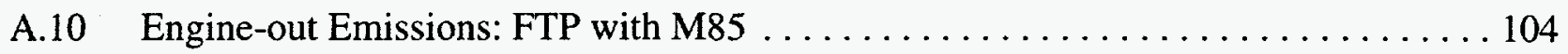

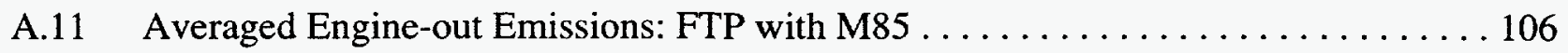

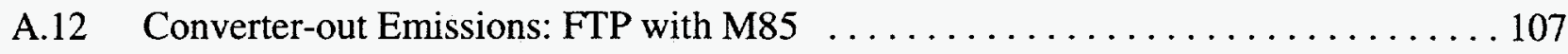

A.13 Averaged Converter-out Emissions: FTP with M85 . . . . . . . . . . . . . . . 109

A.14 Converter-out Emissions: Off-Cycle Test with M85 $\ldots \ldots \ldots \ldots \ldots \ldots \ldots \ldots \ldots$

A.15 Averaged Converter-out Emissions: Off-Cycle Test with M85 $\ldots \ldots \ldots \ldots \ldots 112$

\section{FIGURES}

2.1 Potential of Oxygen-Enriched Intake Air to Meet Year 2004 Standards . . . . . . . 10

2.2 Conceptual Scheme of Intake-Air Oxygen Enrichment

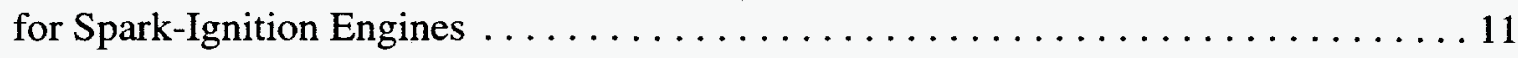

3.1 Exploded View of Typical Oxygen-Enriched Air Module $\ldots \ldots \ldots \ldots \ldots \ldots$

3.2 Simplified Flow Schematics of Vacuum and Pressurized Modes of Operation $\ldots \ldots 15$

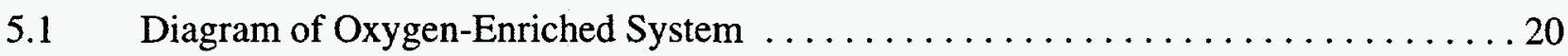

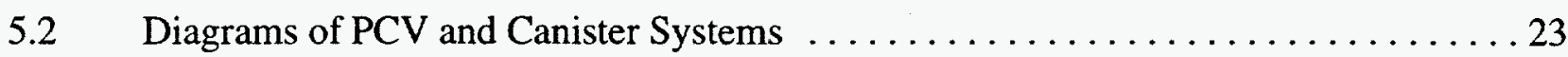

$5.3 \quad$ Federal Test Procedure FTP-75 $\ldots \ldots \ldots \ldots \ldots \ldots \ldots \ldots \ldots \ldots \ldots \ldots \ldots \ldots \ldots \ldots \ldots$

$5.4 \quad$ U.S. Environmental Protection Agency Off-Cycle Test REP05 $\ldots \ldots \ldots \ldots \ldots \ldots 28$ 


\section{FIGURES (Cont.)}

6.1 Engine-out $\mathrm{CO}, \mathrm{THC}$, and $\mathrm{NO}_{\mathrm{x}}$ Emissions: FTP with Indolene $\ldots \ldots \ldots \ldots$

$6.2 \quad$ Vehicle Speeds: First $127 \mathrm{~s}$ of the Cold-Phase FTP with Indolene $\ldots \ldots \ldots \ldots$

6.3 Engine-out, Time-Resolved $\mathrm{CO}, \mathrm{THC}$, and $\mathrm{NO}_{\mathrm{x}}$ Emissions: First $127 \mathrm{~s}$

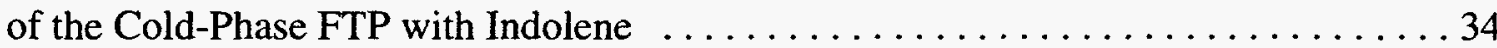

6.4 Effects of Oxygen-Enriched Intake Air on Engine-out Aldehyde Emissions:

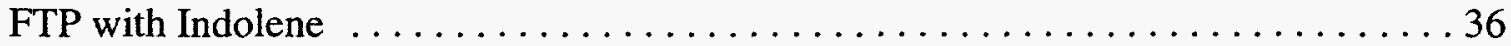

6.5 Effects of Oxygen-Enriched Intake Air on Engine-out Paraffin Emissions:

FTP with Indolene

6.6 Effects of Oxygen-Enriched Intake Air on Engine-out Olefin Emissions:

FTP with Indolene

6.7 Effects of Oxygen-Enriched Intake Air on Engine-out Aromatic Emissions:

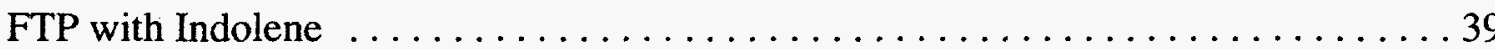

6.8 Effects of Oxygen-Enriched Intake Air on Engine-out Ozone-Forming

Potential: FTP with Indolene

6.9 Effects of Oxygen-Enriched Intake Air on Engine-out Specific Reactivity:

FTP with Indolene

6.10 Converter-out $\mathrm{CO}, \mathrm{THC}$, and $\mathrm{NO}_{x}$ Emissions: FTP with Indolene

6.11 Cumulative Engine-out and Converter-out Average THC and CO Emissions:

Cold-Phase FTP with Indolene

6.12 Converter-out, Time-Resolved $\mathrm{CO}$, THC, and $\mathrm{NO}_{\mathrm{x}}$ Emissions: First $127 \mathrm{~s}$

of the Cold-Phase FTP with Indolene

6.13 Potential Application Strategies for Oxygen-Enriched Intake Air to Meet

Tier II Standards

6.14 Potential Application Strategies for Oxygen-Enriched Intake Air to Meet TLEV Standards 


\section{FIGURES (Cont.)}

6.15 Effects of Oxygen-Enriched Intake Air on Converter-out Aldehyde Emissions:

FTP with Indolene

6.16 Effects of Oxygen-Enriched Intake Air on Converter-out Paraffin Emissions:

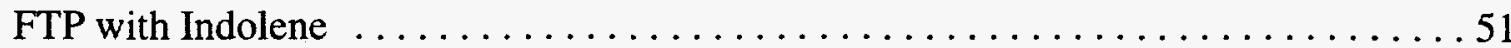

6.17 Effects of Oxygen-Enriched Intake Air on Converter-out Olefin Emissions:

FTP with Indolene

6.18 Effects of Oxygen-Enriched Intake Air on Converter-out Aromatic Emissions:

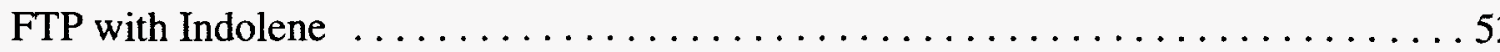

6.19 Effects of Oxygen-Enriched Intake Air on Converter-out Ozone-Forming

Potential: FTP with Indolene

6.20 Converter-out Hydrocarbon Speciation and Ozone-Forming Potential:

After First $127 \mathrm{~s}$ of the Cold-Phase FTP with Indolene

6.21 Engine-out $\mathrm{CO}, \mathrm{THC}$, and $\mathrm{NO}_{\mathrm{x}}$ Emissions of Dodge Spirit and Chevrolet

Lumina: FTP with Indolene

6.22 Converter-out CO, THC, and $\mathrm{NO}_{\mathrm{x}}$ Emissions of Dodge Spirit and Chevrolet

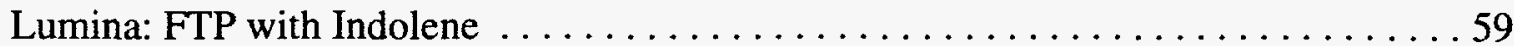

6.23 Percentage Variations in Converter-out $\mathrm{CO}, \mathrm{THC}$, and $\mathrm{NO}_{\mathrm{x}}$ Emissions between Dodge Spirit and Chevrolet Lumina: FTP with Indolene and 25\% Oxygen Enrichment

6.24 Converter-out $\mathrm{CO}, \mathrm{THC}$, and $\mathrm{NO}_{\mathrm{x}}$ Emissions: Off-Cycle Test with Indolene 62

6.25 Engine-out $\mathrm{CO}$, THC, and $\mathrm{NO}_{\mathrm{x}}$ Emissions: FTP with M85 64

6.26 Engine-out NMHC, NMOG, $\mathrm{HCHO}$, and $\mathrm{CH}_{3} \mathrm{OH}$ Emissions: FTP with M85 . . . . 65

6.27 Engine-out $\mathrm{CO}, \mathrm{THC}$, and $\mathrm{NO}_{\mathrm{x}}$ Emissions: First $127 \mathrm{~s}$ of the Cold-Phase FTP with M85

6.28 Converter-out CO, THC, and $\mathrm{NO}_{\mathrm{x}}$ Emissions: FTP with M85 


\section{FIGURES (Cont.)}

6.29 Converter-out NMHC, NMOG, $\mathrm{HCHO}$, and $\mathrm{CH}_{3} \mathrm{OH}$ Emissions:

FTP with M85

6.30 Converter-out, Time-Resolved $\mathrm{CO}$, $\mathrm{THC}$, and $\mathrm{NO}_{\mathrm{x}}$ Emissions:

First $127 \mathrm{~s}$ of the Cold-Phase FTP with M85

6.31 Converter-out $\mathrm{CO}, \mathrm{THC}$, and $\mathrm{NO}_{\mathrm{x}}$ Emissions: Off-Cycle Test with M85 ........ 79

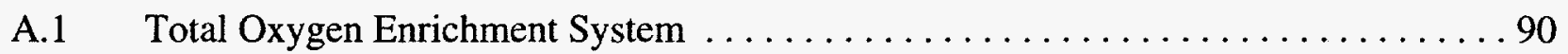

A.2 Oxygen Air Mixing Chamber $\ldots \ldots \ldots \ldots \ldots \ldots \ldots \ldots \ldots \ldots \ldots \ldots \ldots \ldots \ldots \ldots \ldots$ 


\section{ACKNOWLEDGMENTS}

The authors acknowledge the support and guidance of the U.S. Department of Energy, Office of Transportation Technologies, under contract W-31-109-Eng-38. Specifically, the enthusiastic support and technical guidance from John Russell and Richard Wares of the Office of Alternative Fuels are very much appreciated. The authors are grateful to John H. Baudino of AutoResearch Laboratories Incorporated for his technical support and advice on conducting the experiments. The authors acknowledge the personnel of the National Renewable Energy Laboratory, in particular Christopher P. Colucci and Brent Bailey, and those of AutoResearch Laboratories Incorporated, especially E.G. Sweeney, C.H. Schmidt, and P.M. McPartlin. The authors thank G.E. Csazar of AirTek, Inc., for providing the simulator catalyst. The technical advice of Michael J. Brady of the Chrysler Corporation, John W. Hoard of Ford Motor Company, and Carilee Cole of Delphi Automotive Systems in General Motors is greatly appreciated. 


\section{NOMENCLATURE}

$\begin{array}{ll}\text { ANL } & \text { Argonne National Laboratory } \\ \text { AQIRP } & \text { Auto/Oil Air Quality Improvement Research Program } \\ \text { CAA } & \text { Clean Air Act } \\ \text { CARB } & \text { California Air Resources Board } \\ \text { CFR } & \text { Code of Federal Regulations } \\ \text { CH}_{3} \text { OH } & \text { methanol } \\ \text { CO } & \text { carbon monoxide } \\ \text { DOE } & \text { U.S. Department of Energy } \\ \text { EAHU } & \text { enhanced air handling unit } \\ \text { ECU } & \text { engine control unit } \\ \text { EEC } & \text { evaporative emissions control } \\ \text { EHC } & \text { electrically heated catalyst } \\ \text { EPA } & \text { U.S. Environmental Protection Agency } \\ \text { FFV } & \text { flexible-fuel vehicle } \\ \text { FID } & \text { flame ionization detector } \\ \text { FTP } & \text { federal test procedure } \\ \text { HC } & \text { hydrocarbon } \\ \text { HCHO } & \text { formaldehyde } \\ \text { hp } & \text { horsepower } \\ \text { in. } & \text { inch(es) } \\ \text { g } & \text { gram(s) } \\ \text { kmph } & \text { kilometer(s) per hour } \\ \text { kW } & \text { kilowatt(s) } \\ \text { L } & \text { liter(s) } \\ \text { LDV } & \text { light-duty vehicle } \\ \text { LEV } & \text { low-emission vehicle } \\ \text { m } & \text { meter(s) } \\ \text { mg } & \text { milligram(s) } \\ \text { mi } & \text { mile(s) } \\ \text { min } & \text { minute(s) } \\ \text { MIR } & \text { maximum incremental reactivity } \\ \text { ml } & \text { milliliter(s) } \\ \text { MOIR } & \text { maximum ozone incremental reactivity } \\ \text { mph } & \text { mile(s) per hour } \\ \mathrm{N}_{2} & \text { nitrogen } \\ \text { NAAQS } & \text { National Ambient Air Quality Standard } \\ \text { NMHC } & \text { nonmethane hydrocarbon } \\ \text { NMOG } & \text { nonmethane organic gas } \\ \text { NO } & \text { nitrogen oxide } \\ & \end{array}$




$\begin{array}{ll}\mathrm{NO}_{x} & \text { nitrogen oxides } \\ \mathrm{O}_{2} & \text { oxygen } \\ \mathrm{O}_{3} & \text { ozone } \\ \mathrm{OEC} & \text { oxygen-enriched combustion } \\ \mathrm{OEM} & \text { original equipment manufacturer } \\ \text { OFP } & \text { ozone-forming potential } \\ \text { PCV } & \text { positive crank-case ventilation } \\ \text { ppm } & \text { part(s) per million } \\ \text { psi } & \text { pound(s) per square inch } \\ \text { RAF } & \text { reactivity adjustment factor } \\ \text { S } & \text { second(s) } \\ \text { SAE } & \text { Society of Automotive Engineers } \\ \text { scfm } & \text { standard cubic foot (feet) per minute } \\ \text { SI } & \text { spark-ignition } \\ \text { SR } & \text { specific reactivity } \\ \text { THC } & \text { total hydrocarbon } \\ \text { THC-FID } & \text { total hydrocarbon from flame ionization detector } \\ \text { TLEV } & \text { transitional low-emission vehicle } \\ \text { ULEV } & \text { ultra-low-emission vehicle } \\ \text { vol \% } & \text { volume percent } \\ \text { wt \% } & \text { weight percent }\end{array}$




\title{
EVALUATION OF OXYGEN-ENRICHMENT SYSTEM FOR ALTERNATIVE FUEL VEHICLES
}

\author{
by \\ R.B. Poola, R.R. Sekar, and H.K. Ng \\ SUMMARY OF PRESENT WORK
}

Oxygen-enriched combustion is a proven, seriously considered technique for reducing total hydrocarbon (THC) and carbon monoxide (CO) emissions in the exhaust from automotive gasoline engines. This report presents the results on the reduction in exhaust emissions achieved by using oxygen-enriched intake air containing about $23 \%$ and $25 \%$ oxygen (by volume) in a flexible-fuel vehicle (FFV) powered by a spark-ignition engine. Indolene and M85 were used as test fuels. Engine-out and converter-out emission data were collected by following the standard federal test procedure (FTP). Converter-out emission data were also obtained by employing the U.S. Environmental Protection Agency's "off-cycle" (REP05) test. Test data collected include mass emissions; time-resolved (second-by-second) concentrations of THC, $\mathrm{CO}$, and oxides of nitrogen $\left(\mathrm{NO}_{\mathrm{x}}\right)$ emissions; and a complete hydrocarbon (HC) speciation analysis. The report presents a portion of the time-resolved emission data for the initial 127 seconds (s) of the cold-phase FTP (includes the engine start, 20-s idle, and first hill/cycle) to illustrate the effects of oxygen-enriched intake air. In tests with Indolene, engine-out $\mathrm{CO}$ emission levels during the cold phase (bag 1) of the FTP decreased by about $46 \%$ and $50 \%$, respectively, and THC emission levels decreased by about $33 \%$ and $43 \%$, respectively, as a result of using nominal $23 \%$ and $25 \%$ oxygen-enriched intake air instead of ambient air ( $21 \%$ oxygen by volume). However, the corresponding $\mathrm{NO}_{\mathrm{x}}$ emission levels increased by about $56 \%$ and $79 \%$, respectively. Time-resolved, engine-out, FTP emission data indicate that both THC and CO emissions were reduced considerably during the initial $127 \mathrm{~s}$ of the cold phase, without any increase in $\mathrm{NO}_{x}$ emissions in the first $25 \mathrm{~s}$. Engine-out $\mathrm{HC}$ speciation results indicate that during cold-phase FTP, regulated air toxics (formaldehyde, acetaldehyde, benzene, and 1,3-butadiene) and ozone-forming potential (OFP) estimated on the basis of maximum incremental reactivity (MIR) factors were reduced by about $23-43 \%$ with $23 \%$ or $25 \%$ oxygen-enriched air. Converter-out THC, CO, nonmethane hydrocarbon (NMHC), and nonmethane organic gas (NMOG) emissions were also reduced with oxygen-enriched air. When $23 \%$ oxygen-enriched air was used only during the cold phase or $25 \%$ oxygen-enriched air was used only during the first $127 \mathrm{~s}$ of the cold phase (and ambient air was used for the rest of the FTP cycle intake), the emission levels of all three regulated pollutants (CO, NMOG/NMHC, and $\mathrm{NO}_{\mathrm{x}}$ - without adjusting for catalyst deterioration factors) were lower than the California transitional low emission vehicle (TLEV) and Tier II (year 2004) standards. These results indicate that using oxygen-enriched intake air during the cold-phase FTP or initial $127 \mathrm{~s}$ of the cold-phase FTP has the potential to reduce NMHC, NMOG, 
$\mathrm{CO}$, and $\mathrm{NO}_{\mathrm{x}}$ emissions sufficiently to meet future emission standards. The engine-out emissions from bag 3 of the off cycle might pose the greatest challenge for the converter, because engine-out exhaust emissions increase rapidly in both mass and concentration at higher fuel-flow rates. With nominal $23 \%$ oxygen-enriched intake air, reductions of about $70 \%$ in $\mathrm{CO}$ and $80 \%$ in THC were observed from the converter-out, off-cycle test (bag 3). However, the corresponding $\mathrm{NO}_{\mathrm{x}}$ emissions increased by about $88 \%$. Test results with Indolene indicate that using oxygen-enriched intake air (nominal $23 \%$ or $25 \%$ ) can reduce both engine-out and converter-out FTP emission levels, particularly cold-phase and also off-cycle emissions, but at the expense of higher $\mathrm{NO}_{\mathrm{x}}$ emission levels.

Test results with M85 indicate that engine-out THC, NMHC, and NMOG emissions and unburned methanol were considerably reduced in the entire FTP cycle when the oxygen content of the intake air was either $23 \%$ or $25 \%$. The engine-out formaldehyde emissions, which are of particular concern with regard to M85 fuel, were reduced by about $53 \%$ in bag $1,84 \%$ in bag 2, and $59 \%$ in bag 3 when the FTP cycle was followed by $25 \%$ oxygen-enriched intake air. However, CO emissions did not vary appreciably, and $\mathrm{NO}_{\mathrm{x}}$ emission levels were much higher when $23 \%$ or $25 \%$ oxygen-enriched intake air was used. During the cold-phase FTP, reductions of about $42 \%$ in THC, $40 \%$ in unburned methanol, $60 \%$ in NMHC, and $45 \%$ in NMOG were observed in the engine-out exhaust when $25 \%$ oxygen-enriched intake air was used instead of ambient air. However, the corresponding $\mathrm{NO}_{\mathrm{x}}$ emissions increased by about $78 \%$. In general, converter-out emissions were also reduced when oxygen-enriched intake air was used, but to a lesser degree. When nominal $23 \%$ oxygen-enriched intake air was used, reductions of about $67 \%$ in $\mathrm{CO}$ and $52 \%$ in THC were observed from the converter-out, off-cycle test (bag 3 ). The test results indicate that oxygen-enriched intake air (nominal $23 \%$ or $25 \%$ ) will reduce both engine-out and converter-out FTP emissions, particularly during the cold-phase FTP, and off-cycle emissions, but at the expense of higher $\mathrm{NO}_{\mathrm{x}}$ emission levels. The reduction in formaldehyde emissions from the FFVs (operating on M85) as a result of using oxygen-enriched intake air is most significant. In conclusion, oxygen enrichment of intake air in conjunction with a device to reduce $\mathrm{NO}_{\mathrm{x}}$ emissions (for example, by using monatomic nitrogen induced by a pulsed arc) has the potential of becoming a viable technology for controlling exhaust emissions from FFVs. 


\section{INTRODUCTION}

\subsection{PURPOSE}

This report presents results on the reduction in exhaust emissions achieved by using oxygen-enriched intake air on a flexible fuel vehicle (FFV) that used Indolene and M85 as test fuels. The standard federal test procedure (FTP) and the U.S. Environmental Protection Agency's (EPA's) "off-cycle"(REP05) test were followed. The report also provides a review of literature on the oxygen membrane device and design considerations. It presents information on the sources and contributions of cold-phase emissions to the overall exhaust emissions from light-duty vehicles (LDVs) and on the various emission standards and present-day control technologies under consideration. The effects of oxygen-enriched intake air on FTP and off-cycle emissions are discussed on the basis of test results. Conclusions are drawn from the results and discussion, and different approaches for the practical application of this technology in LDVs are recommended.

\subsection{ORGANIZATION OF THIS REPORT}

The report updates and consolidates results of earlier Argonne National Laboratory (ANL) oxygen enrichment investigations conducted for the U.S. Department of Energy (DOE). These studies include using moderate oxygen enrichment (up to $25 \%$ oxygen) of the intake air to reduce cold-phase FTP emissions from LDVs powered by a spark-ignition (SI) engine. It extends the earlier work by evaluating the M85 fuel effects from an FFV. The time-resolved emissions were analyzed in detail, since the major contributions of hydrocarbon (HC) and carbon monoxide ( $\mathrm{CO}$ ) emissions evolve during the initial 127-second (s) period (first hill/cycle) of the cold-phase FTP test cycle. Emission results were analyzed by using the EPA's off-cycle (REP05) test with both Indolene and M85.

Sections 1.3-1.5 briefly review the sources and possible effects of exhaust emissions from light-duty passenger cars, present and future emission regulations, and emission control technologies under investigation to meet the future emission standards. Section 2 covers the concept of oxygenenriched combustion (OEC) and provides background information. A brief review of earlier work with OEC on SI engines is provided in Section 2.3 to examine the emission results. A few recent developments in control technology for nitrogen oxides $\left(\mathrm{NO}_{\mathrm{x}}\right)$ are also listed to provide possible solutions for preventing $\mathrm{NO}_{\mathrm{x}}$ problems resulting from the use of oxygen-enriched intake air. An overview of the previous work with OEC at ANL is described in Section 2.4, followed by major inferences from the literature review; these inferences are summarized in Section 2.5. Section 3 is devoted to oxygen membrane materials, module performance, and design and development issues. The present work scope is highlighted in Section 4. Information on the experimental test set-up, test vehicle, test fuels, and test procedures is presented in Section 5. Section 6.1 provides data on vehicle 
performance (response) in general from using oxygen-enriched intake air. Section 6.2 discusses the results on FTP test cycle (engine-out and converter-out) and off-cycle test (converter-out) emission measurements from using Indolene fuel. The results obtained from using M85 are discussed in Section 6.3. On the basis of the test results, a few recommendations on the practical application of this technology to meet the future emission standards for a light-duty passenger car are provided in Section 7. Section 8 contains the conclusions drawn from the present study, which investigates the use of both Indolene and M85 as test fuels. An extensive reference list dealing with the OEC is provided in Section 9.

\subsection{BACKGROUND}

In response to demands for air quality improvements in urban areas, stringent regulations are now being placed on emissions from the exhaust of light-duty passenger vehicles. According to the EPA's model of driving behavior (FTP-75 cycle), a significant portion of the total pollutants emitted by light-duty passenger vehicles are emitted immediately following the start-up of the engine. The reason for the disproportionate emission levels at cold start-up is simply that the engine block and exhaust manifold are cold, and the catalytic converter has not yet reached its high conversion efficiencies. In general, the catalyst is not fully effective in converting emissions at temperatures below about $250^{\circ} \mathrm{C}$ for $\mathrm{CO}$ and below $250-340^{\circ} \mathrm{C}$ for $\mathrm{HC}$ [1]. Hence, most $\mathrm{CO}$ and $\mathrm{HC}$ emissions are emitted during the cold-phase period (bag 1) of the FTP cycle, when the catalyst is at temperatures below its "light-off" temperature. To compound the problem, most vehicles run fuelrich after a cold start. It is a common practice to operate SI engines with richer fuel-to-air mixtures during initial start-up and warm-up periods for proper operating drivability and acceleration. As a result, there are more unburned and partially burned HCs and more $\mathrm{CO}$ in the exhaust after the start and first $20 \mathrm{~s}$ of idling. The $\mathrm{NO}_{\mathrm{x}}$ emission level is low but increases significantly when the vehicle is accelerated in the first transient. Therefore, the emission characteristics are influenced by both the engine operating conditions and the heating characteristics of the catalytic converter. Potential sources of HCs from the SI engine during the cold-start and warm-up period that are also considered include piston ring crevices (the failure of the flame to penetrate the narrow gap between the cylinder and the piston), mixture preparation (poor mixing and vaporization), oil films (fuel absorption into the oil), flame quenching and combustion kinetics (thicker quench layer and lower post-flame reaction rates), engine warm-up (thermal inertia and heat loss), and valve leakage [2].

Methanol is a potential alternative fuel for motor vehicles because of its superior performance characteristics with regard to improving air quality [3]. Conversion from gasoline to methanol would result in the replacement of a large portion of the reactive $\mathrm{HCs}$ in gasoline exhaust with less reactive methanol, which could thus lower the ozone-forming potential (OFP) of the exhaust. However, methanol-fueled vehicle exhaust also contains significant amounts of photochemically reactive aldehydes (primarily formaldehyde). Previous studies $[4,5]$ have clearly shown that maximum air quality benefit from methanol fuel can be obtained, provided that exhaust 
emissions of formaldehyde are kept to very low levels. The California Air Resources Board (CARB) has enacted a formaldehyde emission standard of 15 milligrams per mile $(\mathrm{mg} / \mathrm{mi})$ for methanol-fueled vehicles. The requirement that this standard be met for at least 5 years or $50,000 \mathrm{mi}$ of vehicle use presents a challenging emission control problem. FFVs that can operate on mixtures of gasoline and methanol are being produced by various manufacturers to give customers the flexibility to select either fuel on the basis of price and availability. An FFV's exhaust contains a broad range of $\mathrm{HC}$ species as well as unburned methanol and formaldehyde. Catalytic control of exhaust emissions from FFVs poses a big problem, because many catalysts have been shown to exhibit tendencies to partially oxidize unburned methanol to formaldehyde at temperatures typically encountered during the converter warm-up period [6]. Thus, the present catalytic converters for FFVs have limitations with regard to the complete oxidation of unburned methanol in addition to the usual requirements related to the control of gasoline-derived exhaust pollutants.

\subsection{EMISSION STANDARDS}

California has adopted low-emission vehicle (LEV) standards that require rigorous reductions in tailpipe emissions. The LEV standards mandate increasingly tighter limits on reactivity-adjusted nonmethane organic gas (NMOG) in place of the present regulations on nonmethane hydrocarbon (NMHC) emissions, and they also regulate the OFP of exhaust emissions. Thus, a major aim of these standards is to suppress the formation of ozone, which is an important component of photochemical smog. To meet the CARB transitional low-emission vehicle (TLEV), LEV, and ultra-low-emission vehicle (ULEV) standards, substantial reductions in $\mathrm{HC}$ and CO emissions during the cold phase of the FTP cycle are required. Similarly, many light-duty passenger cars are required to reduce these emissions to comply with Tier II (year 2004) standards. This growing concern over start-up/cold-phase emissions has led to significant activity by the passenger car manufacturers to develop new emission treatment techniques.

\subsection{COLD-PHASE EMISSION REDUCTION TECHNOLOGIES}

This section provides information on various emission reduction technologies presently under investigation. The exhaust after-treatment methods to reduce cold-phase emissions so far investigated are grouped into three broad categories [1, 7-9]. They are (1) thermal management of the catalytic converter, including low-mass manifolds, double-walled exhaust pipes, electrically heated catalysts (EHCs), exhaust gas burners, exhaust gas igniters, and insulated converters (with vacuum or refractory materials); (2) placement of the converter closer to the exhaust manifold; and (3) management of the interaction between the HCs and the catalyst by using $\mathrm{HC}$ adsorbent or traps in the exhaust. However, the reduced durability, fuel penalty, additional capital costs, unwanted heat in the engine compartment, and complexity of these systems limit their application in vehicles. On the other hand, controlling emissions at the source itself (i.e, during combustion) is an attractive 
alternative. Oxygen enrichment of intake air can potentially reduce $\mathrm{CO}$ and $\mathrm{HC}$ emissions from vehicles powered by an SI engine, especially during start-up periods. Since oxygen enrichment of intake air reduces the engine-out emissions rapidly (even when the engine is cold), it helps to minimize the converter limitations during the cold phase and should improve converter efficiency. This method has an advantage of fewer add-on components and less mechanical complexity, and it is much easier to modify the intake system than the exhaust system. This method might have an advantage over the "chemical reactor" approach. In the latter approach, an air injection pump is employed in conjunction with the heated catalyst to provide a stoichiometric exhaust gas composition. Unfortunately, the air-injection rate and timing and the electrical heat input to the catalyst have to be varied simultaneously with exhaust flow, and if the air-injection exceeds the light-off time, poor $\mathrm{NO}_{\mathrm{x}}$ conversion is expected. On the other hand, an oxygen-enriched intake air system is simple in operation and does not alter the fuel economy, and its power requirement is comparable with that of an air-injection pump and EHC [7]. Oxygen enrichment also has potential to reduce aldehyde emissions and unburned methanol from FFVs operating on methanol or blends of methanol and gasoline. 


\section{OXYGEN-ENRICHED COMBUSTION}

\subsection{THE CONCEPT}

The concept of oxygen-enriched combustion is to increase the oxygen concentration of the combustion air to a level greater than $21 \%$. Likewise, the inert gas concentration (nitrogen) in the inlet mixture is reduced. Instead of restricting the fuel flow, additional oxygen would be supplied to the inlet mixture to provide leaner air-to-fuel ratios (higher oxygen-to-fuel ratios). The fundamental effects of increasing the oxygen content of a reacting fuel oxidant mixture are faster burn rates and the ability to burn more fuel. Both these effects have the potential to lower the exhaust $\mathrm{HC}$ and $\mathrm{CO}$ emission levels and to increase the specific power output of an SI engine. However, $\mathrm{NO}_{\mathrm{x}}$ emission levels are higher with OEC because of higher combustion temperatures. With oxygen enrichment, the engine power increases at a constant engine displacement because the additional oxygen represents the equivalent amount of air that the oxygen is replacing.

Theoretically, oxygen enrichment should have two major effects on combustion: increased flame temperature and increased flame propagation velocity. The increase in power output and reduction in $\mathrm{HC}$ and $\mathrm{CO}$ can be attributed to more effective and higher rates of combustion, whereas the increase in $\mathrm{NO}_{\mathrm{x}}$ formation results from the higher combustion temperature. The higher peak pressures associated with oxygen enrichment are accompanied by higher peak combustion temperatures. Since nitrogen oxide (NO) formation is exponentially dependent upon peak combustion temperatures, the higher peak temperatures account for the higher NO values. In addition to the oxygen-to-fuel ratio, the spark timing also interacts predominantly to result in NO formation. Less spark advance is required for optimized spark timing as the amount of oxygen is increased for lean operation. Increased oxygen concentration and the corresponding decrease in nitrogen concentration have been shown to raise flame speeds. These increased flame speeds increase the rate of pressure rise, and spark timing is reduced accordingly to provide an optimum spark setting [10].

\subsection{BACKGROUND}

It is well-known that the oxygen-enrichment concept has been used to boost the power of aircraft internal combustion engines for short periods of time by increasing oxygen concentration by mass. Because oxygen plays an important role in combustion, the concept of using oxygenenriched air for SI combustion has been studied by several researchers over the last several years. The main motivations for oxygen enrichment in SI-engine applications are to lower the level of HC and other exhaust emissions and improve power density. Although such benefits have been demonstrated by several researchers, the increase of $\mathrm{NO}_{\mathrm{x}}$ emissions and lack of an economical source of on-line oxygen equipment have prevented any practical application of this concept. Recent progress in the development of oxygen-enrichment membrane devices such as the permeable 
oxygen-membrane [11] and of $\mathrm{NO}_{\mathrm{x}}$ control devices has stimulated renewed interest in this concept, especially for SI-engine-powered, light-duty passenger car applications.

\subsection{REVIEW OF LITERATURE}

This review provides a brief summary of previous work that used oxygen enrichment of inlet air for SI engine applications. The earliest attempts at studying the effects of oxygen in the engine process were made by Kuznetsov in 1956 [12]. Wartinbee [10] had undertaken the study of oxygen enrichment to demonstrate the use of oxygen-enriched intake air to provide a lean air-to-fuel ratio (the alternative was restricting the fuel flow). Results indicate that while $\mathrm{HC}$ emissions were reduced substantially, the NO increase and the NO control technologies existing in the 1970s precluded further study. Subsequently, Quader [13] explained the fundamental effects of oxygenenriched air on exhaust emissions and performance of a SI engine with changes in flame temperatures and flame speeds. Willumeit and Bauer [14] observed a lower fuel consumption at leaner air-to-fuel ratios, lower $\mathrm{HC}$ emission levels, and higher $\mathrm{NO}$ emission levels, results similar to those of the previous investigations $[10,13]$. Kajitani et al. [15] examined in-cylinder reactions by using high-speed spectral infrared digital imaging in an SI engine with oxygen-enriched air; they observed increased thermal radiation (due to higher temperature) from the reaction zone throughout the combustion period. Maxwell et al. [16] demonstrated substantial reductions in $\mathrm{CO}$ and $\mathrm{HC}$ emissions from both gasoline and natural gas fuels as a result of using oxygen-enriched intake air. Additional literature dealing with OEC can be found in References 17-26.

The potential merits of oxygen enrichment in the intake air of SI engines are still being contested today. A recent (1992) Japanese study [15] showed an increase in thermal efficiency and a decrease in the exhaust emissions of unburned HCs and CO, while a 1971 General Motors report [10] showed decreases in thermal efficiency, unburned HCs, and $\mathrm{CO}$ emissions. However, both studies reported a substantial increase in $\mathrm{NO}_{x}$ emissions. Converters that currently reduce $\mathrm{NO}$ to $\mathrm{N}_{2}$ and $\mathrm{O}_{2}$ require a reducing atmosphere (i.e., rich air-to-fuel ratios). Conditions for low $\mathrm{HC}$ emissions with oxygen enrichment (lean operation) necessitate the use of lean $\mathrm{NO}_{\mathrm{x}}$ catalytic converters.

Recently, studies of $\mathrm{NO}_{x}$ catalysts that reduce $\mathrm{NO}_{x}$ under lean conditions (e.g., the copper ion-exchanged zeolite and the Pt-loaded zeolite) have been conducted at many research institutes [27-30]. The necessary characteristics for practical use of a lean-burn catalyst are (1) high activity of $\mathrm{NO}_{x}$ conversion under the condition of lean-burn exhaust gases including steam, (2) high efficiency of $\mathrm{HC}, \mathrm{CO}$, and $\mathrm{NO}_{x}$ conversion between stoichiometric and lean conditions, and (3) highdurability performance. The new catalyst formulations and conversion mechanisms reported by Mazda [31] and Toyota [32] Motor Companies are indicative of the progress of lean $\mathrm{NO}_{\mathrm{x}}$ catalyst technology. 


\subsection{OVERVIEW OF PREVIOUS WORK AT ARGONNE}

Argonne National Laboratory (ANL) has been studying the oxygen-enrichment concept for both diesel and gasoline engine applications for the past several years. Recently, the potential benefits of intake-air oxygen enrichment in an SI-engine-powered vehicle (3.1-L Chevrolet Lumina) have been reported [33], on the basis of oxygen-enriched air containing $25 \%$ and $28 \%$ oxygen by volume. The results of both engine-out and catalytic converter-out emissions showed that both $\mathrm{CO}$ and $\mathrm{HC}$ were reduced significantly in all three phases of the FTP test cycle. The catalytic converter also had an improved $\mathrm{CO}$ conversion efficiency under the oxygen-enriched conditions. However, $\mathrm{NO}_{\mathrm{x}}$ emission levels were found to be much higher when $25 \%$ or $28 \%$ oxygen-enriched intake air was used instead of ambient air (nominally $21 \%$ ). Test results also indicate that $28 \%$ oxygen was the upper limit because of engine knock.

An assessment was also made by using the oxygen-enrichment results to determine whether the $\mathrm{NO}_{\mathrm{x}}$ emission problem could be overcome. The supposition was that if the vehicle had a low$\mathrm{NO}_{\mathrm{x}}$-emission engine, but $\mathrm{HC}$ and $\mathrm{CO}$ emission levels were relatively higher, this oxygenenrichment technique would decrease the emissions of $\mathrm{HC}$ and $\mathrm{CO}$ and increase the emissions of $\mathrm{NO}_{x}$, but the vehicle could still meet all the 2004 Tier II standards. After the 1991-model-year LDV certification results [34] were reviewed, five vehicles (Baretta, Capri, Le Baron, Corolla, and Cabriolet) were found to produce extremely low levels of $\mathrm{NO}_{\mathrm{x}}$ emissions. The three-way catalytic converter conversion efficiencies for the $\mathrm{CO}, \mathrm{HC}$, and $\mathrm{NO}_{\mathrm{x}}$ emissions of a Lumina running under ambient air conditions were used to back-calculate the engine emissions of these vehicles using normal air. By assuming the vehicles would behave the same way as the Lumina using $25 \%$ oxygenenriched air, the engine-out $\mathrm{CO}, \mathrm{HC}$, and $\mathrm{NO}_{x}$ emissions were obtained by using the Lumina engine data. Finally these engine emissions were passed through a catalytic converter with $90 \%$ reduction efficiencies for $\mathrm{HC}$ and $\mathrm{CO}$ and a $80 \%$ reduction efficiency for $\mathrm{NO}_{\mathrm{x}}$ to produce the simulated FTPweighted emissions. The simulated, FTP-weighted emissions are shown in Figure 2.1. Both HC and $\mathrm{CO}$ emissions were below the 2004 Tier II standards for all the vehicles, while three vehicles had $\mathrm{NO}_{x}$ emission levels lower than the standards. This simple extrapolation showed that $\mathrm{NO}_{x}$ emissions were a problem in most vehicles, but the problem could be surmountable, provided that the catalytic converter could perform more efficiently under an oxidizing environment.

Apart from improved catalyst formulations, some novel methods are needed to meet the emission levels currently being contemplated. The concept of $\mathrm{NO}_{x}$ control by using free $\mathrm{N}_{2}$ radicals (reverse Zeldovich reactions) is well-known. To generate free $\mathrm{N}_{2}$ radicals, many studies $[35,36]$ injected ammonia and cyanuric acid. Significant reductions in $\mathrm{NO}_{x}$ emissions from using free $\mathrm{N}_{2}$ radicals were reported. Unfortunately, the method did not attract much attention for vehicular applications because of its complexity, its high cost, the difficulty of obtaining the source of ammonia or cyanuric acid, and difficulties in portability. ANL is pursuing a novel method of reducing $\mathrm{NO}_{\mathrm{x}}$ emissions by using a nitrogen plasma that preserves all of the benefits of the oxygenenriched combustion concept [37]. In this system, the inlet air in a hollow-fiber membrane would 


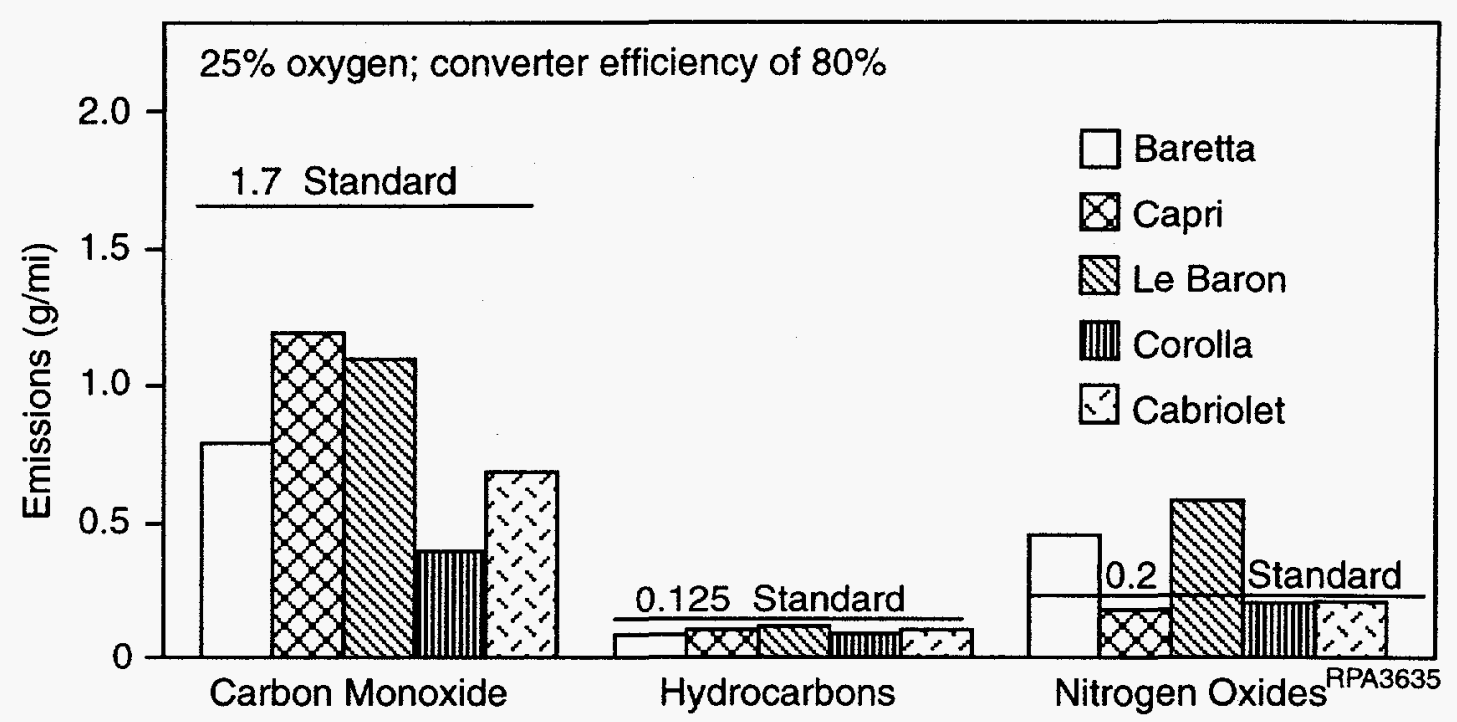

FIGURE 2.1 Potential of Oxygen-Enriched Intake Air to Meet Year 2004

Standards [Source: Ref. 41]

engine combustion, and the nitrogen stream would be used as a source of electrically activated nitrogen, which, in turn, could be used in a post-treatment process to reduce $\mathrm{NO}_{\mathrm{x}}$ emissions. This concept is attractive when compared with the other methods, because nitrogen is generated in the air separation membrane, thereby eliminating the need for additional nitrogen cylinders in the vehicle. Such synergistic use of oxygen-enriched air may lead to improved combustion and cleaner SI engines capable of meeting future emission standards. The conceptual scheme of intake-air oxygen enrichment for SI engines is shown in Figure 2.2. To reduce $\mathrm{NO}_{\mathrm{x}}$ emissions by using monatomic nitrogen, two devices that produce nitrogen plasma have been built and tested in the laboratory, one using an arc discharge and the other using a corona discharge. The laboratory benchscale test data obtained so far show that a $90 \%$ reduction of $\mathrm{NO}_{\mathrm{x}}$ is possible by using either a pulse or continuous arc discharge. Of the two arc discharge devices, the continuous arc device has durability problems. Laboratory experiments with SI engine exhaust are presently being conducted to evaluate the $\mathrm{NO}_{\mathrm{x}}$ conversion efficiencies at different exhaust oxygen levels.

\subsection{SUMMARY}

In summary, the review of literature concerning the application of oxygen-enriched intake air for SI engine applications to reduce certain exhaust emissions suggests the following:

1. Cold-phase $\mathrm{HC}$ and $\mathrm{CO}$ emissions from light-duty passenger cars, which account for about $60-70 \%$ of the total exhaust emissions during the FTP cycle, can be effectively reduced by using a moderate oxygen-enrichment level up to $25 \%$. 


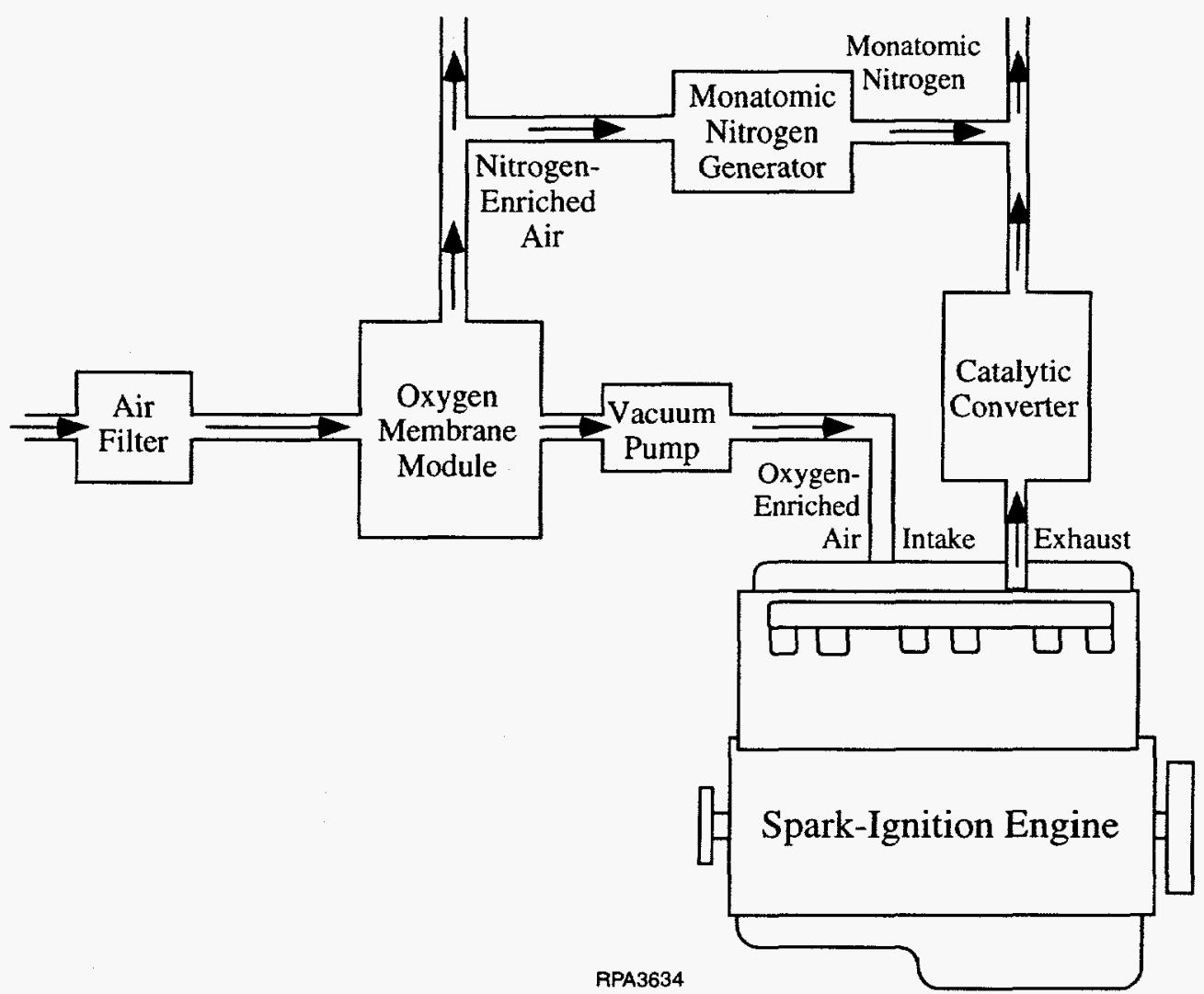

FIGURE 2.2 Conceptual Scheme of Intake-Air Oxygen Enrichment for Spark-Ignition Engines

2. Benefits such as lower $\mathrm{HC}$ and $\mathrm{CO}$ emissions can be achieved by ancrease in oxygen concentration, with an $\mathrm{NO}_{x}$ penalty. Solving the increase in $\mathrm{NO}_{x}$ and finding a suitable membrane device to deliver on-line oxygen are yet to be achieved.

3. Progress has been made in the development of compact oxygen-membrane devices, such as the permeable hollow-fiber membrane module, and of newer $\mathrm{NO}$ control technologies, such as lean $\mathrm{NO}_{\mathrm{x}}$ catalysts, and in using monatomic nitrogen induced by a pulse arc to remove $\mathrm{NO}_{\mathrm{x}}$.

4. Oxygen-enriched intake air, along with a device to reduce $\mathrm{NO}_{\mathrm{x}}$ emissions, has the potential to reduce all the regulated emissions simultaneously and meet the future emission standards. In this regard, using monatomic nitrogen induced by a pulsed arc to remove $\mathrm{NO}_{\mathrm{x}}$ emissions is attractive, since both nitrogenrich air for the monatomic nitrogen generator and oxygen-rich air for intake of the engine can be obtained from a single membrane module. 


\section{OXYGEN-MEMBRANE DEVICE}

\subsection{BACKGROUND}

The viability of inlet-air oxygen enrichment for SI engines depends on the availability of a simple, compact, mechanical system driven by the engine itself that will economically extract oxygen from the air. Apart from the traditional cryogenic method of extracting oxygen from atmospheric air, two different methods have been examined: pressure-swing adsorption and membrane separation. Cryogenic liquefaction is a high-energy, maintenance-intensive process and entails high investment capital. Pressure-swing adsorption is inherently a batch-wise process requiring a complex and relatively bulky control system with high maintenance. The membrane separation process, on the other hand, is characteristically simple, reliable, continuous in operation, and potentially highly economical to operate. Because of their modular nature, membrane systems can meet the needs of both the small- and large-scale user of oxygen-enriched air.

The main emphasis on membrane air separation studies has been in the area of nitrogen generation. The current generation of membranes allows nitrogen purity levels up to $99.5 \%$ to be produced with relative ease, although the economics are significantly improved at lower purity levels. The applications of membranes generating nitrogen include inert gas purging, tire inflation, establishment and maintenance of controlled atmospheres for fruit and vegetable storage and transport, and the disinfestation of grain and beverage dispensing. By comparison, adoption of membrane technology for oxygen generation has not been extensive, primarily because of the lower purity levels that can be achieved with currently available polymeric membranes. Nevertheless, these lower oxygen concentrations (30-35\%) are adequate for internal combustion engine applications.

Considerable progress has occurred in the last 15 years in the development and use of membrane permeators for separation of gas mixtures. These membrane permeators typically use polymers that have the inherent capability of separating components in a gas mixture by their molecular size (because of diffusive effects). While these membranes can be made of metallic or ceramic materials, polymeric materials are used for air separation. These polymers are of different composition and configuration, depending on the manufacturer. Polymeric membranes are formed into thin films or hollow fibers, usually in an asymmetric structure. Membranes having a hollowfiber geometry are most commonly used for manufacturing membrane gas permeators. Physically, these permeators resemble a shell and tube heat exchanger; the fibers are formed into a bundle with each end encased in a tube sheet. The tube bundle is enclosed in a protective shell made from engineered polymer or metal. A gas mixture, such as air, is introduced into the fiber bundle through one end of the permeator. As the air travels down the length of the fiber, oxygen (which is the more permeable species) permeates across the membrane walls. As the air continues to travel down the fiber length, it is thus enriched in nitrogen and exits the permeator at the opposite end. Correspondingly, the gas mixture outside the membrane is enriched in oxygen and is removed by 
a nozzle on the shell side. Figure 3.1 is an exploded-view drawing of a typical oxygen-enriched air module. The capability of a given membrane (in terms of throughput capacity and ability to separate the components in a gas mixture) is governed by the membrane properties (permeability and selectivity) and operating conditions of temperature, differential pressure across the membrane, and percent recovery.

\subsection{MEMBRANE PERFORMANCE PARAMETERS $[11,26]$}

The hollow-fiber membrane in the gas separation process acts as a selective barrier, allowing one gas to permeate through it more readily than the other gas in the mixture. In the case of the oxygen-enriched air modules, oxygen permeates the membrane walls at a higher rate than nitrogen. Membrane performance is generally characterized by permeability, selectivity, recovery, oxygen concentration, and power requirement.

The permeability of a given gas is a membrane property that measures how fast the gas flows across a specific membrane. A detailed study of flow through a membrane involves diffusion toward the membrane surface, desorption into the membrane, permeation through the membrane, and desorption and diffusion away from the membrane. The overall permeability can be a function of flow as well as membrane composition. For a membrane to effectively separate gases, it must not only allow a given gas to permeate through it but also be selective in doing so. Thus, membrane selectivity (or separation factor) is defined as the ratio of gas permeabilities in a membrane.

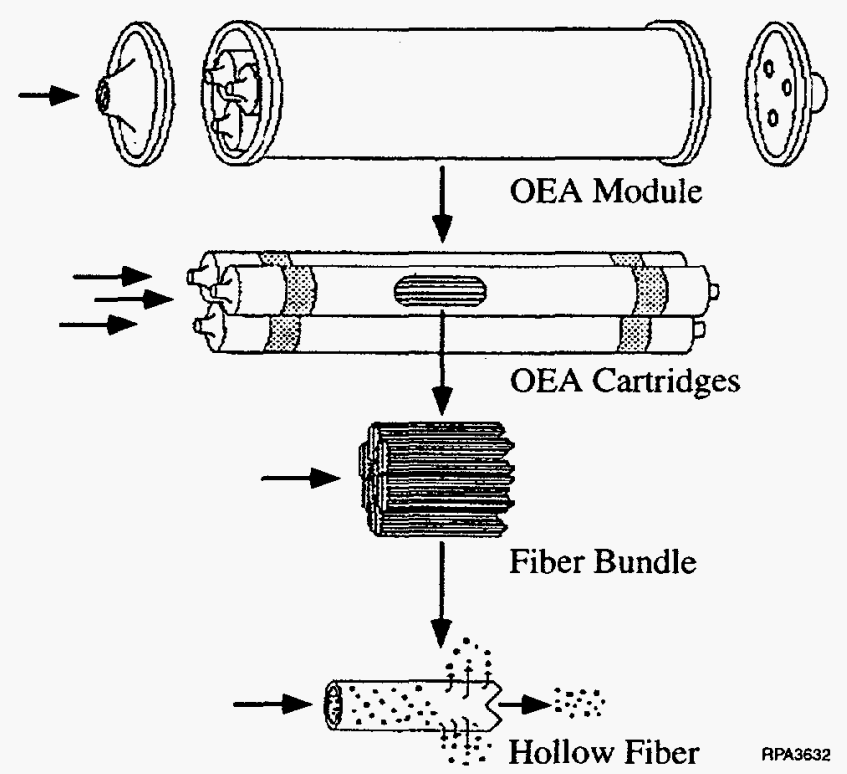

FIGURE 3.1 Exploded View of Typical Oxygen-

Enriched Air Module 
The recovery (or stage cut) of an oxygen-enriched air system is another important measure of performance. This is simply the permeate flow divided by the feed flow. Another term that describes the performance of an oxygen-enriched air system is the available oxygen - the amount of oxygen in the permeate stream available to the end user. Finally, a measure of the amount of work required to run an oxygen-enriched air module is needed to estimate the parasitic power requirements.

\subsection{MEMBRANE CARTRIDGE OPTIONS [11, 26]}

Because the permeate gas flow per unit of membrane area is inherently low, a compact membrane cartridge design is required to achieve economical system designs. The two membrane cartridge options with the best packing densities are the spiral-wound and hollow-fiber geometries.

Spiral-wound cartridges consist of a number of leaves, each containing two flat sheets of membrane separated by porous support material. Spiral-wound cartridges are reasonably compact, and system designs incorporating spirals require simple pressure vessels. However, gas by-pass around the cartridges because of misalignment or failure within the pressure vessel is a potential concern that may reduce spiral-wound cartridge productivity. Also, spiral-wound cartridges are usually operated in a cross-flow mode that tends to slightly lower the achievable oxygen concentrations for a given set of membrane transport characteristics. Additionally, the spiral-wound cartridge has a significant length of glue seams that pose a greater potential for permeate contamination by feed gas than is present in some competitive module geometries.

Hollow-fiber technology provides the cartridge of choice for membrane gas separations. Hollow-fiber cartridges have the best packing density (about 5 to 10 times that of spirals) and are simple to operate and maintain on clean gas streams. The fact that membrane fibers are selfsupported and can operate at a pressure differential of up to several hundred pounds per square inch (psi) greatly simplifies cartridge design and assembly options. Hollow-fiber cartridges have significantly better packing densities than spiral-wound cartridges and are less costly per square foot of active membrane.

\subsection{OPERATING MODES OF MEMBRANE OXYGEN-ENRICHED AIR SYSTEMS $[11,26]$}

Membrane oxygen-enrichment systems are classically operated in either a vacuum mode or a pressurized mode. Figure 3.2 shows simple schematic diagrams of the pressure and vacuum mode oxygen-enriched air modules. Regardless of the mode of operation employed, two operating parameters are keys to the system performance and economics: membrane differential pressure and system compression ratio. The differential pressure is a factor in determining the membrane area 
Pressurized Mode of Operation
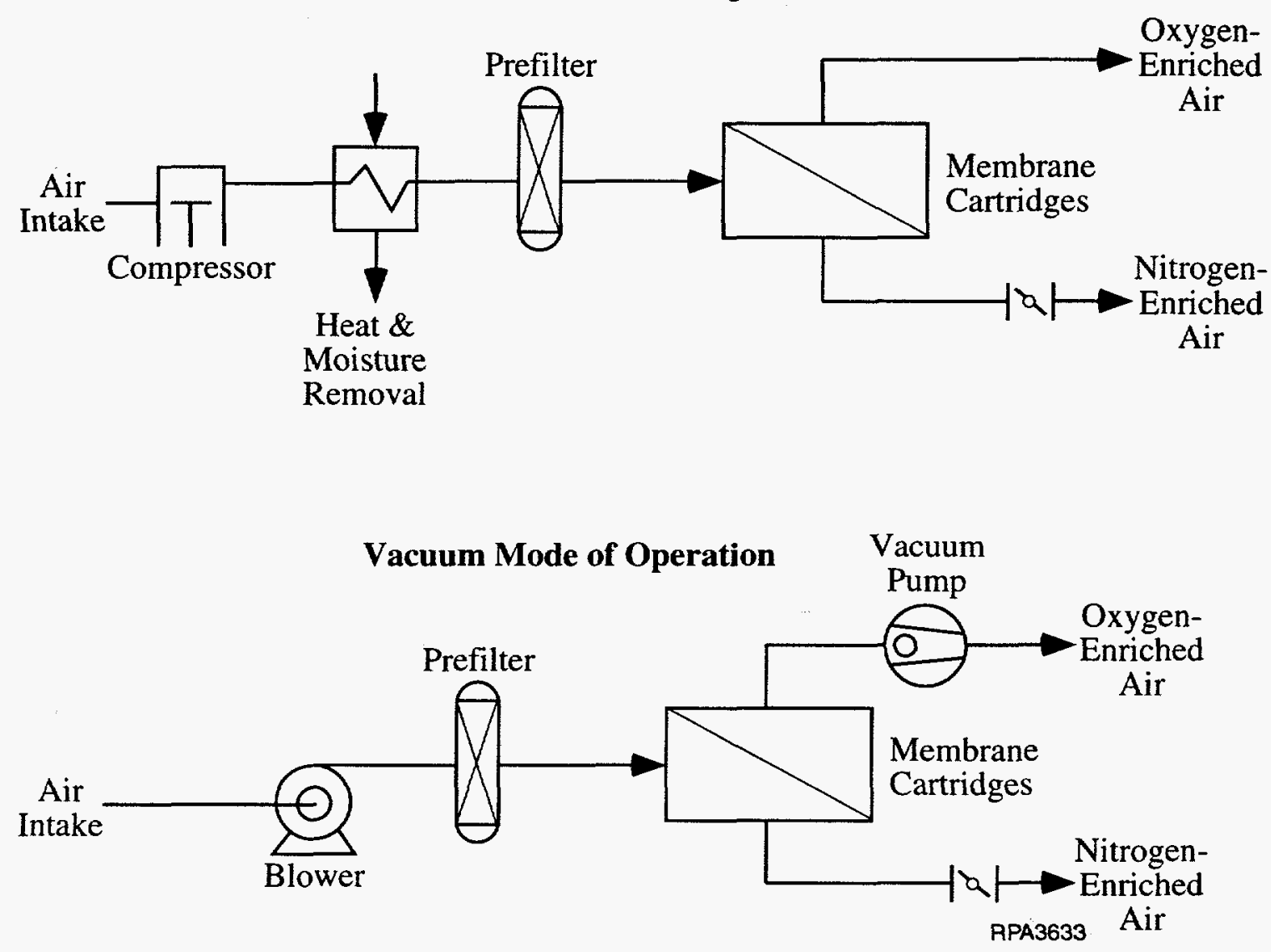

FIGURE 3.2 Simplified Flow Schematics of Vacuum and Pressurized Modes of Operation

requirements, while the compression ratio plays a role in determining the degree of oxygen enrichment.

In the vacuum mode of operation, the feed air is pressurized to slightly above atmospheric, and vacuum is maintained on the other side of the membrane. Oxygen preferentially permeates from the high-pressure side to the low-pressure side of the membrane. The vacuum mode is typically more energy-efficient than the pressurized mode, primarily because only the product stream is compressed. However, the limited differential pressure results in larger membrane area requirements for a given flow rate with vacuum rather than pressure operation.

In the pressurized mode, the feed air is typically pressurized to several atmospheres (absolute), while the permeate is maintained at approximately atmospheric pressure. Higher driving forces are obtained in this mode because of the higher differential pressure; however, the compression ratios are limited unless energy-intensive, high-pressure compressors are used. The major disadvantage of the pressurized mode of operation is increased energy usage relative to the 
vacuum mode. Higher energy usage results because in the vacuum mode, it is only necessary to compress the permeate, which is typically $20-30 \%$ of the feed air volume. Higher conversions are not attainable without sacrificing permeate oxygen concentration because the oxygen driving force decreases as conversion is increased and the feed air is depleted of oxygen. Hence, selection of the preferred mode of operation depends on an economic tradeoff among membrane area costs, compressor costs, and power costs. In the case of generating nitrogen-enriched air for free radical formation and $\mathrm{NO}_{\mathrm{x}}$ reduction, the tradeoff will be pushed toward higher-stage cuts and relatively lower levels of oxygen-enriched air in the permeate.

Prior membrane process development relied on thin-film composite membranes derived from silicon rubber and was based on the spiral-wound module geometry. Silicon rubber membranes are limited in their separation ability for oxygen and nitrogen (separation factor about 2.0) and hence do not economically enable generation of oxygen concentration levels of more than $30 \%$ in a single stage. The choice of the spiral-wound geometry reduces the system's economic attractiveness when compared with a more compact module design. Gollan and Kleper [38] have developed a semipermeable polymeric membrane system that overcomes the limitations of prior membrane technology for oxygen enrichment. This asymmetric membrane displays higher separation factors for oxygen to nitrogen than silicon rubber membranes while exhibiting product flow rates that result in an air separation system more economically attractive to industry. Furthermore, these membranes have been produced in the highly compact hollow-fiber form, which provides the most cost-effective membrane module configuration.

\subsection{PRESENT STATUS OF MEMBRANE MODULE DEVELOPMENT}

The limiting design criteria for development of a membrane for automotive engine applications are the membrane module size and the power requirement to drive the membrane. ANL has been examining a new family of materials $[39,40]$ and comparing them with traditional rubbery polymers (silicon rubber) or glassy polymers (ethyl cellulose and polysulfone) for vehicular applications. An approximate design calculation shows that the power required to drive the membrane is as low as $1.8 \mathrm{~kW}$, the module size is about $0.508 \mathrm{~m}$ in length and $0.483 \mathrm{~m}$ in diameter (20 $\times 19$ in.) when perfluorodioxole membrane material is used to result in a flow rate of $2,832 \mathrm{~L} / \mathrm{min}$ or 100 standard cubic feet per minute ( $\mathrm{scfm}$ ), corresponding to a maximum vehicle speed of 90.93 kilometers per hour $(\mathrm{kmph})$ or 56.5 miles per hour ( $\mathrm{mph}$ ) during the FTP cycle, of either $23 \%$ or $25 \%$ oxygen-enriched air in the (Dodge Spirit, $2.5-\mathrm{L}, 75-\mathrm{kW}$ ) engine intake. Several design factors are being studied to optimize both the membrane size and power requirement. A prototype oxygen-membrane module is under preparation for testing in a vehicle. The mechanism of an oxygen-membrane device to supply oxygen-enriched intake air during the first few minutes after start of the vehicle is currently being developed. 


\section{PRESENT WORK}

This report presents results for an FFV that is powered by an SI engine and uses Indolene and M85 as fuels and intake air containing about $23 \%$ and $25 \%$ oxygen by volume. Bottled oxygen was employed to increase the oxygen content of ambient air to $23 \%$ or $25 \%$ during the tests. Both the FTP-75 and one of the EPA's newly developed off-cycle (REP05) exhaust emission tests were conducted. The complete test matrix is shown in Table 4.1. Data collected include complete HC speciation, mass emissions, and time-resolved (second-by-second) concentrations of total hydrocarbon (THC), $\mathrm{CO}$, and $\mathrm{NO}_{\mathrm{x}}$ emissions. A portion of the time-resolved emissions data for the first $127 \mathrm{~s}$ of the cold-phase FTP are presented to illustrate the effects of oxygen-enriched intake air. The first $127 \mathrm{~s}$ of the FTP includes the engine start, a 20 -s idle, and the first "hill" (cycle) of the test. Detailed analyses of both engine-out and converter-out emissions were made because of converter limitations during this 127 -s period.

This study was intended to determine if such a polymeric membrane oxygen enrichment system, were it in existence today, could be readily retrofit to a SI-engine-powered vehicle so it would perform reasonably yet reduce emissions. Since most vehicles are fitted with three-way catalytic converters that work only in a reducing environment, this experiment would also show whether this oxygen-enrichment technique would have any major impact on converter performance. An optimal level of oxygen enrichment and the optimal duration for its applications were also examined to simultaneously reduce both THC and CO emissions while keeping the $\mathrm{NO}_{\mathrm{x}}$ level low. 
TABLE 4.1 Test Matrix for Dodge Spirit Flexible-Fuel Vehicle ${ }^{\mathrm{a}}$

\begin{tabular}{|c|c|c|c|c|c|c|c|c|c|c|c|}
\hline S. No. & Test No. & Date & $\begin{array}{c}\text { Oxygen } \\
(\%)\end{array}$ & Fuel & Test Type & $\begin{array}{c}\text { Tailpipe or } \\
\text { Engine }\end{array}$ & $\begin{array}{c}\text { Mass } \\
\text { Emissions }\end{array}$ & $\begin{array}{l}\text { Second-by- } \\
\text { Second }\end{array}$ & Speciation & $\begin{array}{c}\text { Bag } 1 \\
\text { Only }\end{array}$ & Remarks \\
\hline 1 & 3287 & $10 / 12 / 94$ & 21 & Indolene & FTP & Tailpipe & $X$ & $\mathrm{X}$ & $\mathrm{X}$ & & \\
\hline 2 & 3288 & $10 / 12 / 94$ & 21 & Indolene & Off & Tailpipe & $\mathrm{X}$ & $\mathrm{X}$ & & & \\
\hline 3 & 3300 & $10 / 13 / 94$ & 21 & Indolene & FTP & Tailpipe & $x$ & & $\mathrm{X}$ & & Lost SBS Data \\
\hline 4 & 3301 & $10 / 13 / 94$ & 21 & Indolene & Off & Tailpipe & $\mathrm{x}$ & $\mathrm{X}$ & & & \\
\hline 5 & 3310 & $10 / 14 / 94$ & 21 & Indolene & FTP & Tailpipe & $X$ & $X$ & $\mathrm{X}$ & & \\
\hline 6 & 3311 & $10 / 14 / 94$ & 21 & Indolene & Off & Tailpipe & $x$ & $x$ & & & \\
\hline 7 & 3330 & $10 / 17 / 94$ & 21 & Indolene & FTP & Tailpipe & $\mathrm{X}$ & $\mathrm{X}$ & & $\mathrm{X}$ & \\
\hline 8 & 3341 & $10 / 18 / 94$ & 25 & Indolene & FTP & Tailpipe & $x$ & $x$ & $\mathrm{X}$ & & \\
\hline 9 & 3342 & $10 / 18 / 94$ & 25 & Indolene & Off & Tailpipe & $\mathrm{x}$ & $x$ & & & \\
\hline 10 & 3349 & $10 / 19 / 94$ & 25 & Indolene & FTP & Tailpipe & $\mathrm{X}$ & $\mathrm{X}$ & $x$ & $r$ & \\
\hline 11 & 3350 & $10 / 19 / 94$ & 25 & Indolene & Off & Tailpipe & $X$ & $X$ & & & \\
\hline 12 & 3359 & $10 / 20 / 94$ & 25 & Indolene & FTP & Tailpipe & $x$ & $\mathrm{X}$ & & $\mathrm{x}$ & \\
\hline 13 & 3372 & $10 / 25 / 94$ & 23 & Indolene & FTP & Tailpipe & $\mathrm{x}$ & $x$ & $\mathrm{X}$ & & \\
\hline 14 & 3373 & $10 / 25 / 94$ & 23 & Indolene & Off & Tailpipe & $x$ & $\mathrm{X}$ & & & \\
\hline 15 & 3374 & $10 / 26 / 94$ & 23 & Indolene & FTP & Tailpipe & $\mathrm{X}$ & $\mathrm{X}$ & & & \\
\hline 16 & 3375 & $10 / 26 / 94$ & 23 & Indolene & Off & Tailpipe & $\mathrm{X}$ & $\mathrm{X}$ & & & \\
\hline 17 & 3388 & $10 / 27 / 94$ & 21 & Indolene & FTP & Tailpipe & $\mathrm{X}$ & $\mathrm{X}$ & & & Conditioning \\
\hline 18 & 3594 & $11 / 30 / 94$ & 21 & Indolene & FTP & Engine-out & $x$ & $x$ & $\mathrm{X}$ & & \\
\hline 19 & 3614 & $12 / 1 / 94$ & 25 & Indolene & FTP & Engine-out & $\mathrm{X}$ & $\mathrm{X}$ & $x$ & & \\
\hline 20 & 3636 & $12 / 6 / 94$ & 23 & Indolene & FTP & Engine-out & $X$ & $X$ & $\mathrm{X}$ & & \\
\hline
\end{tabular}


TABLE 4.1 (Cont.)

\begin{tabular}{|c|c|c|c|c|c|c|c|c|c|c|c|}
\hline S. No. & Test No. & Date & $\begin{array}{c}\text { Oxygen } \\
(\%)\end{array}$ & Fuel & Test Type & $\begin{array}{c}\text { Tailpipe or } \\
\text { Engine }\end{array}$ & $\begin{array}{c}\text { Mass } \\
\text { Emissions } \\
\end{array}$ & $\begin{array}{c}\text { Second-by- } \\
\text { Second }\end{array}$ & Speciation & $\begin{array}{c}\text { Bag } 1 \\
\text { Only } \\
\end{array}$ & Remarks \\
\hline 21 & 3706 & $12 / 20 / 94$ & 21 & M-85 & FTP & Engine-out & $X$ & $X$ & $X$ & & \\
\hline 22 & 3724 & $12 / 23 / 94$ & 25 & M-85 & FTP & Engine-out & $X$ & $\mathrm{X}$ & $X$ & & \\
\hline 23 & 3736 & $12 / 22 / 94$ & 23 & M-85 & FTP & Engine-out & $\mathrm{X}$ & $x$ & & & \\
\hline 24 & 4269 & $4 / 25 / 95$ & 25 & $M-85$ & FTP & Engine-out & $\mathrm{X}$ & $\mathrm{x}$ & & & \\
\hline 25 & 4287 & $4 / 26 / 95$ & 25 & M-85 & FTP & Engine-out & $x$ & $x$ & $x$ & & \\
\hline 26 & 4335 & $5 / 2 / 95$ & 21 & M-85 & FTP & Tailpipe & $\mathrm{X}$ & $\mathrm{x}$ & $x$ & & \\
\hline 27 & 4337 & $5 / 3 / 95$ & 21 & M-85 & FTP & Tailpipe & $x$ & $x$ & $x$ & & \\
\hline 28 & 4364 & $5 / 16 / 95$ & 21 & M-85 & FTP & Tailpipe & $\mathrm{X}$ & $x$ & $x$ & & \\
\hline 29 & 4366 & $5 / 17 / 95$ & 21 & M-85 & FTP & Tailpipe & $X$ & $X$ & & $X$ & \\
\hline 30 & 4380 & $5 / 24 / 95$ & 23 & M-85 & FTP & Tailpipe & $\mathrm{X}$ & $\mathrm{x}$ & $x$ & & \\
\hline 31 & 4390 & $5 / 25 / 95$ & 23 & M-85 & FTP & Tailpipe & $\mathrm{X}$ & $x$ & & & \\
\hline 32 & 4369 & $5 / 18 / 95$ & 25 & M-85 & FTP & Tailpipe & $x$ & $x$ & $\mathrm{X}$ & & \\
\hline 33 & 4371 & $5 / 19 / 95$ & 25 & $M-85$ & FTP & Tailpipe & $\mathrm{X}$ & $\mathrm{X}$ & $\mathrm{X}$ & & \\
\hline 34 & 4377 & $5 / 23 / 95$ & 25 & $M-85$ & FTP & Tailpipe & $X$ & $X$ & & $\mathrm{X}$ & \\
\hline 35 & 4336 & $5 / 2 / 95$ & 21 & $M-85$ & Off & Tailpipe & $X$ & $\mathrm{X}$ & & & \\
\hline 36 & 4338 & $5 / 3 / 95$ & 21 & M-85 & Off & Tailpipe & $\mathrm{X}$ & $x$ & & & \\
\hline 37 & 4381 & $5 / 24 / 95$ & 23 & M-85 & Off & Tailpipe & $\mathrm{X}$ & $\mathrm{X}$ & & & \\
\hline 38 & 4391 & $5 / 25 / 95$ & 23 & M-85 & Off & Tailpipe & $\mathrm{X}$ & $x$ & & & \\
\hline 39 & 4370 & $5 / 18 / 95$ & 25 & $M-85$ & Off & Tailpipe & $x$ & $\mathrm{X}$ & & & \\
\hline 40 & 4372 & $5 / 19 / 95$ & 25 & M-85 & Off & Tailpipe & $X$ & $X$ & & & \\
\hline
\end{tabular}

a $S$. No. = serial number; off $=$ off-cycle test; $X=$ test performed and blank $=$ test not conducted; and SBS $=$ second-by-second. 


\section{EXPERIMENTAL TEST SET-UP AND PROCEDURE}

\subsection{BACKGROUND}

To perform the present experiments, an oxygen-enrichment system designed and built in a previous study [41] was employed. An FFV was selected for the present work to investigate the fuel effects (Indolene and M85) under similar operating conditions. The tests were performed at the AutoResearch Laboratories Incorporated in Harvey, Illinois.

\subsection{OXYGEN-ENRICHMENT SYSTEM}

The experimental setup was made up of the air-handling and the oxygen-supply systems, as shown in Figure 5.1. The air-handling system consisted of a plenum and a 300-scfm blower that continuously provided the plenum with excess air and from which the vehicle drew the intake air (as required) and from which the excess air was purged. This system was designed to handle both ambient air and air enriched up to $30 \%$ with oxygen.

The oxygen-supply system consisted of 12 compressed-oxygen cylinders containing about twice the amount of oxygen required for one FTP emission test. The output pressure of the oxygen cylinders was controlled by a two-stage manual regulator. The oxygen flowed through two liquidoxygen vaporizers and an air-to-air heat exchanger to increase the oxygen's temperature to room

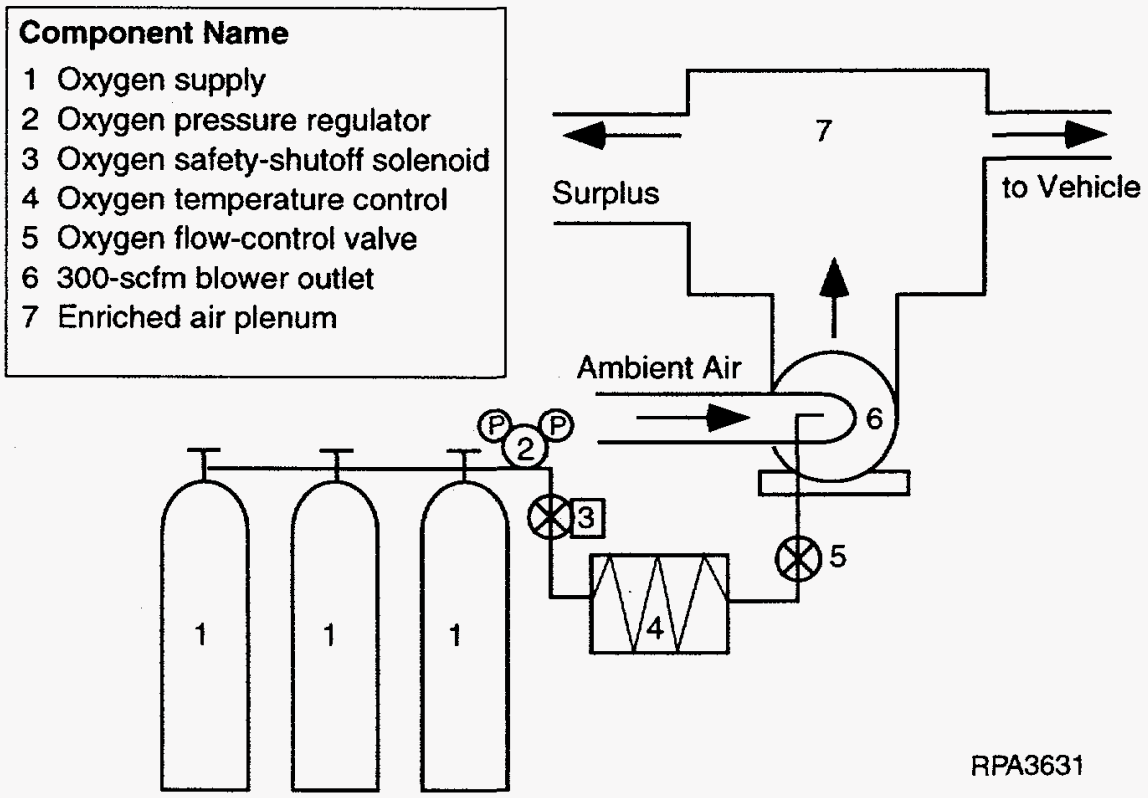

FIGURE 5.1 Diagram of Oxygen-Enriched System 
temperature. The heated air was then fed into the air-handling system immediately before the blower inlet to ensure thorough mixing with ambient air. A well-mixed oxygen-enriched air was uniform in both temperature and oxygen concentration when it reached the plenum. The oxygen rate was controlled manually with a valve placed after the heat exchanger. Before the start of the test, the blower was turned on and the oxygen control valves were opened and controlled to provide a desired oxygen content at the plenum. Once the system was stabilized, the emissions test or conditioning cycle would start. Normally, this process would take about 3-5 minutes. The compressed oxygen from the cylinders had the potential of overpressurizing the air-handling system and feeding the vehicle with excessive oxygen. Therefore, three manually operated emergency shutoff switches were installed in the control panel of the enriched-air-handling system, the emissions lab, and the vehicle. Additional details on the oxygen-enrichment system are given in Reference 41.

\subsection{VEHICLE MODIFICATIONS}

The vehicle selected for this study was a 1993 flexible-fuel Dodge Spirit equipped with a 2.5-L port-fuel-injected engine; the vehicle had an odometer reading of $2,490 \mathrm{~km}$. Table 5.1 gives the major specifications of the test vehicle and engine. The vehicle was modified for tests to use oxygen-enriched air in the same manner it was used during the previous study [41]. Schematic drawings of the original equipment manufacturer's (OEM's) positive crankcase ventilation (PCV) and canister system and the modified PCV and canister system for the enhanced air handling unit

TABLE 5.1 Specifications for Test Vehicle and Engine

\begin{tabular}{ll}
$\begin{array}{l}\text { Vehicle } \\
\text { Model }\end{array}$ & 1993 Dodge Spirit \\
Type & Flexible fuel vehicle (FFV) \\
Odometer reading & $2,756 \mathrm{mi}(2,490 \mathrm{~km})$ \\
Transmission & Four-speed automatic \\
Inertia weight, power & $3,125 \mathrm{lb}, 8.4 \mathrm{hp}$ \\
& \\
Engine & \\
Type & In-line, four-cylinder, two valves \\
& per cylinder, without turbo \\
Displacement & $2.5 \mathrm{~L}$ \\
Compression ratio & $8: 9: 1$ \\
Fuel supply & Multipoint injection \\
Fuel type & Unleaded gasoline/M85 \\
Engine power & 102 hp \\
\hline
\end{tabular}


(EAHU) are shown in Figure 5.2. To avoid drawing oxygen-enriched air through the engine crankcase, the PCV system was modified to draw intake air directly from the oxygen-enrichment system to the intake manifold without having the air pass through the crankcase. A PCV valve was installed on the downstream side of the air filter housing and connected to the PCV port on the intake manifold, bypassing the crankcase. The crankcase was then purged by means of a slow flow of nitrogen. The evaporative emissions control (EEC) system was modified to avoid drawing oxygenenriched air through the carbon canister. The purge line from the canister to the engine was disconnected at the canister and relocated to a port on the air filter housing. This configuration caused the engine to draw only oxygen-enriched air when the canister purge solenoid was activated, instead of ambient air and fuel vapors. The fuel tank vapor line was connected to a remote canister. The exhaust system was modified to allow use of either the OEM's catalyst to obtain tailpipe emissions or a simulator converter to obtain engine-out emissions. The simulator converter did contain a briquette without a catalyst but was modified to give the same back-pressure as that given by an OEM's catalyst. Thermocouples were placed in the exhaust line to obtain temperature data before and after the OEM or simulator catalyst. Additional monitoring of the vehicle's operation during the emission tests was accomplished by monitoring the regulated emission concentrations (NMOG, $\mathrm{CO}$, and $\mathrm{NO}_{\mathrm{x}}$ ), front and rear roll speeds, intake and tailpipe oxygen concentration, intake air pressure and temperature, and dry- and wet-bulb laboratory temperatures on a second-by-second basis.

\subsection{TEST FUELS}

Two types of test fuels were used in this study - a base gasoline (Indolene) and M85. The gasoline used for these tests was Amoco's EPA certification fuel, Indolene. The M85 used for these tests was supplied by BP Oil. Amoco's certification of analysis for Indolene fuel is provided in Table 5.2. The HC portion of the fuel was blended to give M85. Alkylate and iso-crackate refinery streams were used for this $\mathrm{HC}$ blend. These data, along with the percentage methanol and water in the M85, were used to calculate the average molecular weight, hydrogen-to-carbon (H:C) ratio, and density of the M85 fuel for use in the exhaust THC emission calculations. A sample of the HC blend used for the M85 was analyzed to determine its composition by using the PIANO test method. The PIANO HC analysis of Indolene fuel (Table 5.3) is also helpful for interpreting exhaust speciation data. The specification for the M85 fuel and certificate of analysis for methanol (M100) are given in Tables 5.4 and 5.5. The M85 was blended to the low side of the vapor pressure specifications for summer fuel ( 9.0 to $10.9 \mathrm{psi}$ ) to be as close as possible to the vapor pressure of the Indolene (8.7 psi). 
OEM PCV and Canister System

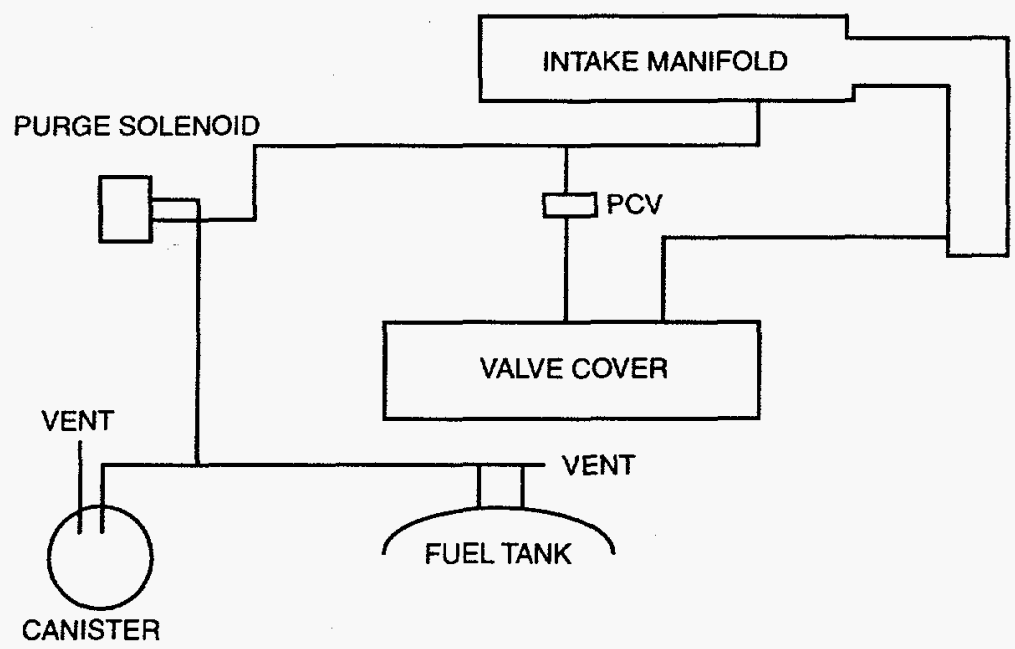

Modified PCV and Canister System for EAHU

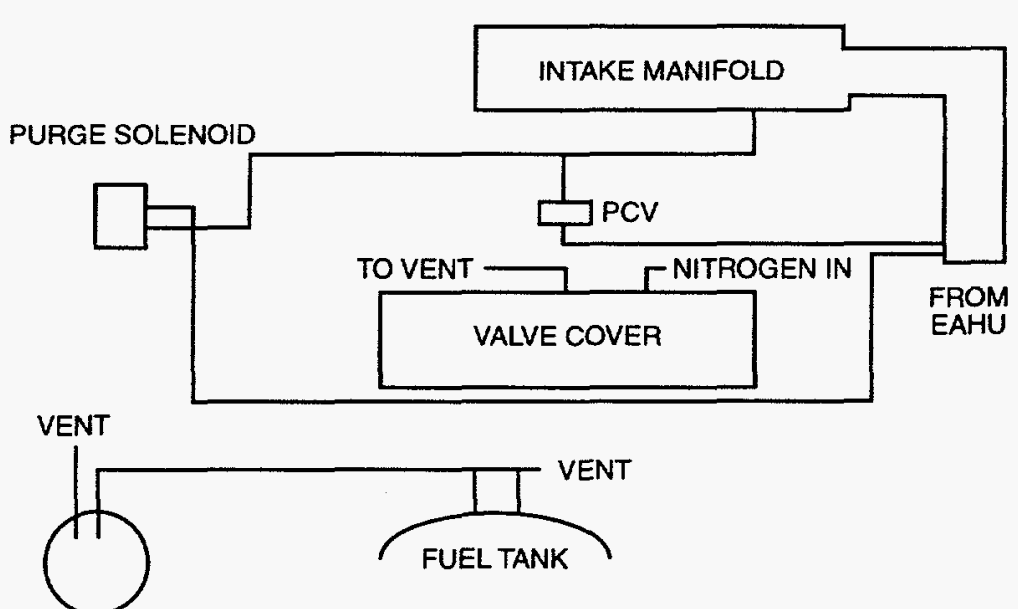

CANISTER

RPA3637

FIGURE 5.2 Diagrams of PCV and Canister Systems 
TABLE 5.2 Certificate of Analysis for Indolene ${ }^{a}$

\begin{tabular}{|c|c|c|}
\hline Property & Result & $\begin{array}{c}\text { ASTM } \\
\text { Test Method }\end{array}$ \\
\hline API gravity & 59.0 & D-287 \\
\hline Specific gravity & 0.7428 & \\
\hline $\begin{array}{l}\text { Distillation temperature }\left({ }^{\circ} \mathrm{F}\right) \\
\text { Initial boiling point } \\
10 \% \text { Evaporated } \\
50 \% \text { Evaporated } \\
90 \% \text { Evaporated } \\
\text { Maximum }\end{array}$ & $\begin{array}{r}77 \\
123 \\
222 \\
305 \\
376\end{array}$ & D-86 \\
\hline RVP (psi) & 8.70 & D-323 \\
\hline Oxidation stability (minimum) & $1440+$ & D-525 \\
\hline Gum (mg/100 ml after wash) & 0.0 & D-381 \\
\hline Lead in gasoline by AA (\%) & $<0.001$ & D-3237 \\
\hline Sulfur (ppm wt) & 65 & D-3120 \\
\hline $\begin{array}{l}\text { Hydrocarbon type, FIA (\%) } \\
\text { Olefins } \\
\text { Aromatics } \\
\text { Saturates }\end{array}$ & $\begin{array}{r}3.1 \\
30.1 \\
66.8\end{array}$ & D-3119 \\
\hline Research octane number, clear & 97.6 & D-2699 \\
\hline Octane sensitivity & 9.5 & D-3231 \\
\hline Phosphorus (g/gal) & $<0.0001$ & D-3343 \\
\hline Carbon weight fraction (\%) & 66.6 & D-3338 \\
\hline Carbon density ( $\mathrm{g}$ of $\mathrm{C} / \mathrm{gal}$ ) & 2431 & \\
\hline Net heating value (Btu/lb) & 18,448 & \\
\hline
\end{tabular}

a ASTM = American Society of Testing Materials, API = American Petroleum Institute, $\mathrm{AA}=$ atomic absorption, FIA = fluorescent indicator absorption, and clear $=$ no additives. 
TABLE 5.3 PIANO Analysis of Indolene

\begin{tabular}{|c|c|c|c|c|c|c|c|c|}
\hline $\begin{array}{l}\text { Carbon } \\
\text { Number }\end{array}$ & $\mathrm{n}$-Paraffins & iso-Paraffins & Aromatics & Napthenes & Olefins & di-Olefins & Unknowns & Total \\
\hline 3 & 0.003 & 0.000 & 0.000 & 0.000 & 0.000 & 0.000 & 0.000 & 0.003 \\
\hline 4 & 1.161 & 0.162 & 0.000 & 0.000 & 0.115 & 0.000 & 0.000 & 1.438 \\
\hline 5 & 6.675 & 8.811 & 0.000 & 0.769 & 0.653 & 0.009 & 0.000 & 16.917 \\
\hline 6 & 3.326 & 23.988 & 1.473 & 6.437 & 0.392 & 0.003 & 0.000 & 35.619 \\
\hline 7 & 0.194 & 6.682 & 1.226 & 1.718 & 0.339 & 0.000 & 0.073 & 10.232 \\
\hline 8 & 0.129 & 25.490 & 2.244 & 0.300 & 0.046 & 0.000 & 0.156 & 28.365 \\
\hline 9 & 0.020 & 2.039 & 2.122 & 0.033 & 0.048 & 0.000 & 0.156 & 4.418 \\
\hline 10 & 0.006 & 0.127 & 1.115 & 0.003 & 0.004 & 0.000 & 0.270 & 1.525 \\
\hline 11 & 0.039 & 0.000 & 0.170 & 0.000 & 0.000 & 0.000 & 0.265 & 0.474 \\
\hline 12 & 0.062 & 0.042 & 0.134 & 0.000 & 0.000 & 0.000 & 0.105 & 0.343 \\
\hline 13 & 0.047 & 0.000 & 0.000 & 0.000 & 0.000 & 0.000 & 0.081 & 0.128 \\
\hline 14 & 0.000 & 0.000 & 0.000 & 0.000 & 0.000 & 0.000 & 0.076 & 0.076 \\
\hline 15 & 0.000 & 0.000 & 0.0000 & 0.000 & 0.000 & 0.000 & 0.000 & 0.000 \\
\hline $\begin{array}{l}\text { Total HC } \\
\text { Oxygenates } \\
\text { Total }\end{array}$ & 11.662 & 67.341 & 8.484 & 9.260 & 1.597 & 0.012 & 1.182 & $\begin{array}{r}99.538 \\
0.465 \\
100.003\end{array}$ \\
\hline
\end{tabular}

\subsection{EXHAUST EMISSIONS TEST PROCEDURE}

Both exhaust emission tests - FTP-75 (Figure 5.3) and the EPA's off-cycle test (Figure 5.4) - were conducted in duplicate. The tests were conducted as specified in the Code of Federal Regulations (CFR) [42], with the five exceptions listed here.

1. The first test conducted with this vehicle was a preconditioning test done by using a modification of the procedure adopted by the Auto/Oil Air Quality Improvement Research Program (AQIRP) [43]. This procedure involves a purge of the evaporative emissions canister, fuel flush, diurnal heat-build, LA4 driving cycle, and engine-off and idle periods. For this study, the canister purge was excluded because the effect of the vehicle's canister was eliminated from these tests. The reason for using this preconditioning procedure in this study was to minimize any fuel carry-over and to set the vehicle's adaptivelearning engine control unit (ECU) for the use of emissions certification gasoline.

2. All exhaust emissions tests were conducted with the vehicle's air intake system connected to the oxygen-enrichment system. 


\begin{tabular}{|c|c|c|c|}
\hline \multirow[b]{2}{*}{ Property } & \multicolumn{2}{|c|}{$\begin{array}{l}\text { Value per Ambient } \\
\text { Temperature Range }\end{array}$} & \multirow[b]{2}{*}{ Test Method } \\
\hline & Summer & Winter & \\
\hline $\begin{array}{l}\text { Methanol plus higher alcohols, } \\
\text { minimum (vol \%) }\end{array}$ & 84 & 84 & ASTM D-4815 (modified) \\
\hline Hydrocarbons plus ethers (vol \%) & $14-16$ & $14-16$ & $\begin{array}{l}\text { Difference between } 100 \text { and } \\
\text { sum of alcohol and water }\end{array}$ \\
\hline RVP (psi) & $9.0-10.9$ & $10.9-13.1$ & $\begin{array}{l}\text { ASTM D-4953, ES14, or } \\
\text { ES15 }\end{array}$ \\
\hline $\begin{array}{l}\text { Acidity as acetic acid, maximum } \\
\text { (wt } \% \text { ) }\end{array}$ & \multicolumn{2}{|l|}{0.005} & ASTM D-1613 \\
\hline $\begin{array}{l}\text { Total chlorine as chlorides, } \\
\text { maximum (wt } \% \text { ) }\end{array}$ & \multicolumn{2}{|l|}{0.0001} & $\begin{array}{l}\text { ASTM D-2988 or D-3120 } \\
\text { (modified) }\end{array}$ \\
\hline $\begin{array}{l}\text { Gum, unwashed, maximum } \\
(\mathrm{mg} / 100 \mathrm{ml})\end{array}$ & \multicolumn{2}{|l|}{100.00} & ASTM D-381 \\
\hline Lead, maximum ( $\mathrm{g} / \mathrm{L})$ & \multicolumn{2}{|l|}{0.002} & $\begin{array}{l}\text { ASTM D-3237 or D-3229 } \\
\text { (modified) }\end{array}$ \\
\hline Phosphorous, maximum (g/L) & \multicolumn{2}{|l|}{0.002} & ASTM D-3231 \\
\hline Water, maximum (wt \%) & \multicolumn{2}{|l|}{0.50} & ASTM E-203 \\
\hline Appearance & \multicolumn{2}{|c|}{$\begin{array}{l}\text { Visibly free of suspended } \\
\text { or precipitate contaminants } \\
\text { when viewed with strong } \\
\text { back lighting }\end{array}$} & \\
\hline
\end{tabular}

3. The diurnal heat build was not performed because the evaporative emissions canister was eliminated from the intake-air system of the engine.

4. A single LA4 preconditioning cycle was run to condition the vehicle before conducting the first set of FTP and off-cycle tests at a specified oxygen concentration. For subsequent tests at the same oxygen concentration, preconditioning was not carried out, because the effect of the evaporative emissions canister was eliminated from this study.

5. The off-cycle emission tests were conducted by using the EPA's REP05 driving schedule, as shown in Figure 5.4. This cycle was developed to represent in-use driving that is outside the boundary of the current FTP driving cycle. The cycle was generated from a composite data set that equally 
TABLE 5.5 Certificate of Analysis for Methanol (M100, used for blending)

\begin{tabular}{ll}
\hline \multicolumn{1}{c}{ Property } & \multicolumn{1}{c}{ Result } \\
\hline & \\
Purity (wt \% of M100) & 99.945 \\
Acetone (ppm) & $<20$ \\
Color, APHA & $<5$ \\
Ethanol (ppm) & 31 \\
Hydrocarbons & Passed the analysis \\
Nonvolatile matter (g/100 ml) & 0.0002 \\
Acidity (wt \%) & 0.00213 \\
Alkalinity (wt \%) & 0.00013 \\
Appearance & $\mathrm{Clear}$ and free from suspended matter \\
Carbonizable substance, APHA & 0 \\
Distillation range & $0.2^{\circ} \mathrm{C}$ \\
Specific gravity at $25^{\circ} \mathrm{C}$ & 0.7875 \\
Permanganate test (min at $15^{\circ} \mathrm{C}$ ) & 68 \\
Chloride (ppm) & $<0.1$ \\
Moisture (wt \%) & 0.0470 \\
Odor & Passed the analysis \\
\hline
\end{tabular}

a $\mathrm{APHA}=$ Scale from 1 to 10 .

represented Los Angeles chase car data and Baltimore 3-parameter instrumented vehicle data. The primary purpose of the cycle is to assess in-use emissions. These tests were conducted immediately after the FTP test, with the first $505 \mathrm{~s}$ of the FTP driving cycle used as an engine warm-up procedure. Exhaust emissions were collected for analysis in three bags (Figure 5.4) similar to the FTP test, rather than in two bags, per the EPA. The factors used to obtain weighted-average emissions were $0.2807,0.5729$, and 0.1464 for bag 1 , bag 2 , and bag 3 , respectively.

The "shake-down" emission tests were conducted by using M85 at three intake-air oxygen concentrations. The specific tests were (1) cold phase for $505 \mathrm{~s}$ with ambient air, (2) complete FTP, (3) off-cycle at $23 \%$ oxygen, and (4) cold or hot for $505 \mathrm{~s}$ at $25 \%$ oxygen-enriched air. One of the main purposes of these tests was to document the constant oxygen concentrations and low-pressure changes of the intake air when the EAHU was used with this vehicle. M85 was used in these tests 


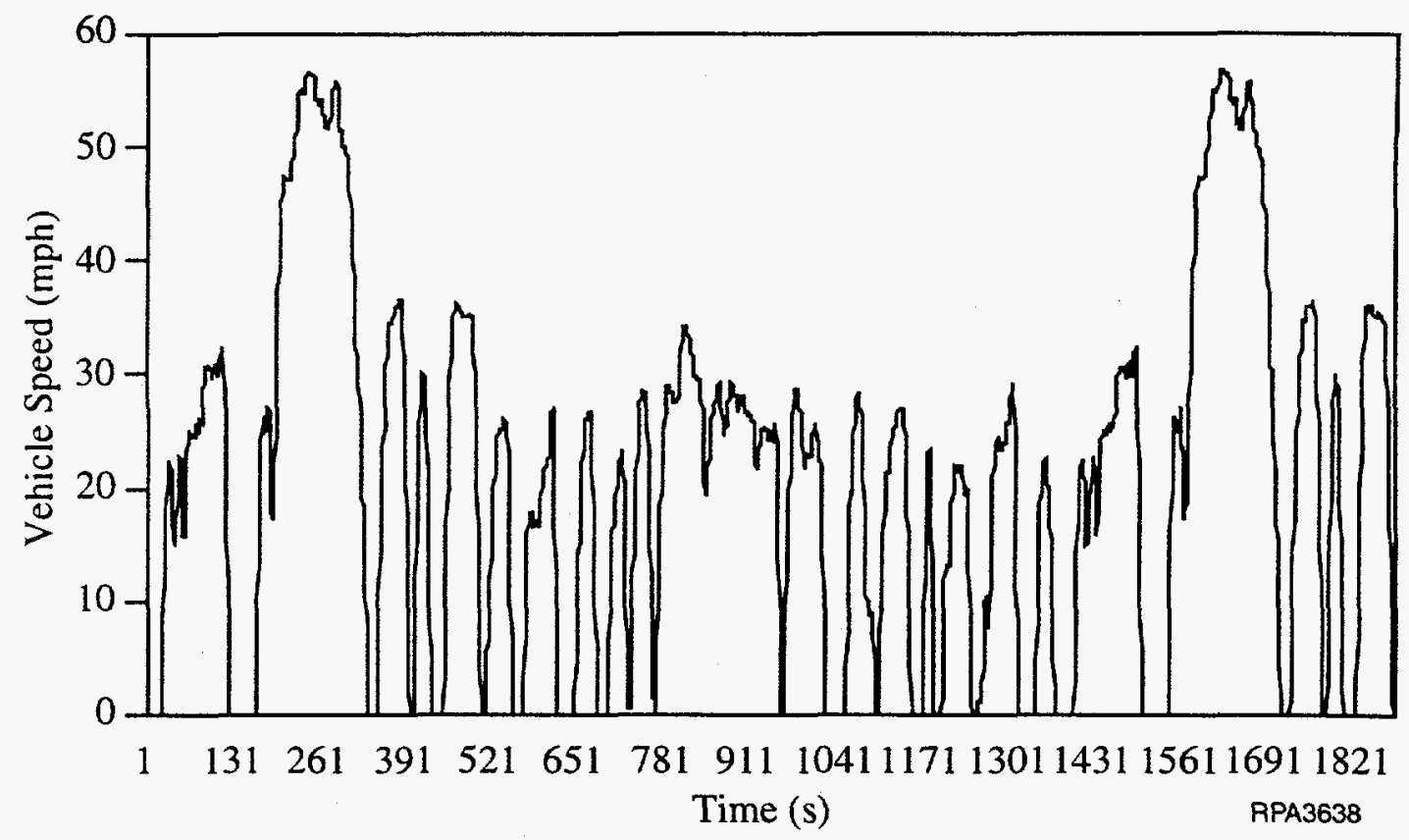

FIGURE 5.3 Federal Test Procedure FTP-75

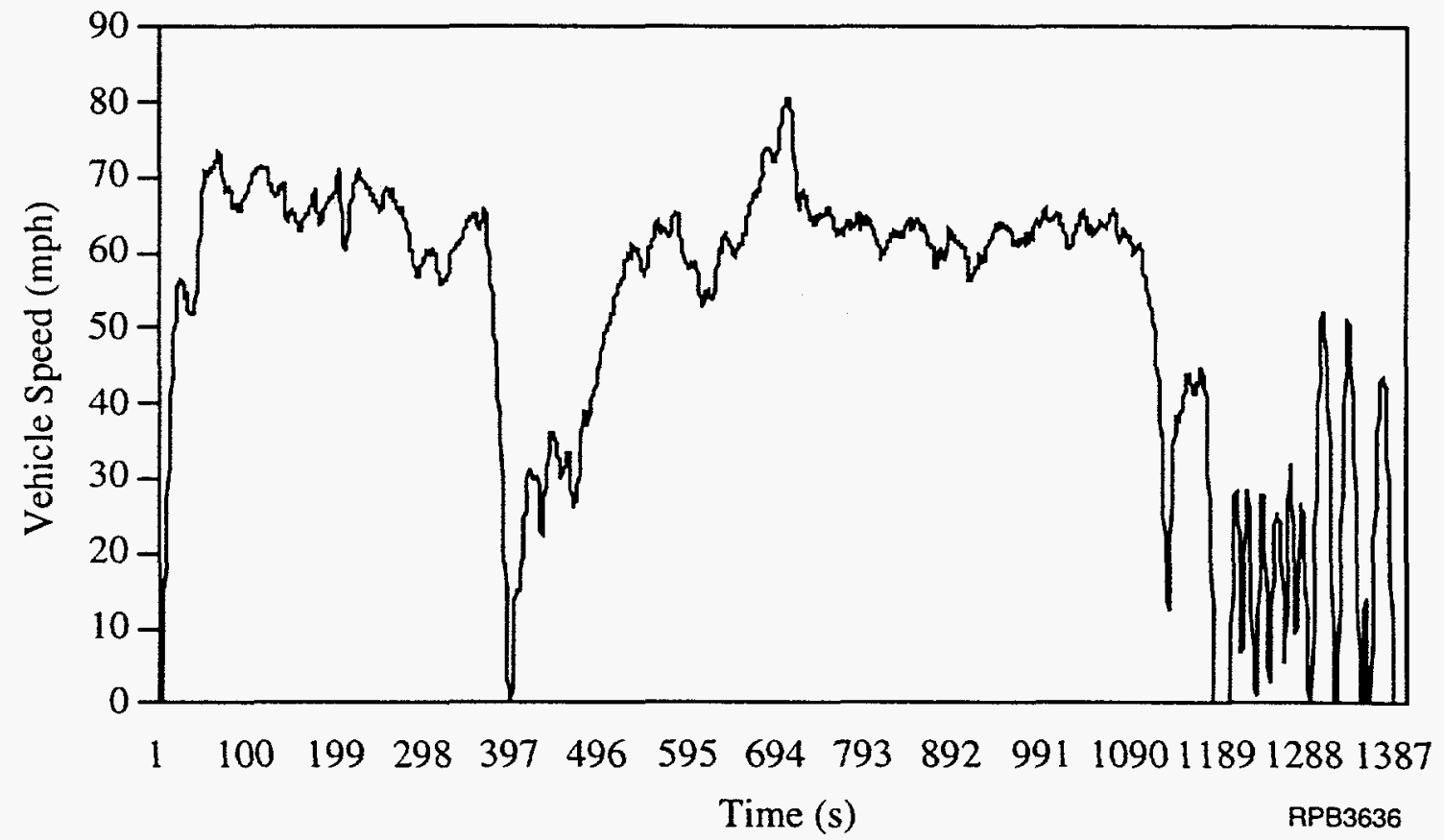

FIGURE 5.4 U.S. Environmental Protection Agency Off-Cycle Test REP05 
to provide samples of emissions from this specific fuel for speciation. In addition to the FTP and offcycle tests, an additional FTP was conducted to collect regulated and speciated emissions data during only the first $127 \mathrm{~s}$ of the cold-phase FTP. Nominal oxygen concentrations of $21 \%, 23 \%$, and $25 \%$ by volume were used for the intake air of the vehicle.

\subsection{HYDROCARBON SPECIATION ANALYSES}

Complete speciation of HCs, aldehydes, and ketones was conducted on the diluted exhaust samples for each of the three phases of the FTP test. A background (dilution air) sample was also speciated for the second phase of the emissions test. HC speciation of each sample was conducted by means of gas-chromatographic methodology to quantitatively identify more than $200 \mathrm{HCs}$. Aldehyde and ketone speciation was conducted by passing the diluted exhaust samples and a continuous background sample through silica gel cartridges impregnated with 2,4-dinitrophenylhydrazine and then analyzing the aldehyde and ketone derivatives by means of high-performance liquid chromatography. Additional details of the speciation procedures used are given in Reference 43. The data were reported in terms of milligrams per mile for each phase of the FTP emissions test for each compound, in addition to the total weighted grams per mile. To obtain speciation samples for the first $127 \mathrm{~s}$ of the cold-phase test, a separate set of timers was set up to start and stop the flow of diluted exhaust to a nominal 2-L Tedlar bag and the aldehyde/ketone cart. 


\section{EXPERIMENTAL RESULTS AND DISCUSSION}

\subsection{VEHICLE PERFORMANCE}

The vehicle ran smoothly when the intake air was enriched with up to $25 \%$ oxygen when both Indolene and M85 were used as test fuels. When oxygen-enriched intake air was used, the vehicle had excellent throttle response, and the driver had to back off the throttle to keep the required speed for the FTP emission tests, which does not happen when ambient intake air is used. Output from the knock sensor was fed to the vehicle's on-board computer to activate spark-timing retardation. Previous study showed that at an oxygen content of greater than $28 \%$, there was an audible knock from the engine. The maximum allowable spark-timing retardation was not enough to alleviate the knocking problem when the oxygen content was higher than $28 \%$. However, in the present experiments, such problems did not occur, since the maximum oxygen level was only about $25 \%$. Evidently, the knock sensor was effective enough to feed the vehicle's on-board computer to activate the spark-timing retardation with oxygen-enriched intake air.

\subsection{EMISSION MEASUREMENTS WITH INDOLENE}

All emissions data presented here are the averages of two or three separate FTP emission tests under similar operating conditions and procedures. From the $\mathrm{HC}$ speciation analyses, more than $200 \mathrm{HCs}$ were identified in both engine-out and converter-out exhaust, but only the most significant species were selected (including the four regulated toxics) to report on and discuss. To facilitate the discussion, these species are grouped into aldehydes, olefins, aromatics, and paraffins. OFP and specific reactivities (SRs) were estimated on the basis of CARB-MIR and maximum ozone incremental reactivity (MOIR) factors. The percentage reduction or increase in various emissions with oxygen-enriched intake air (compared with ambient intake air) was calculated as follows:

$$
\text { Percent variation }=\frac{[\text { mass emissions with ambient air }- \text { mass emissions with oxygen-enriched air }] \times 100}{\text { mass emissions with ambient air }}
$$

\subsubsection{FTP Engine-out Emissions}

The engine-out exhaust emissions during the FTP cycle, with two different oxygenenrichment levels (nominal 23\% and 25\%), are presented in Figure 6.1. Both THC and CO emissions were considerably reduced over the entire FTP cycle, whereas $\mathrm{NO}_{\mathrm{x}}$ emissions were relatively higher with oxygen-enriched air than with ambient air. The variations in $\mathrm{THC}, \mathrm{CO}$, and $\mathrm{NO}_{\mathrm{x}}$ emission characteristics with oxygen-enriched intake air were significant, in particular during the cold phase 

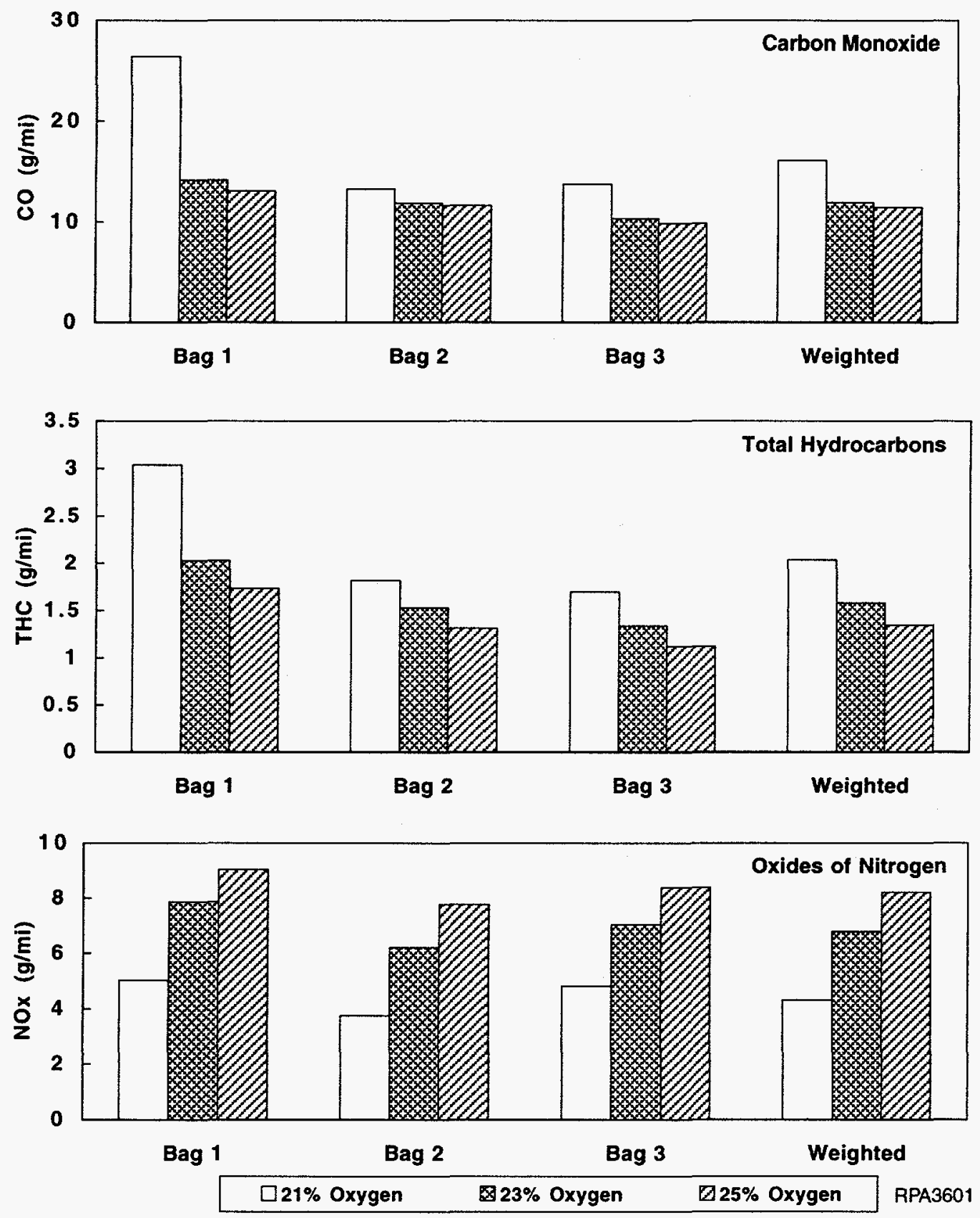

FIGURE 6.1 Engine-out CO, THC, and NO Emissions: FTP with Indolene 
(bag 1) of the FTP test cycle. The percentage reductions in THC emissions were about $33 \%$ and $43 \%$ with $23 \%$ and $25 \%$ oxygen-enriched air, respectively. The reduction in $\mathrm{CO}$ emissions was much greater, about $46 \%$ and $50 \%$ with $23 \%$ and $25 \%$ oxygen-enriched air, respectively. However, the corresponding $\mathrm{NO}_{\mathrm{x}}$ emission levels were higher by about $56 \%$ and $79 \%$. An increase in oxygen level from $23 \%$ to $25 \%$ resulted in marginal additional reductions in THC and CO but greater increases in $\mathrm{NO}_{\mathrm{x}}$ emissions.

Increasing the oxygen content in the engine intake air from $21 \%$ to $23 \%$ or $25 \%$ by volume decreased THC and $\mathrm{CO}$ emissions and increased exhaust $\mathrm{NO}_{x}$, as occurred in many previous investigations [10, 13-16, 33]. These effects were postulated as a result of more complete combustion and higher flame temperatures that occur in the presence of oxygen-enriched air. When oxygen-enriched inlet air is used, more oxygen is made available for oxidation reactions, both in the combustion chamber and in the exhaust. Furthermore, such air permits relatively leaner operation, and oxygen-to-fuel ratios are much closer to stoichiometric, even during the cold-start and warm-up periods. It is expected that the reaction rate will be higher in the combustion chamber with an oxygen-enriched charge, which helps to oxidize the fuel more rapidly. This situation leads to smaller amounts of unburned THC and CO emissions. The higher flame temperatures and/or flame speeds with oxygen-enriched air also cause levels of unburned THC and CO emissions leaving the engine to be lower. Increasing oxygen enrichment increases the flame temperature, with the highest temperature at any given oxygen level occurring near the stoichiometric mixture [13]. Higher flame temperatures have been shown to decrease flame quenching. Consequently, the THC emissions that originate from flame-quenching effects are decreased by oxygen enrichment. Moreover, the higher combustion and exhaust gas temperatures may promote post-flame THC oxidation, which may be an additional cause for the observed decrease in THC emissions. All the above-mentioned factors substantiate the observed lower THC and CO emission levels when oxygen-enriched air (up to $25 \%$ by volume) is used in the engine inlet.

The most important engine variables that affect NO emissions are the air-to-fuel ratio, burned-gas fraction of the in-cylinder unburned mixture, and spark timing. Air-to-fuel ratio and spark timing interact predominantly to cause the high $\mathrm{NO}_{\mathrm{x}}$ emission levels associated with oxygenenriched inlet air [44]. Oxygen enrichment causes higher flame temperatures and faster flame speeds (shorter combustion duration), and higher concentrations of oxygen in the reacting mixtures (higher oxygen-to-fuel ratios) increase the rate of $\mathrm{NO}$ formation. The increase in $\mathrm{NO}_{\mathrm{x}}$ level was evident from the observed results (Figure 6.1). Neither the spark timing nor the ECU calibration was optimized in the present oxygen-enrichment experiments. Hence, recalibration of the ECU for proper air/fuel management and spark timing $[45,46]$ to account for the oxygen-enriched inlet air might help to lower the increase in $\mathrm{NO}_{\mathrm{x}}$ emissions, and it is essential for reducing all the exhaust emissions simultaneously and effectively. The use of exhaust gas recirculation would reduce NO. However, this use is somewhat akin to adding back the nitrogen eliminated through oxygen enrichment. Since the effects on NO emissions are generally the same with nitrogen $\left(\mathrm{N}_{2}\right)$ or exhaust gas [10], the end 
result resembles a substitution of exhaust gas for $\mathrm{N}_{2}$. It is anticipated that the emission results will approach those of the baseline condition as recirculation rates are increased [47].

To examine the effect of oxygen enrichment of intake air on cold-phase FTP exhaust emissions, the emission characteristics for the initial $127 \mathrm{~s}$ during the start-up period were studied in detail. The vehicle speed during the initial $127 \mathrm{~s}$ of the cold-phase FTP (first "hill" or cycle) is shown in (modal analysis) Figure 6.2. In general, when ambient intake air is used, CO emissions start increasing from the key-on (when the ignition is started) and reach their first peak during the engine idle period (about $17 \mathrm{~s}$ from the start-up). The maximum $\mathrm{CO}$ level is reached just prior to the first acceleration peak, and subsequent peaks are synchronized with vehicle acceleration. On the other hand, the first peak of THC and $\mathrm{NO}_{x}$ emissions appears at about 8 and $30 \mathrm{~s}$, respectively, from key-on. During the initial 127-s period, about five to six peaks of both THC and CO emissions were significantly reduced as a result of oxygen-enrichment, as illustrated in Figure 6.3. For example, the first and third peaks of THC emissions (about 850 and 1,040 ppm) were reduced to 250 and $540 \mathrm{ppm}$, respectively, with $25 \%$ oxygen-enriched air. The maximum peak of $\mathrm{CO}$ (about 7,640 ppm) was lowered to about 4,100 and $3,090 \mathrm{ppm}$ with $23 \%$ and $25 \%$ oxygen-enriched air, respectively. The corresponding $\mathrm{NO}_{\mathrm{x}}$ peak was increased from about 130 to $400 \mathrm{ppm}$ when the oxygen level increased from ambient to either $23 \%$ or $25 \%$. Between the $23 \%$ and $25 \%$ oxygen-enrichment levels, the reductions obtained in $\mathrm{CO}$ and $\mathrm{THC}$ emissions were considerable, at $25 \%$. On the other hand, $\mathrm{NO}_{\mathrm{x}}$ emission levels were higher (a two-fold increase) from the increased oxygen-level compared

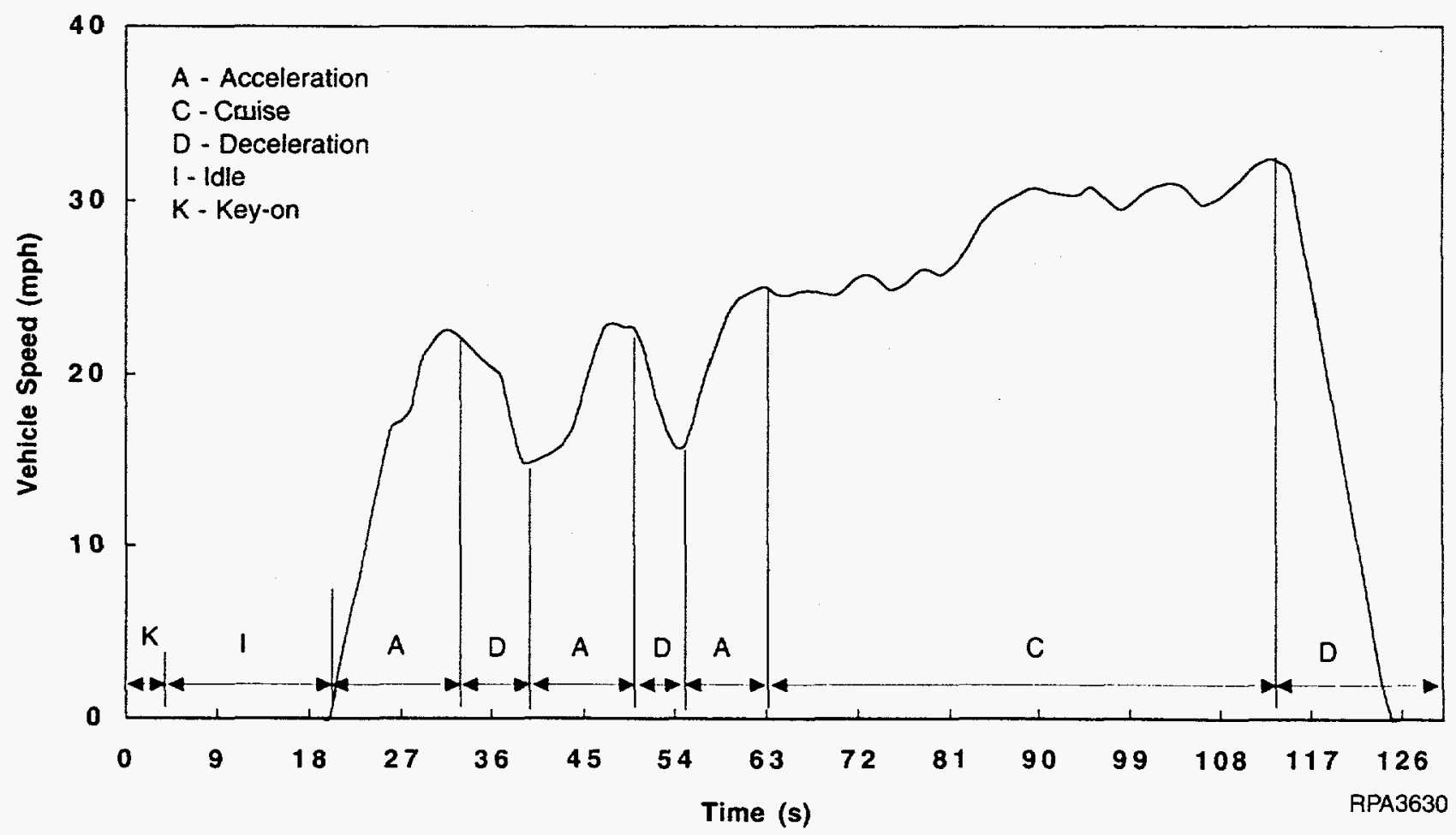

FIGURE 6.2 Vehicle Speeds: First $127 \mathrm{~s}$ of the Cold-Phase FTP with Indolene 

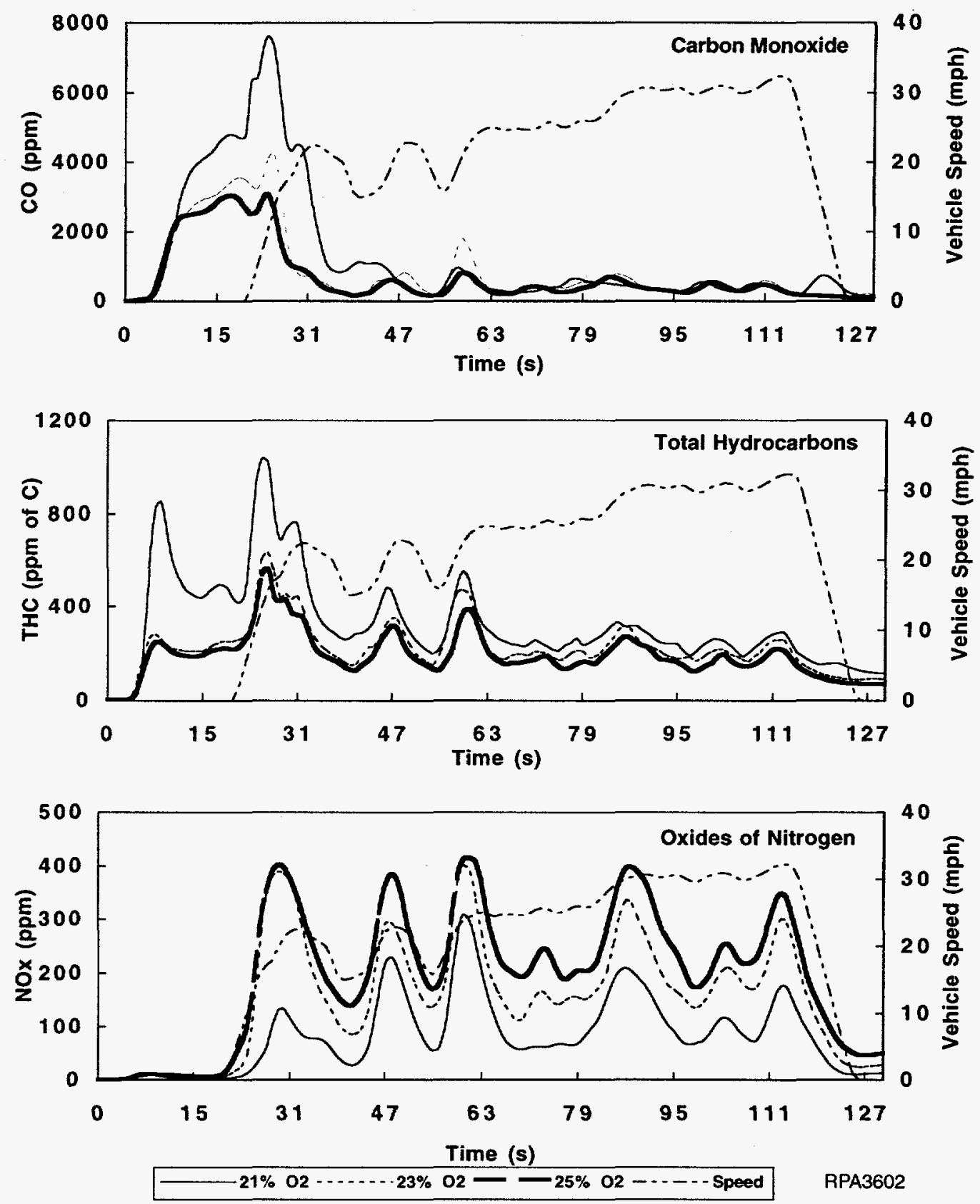

FIGURE 6.3 Engine-out, Time-Resolved CO, THC, and $\mathrm{NO}_{x}$ Emissions: First $127 \mathrm{~s}$ of the Cold-Phase FTP with Indolene 
with those from ambient air. However, the cold-phase $\mathrm{NO}_{\mathrm{x}}$ emissions account for only about 20-30\% of the total exhaust $\mathrm{NO}_{\mathrm{x}}$, so the increase in $\mathrm{NO}_{\mathrm{x}}$ with oxygen-enriched air during the initial $127 \mathrm{~s}$ of the cold phase should pose less of a problem if this technique is used only during the cold phase or initial $127 \mathrm{~s}$ of the cold-phase FTP cycle.

The major engine-out $\mathrm{HC}$ compounds such as aldehydes, aromatics, paraffins, and olefins from the HC speciation analysis are presented in Figures 6.4-6.7. Aldehydes contribute significantly to ozone formation, they have carcinogenic effects, and their odor is considered unpleasant by most. The olefins are also believed to contribute significantly to ozone formation and photochemical smog, particularly such reactive species as ethene, propene, propadiene, isobutene, 2-methyl-1-butene, isoprene, and 1,3-butadiene. Aromatics and paraffins are generally difficult to convert into more harmless species or to eventually convert into carbon dioxide and water at the catalytic converter. It is beneficial if the engine produces only small amounts of aromatics and olefins. Of the exhaust HC compounds, acetaldehyde, formaldehyde, benzene, and 1,3-butadiene are specifically regulated toxics. On the basis of present investigations, oxygen enrichment of the intake air seems to be capable of decreasing the engine-out concentrations of these difficult-to-oxidize species and regulated air toxics. The test results (Figure 6.4) indicate that the aldehyde emissions were considerably reduced with oxygen-enriched (23\%) air, in particular during the cold phase of the FTP cycle. With $23 \%$ enriched oxygen, the reduction in aldehyde emissions was significant; however, with $25 \%$ oxygen-enriched intake air, the percentage reduction was less than that obtained with $23 \%$ oxygen-enriched air. The optimal level of oxygen enrichment required to achieve the lowest possible level of aldehyde emissions was not clear. Of the two different oxygen-enrichment levels, $23 \%$ is beneficial with regard to aldehydes, aromatics, some of the paraffins, and olefin emissions, as shown in Figures 6.4 through 6.7.

Of the six major air pollutants for which National Ambient Air Quality Standards (NAAQSs) have been listed under the Clean Air Act (CAA), ozone continues to be the most pervasive problem. It is the most prevalent photochemical oxidant and an important component of smog. Accordingly, ozone has been identified in the CAA as a common and widespread air pollutant [48]. The MIR and MOIR factors estimate the OFP of individual compounds under different atmospheric conditions, when limited by the availability of $\mathrm{HCs}$ and the $\mathrm{NO}_{\mathrm{x}}$-to-HC ratio, respectively [49]. These factors have the units of grams of ozone per gram of individual $\mathrm{HC}$ species. To date, MIR and MOIR factors for 156 different HC components have been determined from the variation of mathematical climate simulation models in laboratory experiments for the CARB. The maximum OFP can be determined by summing the product of each individual $\mathrm{HC}$ species with its individual MIR or MOIR factors:

$$
O F P=\sum_{i=1}^{156}\left(H C_{i} \times M I R_{i}\right)
$$



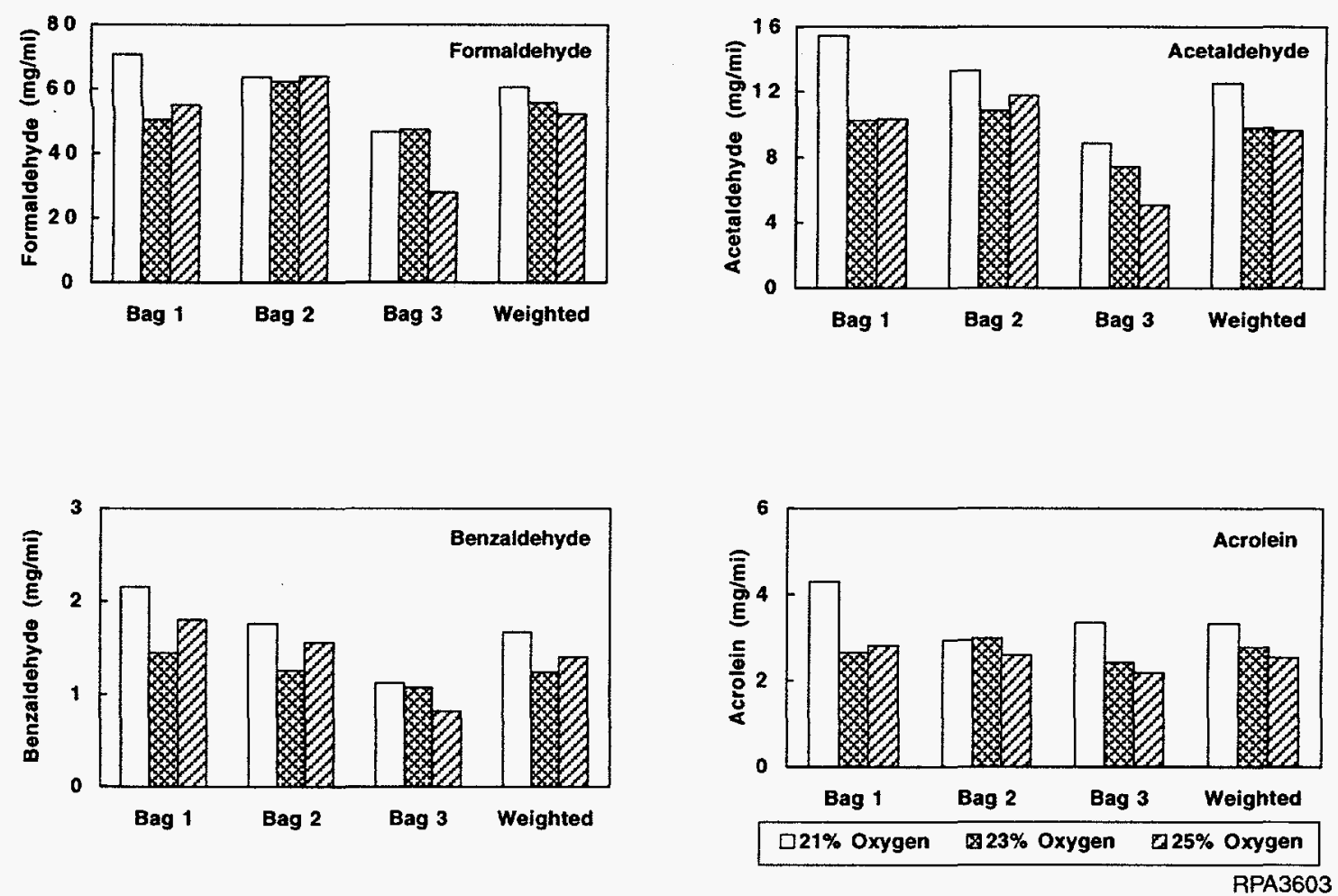

FIGURE 6.4 Effects of Oxygen-Enriched Intake Air on Engine-out Aldehyde Emissions: FTP with Indolene

or

$$
\begin{gathered}
\text { OFP }=\sum_{i=1}^{156}\left(H C_{i} \times \text { MOIR }\right) \\
\text { Units: } \quad \frac{g \text { ozone }}{m i}=\left(\frac{g H C_{i}}{m i}\right) \times\left(\frac{g \text { ozone }}{g H C_{i}}\right)
\end{gathered}
$$

To show how much ozone per gram of the HC emission can be formed, the term "specific reactivity" (SR) has been introduced. It is calculated by:

$$
S R=\frac{O F P}{N M O G}
$$



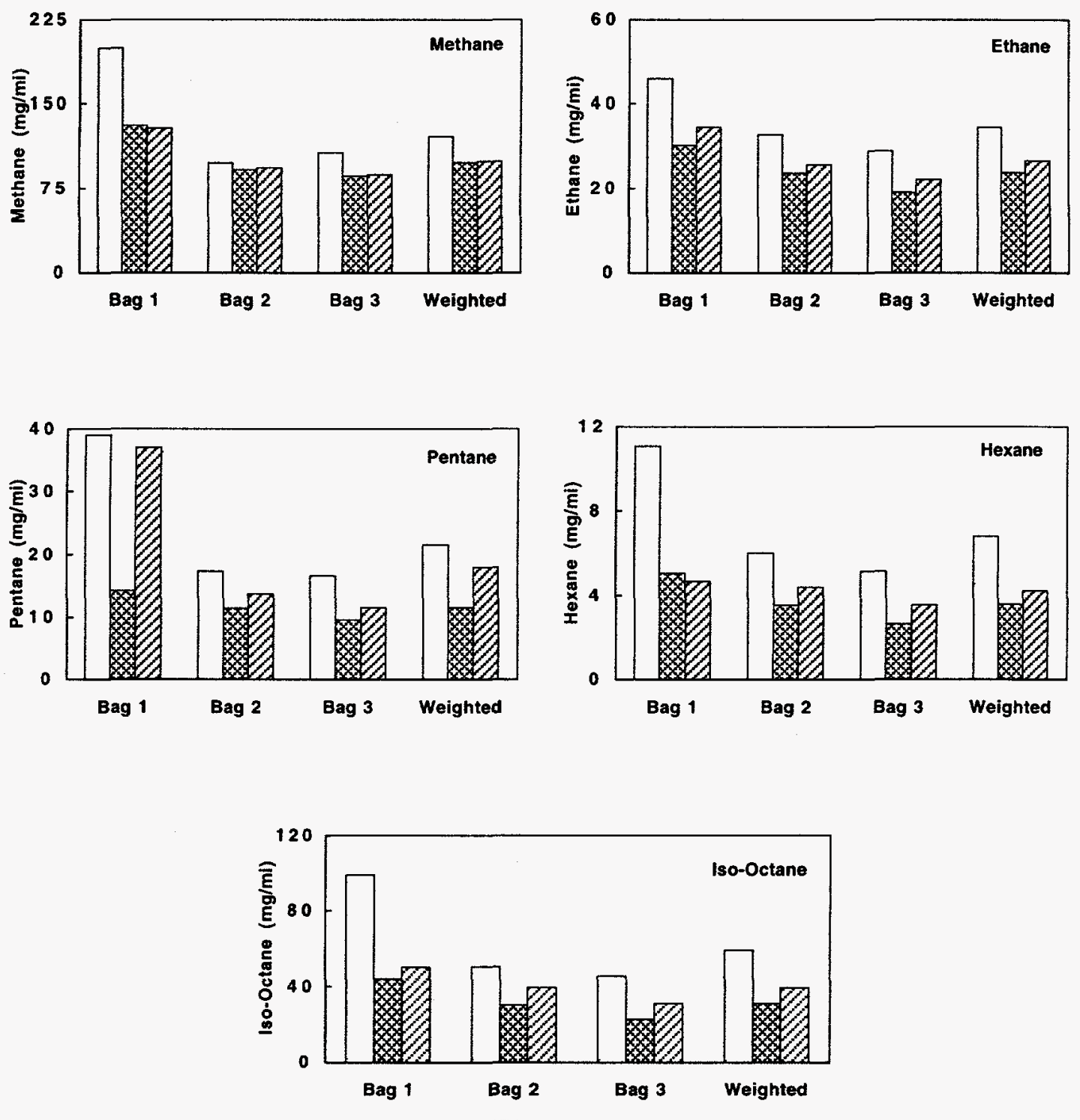

$\square 21 \%$ Oxygen ख $23 \%$ Oxygen $625 \%$ Oxygen

RPA3604

FIGURE 6.5 Effects of Oxygen-Enriched Intake Air on Engine-out Paraffin Emissions: FTP with Indolene 

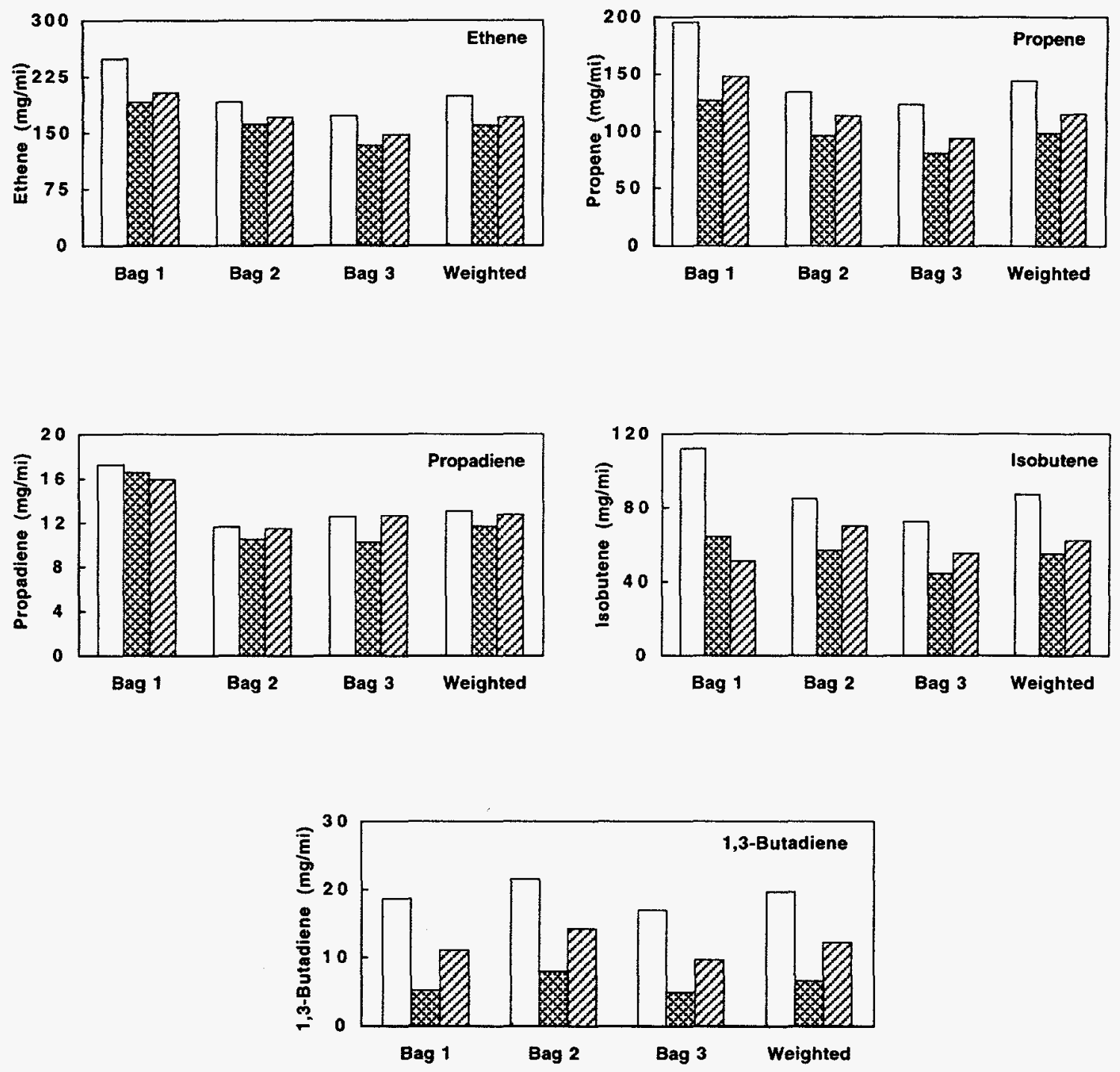

प21\% Oxygen E $23 \%$ Oxygen $625 \%$ Oxygen

RPA3605

FIGURE 6.6 Effects of Oxygen-Enriched Intake Air on Engine-out Olefin Emissions: FTP with Indolene 

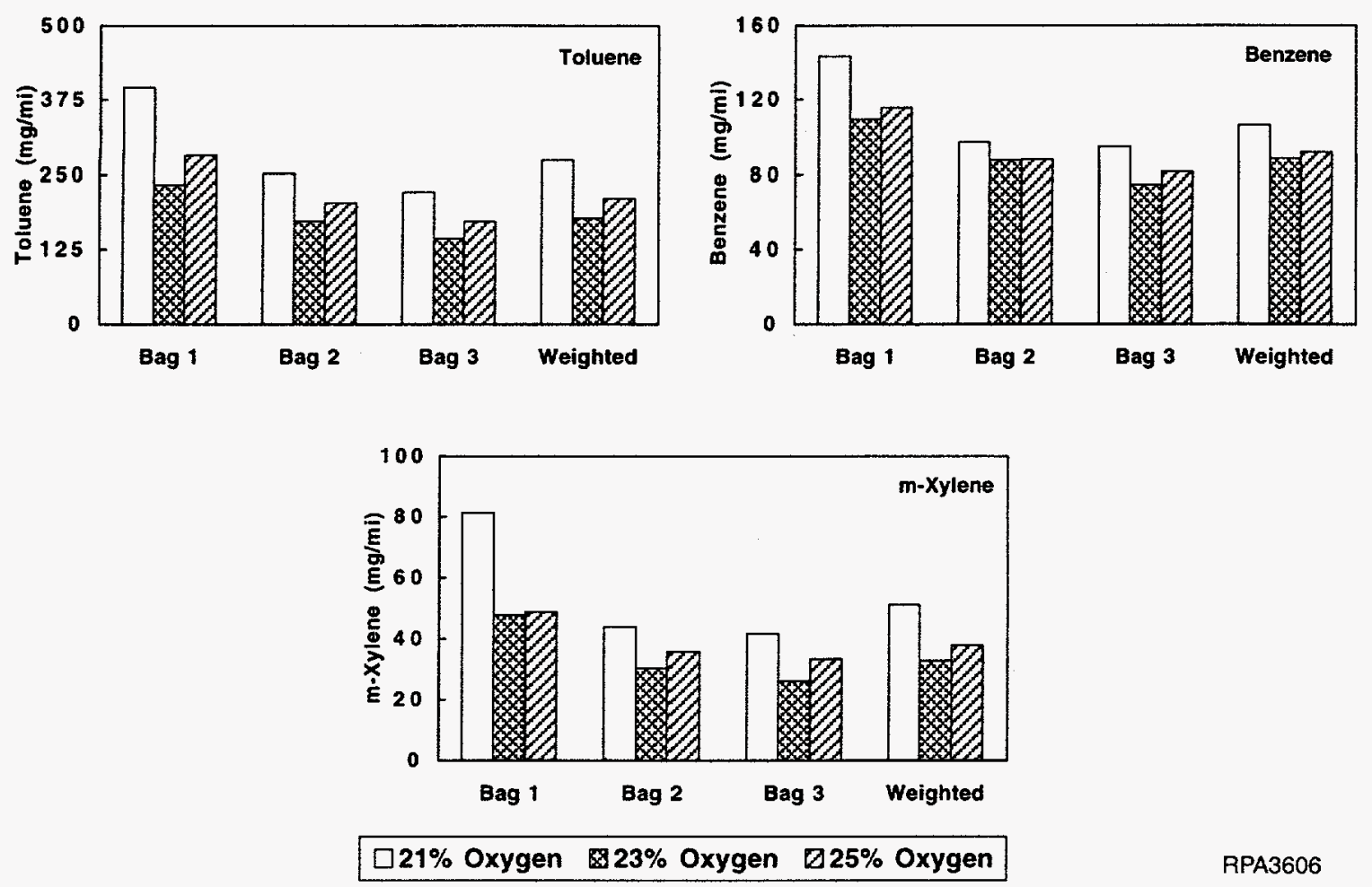

FIGURE 6.7 Effects of Oxygen-Enriched Intake Air on Engine-out Aromatic Emissions: FTP with Indolene

$$
\text { Units: } \quad \frac{g \text { of ozone }}{g \text { of } N M O G}=\frac{g \text { of ozone } / m i}{g \text { of } N M O G / m i}
$$

The THC levels emitted from light-duty passenger vehicles are highest during the coldphase FTP. Consequently, both OFP and SR are of greater significance during this period. Oxygen enrichment changes the composition and also lowers the amount of the HCs emitted, so that OFP is lowered with oxygen-enriched air. The SR variation depends on the maximum OFP estimated and total NMOG. The reductions obtained in the OFP and SR (based MIR and MOIR factors) with 23\% and $25 \%$ oxygen-enriched air are shown in Figure 6.8 and 6.9 , respectively.

The above results indicate that oxygen enrichment significantly reduces engine-out THC and $\mathrm{CO}$ emissions, major toxic species, and OFP, particularly during the cold-phase FTP. These benefits however, are realized at the expense of higher $\mathrm{NO}_{\mathrm{x}}$ emissions. Because the converter is generally not fully effective during the initial cold-phase period, the advantages of lower engine-out emissions with oxygen-enriched air can suitably be exploited during this period. Oxygen-enriched intake air also helps to lower the requirements of the catalytic converter during the cold-phase 

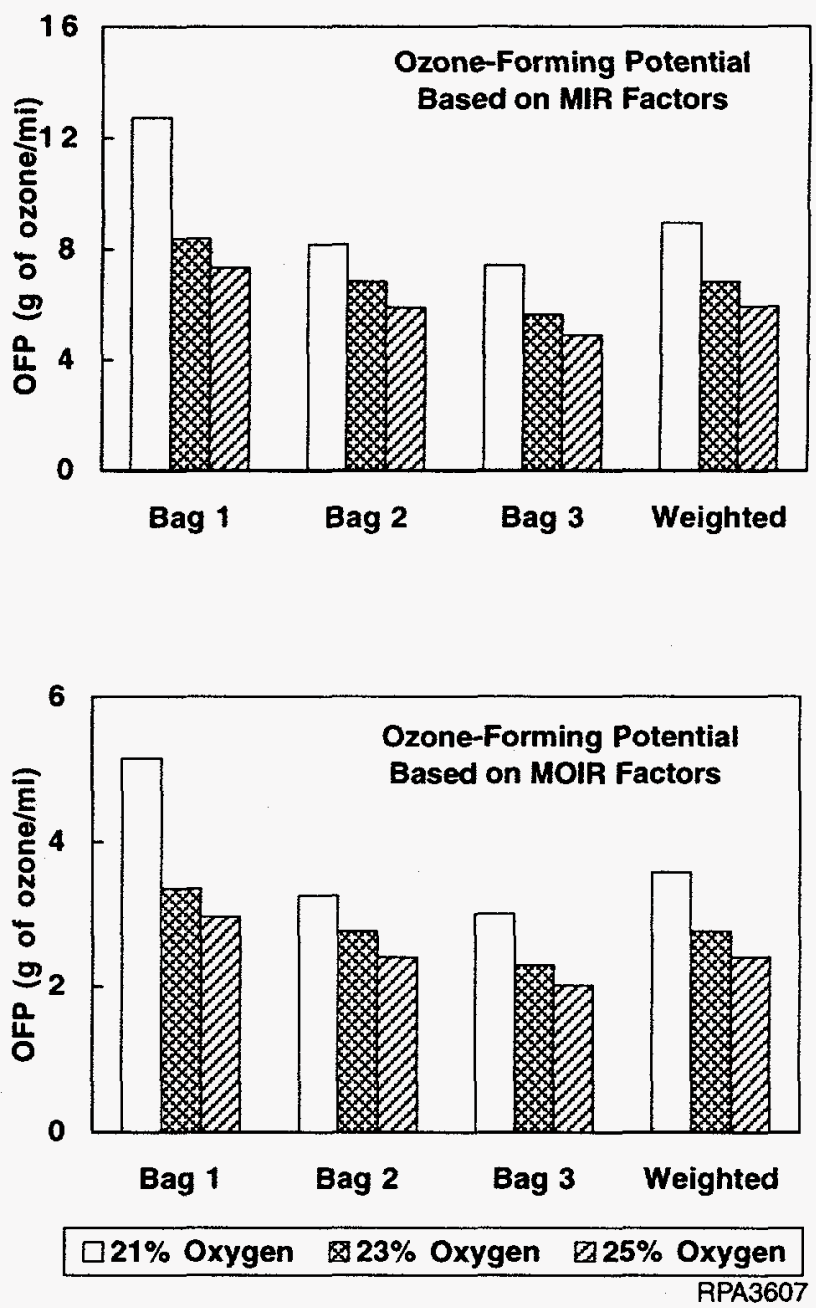

FIGURE 6.8 Effects of Oxygen-Enriched Intake Air on Engine-out Ozone-Forming Potential: FTP with Indolene

period. Oxidation/reduction reactions in the catalyst bed might also be affected because of the change in engine-out exhaust concentration and exhaust gas temperature with oxygen enrichment.

\subsubsection{FTP Converter-out Emissions}

This section presents the results obtained from the converter-out emissions when two different oxygen-enrichment levels are used. All the converter-out emissions data presented are the averages of two or three separate FTP tests performed under similar operating conditions. Figure 6.10 shows the average converter-out THC, $\mathrm{CO}$, and $\mathrm{NO}_{\mathrm{x}}$ emissions during the FTP cycle with two different oxygen-enriched air levels (23\% and 25\%). Both THC and CO emissions were 

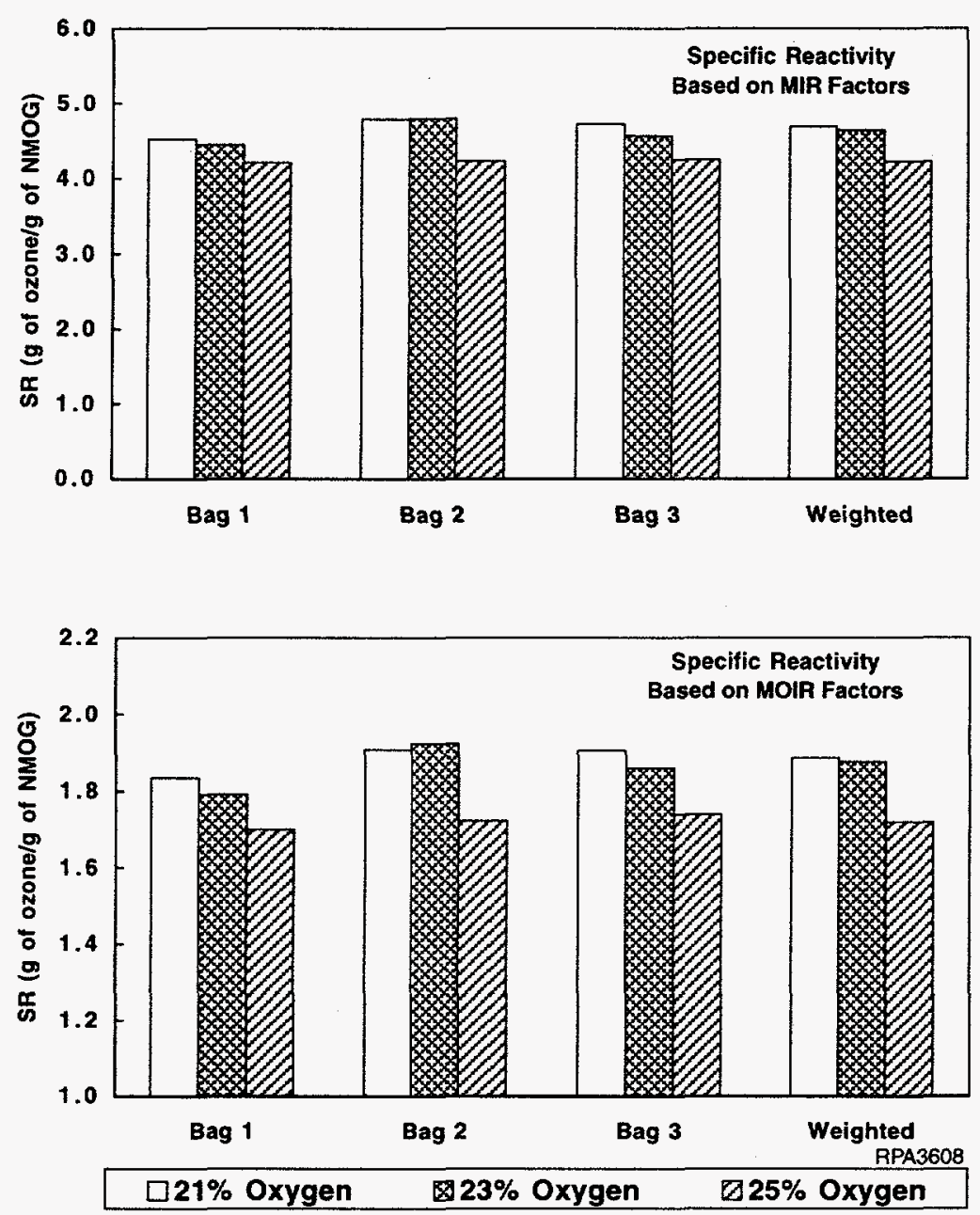

FIGURE 6.9 Effects of Oxygen-Enriched Intake Air on Engine-out Specific Reactivity: FTP with Indolene

reduced with oxygen-enriched air during the entire FTP cycle, and this reduction was quite significant at the higher oxygen-enrichment level (25\%). The reductions in THC and CO emissions were considerable during the cold phase (bag 1) of the FTP cycle with $23 \%$ or $25 \%$ oxygen-enriched air. During the cold phase, THC emissions were reduced by about $16 \%$ and $30 \%$ with $23 \%$ and $25 \%$ oxygen-enrichment levels, respectively. The corresponding $\mathrm{CO}$ emissions were reduced by about $14 \%$ and $37 \%$, respectively. However, $\mathrm{NO}_{\mathrm{x}}$ emission levels were about one to three times higher than those associated with ambient air. The reduction in converter-out THC and CO emissions primarily results from the lower level of engine-out emissions resulting from more complete combustion with oxygen-enriched air. Apparently, the additional oxygen available in the engine-out exhaust provides more oxygen for the catalytic oxidation of the $\mathrm{CO}$. In addition, there were substantially fewer $\mathrm{HCs}$ to compete with $\mathrm{CO}$ for the oxygen. These factors might have influenced the $\mathrm{CO}$ oxidation process in the converter. 

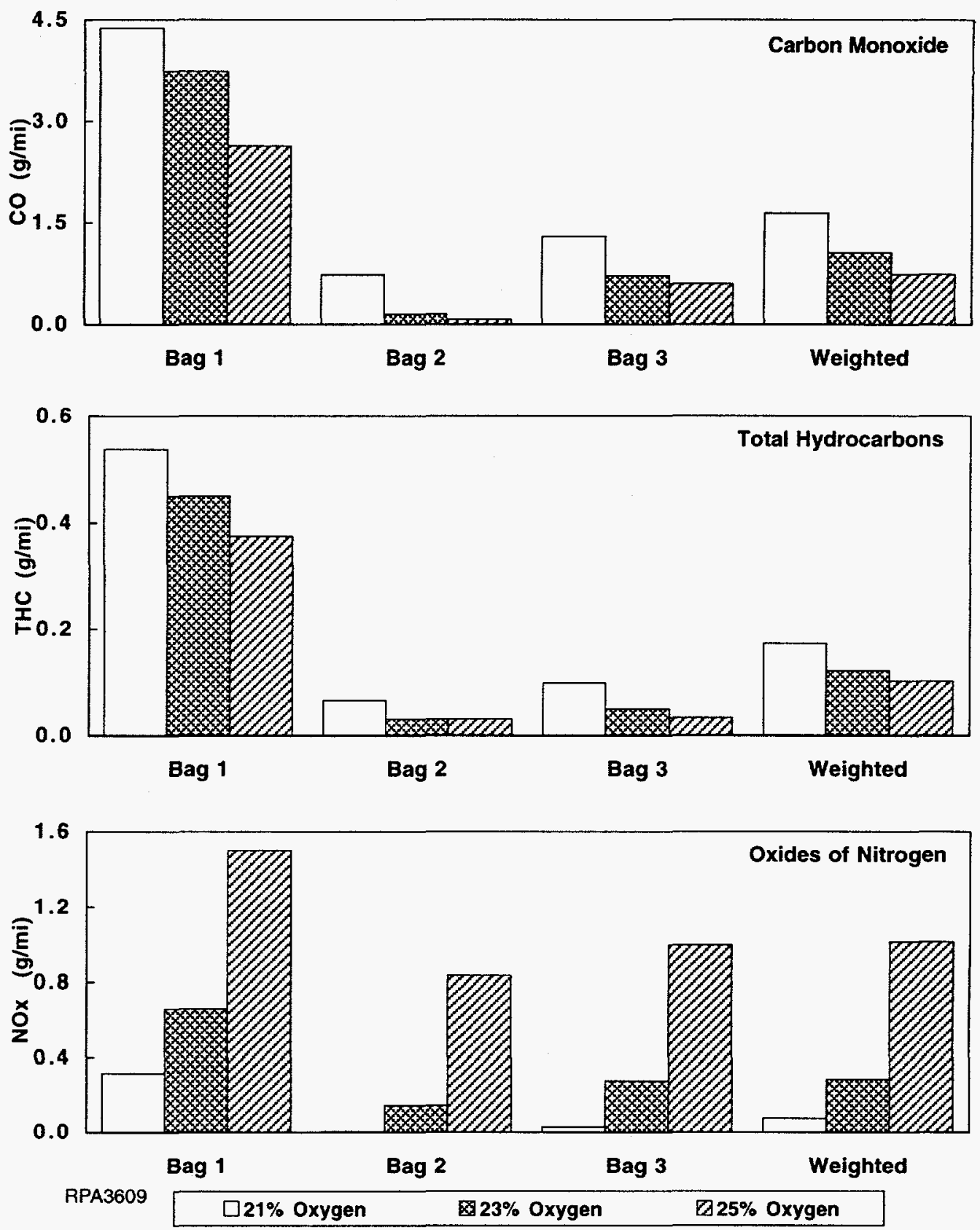

FIGURE 6.10 Converter-out $\mathrm{CO}$, THC, and $\mathrm{NO}_{\mathrm{x}}$ Emissions: FTP with Indolene 
The effect of oxygen-enriched intake air during the cold phase FTP can also be noticed from both the engine-out and converter-out cumulative THC and CO emissions. A comparison of cumulative THC and $\mathrm{CO}$ emissions when ambient air and $25 \%$ oxygen-enriched intake air are used during the cold-phase FTP is shown in Figure 6.11. With ambient air, the cumulative engine-out THC and CO emissions increased continuously over the cold-phase period, and cumulative converter-out emissions continued to increase rapidly until just over $300 \mathrm{~s}$, when they leveled off. In contrast, the cumulative engine-out THC and CO emission levels are much lower with $25 \%$ oxygen-enriched air than ambient air. When $25 \%$ oxygen-enriched air was used, the converter-out THC emissions tended to level off much earlier, and at around $130 \mathrm{~s}$ and thereafter, the increase in cumulative THC emissions was very marginal over time. Similarly, the cumulative converter-out $\mathrm{CO}$ emissions leveled off at about $90 \mathrm{~s}$ with $25 \%$ oxygen-enriched air and at about $300 \mathrm{~s}$ with ambient air. These benefits were attained because of the lower level of engine-out emissions made possible by oxygen-enriched air. The differences in both engine-out and converter-out cumulative emissions over time further demonstrate the reductions obtained in THC and $\mathrm{CO}$ with oxygen enrichment, particularly during the cold-phase FTP.

The time-resolved emissions during the initial $127 \mathrm{~s}$ of the cold-phase FTP cycle with $23 \%$ and $25 \%$ oxygen-enrichment levels are presented in Figure 6.12. Noticeable reductions were obtained by using $25 \%$ oxygen-enriched air rather than a $23 \%$ oxygen level, for both THC and CO. For the initial $30 \mathrm{~s}, 25 \%$ oxygen-enriched air was more effective in lowering the first peak of the THC and CO emissions than was the $23 \%$ oxygen level; thereafter, both the $23 \%$ and $25 \%$ levels had similar effects when compared with those of ambient air. The emission levels of $\mathrm{NO}_{\mathrm{x}}$ were generally higher with both $23 \%$ and $25 \%$ oxygen-enrichment levels. However, during the initial 20 -s period, the $\mathrm{NO}_{\mathrm{x}}$ emissions did not increase with either the $23 \%$ or $25 \%$ oxygen level. Thereafter, they increased with increasing oxygen level. All three $\left(\mathrm{CO}, \mathrm{THC}, \mathrm{NO}_{\mathrm{x}}\right)$ emissions reach their maximum values within 22 to $27 \mathrm{~s}$ from key-on during the first 127-s cold-phase period. Because of the $25 \%$ oxygen-enriched air, the maximum $\mathrm{CO}$ level decreased from about 2,320 to $1,550 \mathrm{ppm}$, THCs decreased from 580 to $400 \mathrm{ppm}$, and $\mathrm{NO}_{\mathrm{x}}$ increased from 180 to $420 \mathrm{ppm}$.

The initial 127-s period of the cold phase is crucial for catalytic converter operation because of the delay in time involved for the catalyst to reach its light-off temperature. The amount of time needed for the heated oxygen sensor to reach operating condition is about $30 \mathrm{~s}$. Thereafter, the engine can be run at a stoichiometric mixture, provided drivability is acceptable [7]. Oxygenenriched intake air helped lower the engine-out THC and CO emission levels during this period. It also helped increase converter efficiency, particularly with regard to THC and CO conversions, because of the relatively higher oxygen concentration in the exhaust. It has been reported [7] that an excess of $1 \%$ oxygen in the exhaust lowers the THC and CO light-off temperatures by $20-30^{\circ} \mathrm{C}$, and $2 \%$ oxygen leads to a decrease of $30-50^{\circ} \mathrm{C}$. The relatively higher oxygen levels in the exhaust and relatively higher exhaust gas temperatures could indirectly help the catalyst to reach its light-off temperature much faster while promoting more oxidation reactions. Catalyst bed temperature measurement (beyond the scope of the present work) would be beneficial to identify the precise time 

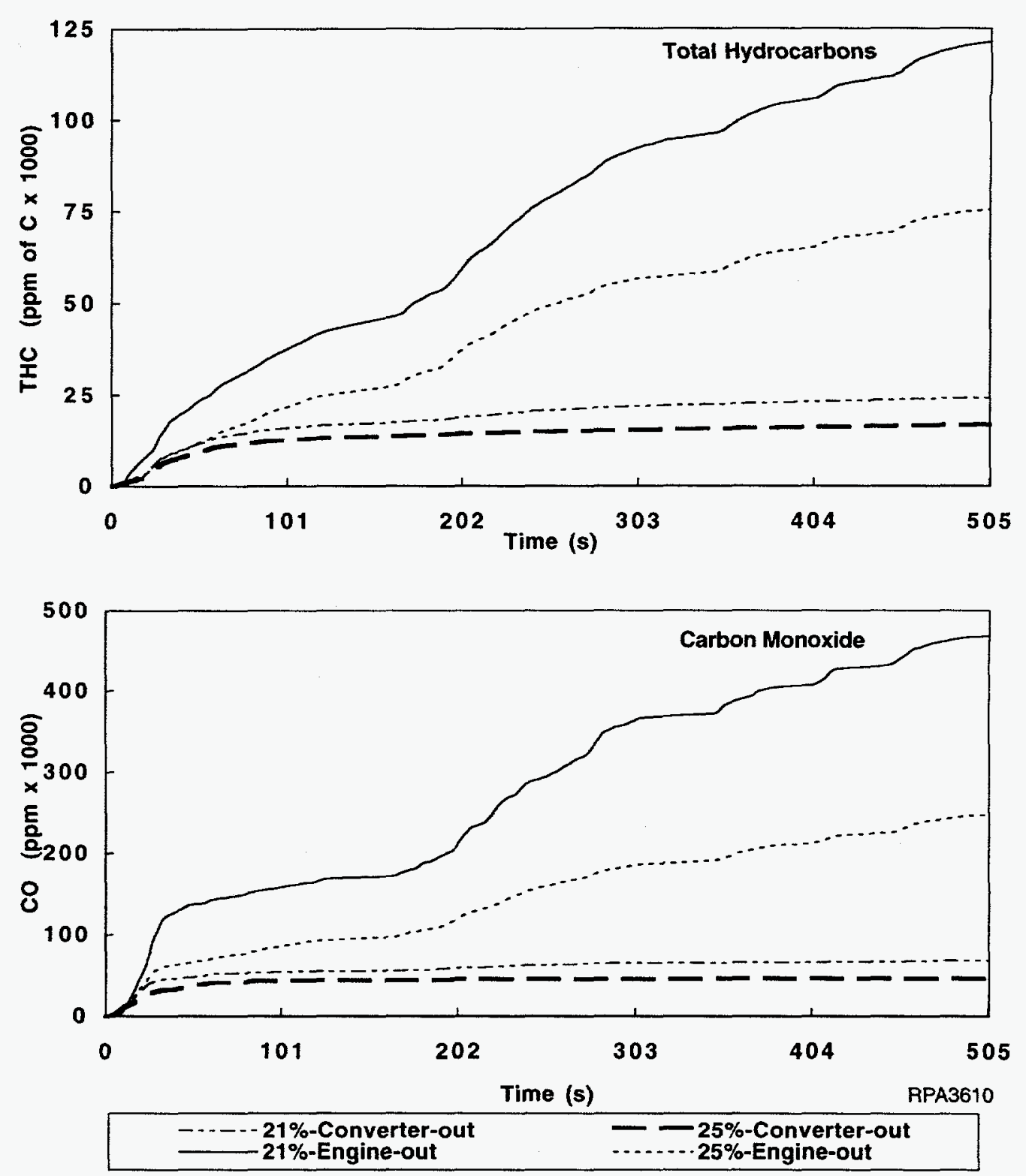

FIGURE 6.11 Cumulative Engine-out and Converter-out Average THC and CO Emissions: Cold-Phase FTP with Indolene 

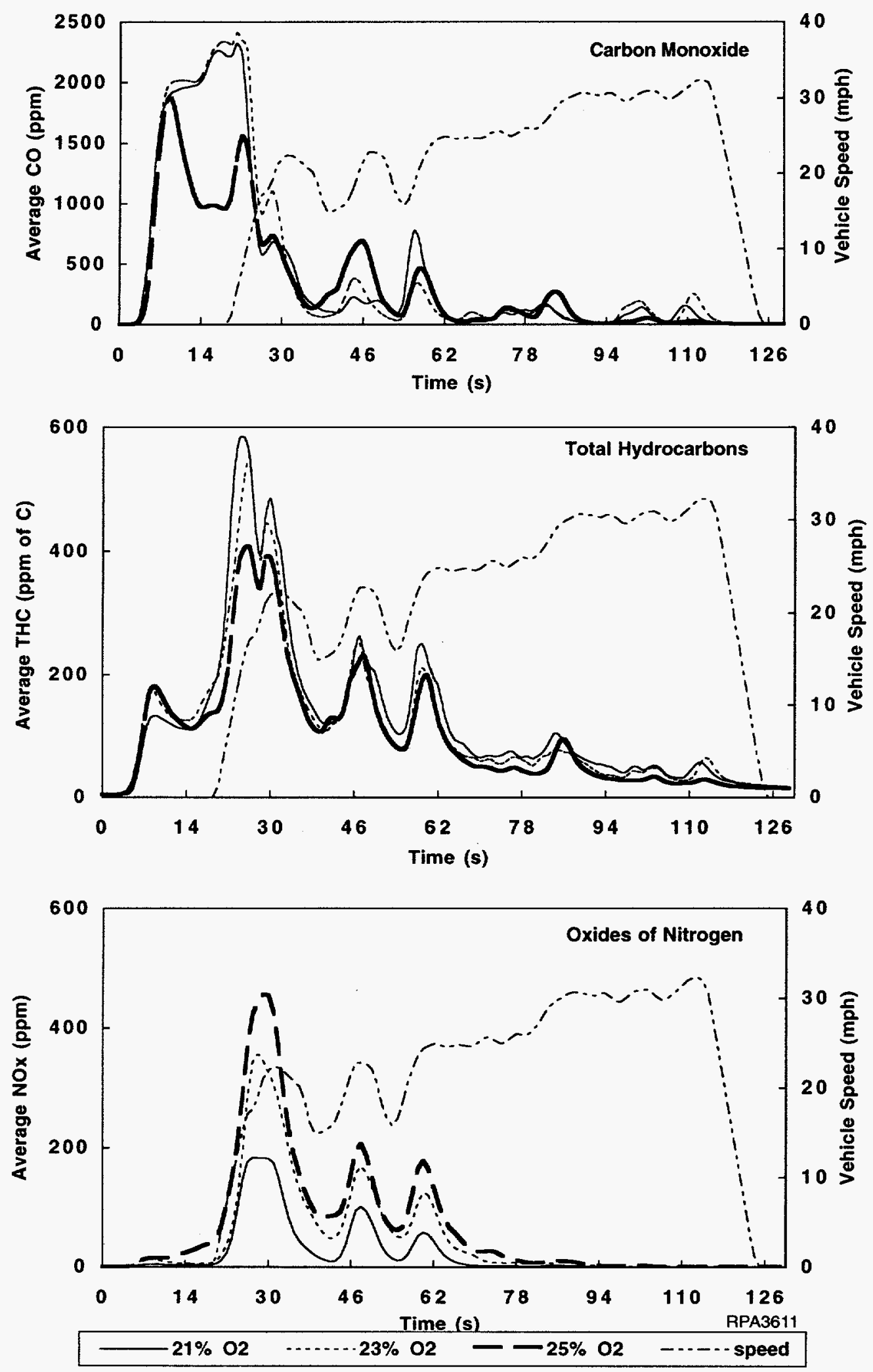

FIGURE 6.12 Converter-out, Time-Resolved CO, THC, and $\mathrm{NO}_{\mathrm{x}}$ Emissions: First $127 \mathrm{~s}$ of the Cold-Phase FTP with Indolene 
that elapses for light-off temperature with and without the oxygen enrichment. The benefits of oxygen enrichment might also vary on the basis of the light-off temperature characteristics of the converter. A converter with an inherently longer light-off time might benefit most from the oxygenenriched inlet air.

It is evident from the time-resolved emissions data that the initial $127-\mathrm{s}$ period of the cold phase is very crucial for catalytic converters because of catalyst light-off temperature limitations. If oxygen-enriched intake air were to be used during only the initial start-up and warm-up periods, the advantages of lower THC and CO emission levels could be obtained while the $\mathrm{NO}_{\mathrm{x}}$ emission level could be kept sufficiently low. To investigate such an application of oxygen-enriched intake air to reduce cold-phase FTP emissions, special tests were conducted in three ways as listed below:

1. $25 \%$ oxygen-enriched intake air only during the initial $127 \mathrm{~s}$ (first hill/cycle) of the cold-phase FTP, and the rest of the FTP cycle with ambient intake air.

2. $23 \%$ oxygen-enriched intake air only during the cold phase $(505 \mathrm{~s})$, and the remaining FTP cycle with ambient intake air.

3. $25 \%$ oxygen-enriched intake air only during the cold phase (505 s), and the remaining FTP cycle with ambient intake air

The results obtained from the above FTP tests, compared with emission standards for LDVs for the year 2004 (Tier II) and with California standards (TLEV), are shown in Figures 6.13 and 6.14 , respectively. The results are also provided in Table 6.1. In the present experiments, the vehicle was driven only about $3,220 \mathrm{~km}$. In the absence of deterioration factors, it is difficult to assess the benefits of oxygen enrichment after a vehicle has operated 80,467 or $160,934 \mathrm{~km}(50,000$ or $100,000 \mathrm{mi}$ ). However, it is expected that engine operation with oxygen-enriched air ( $23 \%$ or $25 \%$ ) would have similar emission benefits irrespective of vehicle mileage, since it basically reduces the engine-out emissions. Therefore, on a conceptual basis, the emission results (not adjusted for deterioration factors) from these special tests were compared with Tier II and TLEV standards. Test results (Figure 6.13 ) indicate that with $25 \%$ oxygen-enriched air only during the first hill (127 s) of the cold-phase FTP cycle, the converter-out weighted-average emissions of $\mathrm{CO}, \mathrm{NMHC}$, and $\mathrm{NO}_{\mathrm{x}}$ were all lower than the Tier II standards. The increase in $\mathrm{NO}_{\mathrm{x}}$ emissions with oxygen-enriched intake air was lower than the standards because of this enriched air's relative contributions (modest) during the 127 -s period of the cycle. When $23 \%$ oxygen-enriched intake air was employed only during the cold-phase FTP, the emission levels of $\mathrm{CO}$ and $\mathrm{NO}_{\mathrm{x}}$ were lower, but the NMHC level was slightly higher (by about 0.003 grams per mile [g/mi]) than the Tier II standards. With $25 \%$ oxygenenriched air used only during the cold-phase FTP, both CO and NMHC emission levels were lower, but $\mathrm{NO}_{\mathrm{x}}$ emission levels were higher than the Tier II standards by about $0.1 \mathrm{~g} / \mathrm{mi}$. In all three cases, the decreases in $\mathrm{CO}$ and NMHC emissions were in the range of 10-23\% more than the Tier II standards. The increase in $\mathrm{NO}_{\mathrm{x}}$ emissions with $25 \%$ oxygen enrichment during only cold-phase 


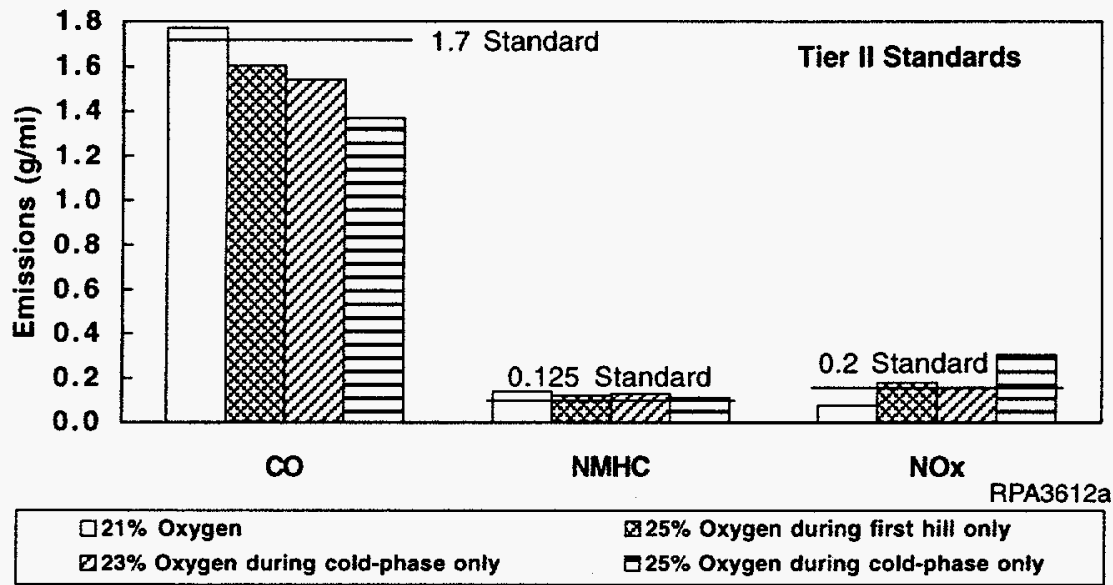

FIGURE 6.13 Potential Application Strategies for Oxygen-Enriched Intake Air to Meet Tier II Standards

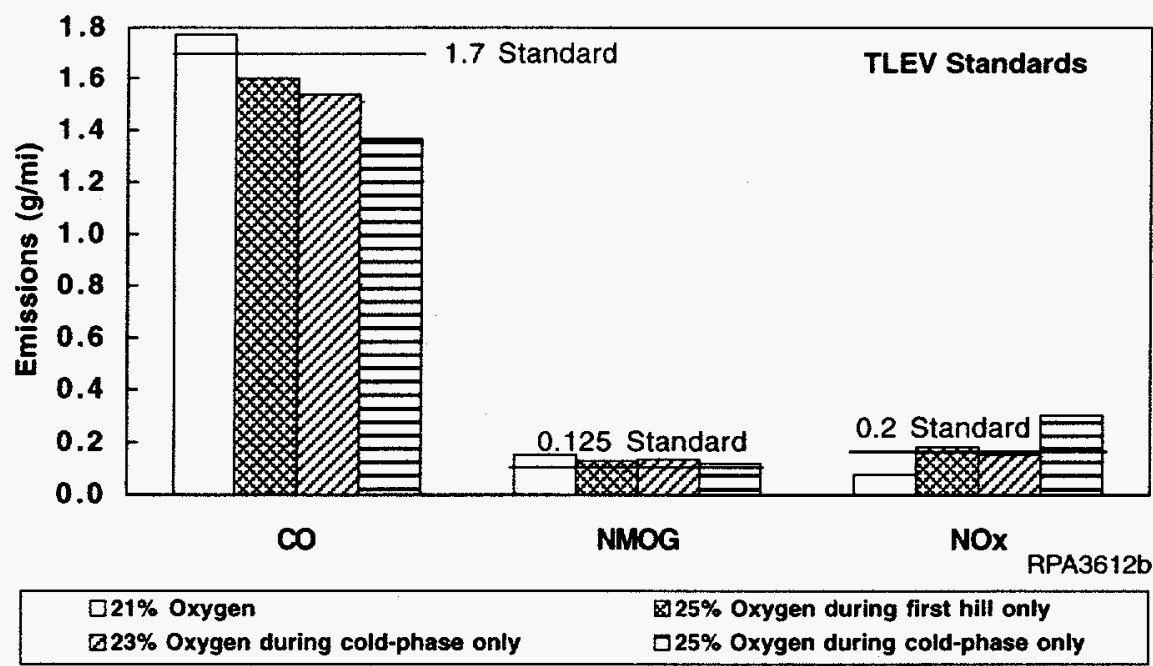

FIGURE 6.14 Potential Application Strategies for Oxygen-Enriched Intake Air to Meet TLEV Standards 
TABLE 6.1 Converter-out Emissions at Various Levels of Oxygen Enrichment and Different Emission Standards: FTP with Indolene

\begin{tabular}{|c|c|c|c|c|c|c|c|c|}
\hline \multirow[b]{2}{*}{ Parameter } & \multicolumn{2}{|c|}{ NMHC $(\mathrm{g} / \mathrm{mi})$} & \multicolumn{2}{|c|}{$\operatorname{NMOG}(\mathrm{g} / \mathrm{mi})$} & \multicolumn{2}{|c|}{$\mathrm{CO}(\mathrm{g} / \mathrm{mi})$} & \multicolumn{2}{|c|}{$\mathrm{No}_{x}(\mathrm{~g} / \mathrm{mi})$} \\
\hline & Bag 1 & Weighted & Bag 1 & Weighted & Bag 1 & Weighted & Bag 1 & Weighted \\
\hline \multicolumn{9}{|l|}{$\mathrm{O}_{2}$ level } \\
\hline Ambient $(21 \%)$ & 0.468 & 0.138 & 0.496 & 0.151 & 4.755 & 1.772 & 0.315 & 0.075 \\
\hline $25 \%$ (initial $127 \mathrm{~s}$ of bag 1 ) & 0.369 & 0.120 & 0.396 & 0.125 & 3.791 & 1.602 & 0.783 & 0.180 \\
\hline $23 \%$ (cold phase only) & 0.410 & 0.128 & 0.416 & 0.133 & 3.743 & 1.540 & 0.655 & 0.151 \\
\hline $25 \%$ (cold phase only) & 0.329 & 0.111 & 0.338 & 0.117 & 2.633 & 1.367 & 1.497 & 0.303 \\
\hline \multicolumn{9}{|l|}{ Emission standard at $50,000 \mathrm{mi}$} \\
\hline Tier II (2004) & $--^{\mathrm{a}}$ & 0.125 & -- & -- & - & 1.7 & -- & 0.2 \\
\hline TLEV & -- & -- & $\cdots$ & 0.125 & -- & 3.4 & -- & 0.4 \\
\hline LEV & -- & -- & -- & 0.075 & -- & 3.4 & -- & 0.2 \\
\hline ULEV & -- & -- & -- & 0.04 & -- & 1.7 & -. & 0.2 \\
\hline
\end{tabular}

a..$-=$ not applicable. 
application can be reduced to a certain extent by proper control of spark timing and recalibration of ECU to account for increased oxygen concentration. A post-treatment $\mathrm{NO}_{\mathrm{x}}$ control device such as a lean $\mathrm{NO}_{\mathrm{x}}$ catalyst or monatomic nitrogen induced by a pulsed arc [37] might also be helpful to comply with the emission standards. To compare California standards, NMOG was used in place of $\mathrm{NMHC}$, as shown in Figure 6.14. Test results indicate that NMOG, $\mathrm{CO}$, and $\mathrm{NO}_{\mathrm{x}}$ emission standards of TLEV can be met by applying $25 \%$ oxygen-enriched intake air either during only the initial 127 -s period or only the cold-phase (505-s) period of the FTP cycle. Therefore, the application of oxygenenriched air ( $23 \%$ or $25 \%$ ) during only the initial start-up and warm-up periods of an LDV has the potential to meet future emission standards, such as those of Tier II and TLEV.

The effects of oxygen-enriched intake air on FTP-cycle, converter-out aldehydes, paraffins, olefins, aromatics, and OFP (from HC speciation analysis) are presented in Figures 6.15-6.19. Aromatics and paraffins, which are generally difficult to convert in the catalytic converter, were considerably reduced in the presence of relatively higher oxygen concentrations in the exhaust with oxygen-enriched intake air. Of the regulated toxics, 1,3-butadiene and benzene were reduced, whereas aldehydes did not vary much as a result of using oxygen-enriched air. The OFP on the basis of MIR and MOIR factors was considerably reduced from using both $23 \%$ and $25 \%$ oxygen-enriched intake air. The HC speciation results during the initial 127-s period of the cold-phase FTP are shown in Figure 6.20. The converter-out, weighted-average emissions of aromatics, paraffins, and olefins (but not aldehydes) and the OFP were reduced by using $25 \%$ oxygen-enriched air.

The amounts of individual HC compounds emitted in the exhaust differed considerably. The CARB has assigned reactivity factors [49] for certain compounds on the basis of their tenedncy to form ozone. Hence, certain $\mathrm{HC}$ compounds have high mass emissions but low assigned reactivity factors and vice versa. If both mass emissions and corresponding reactivity factors are high, the resultant $\mathrm{OFP}$ is also high, and these compounds contribute significantly to overall ozone formation. Of the more than $200 \mathrm{HC}$ compounds identified quantitatively from the $\mathrm{HC}$ speciation analysis, about 40 are considered major contributors (high OFP) to ozone formation. When either $23 \%$ or $25 \%$ oxygen-enriched intake air was employed, the OFPs of all 40 were considerably reduced because of lower HC emissions. The reductions obtained in OFP (on the basis of MIR and MOIR factors) for both engine-out and converter-out emissions from using $23 \%$ and $25 \%$ oxygen-enriched air during the cold-phase FTP are provided in Table 6.2.

To investigate the benefits of oxygen enrichment on various engine/catalytic converters, the results obtained from the previous study [41] on Chevrolet Lumina were compared with the present test-vehicle results on a Dodge Spirit. The engine-out and converter-out emissions of these two vehicles with $25 \%$ oxygen-enriched intake air are presented in Figures 6.21 and 6.22, respectively. The comparison of engine-out exhaust emissions indicates that the reduction obtained as a result of oxygen enrichment was on the same order for both the engines. Although the mass emissions from both engines when ambient air was used were different because of the variation in engine configuration and operating characteristics, the mass emissions resulting from oxygen 

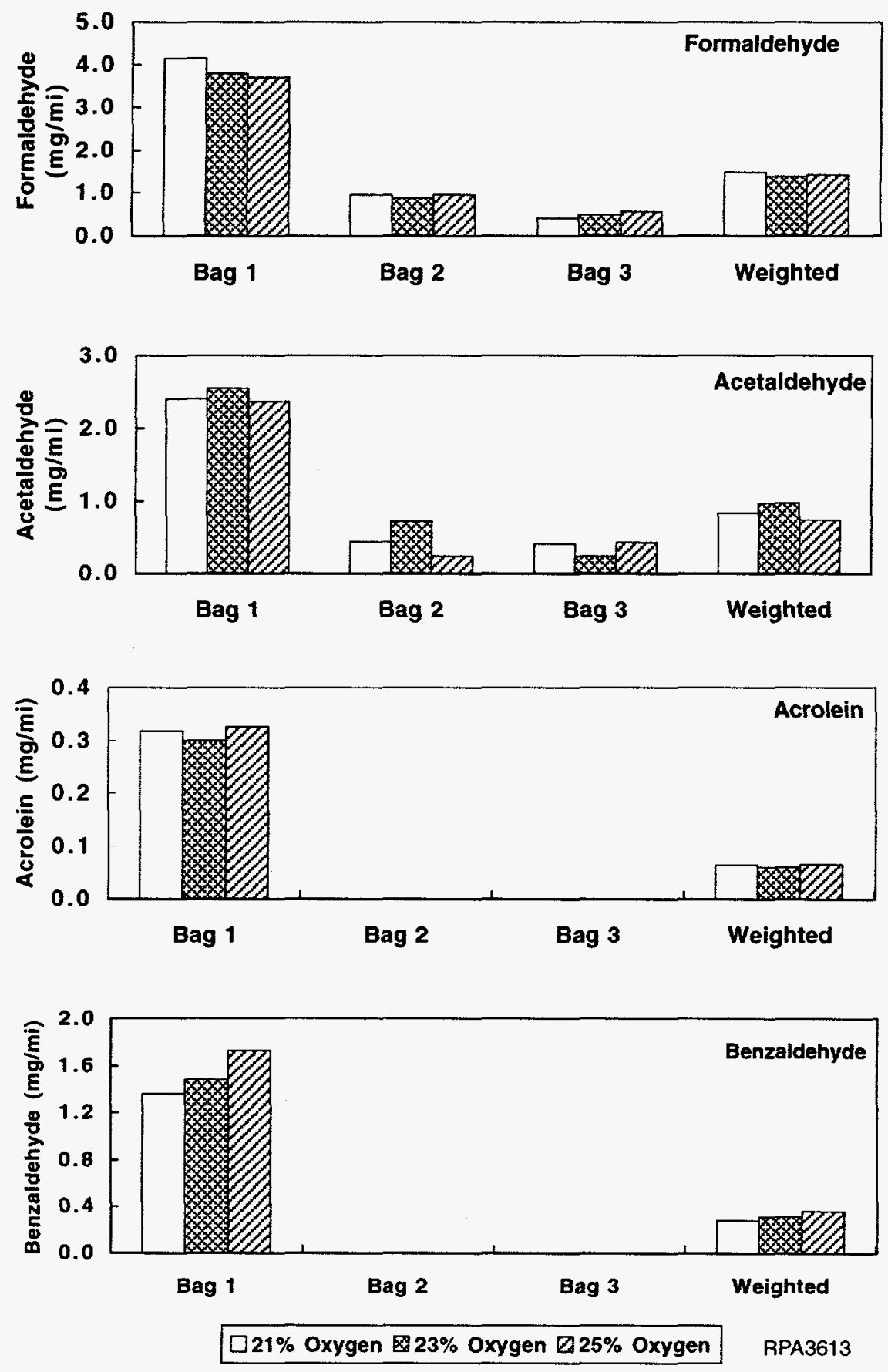

FIGURE 6.15 Effects of Oxygen-Enriched Intake Air on Converter-out Aldehyde Emissions: FTP with Indolene 

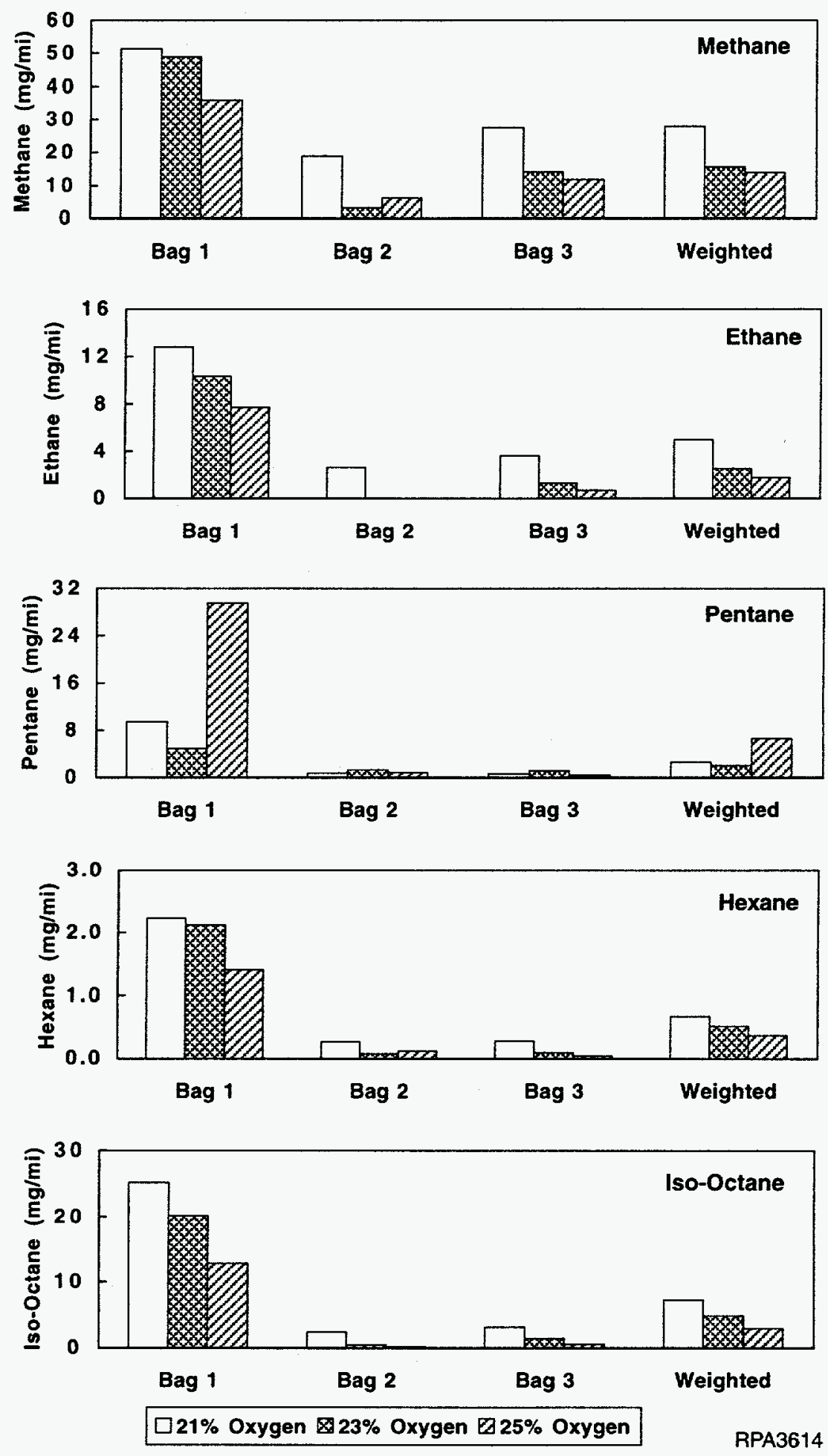

FIGURE 6.16 Effects of Oxygen-Enriched Intake Air on Converter-out Paraffin Emissions: FTP with Indolene 

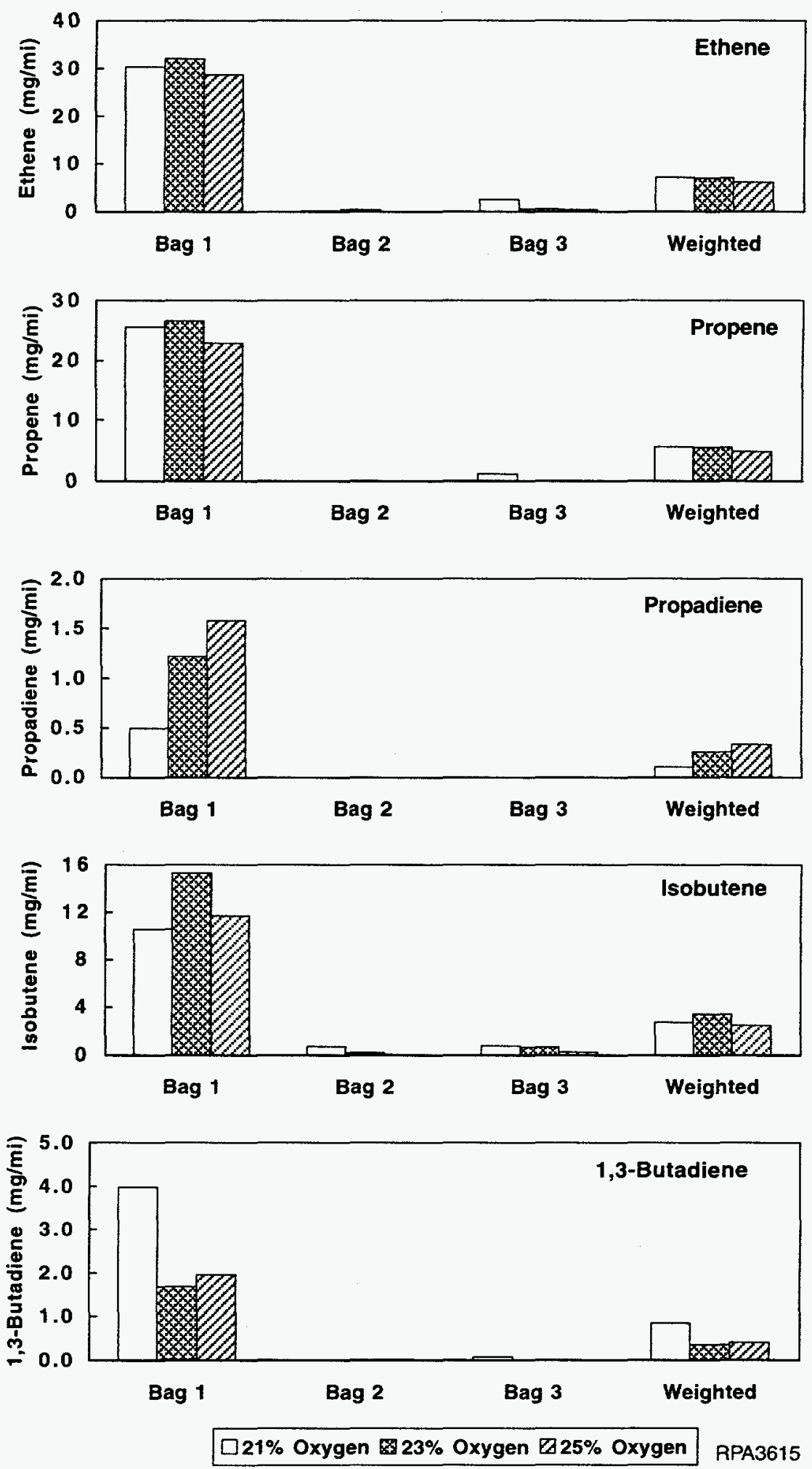

FIGURE 6.17 Effects of Oxygen-Enriched Intake Air on Converter-out Olefin Emissions: FTP with Indolene 

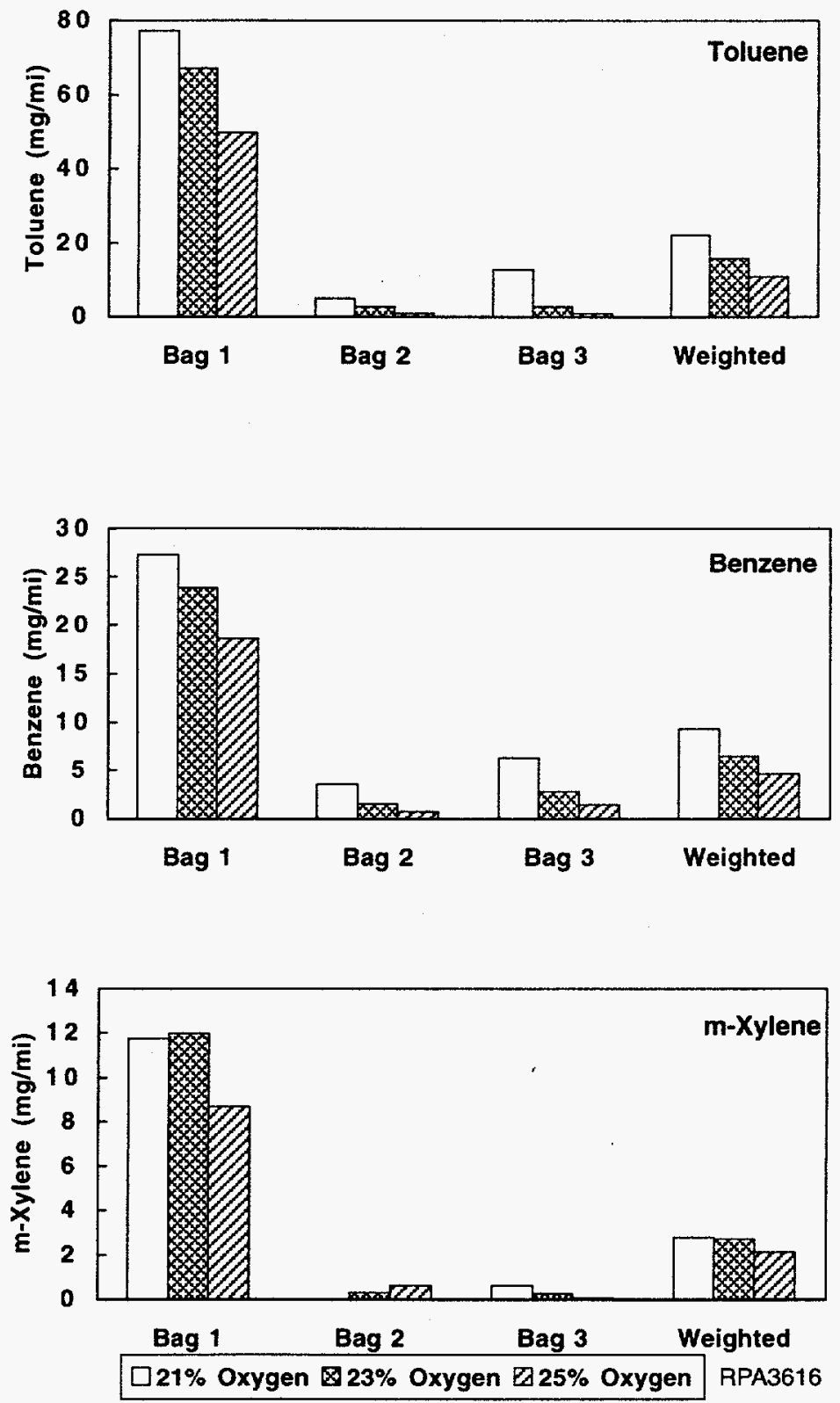

FIGURE 6.18 Effects of Oxygen-Enriched Intake Air on Converter-out Aromatic Emissions: FTP with Indolene 

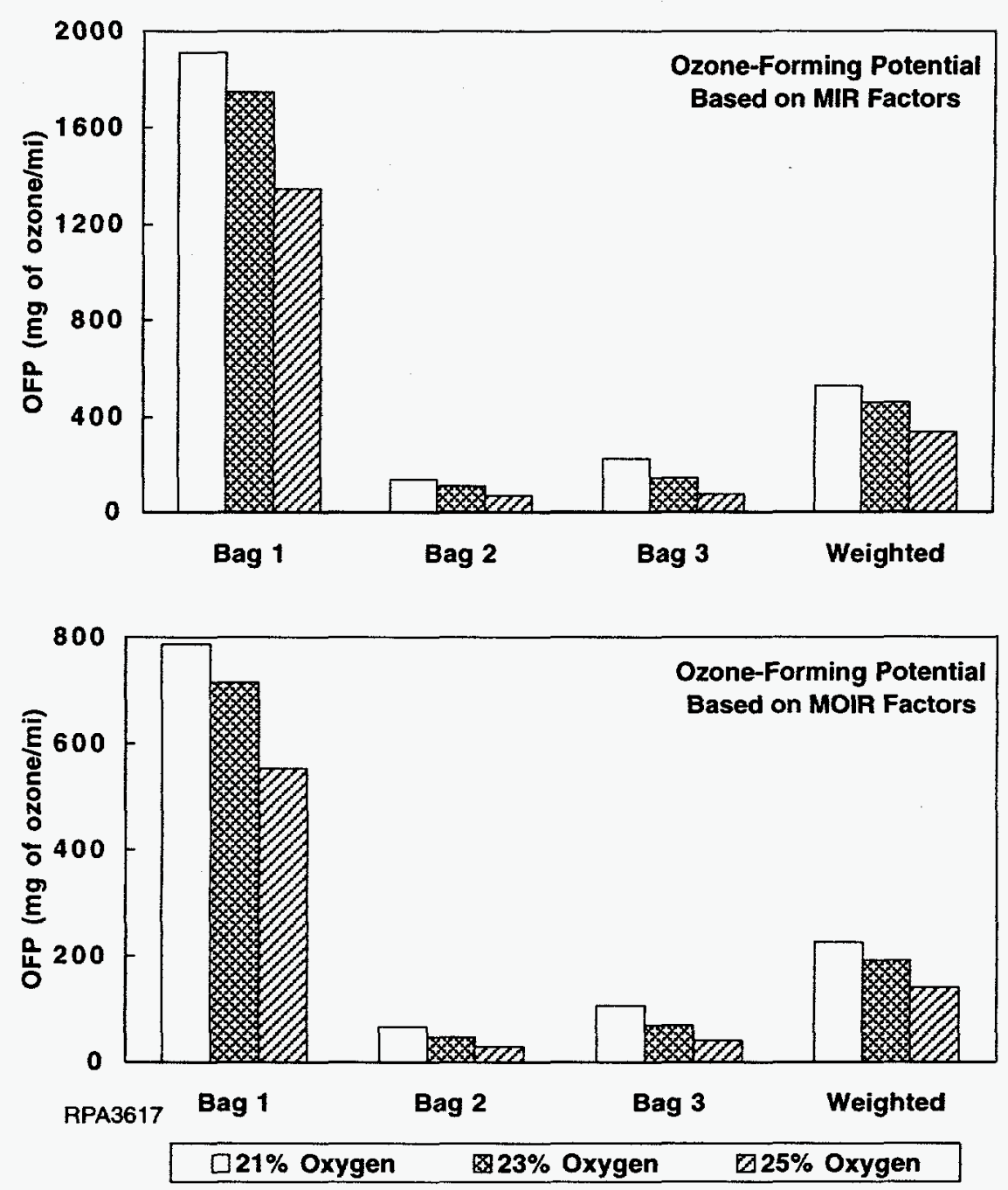

FIGURE 6.19 Effects of Oxygen-Enriched Intake Air on Converter-out Ozone-Forming Potential: FTP with Indolene

enrichment were of about the same magnitude. The only exception in the emission characteristics was found during the bag 2 FTP for the Chevrolet Lumina. Obviously, the engine that produces more engine-out exhaust emissions was benefitted most by oxygen enrichment. The converter-out emissions for both the vehicles were different because of differences in the OEM's converter performance characteristics. Of these two vehicles, the THC and CO emission levels during the bag 1 FTP were relatively higher for the Chevrolet Lumina. Consequently, the emission reductions associated with oxygen enrichment were also greater during this period for the Chevrolet Lumina. The percentage variations in FTP converter-out mass emissions between these two vehicles with $25 \%$ oxygen enrichment are provided in Figure 6.23. 

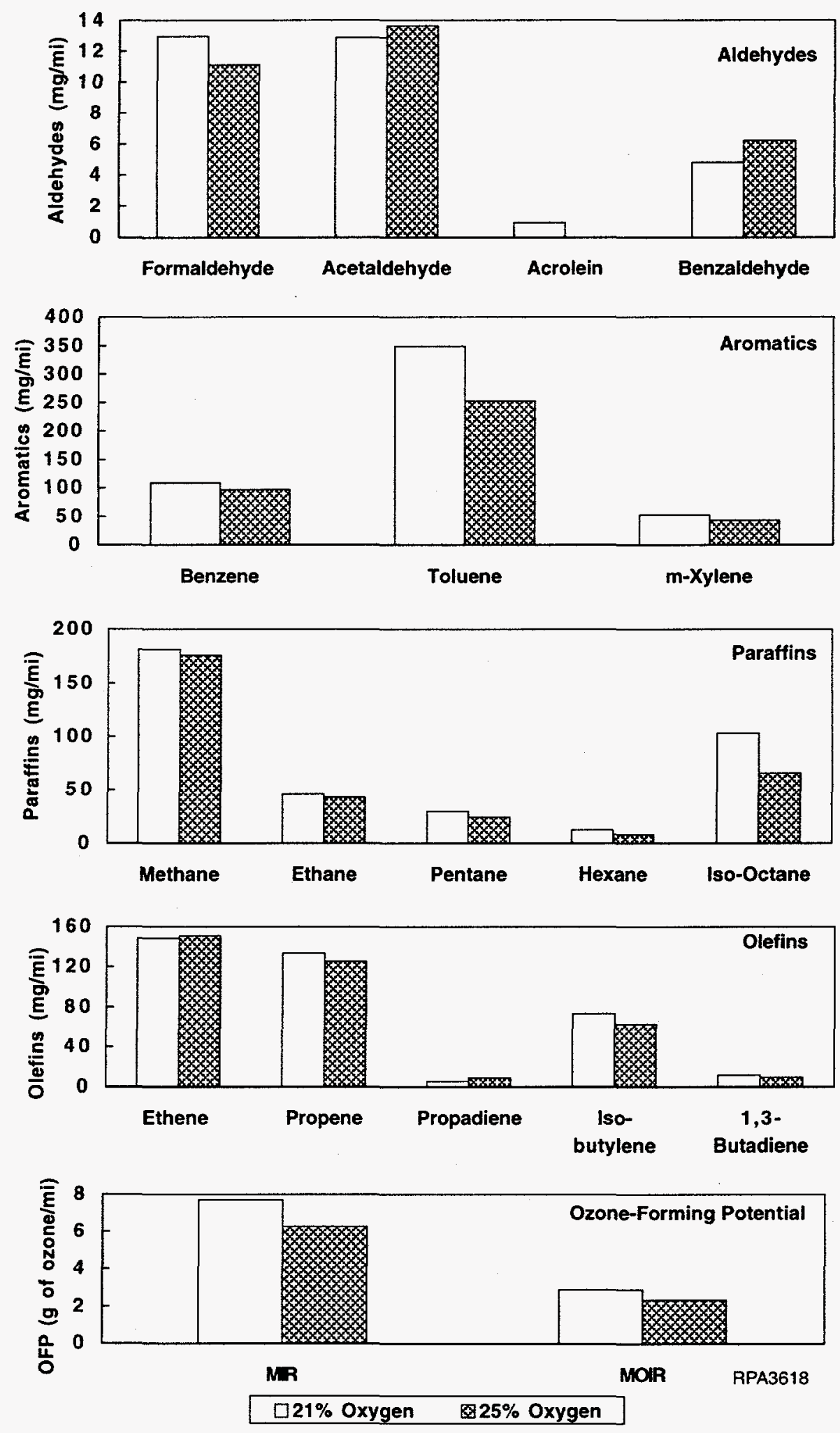

FIGURE 6.20 Converter-out Hydrocarbon Speciation and Ozone-Forming Potential: After First $127 \mathrm{~s}$ of the Cold-Phase FTP with Indolene 
TABLE 6.2 Major Engine-out and Converter-out Ozone-Forming Potential of Hydrocarbons: Cold-Phase FTP with Indolene

\begin{tabular}{|c|c|c|c|c|c|c|c|c|c|c|c|c|}
\hline \multirow[b]{3}{*}{ Compound } & \multicolumn{6}{|c|}{ OFP (mg ozone/mi) Based on MIR per $\mathrm{O}_{2}$ Level } & \multicolumn{6}{|c|}{ OFP (mg ozone/mi) Based on MOIR per $\mathrm{O}_{2}$ Level } \\
\hline & \multicolumn{3}{|c|}{ Engine-out } & \multicolumn{3}{|c|}{ Converter-out } & \multicolumn{3}{|c|}{ Engine-out } & \multicolumn{3}{|c|}{ Converter-out } \\
\hline & $21 \%$ & $23 \%$ & $25 \%$ & $21 \%$ & $23 \%$ & $25 \%$ & $21 \%$ & $23 \%$ & $25 \%$ & $21 \%$ & $23 \%$ & $25 \%$ \\
\hline Ethene (ethylene) & 1811.6 & 1478.3 & 1394.1 & 221.7 & 233.2 & 208.8 & 785.3 & 640.8 & 604.3 & 96.1 & 101.1 & 90.5 \\
\hline Acetylene (ethyne) & 107.9 & 81.8 & 87.4 & 7.0 & 8.5 & 7.3 & 71.2 & 54.0 & 57.7 & 4.6 & 5.6 & 4.8 \\
\hline Propene (propylene) & 1836.2 & 1389.0 & 1190.5 & 239.8 & 249.4 & 214.1 & 736.4 & 557.1 & 477.5 & 96.2 & 100.0 & 85.9 \\
\hline Benzene & 60.2 & 48.6 & 45.9 & 11.5 & 10.0 & 7.8 & 20.1 & 16.2 & 15.3 & 3.8 & 3.3 & 2.6 \\
\hline Toluene & 1082.8 & 771.4 & 635.8 & 210.8 & 183.4 & 135.8 & 249.9 & 178.0 & 146.7 & 48.6 & 42.3 & 31.3 \\
\hline Methylacetylene (propyne) & 86.8 & 85.2 & 90.8 & 1.4 & 2.5 & 4.2 & 46.0 & 45.1 & 48.1 & 0.7 & 1.3 & 2.2 \\
\hline Isobutylene & 595.4 & 272.1 & 343.2 & 56.1 & 81.3 & 62.2 & 216.4 & 98.9 & 124.7 & 20.4 & 29.6 & 22.6 \\
\hline 1,3-Butadiene & 203.0 & 121.1 & 57.6 & 43.4 & 18.2 & 21.2 & 77.5 & 46.3 & 22.0 & 16.6 & 6.9 & 8.1 \\
\hline n-Butane & 22.7 & 15.1 & 10.5 & 20.6 & 11.6 & 12.4 & 14.7 & 9.7 & 6.8 & 13.3 & 7.5 & 8.0 \\
\hline trans-Butene-2 & 122.8 & 82.4 & 73.8 & 21.4 & 17.3 & 12.5 & 46.4 & 31.2 & 27.9 & 8.1 & 6.5 & 4.7 \\
\hline cis-Butene-2 & 101.2 & 66.4 & 60.1 & 11.8 & 11.3 & 9.6 & 38.3 & 25.1 & 22.7 & 4.5 & 4.3 & 3.6 \\
\hline Isopentane & 668.4 & 341.7 & 309.8 & 162.4 & 109.4 & 55.4 & 250.7 & 128.1 & 116.2 & 60.9 & 41.0 & 20.8 \\
\hline 2-Methylbutene-1 & 45.2 & 22.6 & 18.6 & 7.1 & 5.2 & 3.4 & 17.5 & 8.8 & 7.2 & 2.8 & 2.0 & 1.3 \\
\hline n-Pentane & 40.6 & 38.4 & 14.8 & 9.9 & 5.0 & 30.8 & 26.6 & 25.1 & 9.7 & 6.5 & 3.7 & 20.1 \\
\hline 2-Methyl-1,3-butadiene & 42.9 & 18.2 & 0.9 & 13.0 & 11.6 & 9.4 & 16.1 & 6.8 & 0.3 & 4.9 & 4.4 & 3.5 \\
\hline trans-Pentene- 2 & 50.2 & 25.5 & 22.2 & 7.3 & 3.8 & 3.0 & 18.8 & 9.6 & 8.3 & 2.7 & 1.4 & 1.1 \\
\hline 2-Methylbutene-2 & 98.9 & 45.6 & 32.6 & 20.4 & 15.3 & 11.4 & 35.5 & 16.4 & 11.7 & 7.3 & 5.5 & 4.1 \\
\hline 3-Methylpentene-1 & 25.4 & 12.7 & 11.3 & 14.0 & 1.2 & 0.6 & 14.1 & 7.1 & 6.3 & 5.3 & 0.5 & 0.2 \\
\hline 2,3-Dimethylbutene-2 & 95.4 & 47,8 & 42.3 & 23.4 & 18.7 & 12.0 & 35.6 & 17.9 & 15.8 & 8.7 & 7.0 & 4.5 \\
\hline Cyclohexene & 117.7 & 57.3 & 50.3 & 30.1 & 22.8 & 14.6 & 45.7 & 22.2 & 19.5 & 11.7 & 8.8 & 5.7 \\
\hline 2,2,4-Trimethylpentane & 92.2 & 46.8 & 41.0 & 23.4 & 18.7 & 11.9 & 53.5 & 27.2 & 23.8 & 13.6 & 10.9 & 6.9 \\
\hline 2,3,4-Trimethylpentane & 71.7 & 35.8 & 30.5 & 18.7 & 14.6 & 9.2 & 41.2 & 20.6 & 17.6 & 10.7 & 8.4 & 5.3 \\
\hline 2,3,3-Trimethylpentane & 79.2 & 31.0 & 4.0 & 10.1 & 8.2 & 3.2 & 46.2 & 18.1 & 2.3 & 5.9 & 4.8 & 1.8 \\
\hline
\end{tabular}


TABLE 6.2 (Cont.)

\begin{tabular}{|c|c|c|c|c|c|c|c|c|c|c|c|c|}
\hline \multirow[b]{3}{*}{ Compound } & \multicolumn{6}{|c|}{ OFP (mg ozone/mi) Based on MIR per $\mathrm{O}_{2}$ Level } & \multicolumn{6}{|c|}{ OFP (mg ozone/mi) Based on MOIR per $\mathrm{O}_{2}$ Level } \\
\hline & \multicolumn{3}{|c|}{ Engine-out } & \multicolumn{3}{|c|}{ Converter-out } & \multicolumn{3}{|c|}{ Engine-out } & \multicolumn{3}{|c|}{ Converter-out } \\
\hline & $21 \%$ & $23 \%$ & $25 \%$ & $21 \%$ & $23 \%$ & $25 \%$ & $21 \%$ & $23 \%$ & $25 \%$ & $21 \%$ & $23 \%$ & $25 \%$ \\
\hline $\mathrm{m}$-Xylene & 664.1 & 399.7 & 389.6 & 95.8 & 97.8 & 70.6 & 199.4 & 120.0 & 117.0 & 28.8 & 29.4 & 21.2 \\
\hline p-Xylene & 291.5 & 175.0 & 155.6 & 43.2 & 35.1 & 26.6 & 87.9 & 52.8 & 46.9 & 13.0 & 10.6 & 8.0 \\
\hline o-Xylene & 191.8 & 120.3 & 108.5 & 43.6 & 30.7 & 22.0 & 57.9 & 36.3 & 32.8 & 13.2 & 9.3 & 6.6 \\
\hline n-Propylbenzene & 25.5 & 12.0 & 10.3 & 2.9 & 3.4 & 1.9 & 5.9 & 2.8 & 2.4 & 0.7 & 0.8 & 0.4 \\
\hline 3-Ethyltoluene & 361.4 & 193.4 & 162.4 & 45.1 & 52.8 & 36.4 & 108.4 & 58.0 & 48.7 & 13.5 & 15.9 & 10.9 \\
\hline 4-Ethyltoluene & 157.6 & 83.8 & 70.6 & 19.5 & 24.0 & 15.7 & 47.3 & 25.1 & 21.2 & 5.8 & 7.2 & 4.7 \\
\hline 1,3,5-Trimethylbenzene & 252.5 & 144.2 & 122.6 & 50.7 & 40.5 & 27.2 & 76.1 & 43.5 & 36.9 & 15.3 & 12.2 & 8.2 \\
\hline 2-Ethyltoluene & 122.0 & 67.0 & 53.4 & 9.3 & 12.8 & 12.1 & 36.6 & 20.1 & 16.0 & 2.8 & 3.8 & 3.6 \\
\hline tert-Butylbenzene ${ }^{a}$ & 72.0 & 39.2 & 31.7 & 14.4 & 12.1 & 8.3 & 16.6 & 9.0 & 7.3 & 3.3 & 2.8 & 1.9 \\
\hline 1,2,3-Trimethylbenzene & 150.3 & 79.2 & 66.7 & 11.6 & 20.8 & 11.8 & 45.3 & 23.9 & 20.1 & 3.5 & 6.3 & 3.6 \\
\hline Formaldehyde & 505.9 & 392.1 & 359.8 & 29.6 & 27.0 & 26.4 & 147.2 & 114.1 & 104.7 & 8.6 & 7.9 & 7.7 \\
\hline Acetaldehyde & 85.2 & 56.9 & 56.5 & 13.3 & 14.1 & 13.1 & 33.5 & 22.4 & 22.2 & 5.2 & 5.6 & 5.1 \\
\hline Acrolein & 29.0 & 19.0 & 17.9 & 2.1 & 2.0 & 2.2 & 11.1 & 7.3 & 6.8 & 0.8 & 0.8 & 0.8 \\
\hline
\end{tabular}

a Assumed molecular weight. 

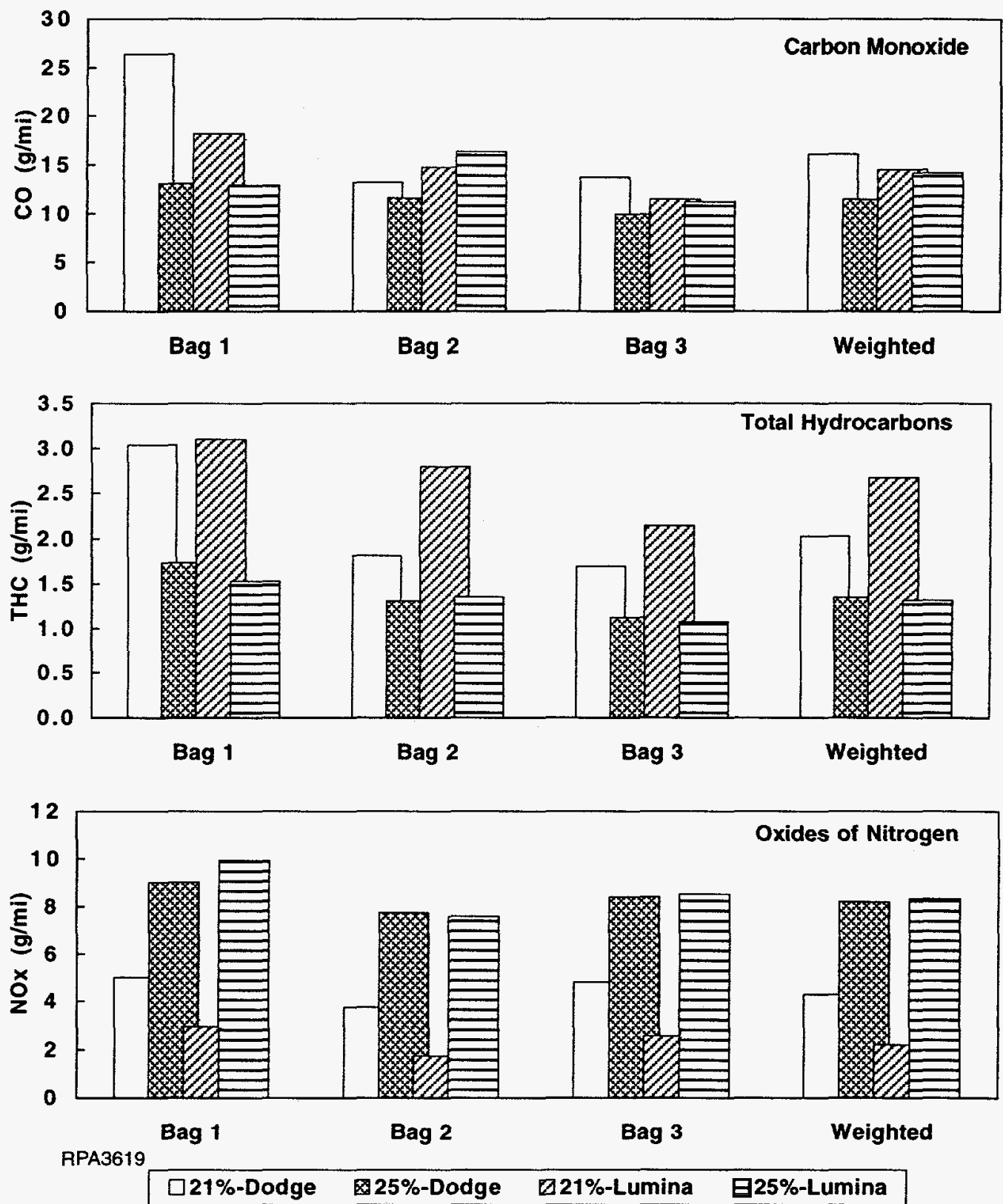

FIGURE 6.21 Engine-out CO, THC, and NO $\mathrm{N}_{\mathrm{x}}$ Emissions of Dodge Spirit and Chevrolet Lumina: FTP with Indolene 

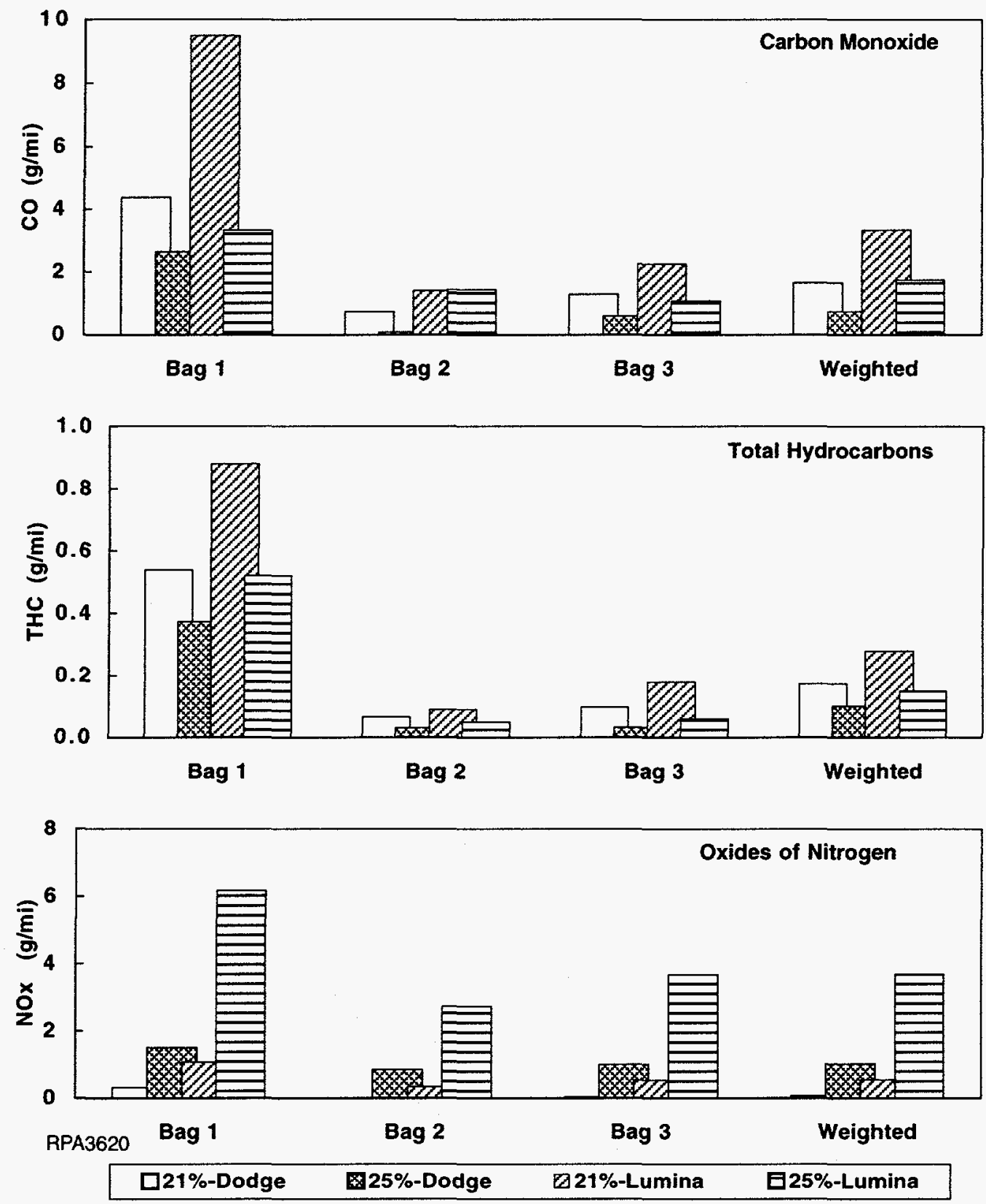

FIGURE 6.22 Converter-out CO, THC, and $\mathrm{NO}_{\mathrm{x}}$ Emissions of Dodge Spirit and Chevrolet Lumina: FTP with Indolene 

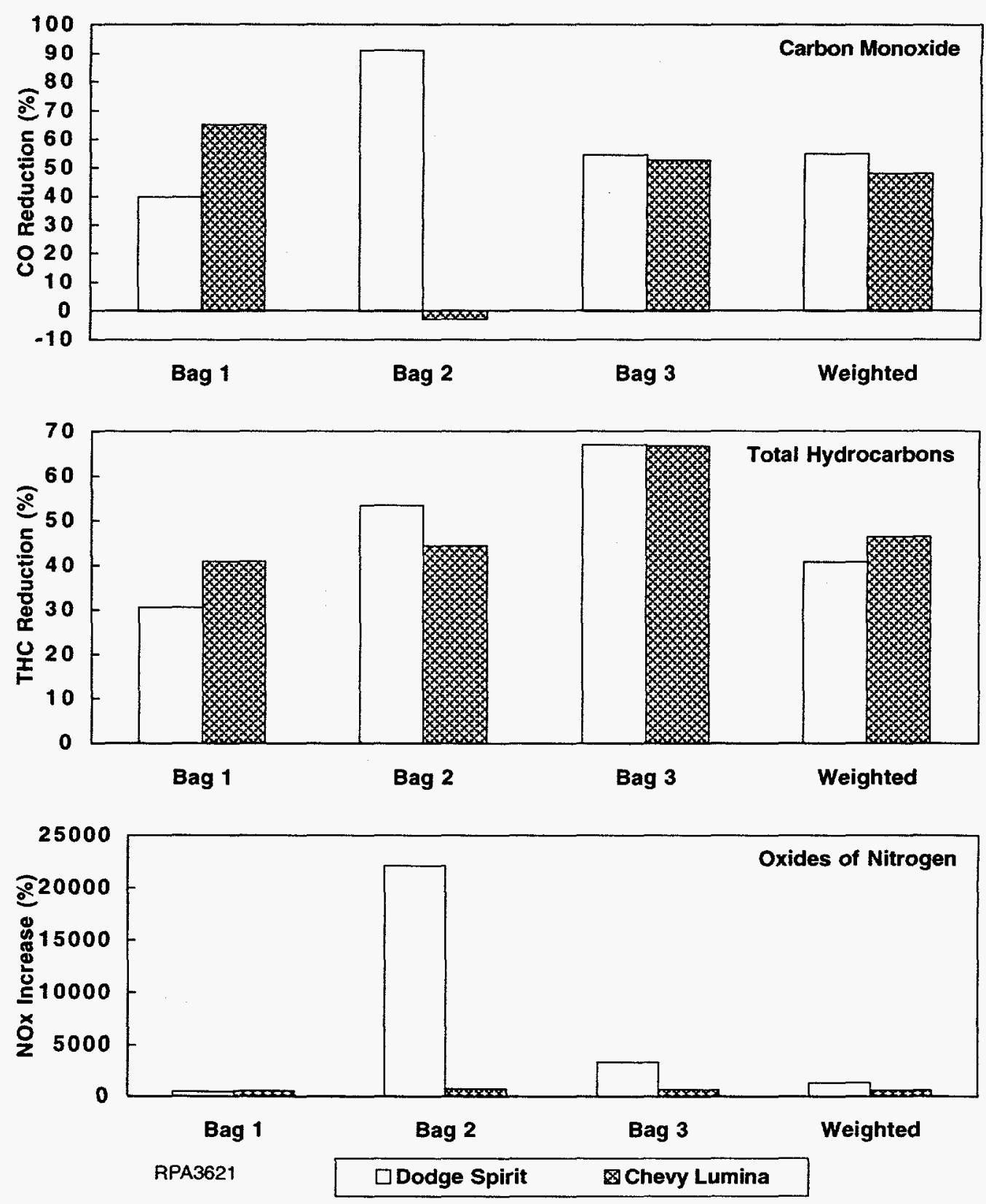

FIGURE 6.23 Percentage Variations in Converter-out CO, THC, and $\mathrm{NO}_{\mathrm{x}}$ Emissions between Dodge Spirit and Chevrolet Lumina: FTP with Indolene and 25\% Oxygen Enrichment 


\subsubsection{Off-Cycle Converter-out Emissions}

The off-cycle test (REP05) is one of various federal cycle tests being considered by the EPA and CARB to add a more severe driving cycle to the FTP. The purpose of this additional driving cycle is to require reduced use of fuel enrichment at high engine speed and load conditions. This cycle was developed to represent in-use driving that is outside the boundaries of the current FTP driving cycle. The cycle was generated from a composite data set that equally represented Los Angeles chase car data and Baltimore 3-parameter instrumented vehicle data. In the present work, the off-cycle emissions were collected in three different bags, as shown in Figure 5.4. Offcycle bag 3 consists of rapid accelerations and decelerations for about $200 \mathrm{~s}$ in the test cycle. The exhaust emissions from this bag 3 off-cycle driving pattern might pose the greatest challenge for conventional catalytic converters, since engine-out exhaust emissions increase rapidly in both mass and concentration at higher fuel flow rates. Nevertheless, the potential benefits of intake-air oxygen enrichment can be applied to reduce these emissions effectively. The reductions obtained with oxygen-enriched air during the off-cycle test are shown in Figure 6.24. The converter-out CO emissions during off-cycle bag 3 decreased from $34.6 \mathrm{~g} / \mathrm{mi}$ to $10.2(70 \%)$ and to $4.8(86 \%)$ when the oxygen level in the intake air increased from $21 \%$ to $23 \%$ and to $25 \%$, respectively. Similarly, THC emissions were reduced from $1.55 \mathrm{~g} / \mathrm{mi}$ to $0.3(37 \%)$ and to 0.21 (57\%) by using $23 \%$ and $25 \%$ oxygen-enriched air, respectively. However, the corresponding $\mathrm{NO}_{\mathrm{x}}$ emissions were increased from $0.139 \mathrm{~g} / \mathrm{mi}$ to $0.262(88 \%)$ and to 0.881 (5.3 times) at the same conditions. The weighted-average, off-cycle emission reductions were promising with oxygen-enrichment, since $\mathrm{NO}_{\mathrm{x}}$ emission levels did not increase beyond $0.118 \mathrm{~g} / \mathrm{mi}$ with $23 \%$ oxygen-enriched air, while both THC and CO were kept at very low levels (about 0.155 and $2.478 \mathrm{~g} / \mathrm{mi}$, respectively). To control $\mathrm{NO}_{\mathrm{x}}$ emissions by using $25 \%$ oxygen-enriched air, methods (relearning of ECU and proper air/fuel and spark-timing management in addition to post-treatment devices such as a monatomic nitrogen-induced device or a lean- $\mathrm{NO}_{\mathrm{x}}$ catalyst) similar to those suggested in the case of the FTP test are required, if bag 3 of the off-cycle is going to be added to the existing FTP test cycle. Hence, 23\% oxygen-enriched air seems to be a compromise for reducing both THC and $\mathrm{CO}$ emissions with less likelihood of increasing $\mathrm{NO}_{\mathrm{x}}$ emissions during the off-cycle test.

\subsection{EMISSION MEASUREMENTS WITH M85}

All emission data presented here are the averages of two or three separate FTPs and two separate off-cycle emission tests conducted under similar operating conditions and procedures. From the HC speciation analysis, the most significant species (including regulated toxics) and OFPs were selected for analysis. The data on THC, NMHC, NMOG, aldehyde, and unburned methanol $\left(\mathrm{CH}_{3} \mathrm{OH}\right)$ levels in the exhaust were obtained from the $\mathrm{HC} /$ aldehyde speciation analysis. Data on THC levels obtained directly from the flame ionization detector (FID) instrument were also presented for comparison (represented as THC-FID). During the FTP cycle tests, the engine-out, 

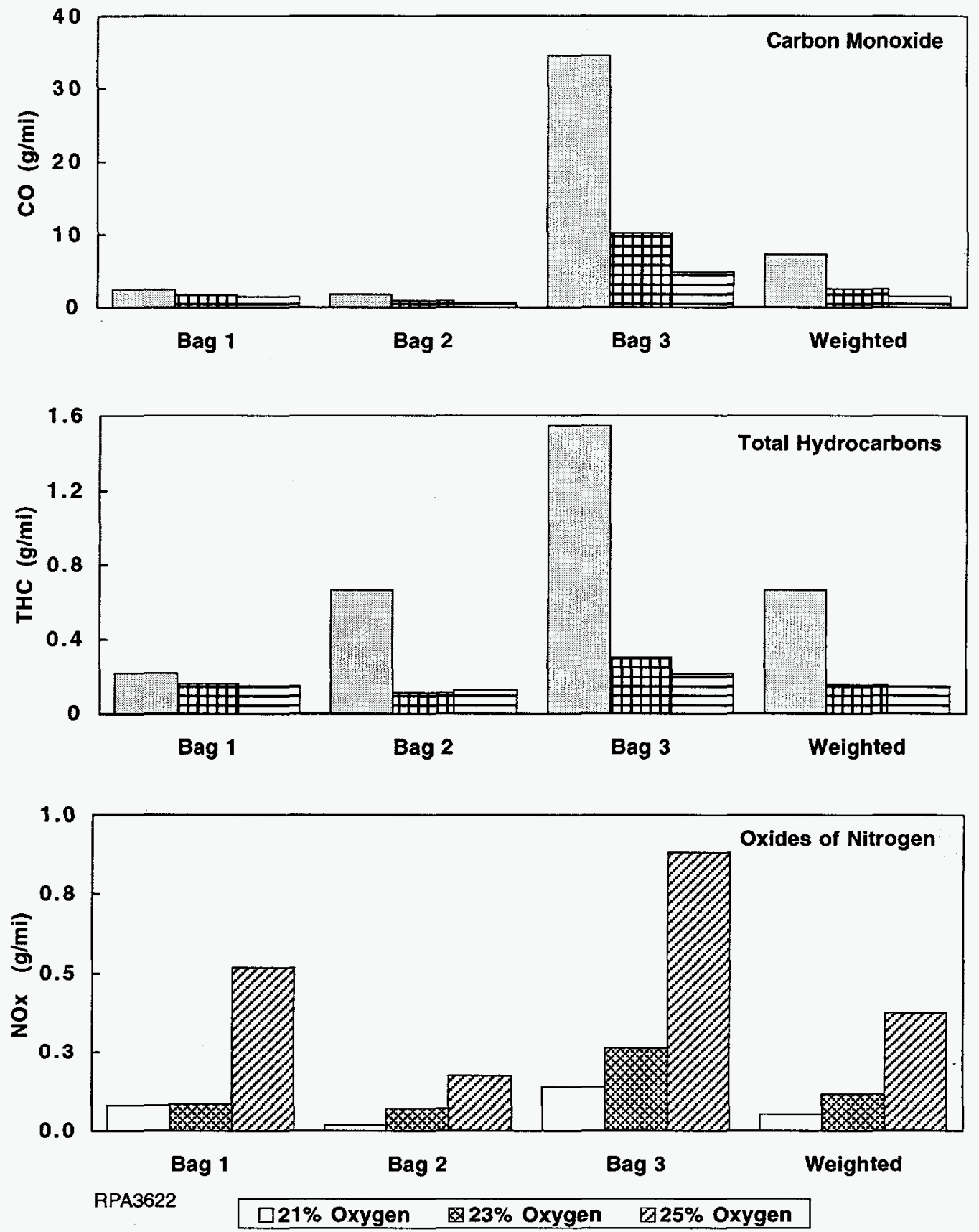

FIGURE 6.24 Converter-out CO, THC, and NO Emissions: Off-Cycle Test with Indolene 
exhaust HC speciation was done only with ambient and $25 \%$ oxygen-enriched intake air experiments. Tests with $23 \%$ oxygen-enriched intake air were not speciated. Also, exhaust $\mathrm{HC} /$ aldehyde speciation analyses were not performed during the off-cycle tests.

\subsubsection{FTP Engine-out Emissions}

The engine-out exhaust emissions (THC-FID, $\mathrm{CO}, \mathrm{NO}_{\mathrm{x}}$ ) from the FTP test cycle when $21 \%, 23 \%$, and $25 \%$ oxygen levels were used in the intake air and M85 was the fuel are presented in Figure 6.25. Results indicate that THC-FID was lower with an increase in the oxygen level from $21 \%$ to $23 \%$ or $25 \%$. However, $\mathrm{CO}$ emissions did not vary appreciably, and $\mathrm{NO}_{\mathrm{x}}$ emission levels were much higher with $23 \%$ or $25 \%$ oxygen-enriched air. The reduction in THC-FID was particularly significant during the cold-phase (bag 1) FTP. For example, during the cold-phase FTP, THC-FID emissions decreased from 2.68 to $1.54 \mathrm{~g} / \mathrm{mi}$ ( $42.5 \%$ reduction) with $25 \%$ oxygen-enriched air. The percentage reduction in THC-FID emissions with M85 fuel was about the same as was the case with Indolene fuel. The fact that exhaust THC is reduced in the same proportion for two different fuels indicates that combustion is improved in the presence of higher oxygen levels in the combustion air. It was found that with $\mathrm{M} 85, \mathrm{NO}_{\mathrm{x}}$ emissions increased with an increase in the oxygen level in a way similar to that observed when Indolene was used as a test fuel. In both cases, an increase of about $90-98 \%$ in $\mathrm{NO}_{x}$ emissions was observed when $25 \%$ oxygen-enriched air was used instead of ambient air. It is presumed that the availability of oxygen and higher combustion temperatures result in increased emissions of $\mathrm{NO}_{\mathbf{x}}$. The availability of oxygen during combustion was greater because of the increase in oxygen concentration in both the inlet air (oxygen-enriched) and M85 (oxygenated fuel). CO emissions did not change appreciably with the increase in the oxygen level of the intake air, since additional oxygen was also available from the oxygenated fuel (M85). CO emission levels were much lower when ambient intake air was used with M85 rather than with Indolene fuel. When M85 was the test fuel, oxygen-enriched intake air probably did not affect the mixture strength (oxygen-to-fuel ratio) very much because of the presence of fuel-bound oxygen. Hence, little variation in $\mathrm{CO}$ emissions was observed.

The effects of intake-air oxygen enrichment on engine-out NMHC, NMOG, formaldehyde (HCHO), and unburned methanol during the FTP test are shown in Figure 6.26. Test results with M85 indicate that engine-out NMHC, NMOG, and unburned methanol were considerably reduced in the entire FTP cycle when the oxygen content of the intake air was either $23 \%$ or $25 \%$. Formaldehyde emissions, which are of specific concern with M85 fuel, were reduced by about 53\% in bag $1,84 \%$ in bag 2 , and $59 \%$ in bag 3 by following the FTP cycle with $25 \%$ oxygen-enriched air. During the cold-phase FTP, reductions of about $42 \%$ in NMHC, $40 \%$ in unburned methanol, and $45 \%$ in NMOG were observed with $25 \%$ oxygen-enriched air when compared with ambient air (nominal $21 \%$ oxygen). The corresponding $\mathrm{NO}_{x}$ emissions increased by about $78 \%$. Formaldehyde emissions are of particular concern with FFVs; the increase in oxygen concentration in the inlet air helps to over come this problem. At the low temperatures typically encountered during the converter 

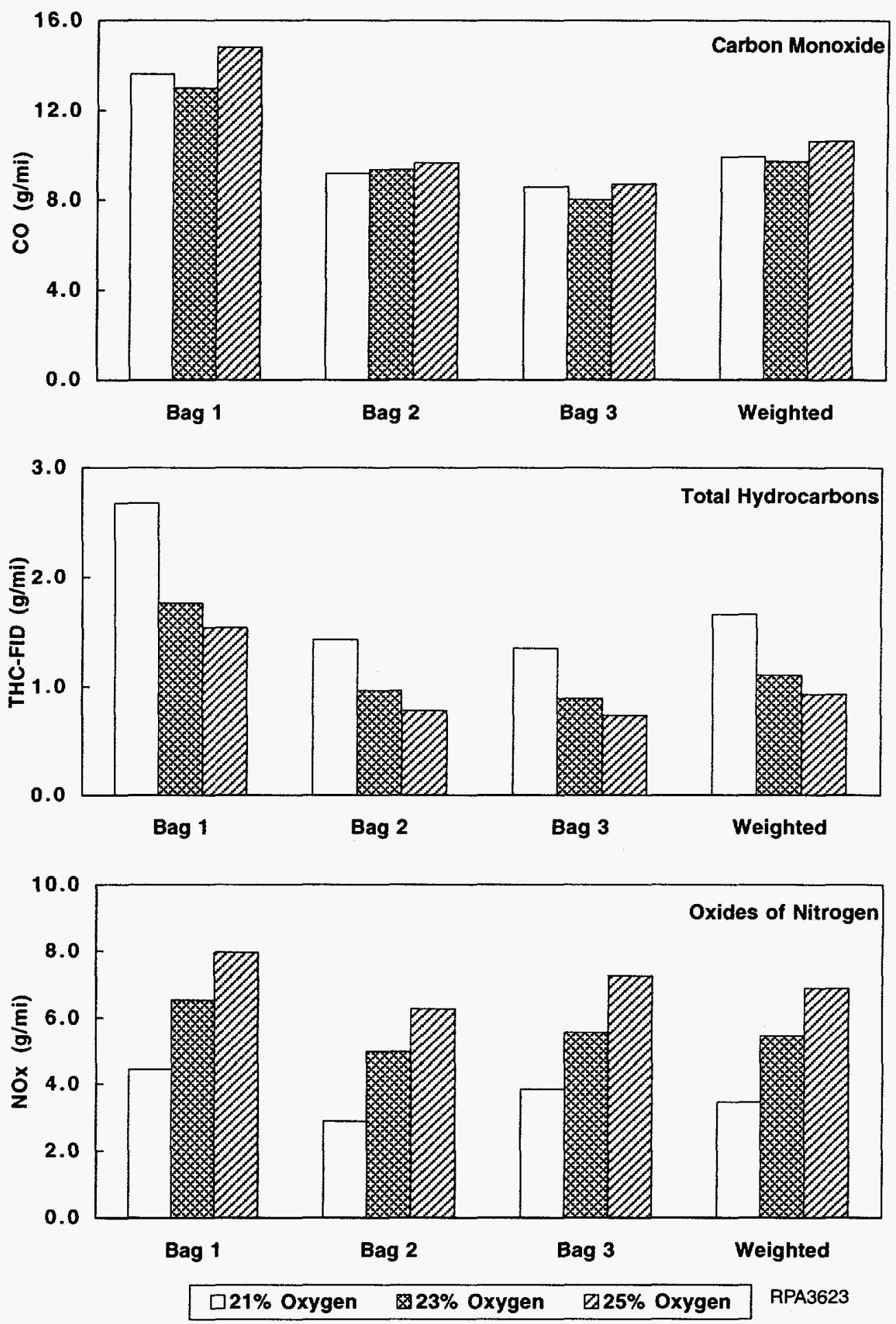

FIGURE 6.25 Engine-out CO, THC, and NO Emissions: FTP with M85 

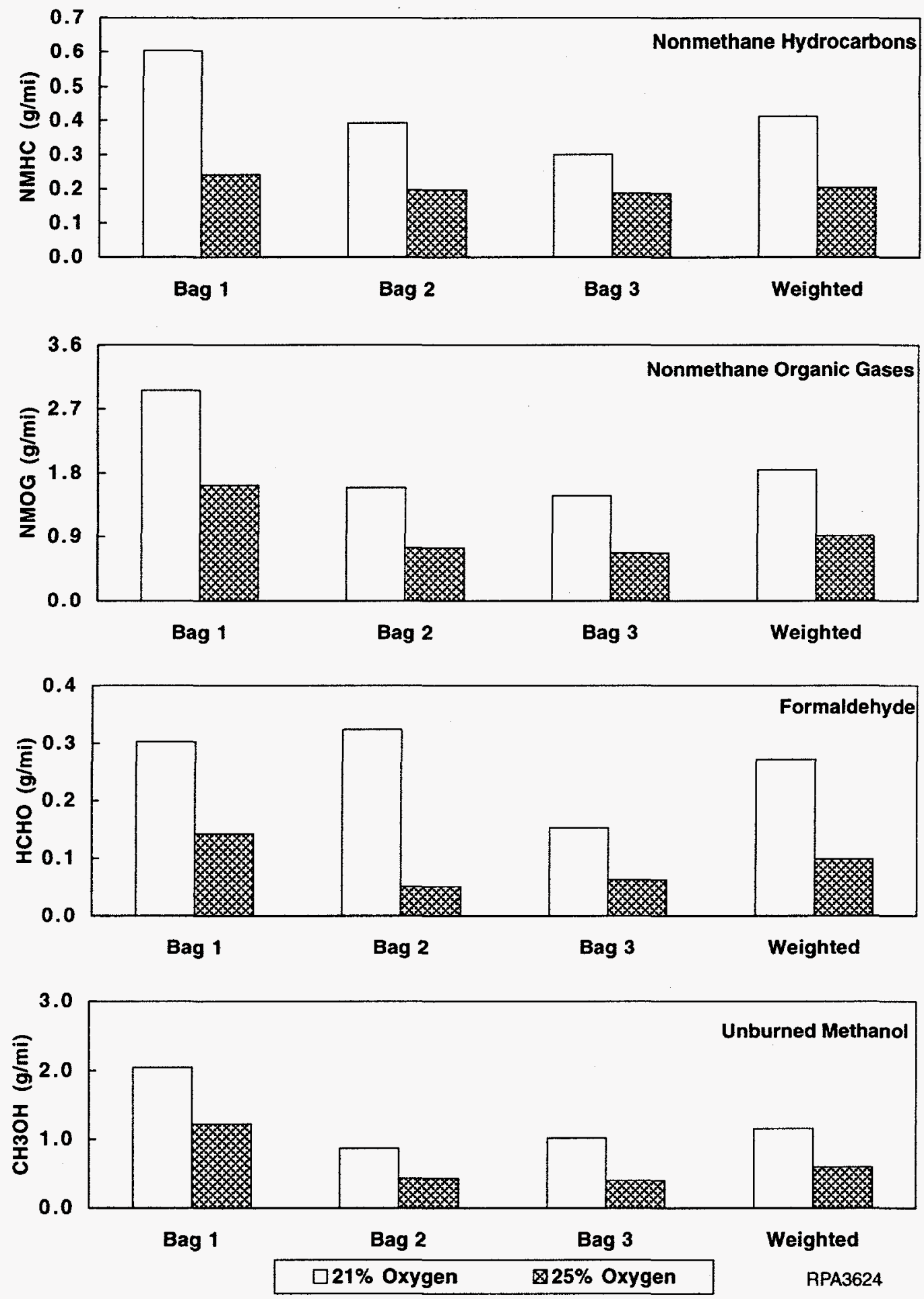

FIGURE 6.26 Engine-out NMHC, NMOG, $\mathrm{HCHO}$, and $\mathrm{CH}_{3} \mathrm{OH}$ Emissions: FTP with M85 
warm-up period, many catalysts exhibit tendencies to partially oxidize unburned methanol to formaldehyde [5]. The presence of enriched oxygen in the intake air would promote complete oxidation of methanol and also promote oxidation of gasoline-derived exhaust pollutants. The lower unburned methanol with 25\% oxygen-enriched air is also evident in Figure 6.26. These factors together contribute toward the lower formaldehyde emission levels observed in the present results.

The FTP cycle, averaged, engine-out HC emission results (from the speciation analyses) with ambient air and $25 \%$ oxygen-enriched air are provided in Table 6.3 . Test results indicate that among the aldehydes, formaldehyde and acrolein were significantly reduced, particularly in bag 1 of the FTP cycle (by about $59 \%$ and $98 \%$, respectively), but little variation occurred in acetaldehyde and benzaldehyde when $25 \%$ oxygen-enriched intake air was used. During the bag 1 FTP cycle, reductions from $38 \%$ to $73 \%$ were observed in olefins (ethene, propene, isobutylene, and 1,3-butadiene), aromatics (benzene, toluene, and $\mathrm{m}$-xylene), and paraffins (methane, ethane, n-pentane, n-hexane, and 2,2,4 trimethlpentane) as a result of the $25 \%$ oxygen-enriched intake air. Similar benefits of fewer $\mathrm{HC}$ emissions were realized with $25 \%$ oxygen-enriched intake air in bag 2 and bag 3 , but to a lesser extent. Since bag 1 contribution is relatively significant when compared with other parts of the FTP cycle, the reductions obtained with $25 \%$ oxygen-enriched intake air can lead to fewer weighted-average emissions. With oxygen-enriched intake air, the reductions obtained in aldehydes and olefins (reactive species) will lead to lower ozone formation, and the reductions obtained in aromatics and paraffins will help reduce the converter limitations by converting them into more harmless species. The OFP from engine-out exhaust during the FTP cycle was calculated on the basis of both MIR and MOIR factors with ambient air and 25\% oxygen-enriched intake air. Results indicate that OFP (based on MIR) was reduced by about $45 \%$ in bag 1 and by about $48 \%$ in the weighted average of the FTP cycle because of the $25 \%$ oxygen-enriched intake air. Specific reactivities were also calculated for both ambient and $25 \%$ oxygen-enriched intake air from the engine-out HCs during the FTP cycle; they are provided along with OFP in Table 6.4.

Cold-phase FTP exhaust emissions were of particular interest in this study. Hence, the timeresolved, engine-out exhaust emissions of THC-FID, $\mathrm{CO}$, and $\mathrm{NO}_{\mathrm{x}}$ emissions were analyzed in detail during the first 127-s period and are shown in Figure 6.27. The time-resolved emissions also exhibit less THC-FID, more $\mathrm{NO}_{\mathrm{x}}$, and a marginal variation in $\mathrm{CO}$ emissions with $25 \%$ oxygen enrichment over ambient air. Significant THC-FID emissions during the first 127-s cold-phase FTP are evident in Figure 6.27, substantiating the observed lower THC-FID mass emissions during the FTP bag 1 period. The reduction in THC-FID varies by about 100 to $450 \mathrm{ppm}$ from several cyclic peak values during the first 127 -s period with either $23 \%$ or $25 \%$ oxygen-enriched air. The reduction in THCFID with oxygen enrichment was realized as early as during the first 20-s (key-on and idling) period. $\mathrm{CO}$ emission levels were observed to be relatively lower during the idling and first acceleration period of the 127-s period when higher oxygen-enriched levels were used. Perhaps the additional oxygen available through intake air helped in meeting the stoichiometric oxygen requirements during the fuel-rich conditions for the first $30 \mathrm{~s}$ of vehicle operation. Consequently, $\mathrm{CO}$ emission levels were relatively lower during the initial $25 \mathrm{~s}$ of the initial cold-start period with $23 \%$ or $25 \%$ oxygen- 


\section{TABLE 6.3 Averaged Engine-out Hydrocarbon Emissions: FTP with M85}

\begin{tabular}{|c|c|c|c|c|c|c|c|c|}
\hline \multirow[b]{3}{*}{ Hydrocarbon } & \multicolumn{8}{|c|}{ Emissions (mg/mi) per Test Period and $\mathrm{O}_{2}$ Level } \\
\hline & \multicolumn{2}{|c|}{ Bag 1} & \multicolumn{2}{|c|}{ Bag 2} & \multicolumn{2}{|c|}{ Bag 3} & \multicolumn{2}{|c|}{ Weighted } \\
\hline & $21 \%$ & $25 \%$ & $21 \%$ & $25 \%$ & $21 \%$ & $25 \%$ & $21 \%$ & $25 \%$ \\
\hline \multicolumn{9}{|l|}{ Aldehydes } \\
\hline Formaldehyde & 302.74 & 142.45 & 323.91 & 99.70 & 152.03 & 63.16 & 272.34 & 98.52 \\
\hline Acetaldehyde & 3.29 & 3.61 & 8.50 & 3.77 & 4.01 & 2.00 & 6.19 & 3.25 \\
\hline Acrolein & 40.23 & 0.41 & 0.42 & 0.39 & 0.22 & 0.19 & 8.61 & 0.34 \\
\hline Benzaldehyde & 0.00 & 0.62 & 0.00 & 0.58 & 0.00 & 0.56 & 0.00 & 0.58 \\
\hline \multicolumn{9}{|l|}{ Olefins } \\
\hline Ethene (ethylene) & 94.84 & 46.12 & 77.20 & 42.91 & 62.88 & 40.05 & 76.92 & 42.79 \\
\hline Propene (propylene) & 57.81 & 22.71 & 43.90 & 18.43 & 33.95 & 16.67 & 44.04 & 18.84 \\
\hline Propadiene & 2.29 & 1.42 & 1.28 & 0.85 & 1.27 & 1.23 & 1.49 & 1.07 \\
\hline Isobutylene & 29.28 & 11.80 & 23.90 & 12.40 & 16.26 & 10.32 & 22.91 & 11.71 \\
\hline 1,3-Butadiene & 4.89 & 2.79 & 4.49 & 2.48 & 3.36 & 2.56 & 4.26 & 2.57 \\
\hline \multicolumn{9}{|l|}{ Aromatics } \\
\hline Benzene & 22.87 & 12.04 & 11.43 & 10.88 & 13.10 & 9.45 & 14.26 & 10.73 \\
\hline Toluene & 9.02 & 5.46 & 6.21 & 5.66 & 6.02 & 4.18 & 6.74 & 5.22 \\
\hline m-Xylene & 4.61 & 1.96 & 3.77 & 3.07 & 2.37 & 2.00 & 3.56 & 2.55 \\
\hline \multicolumn{9}{|l|}{ Paraffins } \\
\hline Methane & 102.82 & 57.17 & 74.20 & 41.28 & 52.77 & 40.72 & 74.24 & 44.42 \\
\hline Ethane & 5.64 & 2.90 & 5.02 & 2.40 & 3.15 & 2.32 & 4.64 & 2.48 \\
\hline n-Pentane & 10.78 & 2.88 & 6.04 & 2.57 & 4.61 & 2.50 & 6.63 & 2.62 \\
\hline n-Hexane & 5.93 & 2.35 & 3.00 & 1.35 & 2.08 & 1.34 & 3.36 & 1.55 \\
\hline 2,2,4-Trimethylpentane & 28.09 & 7.69 & 12.69 & 4.38 & 10.01 & 4.75 & 15.14 & 5.16 \\
\hline
\end{tabular}

enriched air. $\mathrm{NO}_{\mathrm{x}}$ emission levels were found to be much higher with oxygen enrichment than with ambient intake air. Although $\mathrm{NO}_{\mathrm{x}}$ emission levels did not go up during the key-on and idling periods (up to about $20 \mathrm{~s}$ ), they started increasing from the first acceleration of the vehicle. Thereafter, $\mathrm{NO}_{\mathrm{x}}$ increased with an increase in oxygen enrichment, while qualitative patterns similar to those found with ambient intake air were maintained. It was anticipated that higher flame speeds (generally observed with M85 fuel), higher combustion temperatures, and additional oxygen availability would lead to an increase in the $\mathrm{NO}_{x}$ level when oxygen-enriched air was used. Perhaps these effects necessitate a post-treatment device to reduce $\mathrm{NO}_{\mathbf{x}}$ emissions. 
TABLE 6.4 Averaged Engine-out Ozone-Forming Potential and Specific Reactivity: FTP with M85

\begin{tabular}{|c|c|c|c|c|c|c|c|c|}
\hline \multirow[b]{3}{*}{ Test } & \multicolumn{4}{|c|}{$\begin{array}{l}\text { OFP (g ozone/mi) per Factor } \\
\text { and } \mathrm{O}_{2} \text { Level }\end{array}$} & \multicolumn{4}{|c|}{$\begin{array}{l}\text { SR (g ozone/g NMOG) } \\
\text { per Factor and } \mathrm{O}_{2} \text { Level }\end{array}$} \\
\hline & \multicolumn{2}{|c|}{ Based on MIR } & \multicolumn{2}{|c|}{ Based on MOIR } & \multicolumn{2}{|c|}{ Based on MIR } & \multicolumn{2}{|c|}{ Based on MOIR } \\
\hline & $21 \%$ & $25 \%$ & $21 \%$ & $25 \%$ & $21 \%$ & $25 \%$ & $21 \%$ & $25 \%$ \\
\hline Bag 1 & 6.742 & 3.663 & 2.835 & 1.700 & 2.277 & 2.257 & 0.957 & 1.047 \\
\hline Bag 2 & 5.132 & 2.424 & 2.019 & 1.091 & 4.431 & 3.254 & 1.743 & 1.464 \\
\hline Bag 3 & 2.952 & 2.020 & 1.222 & 0.946 & 2.001 & 3.001 & 0.828 & 1.406 \\
\hline Weighted & 5.021 & 2.570 & 2.046 & 1.177 & 2.730 & 2.834 & 1.113 & 1.298 \\
\hline
\end{tabular}

\subsubsection{FTP Converter-out Emissions}

The converter-out exhaust emissions obtained with oxygen enrichment are illustrated in Figures 6.28 and 6.29. It was observed that THC-FID levels were lower, $\mathrm{NO}_{\mathrm{x}}$ levels were much higher, and no appreciable variation in $\mathrm{CO}$ emissions occurred with $23 \%$ or $25 \%$ oxygen-enriched intake air. Oxygen-enriched intake air reduced the THC-FID over the ambient air during the bag 1 FTP by about 12-16\%. During bag 2 and bag 3 periods of the FTP cycle, the THC-FID levels from converter-out emissions were very low and difficult to distinguish from the effects of oxygenenriched air. Because of lower cold-phase THC-FID emission levels, the FTP-weighted average of THC-FID emissions were also lower by about $18 \%$ and $21 \%$ with $23 \%$ and $25 \%$ oxygen-enriched intake air, respectively. The NMHC emissions were reduced by about $38 \%$ in bag $1,66 \%$ in bag 2 , and $52 \%$ in bag 3 with $23 \%$ oxygen-enriched air, and reduced by about $89 \%$ in bag $1,66 \%$ in bag 2 and $72 \%$ in bag 3 with $25 \%$ oxygen-enriched air. During the bag 1 FTP, THC was reduced by about $31 \%$ and $64 \%$ when $23 \%$ and $25 \%$ oxygen-enriched air, respectively, was used. As was the case for engine-out emissions, the $\mathrm{NO}_{\mathrm{x}}$ emission levels were much higher with oxygen enrichment. The weighted-average $\mathrm{NO}_{\mathrm{x}}$ emissions increased from $0.053 \mathrm{~g} / \mathrm{mi}$ with ambient air to 0.189 and $0.496 \mathrm{~g} / \mathrm{mi}$ with $23 \%$ and $25 \%$ oxygen-enriched air, respectively. The CO emissions were essentially similar with ambient air and oxygen-enriched air. This result was anticipated because of the increase in fuel-bound oxygen content during combustion. Contrary to the observed engine-out emissions, the converter-out NMOG, formaldehyde, and unburned methanol emissions were little affected by the use of oxygen-enriched air. In the presence of a catalyzing environment, the additional oxygen available in the exhaust could participate in the chemical reactions with unburned methanol and reactive olefins and paraffins. As a result, the composition of the converter-out exhaust emissions was different from that of the engine-out emissions. Hence, a careful study is necessary to investigate the effects of exhaust gases in the catalytic converter with oxygen-enriched intake air and M85 as 

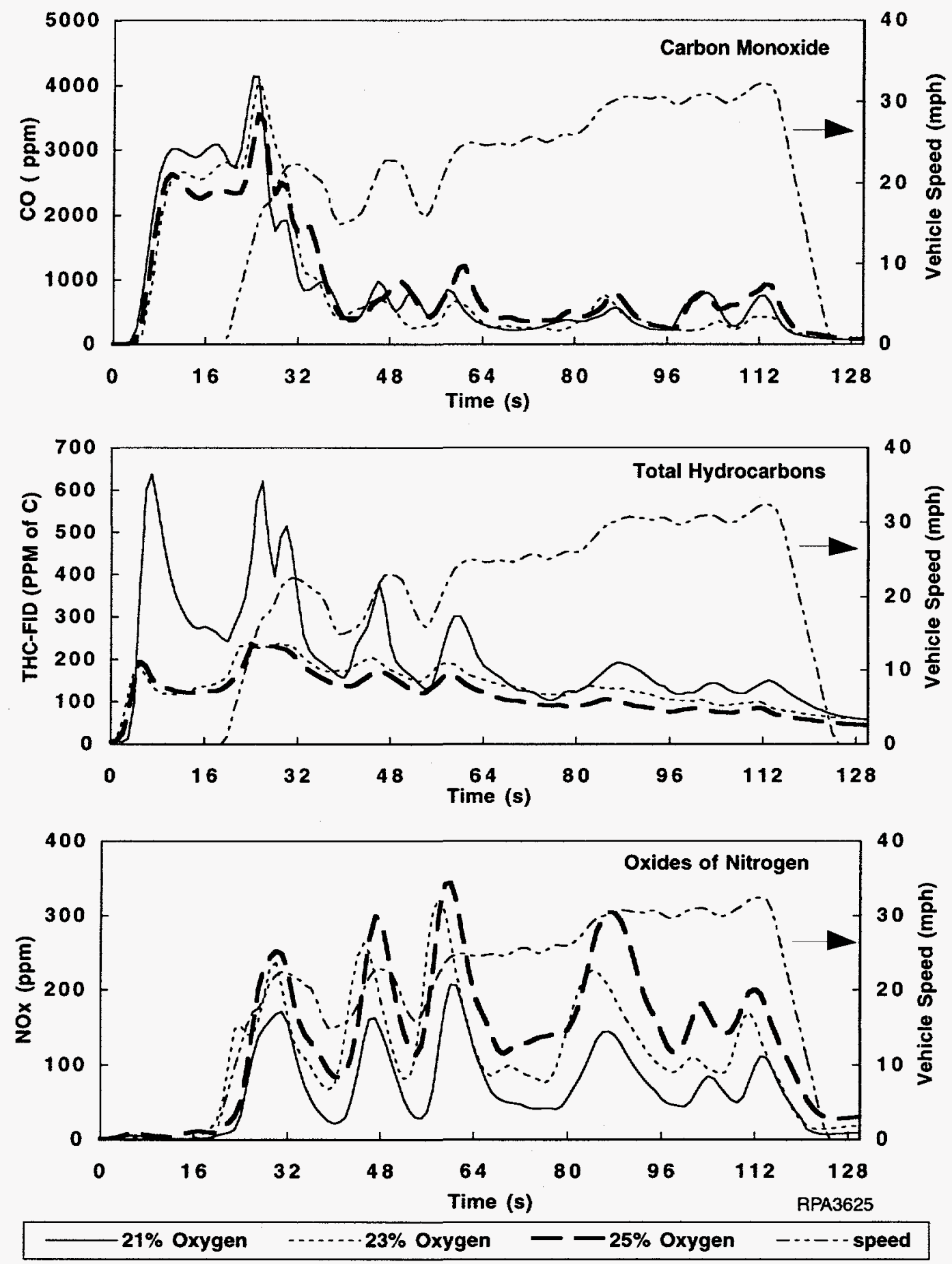

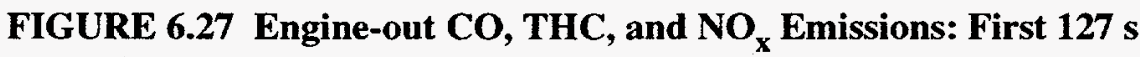
of the Cold-Phase FTP with M85 

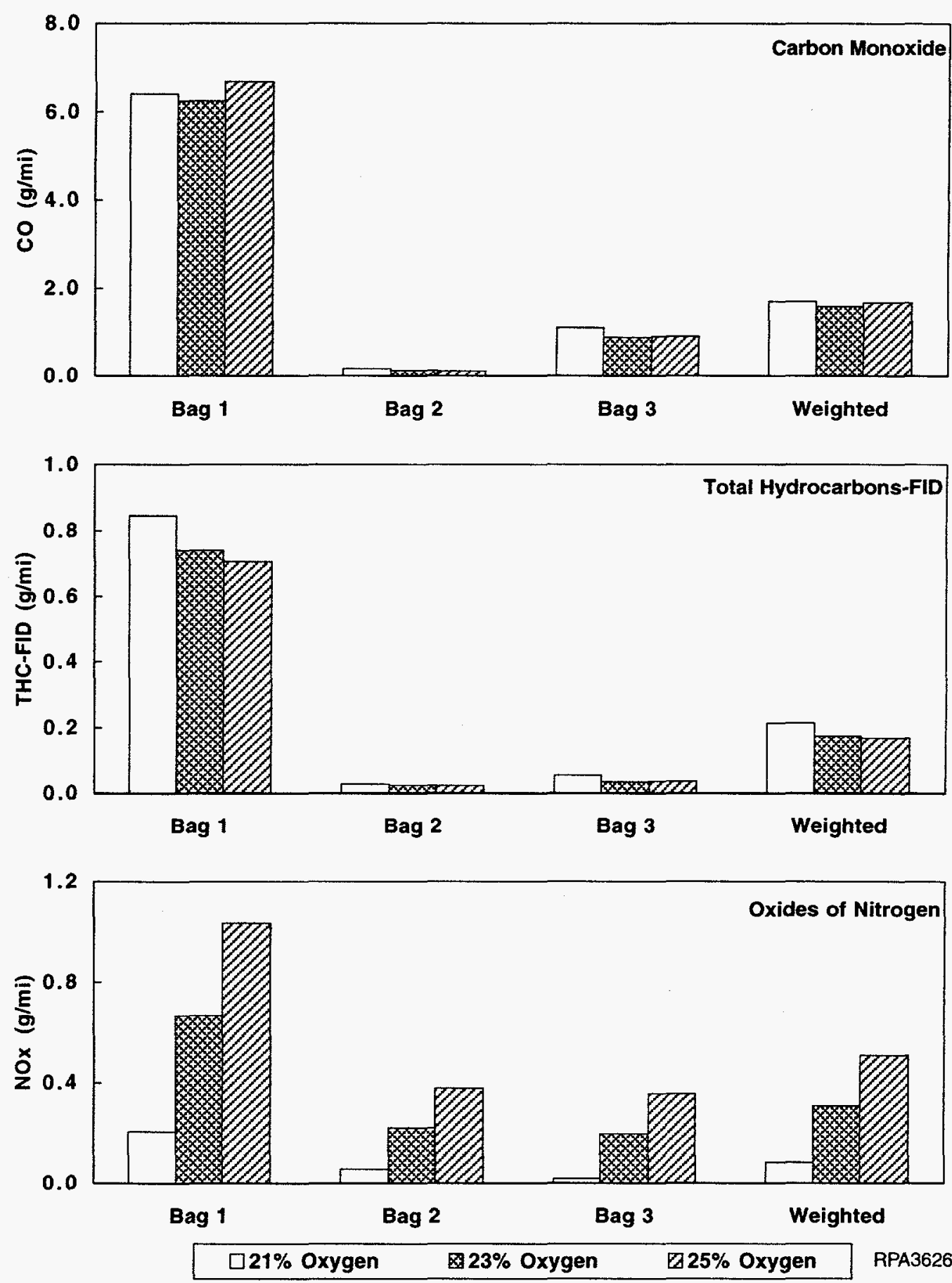

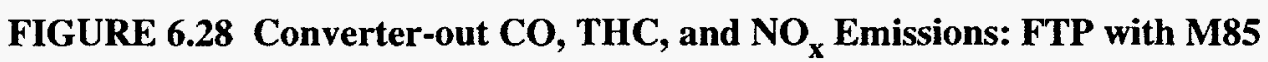



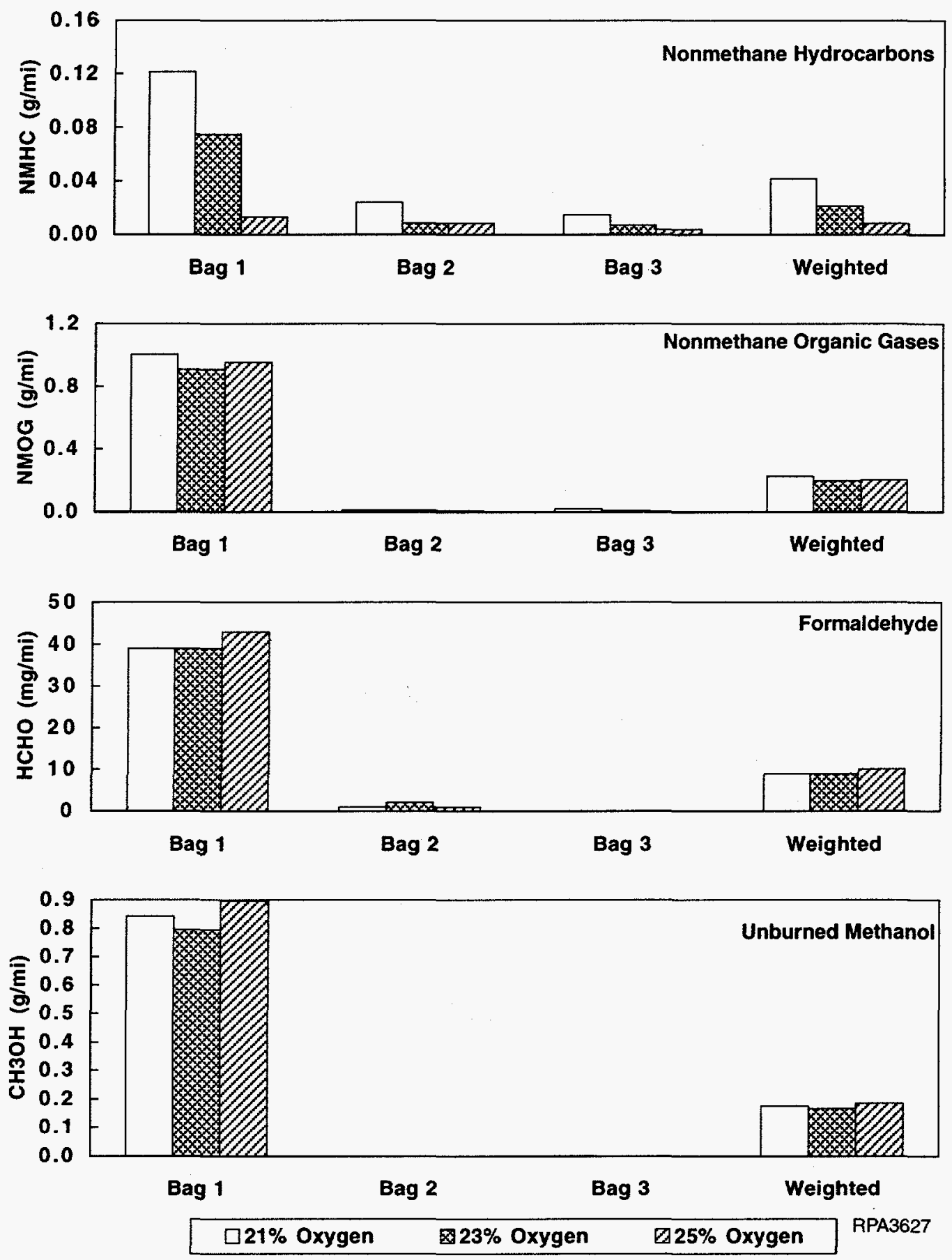

FIGURE 6.29 Converter-out NMHC, NMOG, $\mathrm{HCHO}$, and $\mathrm{CH}_{3} \mathrm{OH}$ Emissions: FTP with M85 
a test fuel. Moreover, the catalytic converter under investigation was not fully aged (having an odometer reading of only $2,490 \mathrm{~km}$ ). Because of difficulties in predicting the nature of chemical reactions with a fresh catalyst, a sufficiently aged catalyst is required to investigate oxygen enrichment effects on aldehyde and other exhaust emissions.

The converter-out, time-resolved emissions of THC-FID, CO, and $\mathrm{NO}_{\mathrm{x}}$ emissions during the first 127-s cold-phase FTP are illustrated in Figure 6.30. Of these exhaust emissions, THC-FID emissions benefit most from oxygen-enriched combustion. During the initial idling and first transient period of vehicle operation (initial $40 \mathrm{~s}$ from key-on), THC-FID emissions were considerably reduced with either $23 \%$ or $25 \%$ oxygen-enriched air. For example, the peak of THC-FID was reduced from about 340 to 140 ppm during the first 30 -s period because of $23 \%$ or $25 \%$ oxygen enrichment. However, there was no appreciable variation in $\mathrm{CO}$ emissions because of oxygenenriched air and M85 fuel. The $\mathrm{NO}_{x}$ emission levels were higher with oxygen-enriched air. During the initial $127 \mathrm{~s}$ of the cold phase, the increase in $\mathrm{NO}_{\mathrm{x}}$ with oxygen enrichment was quite noticeable only between the 25-s to 75-s period. The maximum value of $\mathrm{NO}_{\mathrm{x}}$ increased from about 80 to $200 \mathrm{ppm}$ with $25 \%$ oxygen-enriched air. Because the increase in $\mathrm{NO}_{\mathrm{x}}$ was predominant for only about $50 \mathrm{~s}$ during the 127 -s period of the cold-phase, its relative contribution to overall tailpipe $\mathrm{NO}_{\mathrm{x}}$ emissions would not be severely affected if this technique were to be employed only during the coldphase or initial $127 \mathrm{~s}$ of the cold-phase FTP. Although recalibration of ECU and optimized spark timing might help alleviate the $\mathrm{NO}_{\mathrm{x}}$ problems with oxygen-enriched air, it is still essential to have a post-treatment $\mathrm{NO}_{\mathrm{x}}$ control device to reduce the $\mathrm{NO}_{\mathrm{x}}$ to acceptable levels.

From the HC/aldehyde speciation of converter-out exhaust during the FTP cycle, the variations in some of the emissions of aldehydes, olefins, aromatics, and paraffins with oxygenenriched intake air are presented in Table 6.5. Converter-out aldehyde emissions were little affected by oxygen-enriched intake air. This result occurred partly because of the very low levels of acetaldehyde, acrolein, and benzaldehyde in the converter-out emissions, even with ambient air. The FTP weighted-average formaldehyde emission levels were lower than $10 \mathrm{mg} / \mathrm{mi}$ for both ambient air and oxygen-enriched intake air. The converter-out aldehyde emission trends with oxygenenriched intake air were quite different from those of the engine-out exhaust. This result probably occurred because of the prevailing high conversion efficiencies of the catalytic converter tested in the experiments. Studies involving sufficiently aged catalysts or converters with poor conversion efficiencies might reveal the potential advantages of oxygen-enriched intake air in reducing aldehyde emissions. Among the olefins, ethene and propene were reduced by about 21-62\% with oxygenenriched intake air, the highest reductions being achieved with $25 \%$ enrichment. From the aromatics group, benzene, which is a regulated toxic, and toluene were reduced by about $53 \%$ and $67 \%$ because of the addition of $23 \%$ and $25 \%$ oxygen-enriched intake air, respectively. However, there was little variation in $\mathrm{m}$-xylene. With $23 \%$ or $25 \%$ oxygen-enriched intake air, most of the paraffins (methane, ethane, $n$-pentane, and n-hexane) were reduced by about 27-67\%. It appears that oxygenenriched intake air helps oxidize the majority of aromatics and helps oxidize paraffins (which are difficult to oxidize) in the converter. The reactive species such as ethene and propene, which are 

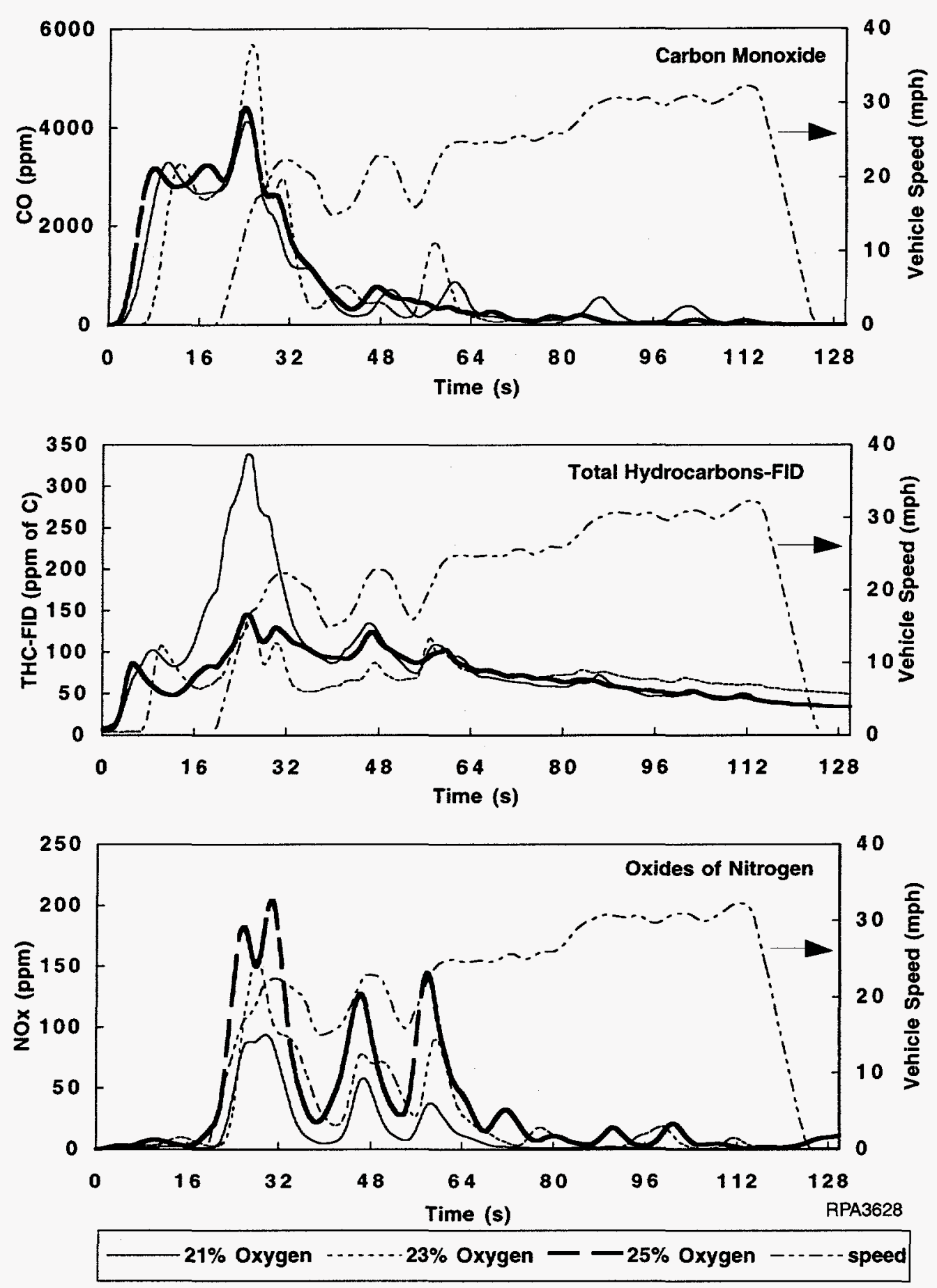

FIGURE 6.30 Converter-out, Time-Resolved CO, THC, and NO Emissions: First 127 s of the Cold-Phase FTP with M85 


\section{TABLE 6.5 Averaged Converter-Out Hydrocarbon Emissions: FTP with M85}

\begin{tabular}{|c|c|c|c|c|c|c|c|c|c|c|c|c|}
\hline \multirow[b]{3}{*}{ Hydrocarbon } & \multicolumn{12}{|c|}{ Emissions $(\mathrm{mg} / \mathrm{mi})$ per Test Period and $\mathrm{O}_{2}$ Level } \\
\hline & \multicolumn{3}{|c|}{ Bag 1} & \multicolumn{3}{|c|}{ Bag 2} & \multicolumn{3}{|c|}{ Bag 3} & \multicolumn{3}{|c|}{ Weighted } \\
\hline & $21 \%$ & $23 \%$ & $25 \%$ & $21 \%$ & $23 \%$ & $25 \%$ & $21 \%$ & $23 \%$ & $25 \%$ & $21 \%$ & $23 \%$ & $25 \%$ \\
\hline \multicolumn{13}{|l|}{ Aldehydes } \\
\hline Formaldehyde & 33.46 & 38.86 & 33.46 & 0.60 & 2.28 & 1.29 & 0.43 & 0.47 & 0.44 & 8.24 & 9.35 & 7.72 \\
\hline Acetaldehyde & 0.74 & 0.73 & 0.74 & 0.40 & 0.06 & 0.16 & 0.49 & 0.00 & 0.13 & 0.58 & 0.18 & 0.27 \\
\hline Acrolein & 0.16 & 0.18 & 0.16 & 0.00 & 0.00 & 0.00 & 0.00 & 0.00 & 0.00 & 0.04 & 0.04 & 0.03 \\
\hline Benzaldehyde & 0.00 & 0.00 & 0.00 & 0.00 & 0.00 & 0.00 & 0.00 & 0.00 & 0.00 & 0.00 & 0.00 & 0.00 \\
\hline \multicolumn{13}{|l|}{ Olefins } \\
\hline Ethene (ethylene) & 9.45 & 7.46 & 4.58 & 0.00 & 0.00 & 0.00 & 0.00 & 0.00 & 0.00 & 1.96 & 1.54 & 0.95 \\
\hline Propene (propylene) & 3.13 & 2.16 & 1.18 & 0.00 & 0.00 & 0.00 & 0.00 & 0.00 & 0.00 & 0.65 & 0.45 & 0.25 \\
\hline Propadiene & 0.00 & 0.00 & 0.00 & 0.00 & 0.00 & 0.00 & 0.00 & 0.00 & 0.00 & 0.00 & 0.00 & 0.00 \\
\hline Isobutylene & 2.27 & 1.68 & 2.92 & 0.00 & 0.45 & 1.13 & 0.00 & 1.56 & 1.30 & 0.00 & 1.01 & 1.55 \\
\hline 1,3-Butadiene & 0.00 & 0.00 & 0.00 & 0.00 & 0.00 & 0.00 & 0.00 & 0.00 & 0.00 & 0.00 & 0.00 & 0.00 \\
\hline \multicolumn{13}{|l|}{ Aromatics } \\
\hline Benzene & 5.72 & 2.40 & 1.87 & 0.79 & 0.00 & 0.00 & 0.80 & 0.00 & 0.40 & 1.82 & 0.50 & 0.50 \\
\hline Toluene & 3.24 & 1.09 & 1.53 & 0.94 & 0.13 & 1.69 & 0.63 & 0.11 & 0.45 & 1.33 & 0.32 & 1.32 \\
\hline m-Xylene & 0.53 & 1.07 & 0.81 & 0.00 & 0.27 & 0.00 & 0.00 & 0.18 & 0.33 & 0.11 & 0.41 & 0.26 \\
\hline \multicolumn{13}{|l|}{ Paraffins } \\
\hline Methane & 40.30 & 28.53 & 22.26 & 7.84 & 2.47 & 3.34 & 12.63 & 10.08 & 7.76 & 15.89 & 9.95 & 8.48 \\
\hline Ethane & 1.25 & 0.62 & 0.48 & 0.00 & 0.00 & 0.00 & 0.00 & 0.00 & 0.00 & 0.26 & 0.13 & 0.10 \\
\hline n-Pentane & 3.58 & 1.63 & 1.16 & 0.92 & 0.40 & 0.55 & 0.64 & 0.11 & 0.54 & 1.39 & 0.58 & 0.67 \\
\hline n-Hexane & 2.47 & 1.81 & 0.67 & 0.22 & 0.17 & 0.13 & 0.26 & 0.13 & 0.10 & 0.70 & 0.50 & 0.23 \\
\hline 2,2,4-Trimethylpentane & 2.47 & 5.63 & 2.38 & 0.58 & 0.00 & 0.19 & 0.96 & 0.37 & 0.15 & 2.48 & 1.27 & 0.63 \\
\hline
\end{tabular}


believed to contribute significantly to ozone formation and photochemical smog, were also considerably reduced when oxygen-enriched intake air was used. These reductions could possibly result from lower engine-out $\mathrm{HC}$ emission levels and also the relatively higher oxygen content in the exhaust gases.

The averaged, converter-out, OFP and SR on the basis of MIR and MOIR factors are provided in Table 6.6. Because of reductions in the OFP of various HC components due to oxygenenriched intake air, the maximum OFP was also lowered. However, unlike the greater reductions in engine-out OFP, nominal reductions of about $10 \%$ to $30 \%$ in converter-out OFP were observed with $23 \%$ or $25 \%$ oxygen-enriched intake air, respectively. The variation in SR was very minor from using oxygen enrichment. These findings indicate that reductions in both SR and NMOG were difficult to obtain by using oxygen-enriched intake air. This result evidently occurs because of greater reductions in NMOG than OFP. For vehicles to meet LEV/ULEV standards, lower SR and NMOG are desirable. These effects warrant that further investigations be conducted on using oxygen-enriched intake air to optimize oxygen-fuel ratios and other operating conditions during the cold phase, a method that could lead to lower SR as well as NMOG levels.

An important aspect of the California LEV legislation is its approach that among the OFPs of various vehicle/fuel concepts within an emission class, only minimal differences exist. The use of vehicles running on alternative fuels leads to a considerably smaller OFP despite nominally equal NMOG emissions because of the lower reactivity of the emission components. The CARB methods take the different reactivities of the emissions within the NMOG limits of the emission classes into consideration. They do so through the introduction of reactivity adjustment factors (RAFs), which are to be defined for all relevant alternative fuels in the three LEV emission classes. The RAF is defined as the quotient of the specific reactivity of the alternative fuel (clean fuel) and the specific reactivity of the "reference fuel" for emissions and certificate tests $[50,51]$ :

$$
R A F=\frac{S R_{\text {Clean Fuel }}}{S R_{\text {Reference Fuel }}}
$$

The measured NMOG value of a vehicle is multiplied by the corresponding RAF, and the result is then compared with the legally specified NMOG limit. Manufacturers have two options when utilizing a RAF for a given fuel. They can establish their own SR for a particular engine family (to be used in the numerator of the RAF equation), or they can use the generic RAF developed by the CARB, which applies to all vehicles and fuels in a given emission category (TLEV, LEV, or ULEV). Both options use the same baseline SR (the denominator of the RAF equation) determined by the CARB. The baseline SR and generic RAFs for different alternate fuels, vehicle classes, and emission classes suggested by the CARB are provided in Table 6.7 . 
TABLE 6.6 Averaged Converter-out Ozone-Forming Potential and Specific Reactivity: FTP with M85

\begin{tabular}{|c|c|c|c|c|c|c|c|c|c|c|c|c|}
\hline \multirow[b]{3}{*}{ Test } & \multicolumn{6}{|c|}{ OFP (g ozone/mi) per Factor and $\mathrm{O}_{2}$ Level } & \multicolumn{6}{|c|}{ SR (g ozone/g NMOG) per Factor and $\mathrm{O}_{2}$ Level } \\
\hline & \multicolumn{3}{|c|}{ Based on MIR } & \multicolumn{3}{|c|}{ Based on MOIR } & \multicolumn{3}{|c|}{ Based on MIR } & \multicolumn{3}{|c|}{ Based on MOIR } \\
\hline & $21 \%$ & $23 \%$ & $25 \%$ & $21 \%$ & $23 \%$ & $25 \%$ & $21 \%$ & $23 \%$ & $25 \%$ & $21 \%$ & $23 \%$ & $25 \%$ \\
\hline Bag 1 & 1424.300 & 1278.984 & 1181.326 & 707.950 & 635.494 & 598.017 & 1.420 & 1.405 & 1.285 & 0.705 & 0.700 & 0.651 \\
\hline Bag 2 & 77.416 & 54.094 & 58.458 & 35.004 & 21.711 & 23.207 & 3.139 & 5.409 & 4.497 & 1.419 & 2.171 & 1.785 \\
\hline Bag 3 & 108.648 & 75.439 & 83.453 & 61.359 & 46.048 & 45.212 & 6.268 & 10.777 & 10.432 & 3.540 & 6.578 & 5.652 \\
\hline Weighted & 365.310 & 313.471 & 298.109 & 181.811 & 155.429 & 148.407 & 1.619 & 1.599 & 1.491 & 0.806 & 0.793 & 0.742 \\
\hline
\end{tabular}


TABLE 6.7 CARB Reactivity Adjustment Factors and Baseline Specific Reactivities for Different Emission and Clean Fuel Categories

\begin{tabular}{|c|c|c|c|c|c|}
\hline \multirow[b]{2}{*}{ Fuel } & \multicolumn{3}{|c|}{ Light-Duty Vehicle } & \multicolumn{2}{|c|}{ Medium-Duty Vehicle } \\
\hline & TLEV & LEV & ULEV & LEV & ULEV \\
\hline \multicolumn{6}{|c|}{ Baseline specific reactivity ( $g$ ozone/g NMOG) } \\
\hline Conventional gasoline & 3.24 & 3.13 & 3.13 & 3.13 & 3.13 \\
\hline \multicolumn{6}{|l|}{ Reactivity adjustment factor } \\
\hline Phase 2 RFG & 0.98 & 0.94 & 0.94 & 0.94 & 0.94 \\
\hline M85 & 0.41 & 0.41 & 0.41 & 0.41 & 0.41 \\
\hline Natural gas & 1.00 & 0.43 & 0.43 & 0.43 & 0.43 \\
\hline Liquefied petroleum gas & 1.00 & 0.50 & 0.50 & 0.50 & 0.50 \\
\hline
\end{tabular}

Source: Ref. 51.

In the present work, four different methods were used to obtain reactivity-adjusted NMOG values; they are shown in Table 6.8 with corresponding RAFs. The SRs for operation with the reference fuel and interim generic RAFs for different fuels were published by the CARB [51]. Therefore, reactivity-adjusted NMOG values were calculated on the basis of a generic RAF of 0.41 and SRs provided for LEV and ULEV emission classes with M85. Since the reference fuel used by the CARB would be different from the reference fuel (Indolene) in the present experiments, the SR based on the Indolene fuel for this particular FFV was employed to estimate the RAF. After obtaining the RAF (with ambient intake air), the same procedure was used to compute reactivityadjusted NMOG values with oxygen-enriched intake air. The computed values are provided in Table 6.8. Results indicate that with a generic RAF of 0.41 (provided by the CARB) with M85, the reactivity-adjusted NMOG was lower than TLEV standards (without considering deterioration factors) and also very close to meeting the LEV standards with either $23 \%$ or $25 \%$ oxygen-enriched air. These lower reactivity-adjusted NMOG values promise oxygen-enriched intake air as a potential candidate in meeting future emission standards.

\subsubsection{Off-Cycle Converter-out Emissions}

Figure 6.31 shows the off-cycle exhaust emissions of THC-FID, $\mathrm{CO}$, and $\mathrm{NO}_{\mathrm{x}}$ when ambient air and two different levels of oxygen enrichment are used. Indolene fuel results (Section 6.2.3) indicate that emission levels from bag 3 of the off cycle were disproportionately higher than those from other bags because of the rapid accelerations and decelerations involved in 
TABLE 6.8 Reactivity-Adjusted, Weighted-Average NMOG Emissions: FTP with M85

\begin{tabular}{|c|c|c|c|c|c|c|c|c|}
\hline \multirow[b]{2}{*}{ Basis } & \multicolumn{3}{|c|}{$\begin{array}{l}\text { Reactivity Adjustment } \\
\text { Factor per } \mathrm{O}_{2} \text { Level }\end{array}$} & \multicolumn{3}{|c|}{$\begin{array}{c}\text { Reactivity-Adjusted NMOG } \\
(\mathrm{g} / \mathrm{mi}) \text { per } \mathrm{O}_{2} \text { Level }\end{array}$} & \multicolumn{2}{|c|}{$\begin{array}{l}\text { California Standarc } \\
(\mathrm{g} / \mathrm{mi}) \text { per Vehicle } \\
\end{array}$} \\
\hline & $21 \%$ & $23 \%$ & $25 \%$ & $21 \%$ & $23 \%$ & $25 \%$ & TLEV & LEV \\
\hline $\begin{array}{l}\text { CARB-specified } \\
\operatorname{RAF}(0.41)\end{array}$ & 0.410 & 0.410 & 0.410 & 0.093 & 0.080 & 0.082 & 0.125 & 0.075 \\
\hline $\begin{array}{l}\text { Specific reactivity } \\
(\text { TLEV })=3.42\end{array}$ & 0.473 & 0.468 & 0.436 & 0.107 & 0.092 & 0.087 & 0.125 & 0.075 \\
\hline $\begin{array}{l}\text { Specific reactivity } \\
(\mathrm{LEV})=3.13\end{array}$ & 0.517 & 0.511 & 0.476 & 0.117 & 0.100 & 0.095 & 0.125 & 0.075 \\
\hline $\begin{array}{l}\text { Specific reactivity } \\
\text { (Indolene) }=3.74\end{array}$ & 0.433 & 0.428 & 0.399 & 0.098 & 0.084 & 0.080 & 0.125 & 0.075 \\
\hline
\end{tabular}

the driving pattern. Conventional catalytic converters cannot control these emissions because of the increase in fuel enrichment during periods of rapid acceleration. Under these conditions, oxygen enrichment might play a major role in bringing the air-to-fuel ratio close to stoichiometric and promoting complete combustion. As a result, THC-FID and $\mathrm{CO}$ emissions from bag 3 were considerably reduced. This reduction occurred in the vehicle fueled by M85. Test results indicate that THC-FID emission levels decreased from $0.308 \mathrm{~g} / \mathrm{mi}$ to $0.149(51 \%)$ and $0.194(37 \%)$ with $23 \%$ and $25 \%$ oxygen-enriched air, respectively. Similarly, $\mathrm{CO}$ emission levels decreased from $16.2 \mathrm{~g} / \mathrm{mi}$ to $5.4(66 \%)$ and to $3.8(76 \%)$ when the intake oxygen level was increased from $21 \%$ to $23 \%$ and $25 \%$, respectively. However, the corresponding $\mathrm{NO}_{\mathrm{x}}$ emission levels increased from $0.21 \mathrm{~g} / \mathrm{mi}$ to 0.82 (2.8 times) and to 1.7 ( 7 times). Although the $\mathrm{NO}_{\mathrm{x}}$ emissions from bag 3 were higher with oxygen-enriched air, as a result of relatively low contributions from the other two bags, the weighted-average emissions did not increase significantly (increased from $0.05 \mathrm{~g} / \mathrm{mi}$ with ambient air to 0.19 and to $0.49 \mathrm{~g} / \mathrm{mi}$ with $23 \%$ and $25 \%$ oxygen-enriched air, respectively). It seems that if oxygen enrichment is employed during only bag 3 of the off cycle, $\mathrm{NO}_{\mathrm{x}}$ emissions can be decreased to a greater extent, while the maximum benefits from reducing THC-FID and CO emissions simultaneously are obtained. Proper ECU calibration to account for higher intake-air oxygen levels and a post-treatment $\mathrm{NO}_{\mathrm{x}}$ control device would help to decrease the $\mathrm{NO}_{\mathrm{x}}$ to very low levels. 

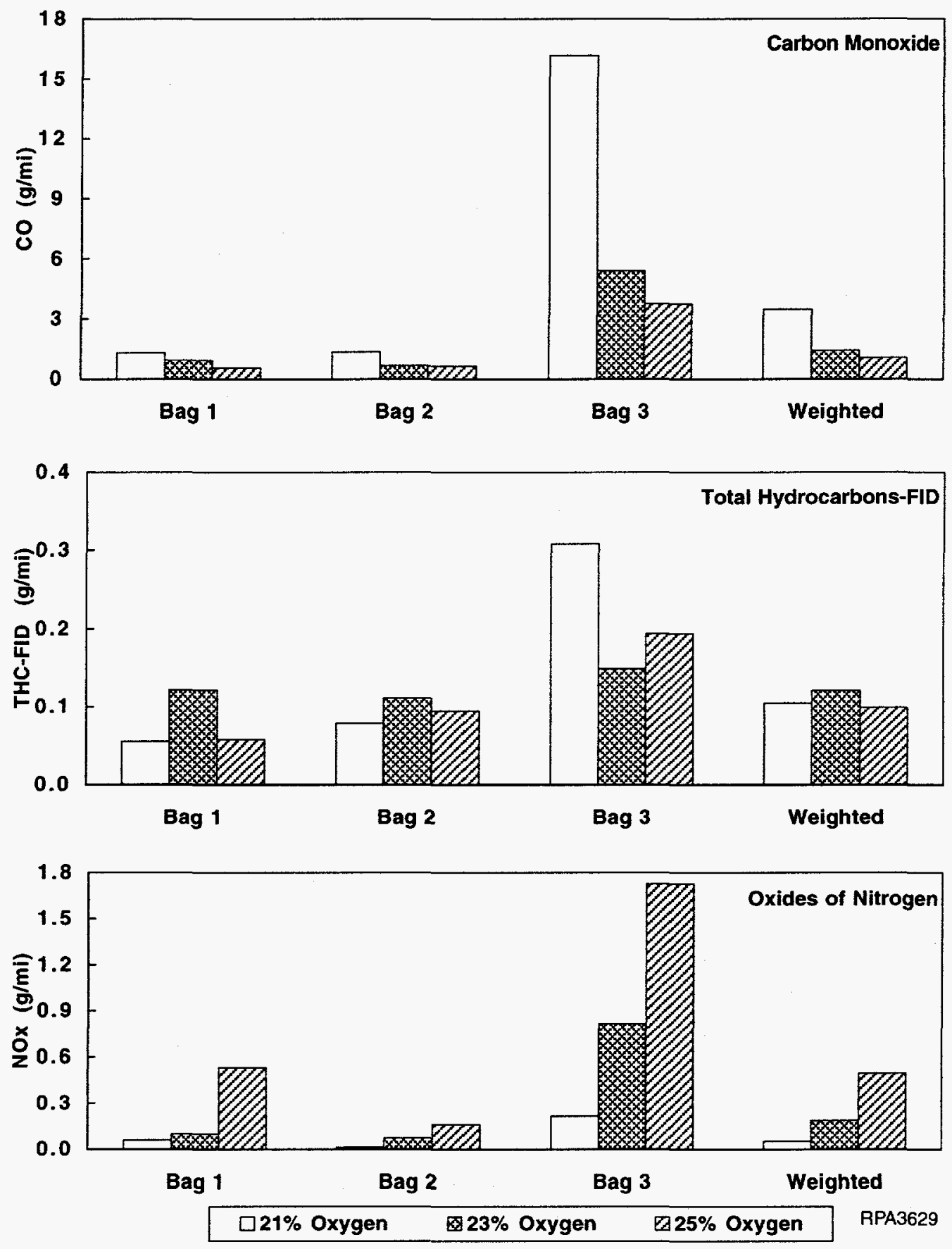

FIGURE 6.31 Converter-out CO, THC, and NO $\mathrm{N}_{\mathrm{x}}$ Emissions: Off-Cycle Test with M85 


\section{RECOMMENDATIONS}

The suitability of a given oxygen-enrichment level for a particular engine depends on the desired reductions of both THC and $\mathrm{CO}$, as well as on the simultaneous control of $\mathrm{NO}_{\mathrm{x}}$ emissions (without exceeding the emissions standards). Three different approaches for oxygen-enriched intake air applications for LDVs have been attempted in the present work and are listed below. Data on the FTP (converter-out) weighted-average emissions (not adjusted for catalyst deterioration factors) from these three application strategies that use Indolene as a test fuel are compared with emissions standards, such as TLEV and Tier II standards.

1. $25 \%$ oxygen-enriched air during only the initial $127 \mathrm{~s}$ of the cold-phase FTP cycle. In this case, $25 \%$ oxygen-enriched air is supplied only during the initial $127 \mathrm{~s}$ period of the cold phase. For the remaining $378 \mathrm{~s}$ of bag 1 , bag 2 , and bag 3 of the FTP cycle, ambient air is supplied. As a result, the FTP weightedaverage emission levels of NMHC and $\mathrm{CO}$ are lower than the Tier II standards; the level of NMOG is lower than TLEV standards; and $\mathrm{NO}_{\mathrm{x}}$ emission levels are lower than both Tier II and TLEV standards. With this technique, the increase in $\mathrm{NO}_{\mathrm{x}}$ can be alleviated to a certain extent while NMHC/NMOG and CO emissions are reduced.

2. $23 \%$ oxygen-enriched air during only the cold-phase FTP cycle. In this approach, 23\% oxygen-enriched intake air is supplied only during bag 1 of the FTP cycle. During bag 2 and bag 3 periods, ambient air is employed. As a result, both $\mathrm{CO}$ and $\mathrm{NO}_{\mathrm{x}}$ emission levels are lower, but NMHC or NMOG levels are relatively higher than TLEV/Tier II standards.

3. $25 \%$ oxygen-enriched air during only the cold-phase FTP cycle. In this approach, 25\% oxygen-enriched intake air is supplied only during bag 1 of the FTP cycle. During bag 2 and bag 3 periods, ambient air is employed. As a result, NMOG/NMHC and CO emissions can meet TLEV/Tier II standards. $\mathrm{NO}_{\mathrm{x}}$ emission levels can meet TLEV but are slightly higher (about $0.1 \mathrm{~g} / \mathrm{mi}$ ) than Tier II standards. One method of meeting the requirement of low $\mathrm{NO}_{\mathrm{x}}$ levels with this technique might be to use optimized spark timing, a lean- $\mathrm{NO}_{\mathrm{x}}$ catalyst, or monatomic nitrogen to reduce $\mathrm{NO}_{\mathrm{x}}$.

To meet the TLEV/LEV's formaldehyde, reactivity-adjusted NMOG, and CO emission levels with an M85-fueled FFV, either $23 \%$ or $25 \%$ oxygen-enriched intake air could be used. However, the accompanying $\mathrm{NO}_{\mathrm{x}}$ emissions would exceed the standards. Hence, oxygen-enriched intake air application strategies (like those described in the case of Indolene fuel), such as using oxygen-enriched intake air during only the initial $127 \mathrm{~s}$ or only bag 1 of the cold-phase FTP cycle, might be beneficial in reducing all the emissions enough to meet future emission standards. 


\section{CONCLUSIONS}

Present investigations of using oxygen-enriched intake air in a 1993 flexible-fuel Dodge Spirit (passenger LDV) with a 2.5-L port-fuel-injected engine and an odometer reading of $2,490 \mathrm{~km}$ have led to the following conclusions.

\subsection{TESTS WITH INDOLENE}

1. Oxygen enrichment of intake air has the potential to reduce both THC and CO emissions, particularly during cold-phase FTP. It reduces the engine-out emissions because higher flame temperatures and more complete combustion result in lower converter-out emissions before converter light-off.

2. Engine-out CO emissions were reduced by about $46 \%$ and $50 \%$ and THC emissions were reduced by about $33 \%$ and $43 \%$ during the cold phase of the FTP cycle as a result of using $23 \%$ and $25 \%$ oxygen-enriched intake air, respectively. However, $\mathrm{NO}_{x}$ emissions increased by about $56 \%$ and $79 \%$ under the same conditions. The increase in $\mathrm{NO}_{\mathrm{x}}$ emissions was possibly a result of higher combustion temperatures and higher oxygen levels in the combustion air.

3. When $25 \%$ oxygen-enriched intake air was used, the FTP converter-out, weighted-average $\mathrm{THC}$ and $\mathrm{CO}$ emission levels were reduced by about $41 \%$ and $55 \%$, respectively, from emission levels when ambient air was used. However, the $\mathrm{NO}_{\mathrm{x}}$ emission level was higher (increased from 0.075 to $1.01 \mathrm{~g} / \mathrm{mi}$ ), which necessitates a post-treatment device or proper control of spark timing and air-to-fuel management to account for the increased oxygen level in the intake air.

4. The oxygen-enrichment level for a particular engine depends on the THC and $\mathrm{CO}$ reductions desired and on the proper control of $\mathrm{NO}_{x}$ to comply with future emission standards. The most promising strategies are to use up to $25 \%$ oxygen-enriched air either during only the initial $127 \mathrm{~s}$ of the cold-phase FTP or to use $23 \%$ oxygen-enriched intake air during only the cold-phase FTP. Both strategies have the potential to meet the Tier II and California TLEV emission standards for $\mathrm{NMOG} / \mathrm{NMHC}, \mathrm{CO}$, and $\mathrm{NO}_{\mathrm{x}}$.

5. The concentrations of regulated air toxics (benzene, formaldehyde, acetaldehyde, and 1,3-butadiene) and the OFP (on the basis of MIR factors) 
are reduced by about $23-33 \%$ with either $23 \%$ or $25 \%$ oxygen-enriched intake air. As a result of the lower cold-phase THC when oxygen-enriched air is used, the levels of about $40 \mathrm{HCs}$ that have a tendency to form ozone are considerably reduced.

6. Exhaust THC and $\mathrm{CO}$ emissions from bag 3 during the EPA's off-cycle test are difficult to control by means of conventional catalytic converters, because of rapid accelerations and decelerations during the driving cycle. However, with moderate oxygen enrichment of intake air (up to $23 \%$ oxygen), about $60 \%$ to $70 \%$ of THC and $\mathrm{CO}$ emissions can be reduced. The increase in $\mathrm{NO}_{\mathrm{x}}$ emissions due to such moderate oxygen enrichment may pose less of a problem, and the emission standards will be met.

\subsection{TESTS WITH M85}

1. Oxygen-enriched intake air has the potential to reduce engine-out THC, NMHC, NMOG, unburned methanol, and formaldehyde emissions, particularly during the cold-phase FTP cycle of FFVs operating on M85. However, it has little effect on $\mathrm{CO}$ emissions, and $\mathrm{NO}_{\mathrm{x}}$ emission levels are much higher because of the availability of oxygen in both the intake air and oxygenated fuel.

2. During the cold-phase FTP, the engine-out THC-FID was reduced by about $34 \%$ and $42 \%$, but $\mathrm{NO}_{\mathrm{x}}$ emissions were increased by about $46 \%$ and $78 \%$ when $23 \%$ and $25 \%$ oxygen-enriched intake air, respectively, was used. When M85 was used, the reductions in engine-out THC emissions and the increase in $\mathrm{NO}_{\mathrm{x}}$ emissions obtained with oxygen-enriched intake air were on about the same order as those obtained when Indolene fuel was used. The major difference between using Indolene or M85 with oxygen-enriched intake air was in $\mathrm{CO}$ emissions, because fuel-bound oxygen was present in the case of M85.

3. Engine-out formaldehyde emissions, which are of particular concern with regard to FFVs operating on M85, were reduced by about $53 \%$ in bag $1,84 \%$ in bag 2 , and $59 \%$ in bag 3 by following the FTP cycle with $25 \%$ oxygenenriched intake air. During the cold-phase FTP, reductions of about $42 \%$ in THC, $60 \%$ in NMHC, $45 \%$ in NMOG, and $40 \%$ in unburned methanol were observed in the engine-out emissions when $25 \%$ oxygen-enriched intake air was used instead of ambient air. 
4. Converter-out THC emissions were reduced by about $32 \%$ and $64 \%$ and NMHC emissions were reduced by about $38 \%$ and $89 \%$ during the cold-phase FTP from using nominal $23 \%$ and $25 \%$ oxygen-enriched intake air, respectively. The FTP, converter-out, weighted averages of formaldehyde emissions with $23 \%$ or $25 \%$ oxygen-enriched intake air were lower than $10 \mathrm{mg} / \mathrm{mi}$. In general, the converter-out NMOG and unburned methanol emissions resulting from using oxygen-enriched air were also lower, but to a lesser extent.

5. The OFP (on the basis of MIR/MOIR factors) of the FTP converter-out, exhaust HCs was reduced by about $10 \%$ and $30 \%$ with $23 \%$ and $25 \%$ oxygenenriched intake air, respectively. However, the variation in SR with oxygenenriched intake air was very minor. The reactivity-adjusted NMOG level based on the CARB generic RAF (0.41 for M85) was lower than California TLEV standards with either $23 \%$ or $25 \%$ oxygen-enriched intake air.

6. The FFVs operating on M85 with $23 \%$ oxygen-enriched intake air can meet (without adjusting for catalyst deterioration factors) reactivity-adjusted NMOG, $\mathrm{CO}, \mathrm{NO}_{\mathrm{x}}$, and formaldehyde emission standards of the TLEV. An optimized oxygen-enrichment level with a $\mathrm{NO}_{\mathrm{x}}$ control device such as monatomic nitrogen has the potential to meet LEV standards.

7. With nominal $23 \%$ oxygen-enriched intake air, reductions of about $67 \%$ in $\mathrm{CO}$ and $52 \%$ in THC-FID emissions were observed from the bag 3, converterout, off-cycle test. However, the corresponding $\mathrm{NO}_{\mathrm{x}}$ emission levels were higher (increased from 0.214 to $0.815 \mathrm{~g} / \mathrm{mi}$ ). The increase in $\mathrm{NO}_{\mathrm{x}}$ emissions with oxygen-enriched intake air necessitates a post-treatment control device. 


\section{REFERENCES}

1. Burch, S.D., T.F. Potter, M.A. Keyser, M.J. Brady, and K.F. Michaels, 1995, "Reducing ColdStart Emissions by Catalytic Converter Thermal Management," SAE Paper 950409.

2. Boam, D.J., I.C. Finlay, T.W. Biddulph, T.A. Ma, R. Lee, S.H. Richardson, J. Bloomfield, J.A. Green, S. Wallace, W.A. Woods, and P. Brown, 1994, "The Sources of Unburnt Hydrocarbon Emissions from Spark-Ignition Engines during Cold Starts and Warm-up," Institute of Mechanical Engineers Journal of Automobile Engineering 208:1-11.

3. Harris, J.N., A.G. Russell, and J.B. Milford, 1988, “Air Quality Implications of Methanol Fuel Utilization," SAE Paper 881198.

4. Moses, G., and C. Saricks, 1987, "A Review of Methanol Vehicles and Air Quality Impacts," SAE Paper 872053.

5. Oh, S.H., and E.J. Bissett, 1993, "Mathematical Modeling of Monolith Warmup Behavior in Variable-Fuel Vehicle Exhaust," SAE Paper 932721.

6. McCabe, R.W., and P.J. Mitchell, 1986, "Exhaust-Catalyst Development for Methanol-Fueled Vehicles: 1. A Comparative Study of Methanol Oxidation over Alumina-Supported Catalysts Containing Group 9, 10, and 11 Metals," Applied Catalysis, Vol. 27.

7. Gottberg, I., J.E. Rydquist, O. Backlund, S. Wallman, W. Maus, R. Bruck, and H. Swars, 1991, "New Potential Exhaust Gas After-Treatment Technologies for Clean Car Legislation," SAE Paper 910840.

8. Laing, P.M., 1994, "Development of an Alternator-Powered Electrically-Heated Catalyst System," SAE Paper 941042.

9. Burk, P.L., J.K. Hochmuth, D.R. Anderson, S. Sung, S.J. Tauster, C.O. Tolentino, J. Rogalo, G. Miles, M. Niejako, A. Punke, and U. Dahle, 1995, "Cold Start Hydrocarbon Emissions Control," SAE Paper 950410.

10. Wartinbee, W.J., Jr., 1971 “Emissions Study of Oxygen-Enriched Air," SAE Paper 710606.

11. Gollan, A.Z., and M.H. Kleper, 1985, Research into an Asymmetric Membrane Hollow Fibre Device for Oxygen-Enriched Air Production, Phase II Report, DOE/ID-12429, U.S. Department of Energy, Dec. 
12. Kuznetsov, E.V., 1956, "Effect of $\mathrm{O}_{2}$ Concentration on the Engine Process," paper in a series on internal combustion engines, Academy of Sciences of the U.S.S.R.

13. Quader, A.A., 1978, "Exhaust Emissions and Performance of a Spark-Ignition Engine Using Oxygen-Enriched Intake Air," Combustion Science and Technology 19:81-86.

14. Willumeit, H.P., and M. Bauer, 1988, "Emissions and Performance of an S.I. Engine Inducting Oxygen-Enriched Combustion Air," MTZ Motortechnische Zeitschrift 49:149-152.

15. Kajitani, S., N. Sawa, T. McComiskey, and K.T. Rhee, 1992, "A Spark Ignition Engine Operated by Oxygen Enriched Air," SAE Paper 922174.

16. Maxwell, T.T., V. Setty, J.C. Jones, and R. Narayan, 1993, "The Effect of Oxygen Enriched Air on the Performance and Emissions of an Internal Combustion Engine," SAE Paper 932804.

17. Gollan, A., and M.H. Kleper, 1986, "Key Factors Affecting the Economics of Oxygen-Enriched Air Production Via Membranes," presented at Symposium on Industrial Combustion Technologies, April.

18. Kimura, S.G., and W.R. Browall, 1986, "Membrane Oxygen Enrichment, I. Demonstration of Membrane Oxygen Enrichment for Natural Gas Combustion," J. Membrane Science 29:69-77.

19. Matson, S.L., W.J. Ward, S.G. Kimura, and W.R. Browall, 1986, "Membrane Oxygen Enrichment, II. Economic Assessment,” J. Membrane Science 29:79-96.

20. Stern, S.A., 1986, “New Developments in Membrane Processes for Gas Separations," Chapter 1 in Synthetic Membranes, M.B. Chenoweth (editor), MMI Press Symposium Series, Vol. 5, Harwood Academic Publishers, New York, N.Y., pp. 1-37.

21. Rautenbach, R., and W. Dahm, 1987, "Oxygen and Methane Enrichment - A Comparison of Module Arrangements in Gas Permeation," Chemical Engineering Technology 10:256-261.

22. Kobayashi, H., 1987, Oxygen-Enriched Combustion System Performance Study, DOE/ID-12597-1, U.S. Department of Energy.

23. Koros, W.J., and R.T. Chern; 1987, "Separation of Gas Mixture Using Polymer Membranes," Chapter 20 in Handbook of Separation Process Technology, R.W. Rousseau (editor), Wiley Inter Science Publishers, New York, N.Y., pp. 862-953. 
24. Detuncq, B., and J. Williams, 1988, "Performance of a Spark-Ignition Engine Fueled by Natural Gas Using Oxygen Enriched Air," presented at International Fuels and Lubricants Meeting, Portland, Ore.

25. Wu, Y.C.L., 1988, Oxygen Enriched Combustion in Internal Combustion Engines, prepared by Argonne National Laboratory, Argonne, Ill., for Engineering Research and Consulting, Inc., Tullahoma, Tenn., Aug.

26. Ragland, K.W., and J.G. Whipple, 1989, Test and Evaluation of Polymeric Membranes for Oxygen-Enrichment of Air, DOE/ID-12710-1, U.S. Department of Energy, July.

27. Inui, T., S. Kojo, M. Shibata, T. Yoshida, and S. Iwamoto, 1991, "NO Decomposition on CuIncorporated A-Zeolites under the Reaction of Excess Oxygen with a Small Amount of Hydrocarbons," in Studies in Surface Science and Catalysis, Elsevier, Amsterdam, pp. 355-364.

28. Hirabayashi et al., 1993, "Selective Catalytic Reduction of NO over Noble Metal Catalysts," Catalyst 35:402.

29. Inui et al., 1991, "NO Decomposition under Excess Oxygen Conditions," Catalyst 33:77.

30. Takita et al., 1994, article in Catalyst $36: 84$.

31. Takami, A., T. Takemoto, H. Iwakuni, F. Saito, and K. Komatsu, 1995, "Development of Lean Burn Catalyst," SAE Paper 950746.

32. Miyoshi, N., S. Matsumoto, J. Katoh, T. Tanaka, J. Harada, N. Takahashi, K. Yokota, M. Sugiura, and K. Kasahara, 1995, "Development of New Concept Three-Way Catalyst for Automotive Lean-Burn Engines," SAE Paper 950809.

33. Ng, H.K., R.R. Sekar, S.W. Kraft, and K.R. Stamper, 1993, "The Potential Benefits of Intake Air Oxygen-Enrichment in Spark Ignition Engine Powered Vehicle," SAE Paper 932803.

34. U.S. Environmental Protection Agency, 1991, "Control of Air Pollution from New Motor Vehicle and New Vehicle Engine — Federal Certification Results for 1991 Model Year."

35. Fenimore, C.P., 1980, "Destruction of $\mathrm{NO}$ by $\mathrm{NH}_{3}$ in Lean Burnt Gas," Combustion and Flame 37:245-250.

36. Hilliard, J.C., and F.J. Weinburg, 1976, "Effect of Nitrogen Containing Plasma on Stability, NO Formation and Sooting of Flames," Nature 259(5544):556-557. 
37. Ng, H.K., V.J. Novick, and R.R. Sekar, 1995, "Using Monatomic Nitrogen Induced by a Pulsed Arc to Remove Nitrogen Oxides from a Gas Stream," ASME Fall Technical Conference, Vol. 25-1 on internal combustion engines, pp. 73-80.

38. Gollan, A., and M.H. Kleper, 1986, "Membrane-Based Air Separation," AIChE Symposium Series 250(82):35-47.

39. Nemser, S.M., 1991, “Air Intake System for Mobile Engines,” U.S. Patent 5,051,113.

40. Nemser, S.M., and I.C. Roman, 1991, "Perfluorodioxole Membranes," U.S. Patent 5,051,114.

41. Ng, H.K., and R.R. Sekar, 1994, Potential Benefits of Oxygen-Enriched Intake Air in a Vehicle Powered by a Spark-Ignition Engine, ANL/ESD/TM-64, Argonne National Laboratory, Argonne, Ill., April.

42. Code of Federal Regulations, Title 40, Part 86, Subpart B, revised as of July 1993.

43. Sweeney, E.G., J.H. Baudino, and C.H. Schmidt, 1992, "Composition of Gasoline Vehicle Emissions - An Analytical Speciation Program," SAE Paper 922253.

44. Heywood, J.B., 1989, Internal Combustion Engine Fundamentals, McGraw-Hill, Inc.

45. Ohata, A., M. Ohashi, M. Nasu, and T. Inoue, 1995, "Model Based Air Fuel Ratio Control for Reducing Exhaust Gas Emissions," SAE Paper 950075.

46. Kampelmuhler, F.T., R. Paulitsch, and K. Gschweitl, 1993, "Automatic ECU-Calibration An Alternative to Conventional Methods," SAE Paper 930395.

47. Quader, A.A., 1971, "Why Intake Charge Dilution Decreases Nitric Oxide Emission from Spark Ignition Engines," SAE Paper 710009.

48. National Academy Press, 1991, Rethinking the Ozone Problem in Urban and Regional Air Pollution, Washington, D.C.

49. California Air Resources Board, 1991, California Air Resources Board Reactivity (MIR and MOIR) Assignments, Nov. 14.

50. Kroll, M., G. Decker, A. Hartung, A. Postulka, and B. Georgi, 1993, "Influence of Fuel Composition on NMOG-Emissions and Ozone-Forming Potential," SAE Paper 932676.

51. California Air Resources Board, 1995, Proposed Amendments to Low-Emission Vehicle Regulations, Staff Report, Aug. 


\section{APPENDIX:}

\section{EQUIPMENT AND DATA}

\section{A.1 EQUIPMENT PHOTOGRAPHS}

Figure A.1 is a photograph of the total oxygen enrichment system, and Figure A.2 shows the oxygen air mixing chamber.

\section{A.2 DATA}

Data on the various test runs and average exhaust (mass) emissions collected from this experimental work are provided in the Tables A.1-A.15. The large volume of time-resolved emission data and hydrocarbon speciation analyses results collected from all the experiments could not be reproduced here in detail but have been recorded on an electronic file (3.5-in. microdisk). Contact the author of this document if you are interested in more information on the material on disk. 


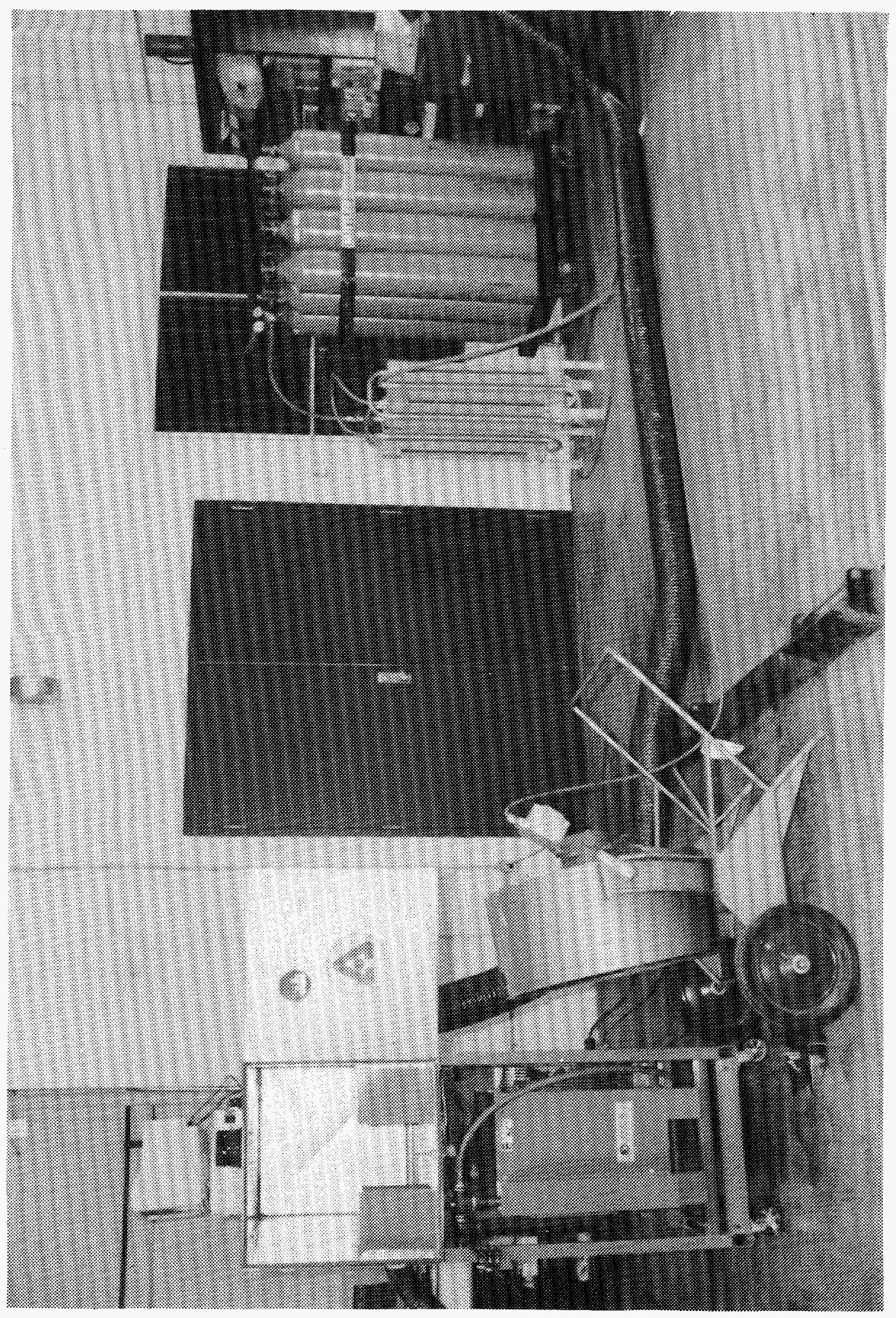

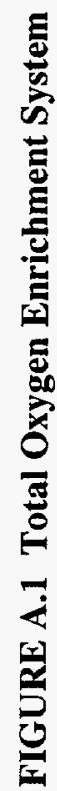




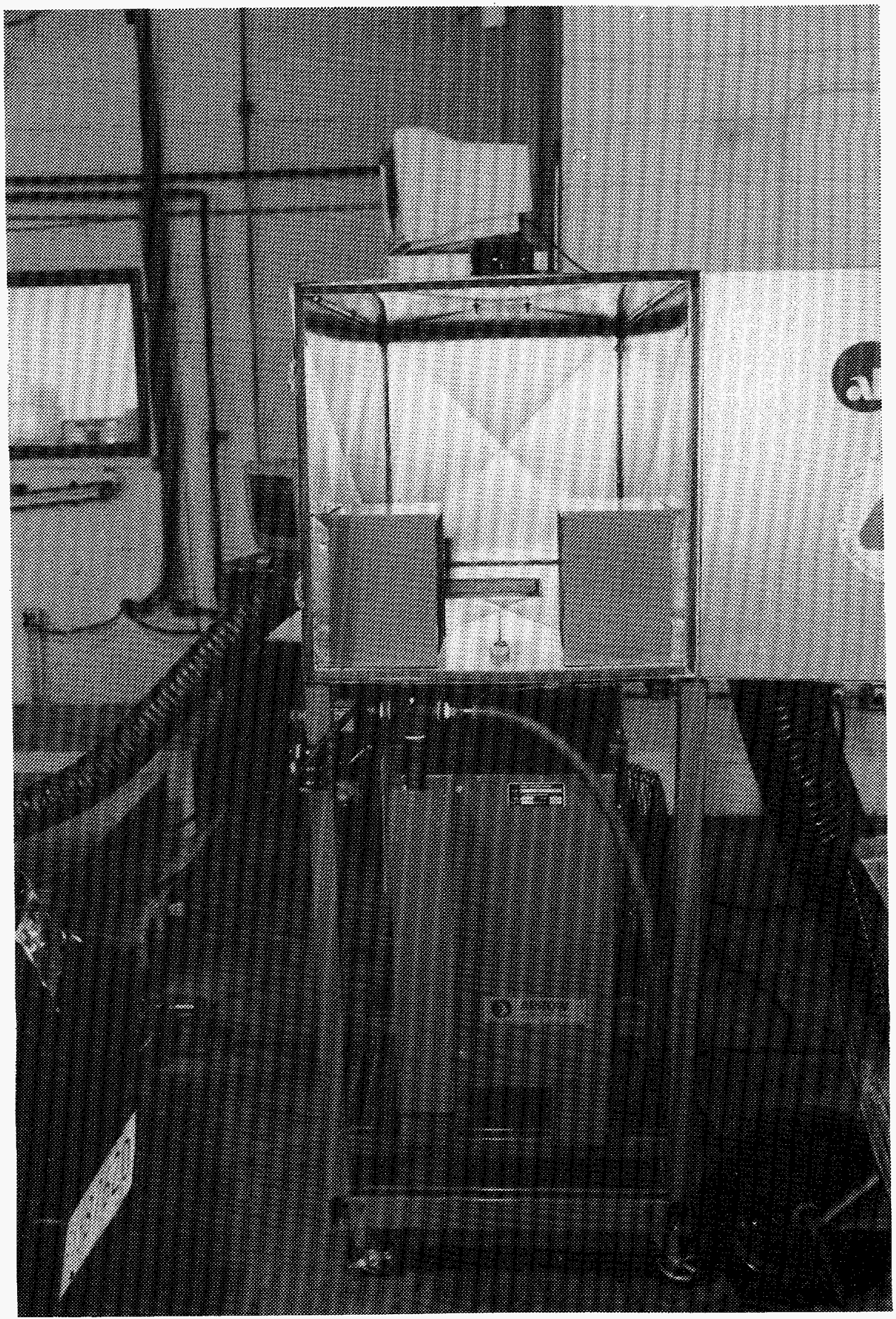

FIGURE A.2 Oxygen Air Mixing Chamber 
TABLE A.1 Engine-out Emissions: FTP with Indolene

\begin{tabular}{|c|c|c|c|}
\hline Nominal $\mathrm{O}_{2}$ level (\%) & 21 & 23 & 25 \\
\hline Test number & 3594 & 3636 & 3614 \\
\hline Test date & $11 / 30 / 94$ & $12 / 06 / 94$ & $12 / 01 / 94$ \\
\hline Vehicle odometer (mi) & 1980 & 2018 & 1999 \\
\hline \multicolumn{4}{|l|}{ Cold transient $(\mathrm{g} / \mathrm{mi})$} \\
\hline HC-FID & 3.035 & 2.027 & 1.751 \\
\hline $\mathrm{HC}^{\mathrm{a}}$ & 3.035 & 2.027 & 1.731 \\
\hline $\mathrm{NMHC}^{\mathrm{b}}$ & 2.811 & 1.876 & 1.580 \\
\hline OMHCE & 3.035 & 2.027 & 1.824 \\
\hline OMNMHCE & 2.811 & 1.876 & 1.672 \\
\hline NMOG & 2.811 & 1.876 & 1.739 \\
\hline $\mathrm{CH}_{3} \mathrm{OH}$ & c & c & c \\
\hline $\mathrm{C}_{2} \mathrm{H}_{5} \mathrm{OH}$ & c & c & $\mathrm{c}$ \\
\hline $\mathrm{HCHO}^{d}$ & 0.000 & 0.000 & 0.045 \\
\hline $\mathrm{CH}_{3} \mathrm{CHO}^{\mathrm{d}}$ & 0.000 & 0.000 & 0.114 \\
\hline $\mathrm{CO}$ & 26.410 & 14.127 & 13.120 \\
\hline $\mathrm{NO}_{\mathrm{x}}$ & 5.039 & 7.861 & 9.027 \\
\hline $\mathrm{CO}_{2}$ & 389.380 & 397.300 & 405.030 \\
\hline Fuel economy (mpg) & 20.25 & 20.94 & 20.68 \\
\hline \multicolumn{4}{|l|}{ Stabilized (g/mi) } \\
\hline HC-FID & 1.813 & 1.530 & 1.327 \\
\hline $\mathrm{HC}^{\mathrm{a}}$ & 1.813 & 1.530 & 1.306 \\
\hline $\mathrm{NMHC}^{\mathrm{b}}$ & 1.705 & 1.429 & 1.217 \\
\hline OMHCE & 1.813 & 1.530 & 1.408 \\
\hline OMNMHCE & 1.705 & 1.429 & 1.319 \\
\hline NMOG & 1.705 & 1.429 & 1.393 \\
\hline $\mathrm{CH}_{3} \mathrm{OH}$ & c & c & c \\
\hline $\mathrm{C}_{2} \mathrm{H}_{5} \mathrm{OH}$ & c & c & $\mathrm{c}$ \\
\hline $\mathrm{HCHO}^{d}$ & 0.000 & 0.000 & 0.056 \\
\hline $\mathrm{CH}_{3} \mathrm{CHO}^{\mathrm{d}}$ & 0.000 & 0.000 & 0.120 \\
\hline $\mathrm{CO}$ & 13.253 & 11.852 & 11.608 \\
\hline $\mathrm{NO}_{\mathrm{x}}$ & 3.750 & 6.207 & 7.752 \\
\hline $\mathrm{CO}_{2}$ & 390.480 & 392.170 & 400.760 \\
\hline Fuel economy (mpg) & 21.39 & 21.46 & 21.06 \\
\hline
\end{tabular}


TABLE A.1 (Cont.)

\begin{tabular}{|c|c|c|c|}
\hline $\begin{array}{l}\text { Nominal } \mathrm{O}_{2} \text { level }(\%) \\
\text { Test number } \\
\text { Test date } \\
\text { Vehicle odometer (mi) }\end{array}$ & $\begin{array}{c}21 \\
3594 \\
11 / 30 / 94 \\
1980 \\
\ldots . . .\end{array}$ & 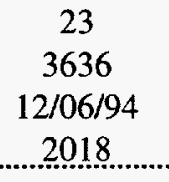 & $\begin{array}{c}25 \\
3614 \\
12 / 01 / 94 \\
1999\end{array}$ \\
\hline \multicolumn{4}{|l|}{ Hot transient $(\mathrm{g} / \mathrm{mi})$} \\
\hline HC-FID & 1.691 & 1.332 & 1.132 \\
\hline $\mathrm{HC}^{\mathrm{a}}$ & 1.691 & 1.332 & 1.118 \\
\hline $\mathrm{NMHC}^{\mathrm{b}}$ & 1.573 & 1.232 & 1.028 \\
\hline OMHCE & 1.691 & 1.332 & 1.190 \\
\hline OMNMHCE & 1.573 & 1.232 & 1.100 \\
\hline NMOG & 1.573 & 1.232 & 1.153 \\
\hline $\mathrm{CH}_{3} \mathrm{OH}$ & $\mathrm{c}$ & c & c \\
\hline $\mathrm{C}_{2} \mathrm{H}_{5} \mathrm{OH}$ & $\mathrm{c}$ & c & c \\
\hline $\mathrm{HCHO}^{\mathrm{d}}$ & 0.000 & 0.000 & 0.042 \\
\hline $\mathrm{CH}_{3} \mathrm{CHO}^{\mathrm{d}}$ & 0.000 & 0.000 & 0.082 \\
\hline $\mathrm{CO}$ & 13.749 & 10.339 & 9.888 \\
\hline $\mathrm{NO}_{x}$ & 4.828 & 7.041 & 8.398 \\
\hline $\mathrm{CO}_{2}$ & 334.690 & 341.760 & 356.540 \\
\hline Fuel economy (mpg) & 24.66 & 24.63 & 23.73 \\
\hline \multicolumn{4}{|l|}{ Weighted ( $\mathrm{g} / \mathrm{mi})$} \\
\hline HC-FID & 2.033 & 1.578 & 1.361 \\
\hline $\mathrm{HC}^{\mathrm{a}}$ & 2.033 & 1.578 & 1.342 \\
\hline NMHC ${ }^{b}$ & 1.898 & 1.467 & 1.240 \\
\hline OMHCE & 2.033 & 1.578 & 1.434 \\
\hline OMNMHCE & 1.898 & 1.467 & 1.332 \\
\hline NMOG & 1.898 & 1.467 & 1.399 \\
\hline $\mathrm{CH}_{3} \mathrm{OH}$ & c & $\mathrm{c}$ & c \\
\hline $\mathrm{C}_{2} \mathrm{H}_{5} \mathrm{OH}$ & c & $\mathrm{c}$ & $\mathrm{c}$ \\
\hline $\mathrm{HCHO}^{d}$ & 0.000 & 0.000 & 0.050 \\
\hline $\mathrm{CH}_{3} \mathrm{CHO}^{\mathrm{d}}$ & 0.000 & 0.000 & 0.109 \\
\hline $\mathrm{CO}$ & 16.115 & 11.907 & 11.449 \\
\hline $\mathrm{NO}_{\mathrm{x}}$ & 4.313 & 6.779 & 8.193 \\
\hline $\mathrm{CO}_{2}$ & 374.930 & 379.360 & 389.530 \\
\hline Fuel economy (mpg) & 21.93 & 22.13 & 21.65 \\
\hline
\end{tabular}

a Corrected for methanol, ethanol, formaldehyde, and acetaldehyde concentrations by using response factors on propane-calibrated FID.

b Corrected for methane concentration in addition to concentrations mentioned in footnote a by using response factors on propanecalibrated FID.

c Not speciated.

d Based on only composite background aldehydes. 
TABLE A.2 Averaged Engine-out Hydrocarbon Emissions: FTP with Indolene

\begin{tabular}{|c|c|c|c|c|c|c|c|c|c|c|c|c|}
\hline \multirow[b]{3}{*}{ Hydrocarbon } & \multicolumn{12}{|c|}{ Emissions $(\mathrm{mg} / \mathrm{mi})$ per Test Period and $\mathrm{O}_{2}$ Level } \\
\hline & \multicolumn{3}{|c|}{ Bag 1} & \multicolumn{3}{|c|}{ Bag 2} & \multicolumn{3}{|c|}{ Bag 3} & \multicolumn{3}{|c|}{ Weighted } \\
\hline & $21 \%$ & $23 \%$ & $25 \%$ & $21 \%$ & $23 \%$ & $25 \%$ & $21 \%$ & $23 \%$ & $25 \%$ & $21 \%$ & $23 \%$ & $25 \%$ \\
\hline \multicolumn{13}{|l|}{ Aldehydes } \\
\hline Formaldehyde & 70.76 & 50.32 & 54.84 & 63.60 & 62.20 & 63.68 & 46.47 & 47.08 & 27.78 & 60.38 & 55.60 & 51.95 \\
\hline Acetaldehyde & 15.44 & 10.23 & 10.30 & 13.30 & 10.82 & 11.75 & 8.84 & 7.43 & 5.09 & 12.52 & 9.77 & 9.62 \\
\hline Acrolein & 4.29 & 2.65 & 2.81 & 2.94 & 3.00 & 2.59 & 3.36 & 2.42 & 2.19 & 3.33 & 2.77 & 2.53 \\
\hline Benzaldehyde & 2.15 & 1.44 & 1.80 & 1.76 & 1.25 & 1.56 & 1.12 & 1.08 & 0.82 & 1.67 & 1.24 & 1.40 \\
\hline \multicolumn{13}{|l|}{ Olefins } \\
\hline Ethene (ethylene) & 248.50 & 191.24 & 202.79 & 191.04 & 161.41 & 170.17 & 173.04 & 133.75 & 147.91 & 198.00 & 160.00 & 170.81 \\
\hline Propene (propylene) & 195.34 & 126.65 & 147.77 & 133.64 & 95.88 & 113.15 & 122.80 & 80.44 & 93.73 & 143.45 & 98.01 & 114.99 \\
\hline Propadiene & 17.32 & 16.59 & 15.94 & 11.67 & 10.55 & 11.51 & 12.51 & 10.28 & 12.61 & 13.07 & 11.73 & 12.73 \\
\hline Isobutylene & 112.12 & 64.63 & 51.24 & 85.14 & 56.75 & 70.23 & 72.58 & 44.57 & 55.32 & 87.28 & 55.04 & 62.18 \\
\hline 1,3-Butadiene & 18.64 & 5.29 & 11.12 & 21.45 & 7.93 & 14.20 & 16.93 & 5.03 & 9.65 & 19.62 & 6.59 & 12.31 \\
\hline \multicolumn{13}{|l|}{ Aromatics } \\
\hline Benzene & 143.41 & 109.34 & 115.76 & 97.44 & 87.54 & 88.21 & 94.99 & 74.61 & 81.39 & 106.29 & 88.51 & 92.05 \\
\hline Toluene & 396.63 & 232.89 & 282.57 & 251.84 & 172.37 & 203.00 & 221.47 & 142.76 & 170.79 & 273.50 & 176.77 & 210.64 \\
\hline m-Xylene & 81.39 & 47.75 & 48.98 & 43.83 & 30.32 & 35.69 & 41.56 & 26.10 & 33.36 & 50.99 & 32.76 & 37.80 \\
\hline \multicolumn{13}{|l|}{ Paraffins } \\
\hline Methane & 199.14 & 130.81 & 128.36 & 97.43 & 91.32 & 92.89 & 106.60 & 85.81 & 87.02 & 121.02 & 97.97 & 98.63 \\
\hline Ethane & 46.06 & 30.18 & 34.46 & 32.80 & 23.56 & 25.52 & 28.87 & 19.07 & 22.15 & 34.47 & 23.70 & 26.45 \\
\hline n-Pentane & 39.05 & 14.23 & 36.95 & 17.32 & 11.46 & 13.76 & 16.62 & 9.57 & 11.49 & 21.63 & 11.51 & 17.95 \\
\hline n-Hexane & 11.04 & 5.07 & 4.70 & 6.02 & 3.54 & 4.41 & 5.16 & 2.64 & 3.54 & 6.82 & 3.61 & 4.23 \\
\hline 2,2,4-Trimethylpentane & 99.14 & 44.04 & 50.29 & 50.53 & 30.07 & 39.32 & 45.43 & 22.60 & 31.04 & 59.20 & 30.91 & 39.31 \\
\hline
\end{tabular}




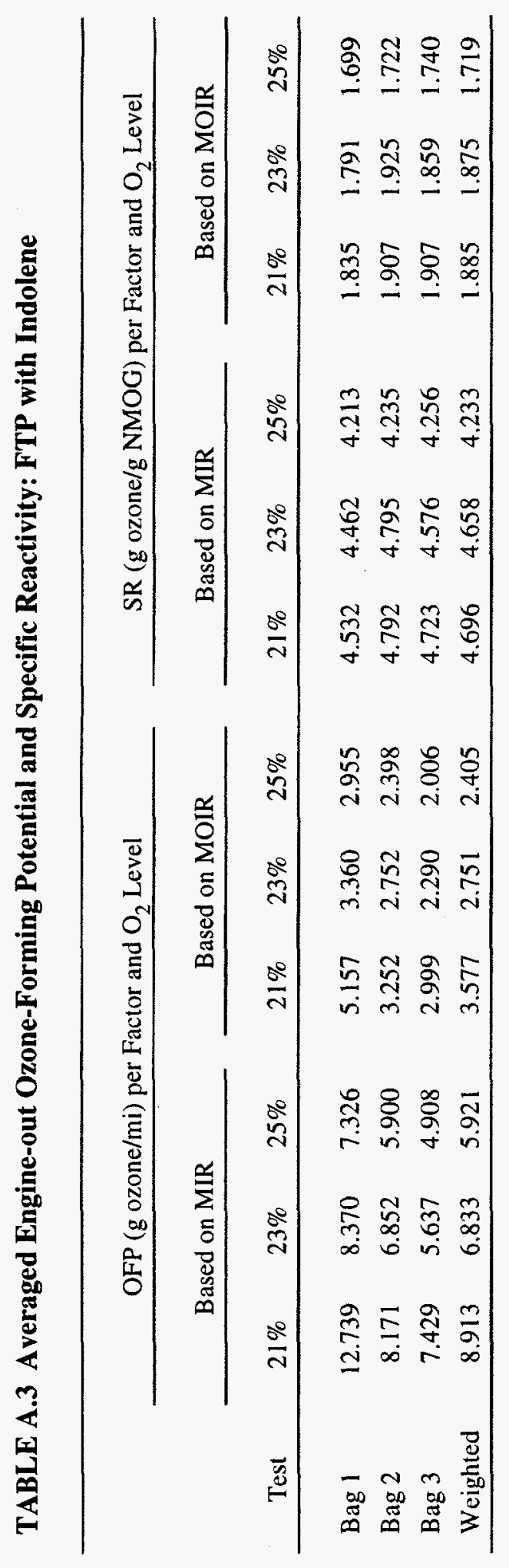


TABLE A.4 Converter-out Emissions: FTP with Indolene

\begin{tabular}{|c|c|c|c|c|c|c|c|c|c|}
\hline Nominal $\mathrm{O}_{2}$ level (\%) & 21 & 21 & $2 I$ & 21 & 23 & 23 & 25 & 25 & 25 \\
\hline Test number & 3287 & 3300 & 3310 & 3330 & 3372 & 3374 & 3341 & 3349 & 3359 \\
\hline Test date & $10 / 12 / 94$ & $10 / 13 / 94$ & $10 / 14 / 94$ & $10 / 17 / 94$ & $10 / 25 / 94$ & $10 / 26 / 94$ & $10 / 18 / 94$ & $10 / 19 / 94$ & $10 / 20 / 94$ \\
\hline ...ehicle odometer (mi) & .......1584 & .......1618. & ........1653. & ........1696. & ........1827. & ........1885. & .......1739. & .......1773. & .......1808. \\
\hline \multicolumn{10}{|l|}{ Cold transient, $(\mathrm{g} / \mathrm{mi})$} \\
\hline HC-FID & 0.524 & 0.582 & 0.470 & 0.576 & 0.465 & 0.436 & 0.369 & 0.373 & 0.380 \\
\hline$H C^{a}$ & 0.524 & 0.581 & 0.470 & $\mathrm{c}$ & 0.465 & c & 0.369 & 0.372 & d \\
\hline $\mathrm{NMHC}^{\mathrm{b}}$ & 0.465 & 0.514 & 0.426 & $\mathrm{c}$ & 0.410 & c & 0.331 & 0.328 & d \\
\hline OMHCE & 0.527 & 0.585 & 0.473 & $\mathfrak{c}$ & 0.468 & c & 0.372 & 0.378 & $d$ \\
\hline OMNMHCE & 0.468 & 0.517 & 0.429 & c & 0.413 & c & 0.334 & 0.334 & d \\
\hline NMOG & 0.471 & 0.521 & 0.432 & c & 0.416 & $\mathrm{c}$ & 0.337 & 0.339 & d \\
\hline $\mathrm{CH}_{3} \mathrm{OH}$ & c & c & c & c & c & c & $c$ & $c$ & d \\
\hline $\mathrm{C}_{2} \mathrm{H}_{5} \mathrm{OH}$ & c & $\mathrm{c}$ & c & c & c & $\mathrm{c}$ & $\mathrm{c}$ & $\mathrm{c}$ & d \\
\hline HCHO & 0.004 & 0.004 & 0.004 & c & 0.004 & $c$ & 0.004 & 0.007 & d \\
\hline $\mathrm{CH}_{3} \mathrm{CHO}$ & 0.002 & 0.003 & 0.002 & c & 0.002 & c & 0.002 & 0.004 & d \\
\hline $\mathrm{CO}$ & 3.772 & 5.706 & 3.287 & 4.760 & 3.906 & 3.581 & 2.475 & 2.718 & 2.707 \\
\hline $\mathrm{NO}_{x}$ & 0.342 & 0.321 & 0.291 & 0.306 & 0.616 & 0.695 & 1.565 & 1.574 & 1.354 \\
\hline $\mathrm{CO}_{2}$ & 450.880 & 439.940 & 437.200 & 438.080 & $\mathbf{4 4 3 . 0 1 0}$ & 440.760 & 445.190 & 451.770 & 455.880 \\
\hline Fuel economy (mpg) & 19.45 & 19.79 & 20.10 & 19.94 & 19.79 & 19.92 & 19.81 & 19.51 & 19.33 \\
\hline \multicolumn{10}{|l|}{ Stabilized ( $\mathrm{g} / \mathrm{mi})$} \\
\hline HC-FID & 0.078 & 0.068 & 0.051 & 0.067 & 0.032 & 0.029 & 0.029 & 0.032 & 0.031 \\
\hline $\mathrm{HC}^{\mathrm{a}}$ & 0.078 & 0.068 & 0.051 & $\mathrm{c}$ & 0.031 & $\mathrm{c}$ & 0.029 & 0.032 & $d$ \\
\hline $\mathrm{NMHC}^{\mathrm{b}}$ & 0.056 & 0.045 & 0.036 & $c$ & 0.028 & c & 0.023 & 0.240 & d \\
\hline OMHCE & 0.079 & 0.069 & 0.051 & c & 0.032 & c & 0.029 & 0.033 & d \\
\hline OMNMHCE & 0.056 & 0.046 & 0.036 & $\mathrm{c}$ & 0.029 & $c$ & 0.024 & 0.025 & d \\
\hline NMOG & 0.057 & 0.047 & 0.037 & $\mathrm{c}$ & 0.029 & c & 0.024 & 0.027 & d \\
\hline $\mathrm{CH}_{3} \mathrm{OH}$ & $\mathrm{c}$ & c & c & c & c & $\mathrm{c}$ & c & c & d \\
\hline $\mathrm{C}_{2} \mathrm{H}_{5} \mathrm{OH}$ & c & c & c & c & $c$ & c & c & c & d \\
\hline HCHO & 0.001 & 0.001 & 0.001 & c & 0.001 & c & 0.001 & 0.002 & d \\
\hline $\mathrm{CH}_{3} \mathrm{CHO}$ & 0.000 & 0.000 & 0.000 & c & 0.001 & $c$ & 0.000 & 0.001 & d \\
\hline $\mathrm{CO}$ & 0.782 & 0.727 & 0.664 & 0.769 & 0.201 & 0.099 & 0.091 & 0.044 & 0.064 \\
\hline $\mathrm{NO}_{x}$ & 0.004 & 0.005 & 0.000 & 0.006 & 0.135 & 0.149 & 0.660 & 0.970 & 0.874 \\
\hline $\mathrm{CO}_{2}$ & 452.340 & 443.550 & 437.300 & 437.540 & 446.570 & 444.730 & 450.730 & 446.330 & 454.050 \\
\hline Fuel economy (mpg) & 19.65 & 20.04 & 20.34 & 20.32 & 19.95 & 20.04 & 19.78 & 19.98 & 19.64 \\
\hline \multicolumn{10}{|l|}{ Hot transient $(\mathrm{g} / \mathrm{mi})$} \\
\hline HC-FID & 0.104 & 0.092 & 0.091 & 0.105 & 0.051 & 0.047 & 0.030 & 0.035 & 0.032 \\
\hline $\mathrm{HC}^{\mathrm{a}}$ & 0.104 & 0.092 & 0.091 & 0.062 & 0.051 & c & 0.030 & 0.034 & d \\
\hline $\mathrm{NMHC}^{\mathbf{b}}$ & 0.071 & 0.056 & 0.062 & $c$ & 0.033 & c & 0.017 & 0.020 & d \\
\hline OMHCE & 0.105 & 0.092 & 0.091 & c & 0.051 & c & 0.031 & 0.035 & d \\
\hline OMNMHCE & 0.072 & 0.057 & 0.062 & $c$ & 0.034 & c & 0.018 & 0.020 & d \\
\hline NMOG & 0.072 & 0.057 & 0.062 & $\mathrm{c}$ & 0.034 & c & 0.018 & 0.021 & d \\
\hline $\mathrm{CH}_{3} \mathrm{OH}$ & c & c & $\mathrm{c}$ & $\mathrm{c}$ & $\mathrm{c}$ & c & c & $\mathrm{c}$ & $d$ \\
\hline $\mathrm{C}_{2} \mathrm{H}_{5} \mathrm{OH}$ & $\mathrm{c}$ & c & c & c & $\mathfrak{c}$ & c & c & c & $d$ \\
\hline $\mathrm{HCHO}$ & 0.010 & 0.000 & 0.000 & c & 0.001 & c & 0.000 & 0.001 & d \\
\hline $\mathrm{CH}_{3} \mathrm{CHO}$ & 0.000 & 0.000 & 0.000 & c & 0.000 & $\mathrm{c}$ & 0.000 & 0.000 & d \\
\hline $\mathrm{CO}$ & 1.134 & 1.383 & 1.232 & 1.413 & 0.748 & 0.692 & 0.513 & 0.655 & 0.602 \\
\hline $\mathrm{NO}_{x}$ & 0.040 & 0.020 & 0.025 & 0.031 & 0.318 & 0.228 & 0.868 & 0.995 & 1.124 \\
\hline $\mathrm{CO}_{2}$ & 386.410 & 374.930 & 375.540 & 369.710 & 384.000 & 382.000 & 386.540 & 382.870 & 388.320 \\
\hline Fuel economy (mpg) & 22.96 & 23.63 & 23.61 & 23.96 & 23.15 & 23.27 & 23.02 & 23.23 & 22.91 \\
\hline
\end{tabular}


TABLE A.4 (Cont.)

\begin{tabular}{|c|c|c|c|c|c|c|c|c|c|}
\hline Nominal $\mathrm{O}_{2}$ level (\%) & 21 & 21 & 21 & 21 & 23 & 23 & 25 & 25 & 25 \\
\hline Test number & 3287 & 3300 & 3310 & 3330 & 3372 & 3374 & 3341 & 3349 & 3359 \\
\hline Test date & $10 / 12 / 94$ & $10 / 13 / 94$ & $10 / 14 / 94$ & $10 / 17 / 94$ & $10 / 25 / 94$ & $10 / 26 / 94$ & $10 / 18 / 94$ & $10 / 19 / 94$ & $10 / 20 / 94$ \\
\hline ...Yhicle odometer.(mi). & .....1584. & 1618 & ............. & 1696. & 1827 & 1885 & 1739 & 1773 & .1808. \\
\hline \multicolumn{10}{|l|}{ Weighted $(\mathrm{g} / \mathrm{mi})$} \\
\hline HC-FID & 0.178 & 0.181 & 0.149 & 0.183 & 0.126 & 0.118 & 0.100 & 0.103 & 0.104 \\
\hline $\mathrm{HC}^{\mathrm{a}}$ & 0.178 & 0.181 & 0.149 & $\mathfrak{c}$ & 0.126 & $\mathrm{c}$ & 0.100 & 0.103 & d \\
\hline $\mathrm{NMHC}^{\mathrm{b}}$ & 0.145 & 0.145 & 0.124 & c & 0.108 & c & 0.085 & 0.086 & d \\
\hline OMHCE & 0.179 & 0.182 & 0.150 & c & 0.128 & $\mathrm{c}$ & 0.101 & 0.105 & d \\
\hline OMNMHCE & 0.146 & 0.147 & 0.125 & $c$ & 0.110 & c & 0.086 & 0.088 & $d$ \\
\hline NMOG & 0.147 & 0.148 & 0.126 & $c$ & 0.111 & c & 0.087 & 0.090 & d \\
\hline $\mathrm{CH}_{3} \mathrm{OH}$ & c & $\mathrm{c}$ & $c$ & $c$ & $\mathrm{c}$ & c & $\mathrm{c}$ & c & d \\
\hline $\mathrm{C}_{2} \mathrm{H}_{5} \mathrm{OH}$ & $\mathfrak{c}$ & c & $c$ & c & $c$ & $\mathfrak{c}$ & $c$ & c & d \\
\hline $\mathrm{HCHO}$ & 0.002 & 0.002 & 0.001 & c & 0.001 & $\mathrm{c}$ & 0.001 & 0.003 & $\mathrm{~d}$ \\
\hline $\mathrm{CH}_{3} \mathrm{CHO}$ & 0.001 & 0.001 & 0.010 & $\mathrm{c}$ & 0.001 & c & 0.001 & 0.001 & d \\
\hline $\mathrm{CO}$ & 1.498 & 1.939 & 1.363 & 1.772 & 1.118 & 0.983 & 0.700 & 0.766 & 0.760 \\
\hline $\mathrm{NO}_{\mathrm{x}}$ & 0.084 & 0.075 & 0.067 & 0.075 & 0.284 & 0.284 & 0.904 & 1.102 & 1.042 \\
\hline $\mathrm{CO}_{2}$ & 433.940 & 423.960 & 420.330 & 419.040 & 428.660 & 426.680 & 431.960 & 430.020 & 436.380 \\
\hline Fuel economy (mpg) & 20.42 & 20.86 & 20.09 & 21.12 & 20.70 & 20.81 & 20.58 & 20.67 & 20.37 \\
\hline
\end{tabular}

a Corrected for methanol, ethanol, formaldehyde, and acetaldehyde concentrations by using response factors on propane-calibrated FID.

b Corrected for methane concentration in addition to concentrations mentioned in footnote a by using response factors on propane-calibrated FID.

c Not speciated.

d Based on only composite background aldehydes. 
TABLE A.5 Averaged Converter-out Emissions:

FTP with Indolene

\begin{tabular}{|c|c|c|c|}
\hline \multirow{2}{*}{$\begin{array}{l}\text { Emissions and } \\
\text { Fuel Economy } \\
\text { per Test Period }\end{array}$} & \multicolumn{3}{|c|}{$\mathrm{O}_{2}$ Level (\%) } \\
\hline & 21 & 23 & 25 \\
\hline \multicolumn{4}{|l|}{ Bag 1} \\
\hline \multicolumn{4}{|l|}{ Emission $(\mathrm{g} / \mathrm{mi})$} \\
\hline $\mathrm{HC}$ & 0.538 & 0.451 & 0.374 \\
\hline $\mathrm{CO}$ & 4.381 & 3.744 & 2.633 \\
\hline $\mathrm{NO}_{\mathrm{x}}$ & 0.315 & 0.655 & 1.497 \\
\hline $\mathrm{CO}_{2}$ & 441.530 & 441.890 & 450.940 \\
\hline Fuel economy (mpg) & 19.82 & 19.89 & 19.55 \\
\hline \multicolumn{4}{|l|}{ Bag 2} \\
\hline \multicolumn{4}{|l|}{ Emission $(\mathrm{g} / \mathrm{mi})$} \\
\hline $\mathrm{HC}$ & 0.066 & 0.031 & 0.031 \\
\hline $\mathrm{CO}$ & 0.735 & 0.15 & 0.066 \\
\hline $\mathrm{NO}_{\mathrm{x}}$ & 0.004 & 0.142 & 0.835 \\
\hline $\mathrm{CO}_{2}$ & 442.680 & 445.650 & 450.360 \\
\hline Fuel economy (mpg) & 20.08 & 20.00 & 19.80 \\
\hline \multicolumn{4}{|l|}{ Bag 3} \\
\hline \multicolumn{4}{|l|}{ Emission $(\mathrm{g} / \mathrm{mi})$} \\
\hline $\mathrm{HC}$ & 0.098 & 0.049 & 0.032 \\
\hline $\mathrm{CO}$ & 1.291 & 0.72 & 0.59 \\
\hline $\mathrm{NO}_{\mathrm{x}}$ & 0.029 & 0.273 & 0.996 \\
\hline $\mathrm{CO}_{2}$ & 376.650 & 383.000 & 385.900 \\
\hline Fuel economy (mpg) & 23.54 & 23.21 & 23.05 \\
\hline \multicolumn{4}{|l|}{ Weighted average } \\
\hline \multicolumn{4}{|l|}{ Emission $(\mathrm{g} / \mathrm{mi})$} \\
\hline $\mathrm{HC}$ & 0.173 & 0.122 & 0.102 \\
\hline $\mathrm{CO}$ & 1.643 & 1.051 & 0.742 \\
\hline $\mathrm{NO}_{\mathrm{x}}$ & 0.075 & 0.284 & 1.016 \\
\hline $\mathrm{CO}_{2}$ & 424.320 & 427.670 & 432.780 \\
\hline Fuel economy (mpg) & 20.62 & 20.76 & 20.54 \\
\hline
\end{tabular}


TABLE A.6 Averaged Converter-out Hydrocarbon Emissions: FTP with Indolene

\begin{tabular}{|c|c|c|c|c|c|c|c|c|c|c|c|c|}
\hline \multirow[b]{3}{*}{ Hydrocarbon } & \multicolumn{12}{|c|}{ Emissions $(\mathrm{mg} / \mathrm{mi})$ per Test Period and $\mathrm{O}_{2}$ Level } \\
\hline & \multicolumn{3}{|c|}{ Bag 1} & \multicolumn{3}{|c|}{ Bag 2} & \multicolumn{3}{|c|}{ Bag 3} & \multicolumn{3}{|c|}{ Weighted } \\
\hline & $21 \%$ & $23 \%$ & $25 \%$ & $21 \%$ & $23 \%$ & $25 \%$ & $21 \%$ & $23 \%$ & $25 \%$ & $21 \%$ & $23 \%$ & $25 \%$ \\
\hline \multicolumn{13}{|l|}{ Aldehydes } \\
\hline Formaldehyde & 4.15 & 3.78 & 3.70 & 0.96 & 0.89 & 0.97 & 0.42 & 0.49 & 0.56 & 1.47 & 1.38 & 1.42 \\
\hline Acetaldehyde & 2.41 & 2.56 & 2.37 & 0.43 & 0.72 & 0.25 & 0.41 & 0.24 & 0.43 & 0.84 & 0.97 & 0.74 \\
\hline Acrolein & 0.32 & 0.30 & 0.33 & 0.00 & 0.00 & 0.00 & 0.00 & 0.00 & 0.00 & 0.06 & 0.06 & 0.07 \\
\hline Benzaldehyde & 1.36 & 1.48 & 1.73 & 0.00 & 0.00 & 0.00 & 0.00 & 0.00 & 0.00 & 0.28 & 0.31 & 0.36 \\
\hline \multicolumn{13}{|l|}{ Olefins } \\
\hline Ethene (ethylene) & 30.41 & 31.99 & 28.65 & 0.16 & 0.41 & 0.00 & 2.40 & 0.50 & 0.39 & 7.04 & 6.97 & 6.05 \\
\hline Propene (propylene) & 25.51 & 26.53 & 22.78 & 0.00 & 0.00 & 0.00 & 1.09 & 0.00 & 0.00 & 5.59 & 5.49 & 4.72 \\
\hline Propadiene & 0.49 & 1.22 & 1.58 & 0.00 & 0.00 & 0.00 & 0.00 & 0.00 & 0.00 & 0.10 & 0.25 & 0.33 \\
\hline Isobutylene & 10.57 & 15.32 & 11.72 & 0.70 & 0.21 & 0.07 & 0.77 & 0.66 & 0.25 & 2.76 & 3.46 & 2.53 \\
\hline 1,3-Butadiene & 3.98 & 1.67 & 1.95 & 0.00 & 0.00 & 0.02 & 0.07 & 0.00 & 0.00 & 0.84 & 0.35 & 0.41 \\
\hline \multicolumn{13}{|l|}{ Aromatics } \\
\hline Benzene & 27.31 & 23.84 & 18.60 & 3.61 & 1.49 & 0.76 & 6.35 & 2.78 & 1.47 & 9.27 & 6.47 & 4.65 \\
\hline Toluene & 77.20 & 67.19 & 49.75 & 4.86 & 2.64 & 0.76 & 12.80 & 2.52 & 0.88 & 22.02 & 15.96 & 10.95 \\
\hline $\mathrm{m}$-Xylene & 11.74 & 11.99 & 8.66 & 0.33 & 0.29 & 0.62 & 0.63 & 0.25 & 0.07 & 2.78 & 2.70 & 2.13 \\
\hline \multicolumn{13}{|l|}{ Paraffins } \\
\hline Methane & 51.31 & 48.86 & 36.19 & 18.90 & 3.16 & 6.05 & 27.57 & 14.10 & 11.79 & 27.99 & 15.62 & 13.88 \\
\hline Ethane & 12.79 & 10.37 & 7.74 & 2.65 & 0.00 & 0.00 & 3.62 & 1.34 & 0.70 & 5.02 & 2.51 & 1.80 \\
\hline n-Pentane & 9.52 & 4.81 & 29.63 & 0.70 & 1.23 & 0.81 & 0.65 & 1.16 & 0.46 & 2.51 & 1.95 & 6.68 \\
\hline n-Hexane & 2.23 & 2.12 & 1.41 & 0.26 & 0.08 & 0.12 & 0.28 & 0.10 & 0.04 & 0.67 & 0.51 & 0.37 \\
\hline 2,2,4-Trimethylpentane & 25.21 & 20.14 & 12.84 & 2.35 & 0.45 & 0.19 & 3.16 & 1.42 & 0.55 & 7.31 & 4.79 & 2.90 \\
\hline
\end{tabular}


TABLE A.7 Averaged Converter-out Ozone-Forming Potential and Specific Reactivity: FTP with Indolene

\begin{tabular}{|c|c|c|c|c|c|c|c|c|c|c|c|c|}
\hline \multirow[b]{3}{*}{ Test } & \multicolumn{6}{|c|}{ OFP (g ozone/mi) per Factor and $\mathrm{O}_{2}$ Level } & \multicolumn{6}{|c|}{ SR (g ozone/g NMOG) per Factor and $\mathrm{O}_{2}$ Level } \\
\hline & \multicolumn{3}{|c|}{ Based on MIR } & \multicolumn{3}{|c|}{ Based on MOIR } & \multicolumn{3}{|c|}{ Based on MIR } & \multicolumn{3}{|c|}{ Based on MOIR } \\
\hline & $21 \%$ & $23 \%$ & $25 \%$ & $21 \%$ & $23 \%$ & $25 \%$ & $21 \%$ & $23 \%$ & $25 \%$ & $21 \%$ & $23 \%$ & $25 \%$ \\
\hline Bag 1 & 1911.80 & 1749.47 & 1346.29 & 786.87 & 715.59 & 553.63 & 4.03 & 4.21 & 3.98 & 1.66 & 1.72 & 1.64 \\
\hline Bag 2 & 135.15 & 109.10 & 68.29 & 65.92 & 46.18 & 29.24 & 2.88 & 3.76 & 2.68 & 1.40 & 1.59 & 1.15 \\
\hline Bag 3 & 222.45 & 142.80 & 74.51 & 106.50 & 69.34 & 40.41 & 3.49 & 4.20 & 3.82 & 1.67 & 2.04 & 2.07 \\
\hline Weighted & 524.90 & 457.63 & 334.63 & 225.98 & 191.00 & 140.88 & 3.74 & 4.12 & 3.78 & 1.61 & 1.72 & 1.59 \\
\hline
\end{tabular}


TABLE A.8 Converter-out Emissions: Off-Cycle Test with Indolene

\begin{tabular}{|c|c|c|c|c|c|c|c|}
\hline Nominal $\mathrm{O}_{2}$ level (\%) & 21 & 21 & 21 & 23 & 23 & 25 & 25 \\
\hline Test number & 3288 & 3301 & 3311 & 3373 & 3375 & 3342 & 3350 \\
\hline Test date & $10 / 12 / 94$ & $10 / 13 / 94$ & $10 / 14 / 94$ & $10 / 25 / 94$ & $10 / 26 / 94$ & $10 / 18 / 94$ & $10 / 19 / 94$ \\
\hline Vehicle odometer (mi) & 1595 & 1629 & 1664 & $1861 \ldots$ & 1896 & 1749 & 1784 \\
\hline \multicolumn{8}{|l|}{ Cold transient $(\mathrm{g} / \mathrm{mi})$} \\
\hline HC-FID & 0.215 & 0.228 & 0.215 & 0.177 & 0.148 & 0.144 & 0.156 \\
\hline $\mathrm{HC}^{\mathrm{a}}$ & 0.214 & 0.228 & 0.215 & 0.177 & c & 0.144 & 0.156 \\
\hline $\mathrm{NMHC}^{\mathrm{b}}$ & 0.184 & 0.198 & 0.191 & 0.159 & c & 0.135 & 0.140 \\
\hline OMHCE & 0.216 & 0.228 & 0.216 & 0.178 & c & 0.145 & 0.156 \\
\hline OMNMHCE & 0.185 & 0.199 & 0.191 & 0.160 & c & 0.135 & 0.140 \\
\hline NMOG & 0.186 & 0.200 & 0.192 & 0.160 & c & 0.136 & 0.141 \\
\hline $\mathrm{CH}_{3} \mathrm{OH}$ & c & c & c & c & c & c & c \\
\hline $\mathrm{C}_{2} \mathrm{H}_{5} \mathrm{OH}$ & c & $\mathrm{c}$ & c & c & c & c & $\mathrm{c}$ \\
\hline HCHO & 0.001 & 0.001 & 0.001 & 0.001 & c & 0.001 & 0.001 \\
\hline $\mathrm{CH}_{3} \mathrm{CHO}$ & 0.001 & 0.001 & 0.001 & 0.000 & $\mathrm{c}$ & 0.000 & 0.000 \\
\hline $\mathrm{CO}$ & 2.353 & 5.763 & 2.523 & 2.066 & 1.461 & 1.295 & 1.530 \\
\hline $\mathrm{NO}_{\mathrm{x}}$ & 0.121 & 0.037 & 0.085 & 0.101 & 0.172 & 0.535 & 0.501 \\
\hline $\mathrm{CO}_{2}$ & 413.200 & 330.390 & 340.020 & 360.830 & 334.760 & 355.560 & 360.410 \\
\hline Fuel economy (mpg) & 21.36 & 26.22 & 25.88 & 25.15 & 26.43 & 24.69 & 24.55 \\
\hline \multicolumn{8}{|l|}{ Stabilized $(\mathrm{g} / \mathrm{mi})$} \\
\hline HC-FID & 1.443 & 0.170 & 0.384 & 0.124 & 0.101 & 0.134 & 0.125 \\
\hline $\mathrm{HC}^{\mathrm{a}}$ & 1.443 & 0.170 & 0.384 & 0.124 & c & 0.134 & 0.125 \\
\hline $\mathrm{NMHC}^{\mathrm{b}}$ & 1.431 & 0.149 & 0.341 & 0.116 & $\mathrm{c}$ & 0.129 & 0.122 \\
\hline OMHCE & 1.443 & 0.170 & 0.364 & 0.124 & $c$ & 0.134 & 0.126 \\
\hline OMNMHCE & 1.431 & 0.150 & 0.341 & 0.116 & $\mathrm{c}$ & 0.129 & 0.123 \\
\hline NMOG & 1.431 & 0.150 & 0.341 & 0.117 & c & 0.130 & 0.123 \\
\hline $\mathrm{CH}_{3} \mathrm{OH}$ & $\mathrm{c}$ & c & $\mathrm{c}$ & $\mathrm{c}$ & c & $\mathrm{c}$ & c \\
\hline $\mathrm{C}_{2} \mathrm{H}_{5} \mathrm{OH}$ & c & c & c & $\mathrm{c}$ & c & $\mathrm{c}$ & c \\
\hline $\mathrm{HCHO}$ & 0.000 & 0.001 & 0.000 & 0.001 & $\mathrm{c}$ & 0.001 & 0.001 \\
\hline $\mathrm{CH}_{3} \mathrm{CHO}$ & 0.000 & 0.000 & 0.000 & 0.000 & $\mathrm{c}$ & 0.000 & 0.000 \\
\hline $\mathrm{CO}$ & 75.887 & 1.666 & 1.826 & 1.004 & 0.729 & 0.696 & 0.537 \\
\hline $\mathrm{NO}_{\mathrm{x}}$ & 0.010 & 0.006 & 0.04 & 0.040 & 0.102 & 0.176 & 0.175 \\
\hline $\mathrm{CO}_{2}$ & 271.620 & 315.650 & 318.640 & 321.790 & 327.170 & 331.640 & 330.870 \\
\hline Fuel economy (mpg) & 22.54 & 27.98 & 27.650 & 27.55 & 27.14 & 26.78 & 26.86 \\
\hline
\end{tabular}


TABLE A.8 (Cont.)

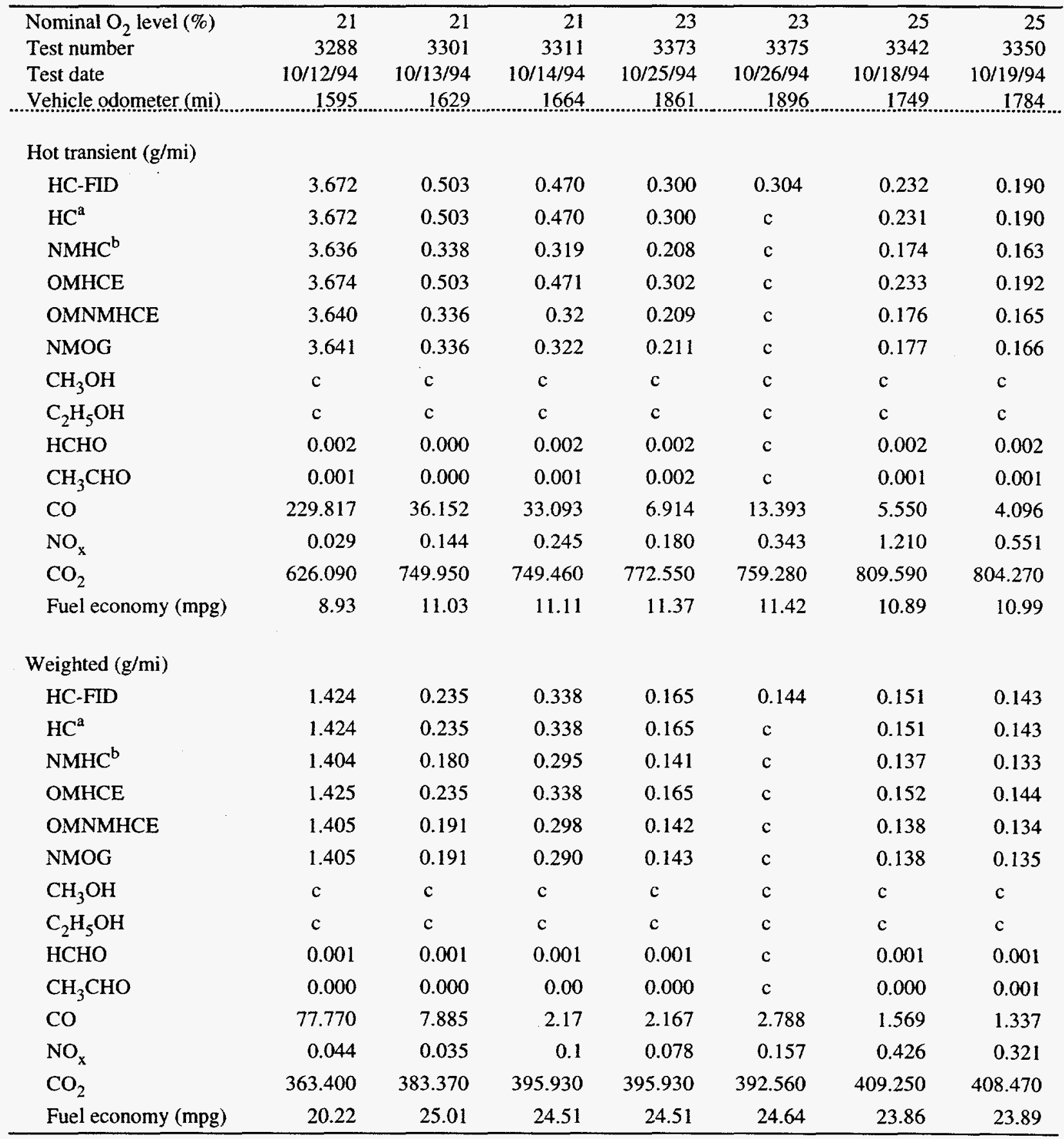

a Corrected for methanol, ethanol, formaldehyde, and acetaldehyde concentrations by using response factors on propane-calibrated FID.

b Corrected for methane concentration in addition to concentrations mentioned in footnote a by using response factors on propane-calibrated FID.

c Not speciated. 
TABLE A.9 Averaged Converter-out Emissions:

Off-Cycle Test with Indolene

\begin{tabular}{|c|c|c|c|}
\hline \multirow{2}{*}{$\begin{array}{l}\text { Emissions and } \\
\text { Fuel Economy } \\
\text { per Test Period }\end{array}$} & \multicolumn{3}{|c|}{$\mathrm{O}_{2}$ Level (\%) } \\
\hline & 21 & 23 & 25 \\
\hline \multicolumn{4}{|l|}{ Bag 1} \\
\hline \multicolumn{4}{|l|}{ Emission $(\mathrm{g} / \mathrm{mi})$} \\
\hline $\mathrm{HC}$ & 0.219 & 0.163 & 0.149 \\
\hline $\mathrm{CO}$ & 3.546 & 1.461 & 1.413 \\
\hline $\mathrm{NO}_{\mathrm{x}}$ & 0.081 & 0.137 & 0.518 \\
\hline $\mathrm{CO}_{2}$ & 361.200 & 347.790 & 357.990 \\
\hline Fuel economy (mpg) & 24.49 & 25.79 & 24.62 \\
\hline
\end{tabular}

Bag 2

Emission ( $\mathrm{g} / \mathrm{mi})$

$\begin{array}{lrrr}\mathrm{HC} & 0.666 & 0.113 & 0.129 \\ \mathrm{CO} & 1.746 & 0.867 & 0.617 \\ \mathrm{NO}_{\mathrm{x}} & 0.018 & 0.071 & 0.176 \\ \mathrm{CO}_{2} & 301.970 & 324.480 & 331.260 \\ \text { l economy (mpg) } & 26.06 & 27.35 & 26.82\end{array}$

Bag 3

Emission (g/mi)

$\begin{array}{lrrr}\mathrm{HC} & 1.548 & 0.302 & 0.211 \\ \mathrm{CO} & 34.62 & 10.15 & 4.823 \\ \mathrm{NO}_{\mathrm{x}} & 0.139 & 0.262 & 0.881 \\ \mathrm{CO}_{2} & 708.500 & 765.920 & 806.930 \\ \text { leconomy (mpg) } & 10.36 & 11.4 & 10.94\end{array}$

Weighted average

Emission ( $\mathrm{g} / \mathrm{mi})$

$\begin{array}{lrrr}\mathrm{HC} & 0.665 & 0.155 & 0.147 \\ \mathrm{CO} & 11.502 & 2.478 & 1.453 \\ \mathrm{NO}_{\mathrm{x}} & 0.052 & 0.018 & 0.374 \\ \mathrm{CO}_{2} & 380.900 & 394.250 & 408.860 \\ \text { el economy (mpg) } & 23.25 & 24.58 & 23.88\end{array}$


TABLE A.10 Engine-out Emissions: FTP with M85

\begin{tabular}{|c|c|c|c|c|c|}
\hline Nominal $\mathrm{O}_{2}$ level (\%) & 21 & 23 & 25 & 25 & 25 \\
\hline Test number & 3706 & 3736 & 3724 & 4369 & 4287 \\
\hline Test date & $12 / 20 / 94$ & $12 / 23 / 94$ & $12 / 22 / 95$ & $04 / 25 / 95$ & $04 / 28 / 95$ \\
\hline Vehicle odometer (mi) & 2091 &. .21 & 2109 & 2276 & 2295 \\
\hline \multicolumn{6}{|l|}{ Cold transient $(\mathrm{g} / \mathrm{mi})$} \\
\hline HC-FID & 2.680 & 1.765 & 1.537 & 1.667 & 1.425 \\
\hline $\mathrm{HC}^{\mathrm{a}}$ & 0.681 & c & 0.342 & c & 0.311 \\
\hline $\mathrm{NMHC}^{b}$ & 0.603 & c & 0.283 & c & 0.242 \\
\hline OMHCE & 1.712 & $\mathrm{c}$ & 1.001 & $\mathrm{c}$ & 0.915 \\
\hline OMNMHCE & 1.634 & c & 0.941 & $\mathrm{c}$ & 0.846 \\
\hline NMOG & 2.961 & c & 1.788 & $\mathrm{c}$ & 1.623 \\
\hline $\mathrm{CH}_{3} \mathrm{OH}$ & 2.049 & $\mathrm{c}$ & 1.313 & c & 1.228 \\
\hline $\mathrm{C}_{2} \mathrm{H}_{5} \mathrm{OH}$ & 0.002 & $\mathrm{c}$ & 0.001 & $\mathrm{c}$ & 0.007 \\
\hline $\mathrm{HCHO}$ & 0.303 & c & 0.187 & c & 0.142 \\
\hline $\mathrm{CH}_{3} \mathrm{CHO}$ & 0.003 & c & 0.004 & c & 0.003 \\
\hline $\mathrm{CO}$ & 13.611 & 13.018 & 13.686 & 17.153 & 15.946 \\
\hline $\mathrm{NO}_{\mathrm{x}}$ & 4.463 & 6.535 & 8.257 & 7.547 & 8.103 \\
\hline $\mathrm{CO}_{2}$ & 360.810 & 363.850 & 372.140 & 365.260 & 366.820 \\
\hline Fuel economy (mpg) & 12.19 & 12.20 & 11.91 & 11.96 & 11.97 \\
\hline \multicolumn{6}{|l|}{ Stabilized ( $\mathrm{g} / \mathrm{mi})$} \\
\hline HC-FID & 1.428 & 0.961 & 0.823 & 0.763 & 0.752 \\
\hline $\mathrm{HC}^{\mathrm{a}}$ & 0.442 & $\mathrm{c}$ & 0.164 & $\mathrm{c}$ & 0.235 \\
\hline $\mathrm{NMHC}^{\mathrm{b}}$ & 0.392 & c & 0.128 & c & 0.197 \\
\hline OMHCE & 0.968 & c & 0.494 & c & 0.478 \\
\hline OMNMHCE & 0.918 & c & 0.458 & $\mathrm{c}$ & 0.439 \\
\hline NMOG & 1.583 & c & 0.889 & $\mathrm{c}$ & 0.745 \\
\hline $\mathrm{CH}_{3} \mathrm{OH}$ & 0.864 & c & 0.760 & c & 0.436 \\
\hline $\mathrm{C}_{2} \mathrm{H}_{5} \mathrm{OH}$ & 0.002 & c & 0.001 & $\mathrm{c}$ & 0.009 \\
\hline HCHO & 0.324 & c & 0.000 & c & 0.100 \\
\hline $\mathrm{CH}_{3} \mathrm{CHO}$ & 0.001 & c & 0.000 & c & 0.003 \\
\hline $\mathrm{CO}$ & 9.184 & 9.352 & 9.434 & 9.474 & 10.094 \\
\hline $\mathrm{NO}_{\mathrm{x}}$ & 2.882 & 4.979 & 6.405 & 6.041 & 6.345 \\
\hline $\mathrm{CO}_{2}$ & 341.190 & 352.860 & 360.890 & 334.680 & 343.390 \\
\hline Fuel economy (mpg) & 13.17 & 12.80 & 12.52 & 13.47 & 13.09 \\
\hline
\end{tabular}


TABLE A.10 (Cont.)

\begin{tabular}{|c|c|c|c|c|c|}
\hline Nominal $\mathrm{O}_{2}$ level (\%) & 21 & 23 & 25 & 25 & 25 \\
\hline Test number & 3706 & 3736 & 3724 & 4369 & 4287 \\
\hline Test date & $12 / 20 / 94$ & $12 / 23 / 94$ & $12 / 22 / 95$ & $04 / 25 / 95$ & $04 / 28 / 95$ \\
\hline Vehicleodometer (mi)....... & 2091. & $\ldots 21 \ldots$ & 2109 & 2276 & 2295 \\
\hline \multicolumn{6}{|l|}{ Hot transient $(\mathrm{g} / \mathrm{mi})$} \\
\hline HC-FID & 1.352 & 0.890 & 0.732 & 0.737 & 0.727 \\
\hline $\mathrm{HC}^{\mathrm{a}}$ & 0.348 & $\mathrm{c}$ & 0.231 & $\mathrm{c}$ & 0.230 \\
\hline $\mathrm{NMHC}^{\mathrm{b}}$ & 0.300 & $\mathrm{c}$ & 0.200 & $c$ & 0.187 \\
\hline OMHCE & 0.861 & $\mathrm{c}$ & 0.443 & c & 0.446 \\
\hline OMNMHCE & 0.813 & c & 0.412 & $\mathrm{c}$ & 0.403 \\
\hline NMOG & 1.475 & c & 0.685 & c & 0.673 \\
\hline $\mathrm{C}_{2} \mathrm{H}_{5} \mathrm{OH}$ & 0.000 & c & 0.001 & c & 0.018 \\
\hline HCHO & 0.152 & c & 0.053 & $\mathrm{c}$ & 0.063 \\
\hline $\mathrm{CH}_{3} \mathrm{CHO}$ & 0.000 & c & 0.002 & $\mathrm{c}$ & 0.002 \\
\hline $\mathrm{CO}$ & 8.582 & 8.024 & 8.663 & 8.266 & 9.213 \\
\hline $\mathrm{NO}_{\mathrm{x}}$ & 3.847 & 5.569 & 7.254 & 7.091 & 7.428 \\
\hline $\mathrm{CO}_{2}$ & 307.490 & 307.510 & 319.510 & 314.310 & 312.330 \\
\hline Fuel economy (mpg) & 14.59 & 14.69 & 14.12 & 14.38 & 14.39 \\
\hline \multicolumn{6}{|l|}{ Weighted $(\mathrm{g} / \mathrm{mi})$} \\
\hline HC-FID & 1.666 & 1.108 & 0.946 & 0.943 & 0.884 \\
\hline $\mathrm{HC}^{\mathrm{a}}$ & 0.466 & c & 0.219 & $\mathrm{c}$ & 0.250 \\
\hline $\mathrm{NMHC}^{\mathrm{b}}$ & 0.411 & $\mathrm{c}$ & 0.180 & $\mathrm{c}$ & 0.204 \\
\hline OMHCE & 1.093 & $\mathrm{c}$ & 0.585 & $\mathrm{c}$ & 0.560 \\
\hline OMNMHCE & 1.038 & $\mathrm{c}$ & 0.545 & c & 0.514 \\
\hline NMOG & 1.839 & $\mathrm{c}$ & 1.020 & c & 0.907 \\
\hline $\mathrm{CH}_{3} \mathrm{OH}$ & 1.153 & $\mathrm{c}$ & 0.784 & $\mathrm{c}$ & 0.591 \\
\hline $\mathrm{C}_{2} \mathrm{H}_{5} \mathrm{OH}$ & 0.001 & c & 0.001 & c & 0.011 \\
\hline $\mathrm{HCHO}$ & 0.272 & c & 0.053 & $\mathrm{c}$ & 0.099 \\
\hline $\mathrm{CH}_{3} \mathrm{CHO}$ & 0.001 & c & 0.001 & $\mathrm{c}$ & 0.003 \\
\hline $\mathrm{CO}$ & 9.935 & 9.747 & 10.105 & 10.736 & 11.064 \\
\hline $\mathrm{NO}_{\mathrm{x}}$ & 3.474 & 5.464 & 7.023 & 6.642 & 7.006 \\
\hline $\mathrm{CO}_{2}$ & 336.000 & 342.680 & 351.850 & 335.420 & 339.710 \\
\hline Fuel economy (mpg) & 13.31 & 13.13 & 12.78 & 13.35 & 13.16 \\
\hline
\end{tabular}

a Corrected for methanol, ethanol, formaldehyde, and acetaldehyde concentrations by using response factors on propane-calibrated FID.

b Corrected for methane concentration in addition to concentrations mentioned in footnote a by using response factors on propane-calibrated FID.

c Not speciated. 
TABLE A.11 Averaged Engine-out Emissions:

FTP with $M 85$

\begin{tabular}{|c|c|c|c|}
\hline \multirow{2}{*}{$\begin{array}{l}\text { Emissions and } \\
\text { Fuel Economy } \\
\text { per Test Period }\end{array}$} & \multicolumn{3}{|c|}{$\mathrm{O}_{2}$ Level (\%) } \\
\hline & 21 & 23 & 25 \\
\hline \multicolumn{4}{|l|}{ Bag 1} \\
\hline \multicolumn{4}{|l|}{ Emission $(\mathrm{g} / \mathrm{mi})$} \\
\hline HC-FID & 2.68 & 1.765 & 1.543 \\
\hline $\mathrm{CO}$ & 13.611 & 13.018 & 14.816 \\
\hline $\mathrm{NO}_{\mathrm{x}}$ & 4.463 & 6.535 & 7.969 \\
\hline $\mathrm{HCHO}$ & 0.303 & - & 0.142 \\
\hline $\mathrm{CO}_{2}$ & 360.810 & 363.850 & 368.070 \\
\hline Fuel economy (mpg) & 12.19 & 12.20 & 11.95 \\
\hline \multicolumn{4}{|l|}{ Bag 2} \\
\hline \multicolumn{4}{|l|}{ Emission (g/mi) } \\
\hline HC-FID & 1.428 & 0.961 & 0.779 \\
\hline $\mathrm{CO}$ & 9.184 & 9.352 & 9.6673 \\
\hline $\mathrm{NO}_{\mathrm{x}}$ & 2.882 & 4.979 & 6.2636 \\
\hline $\mathrm{HCHO}$ & 0.324 & - & 0.0505 \\
\hline $\mathrm{CO}_{2}$ & 341.190 & 352.860 & 346.320 \\
\hline Fuel economy (mpg) & 13.17 & 12.80 & 13.03 \\
\hline \multicolumn{4}{|l|}{ Bag 3} \\
\hline \multicolumn{4}{|l|}{ Emission (g/mi) } \\
\hline HC-FID & 1.352 & 0.89 & 0.732 \\
\hline $\mathrm{CO}$ & 8.582 & 8.024 & 8.714 \\
\hline $\mathrm{NO}_{\mathrm{x}}$ & 3.847 & 5.569 & 7.257 \\
\hline $\mathrm{HCHO}$ & 0.152 & - & 0.063 \\
\hline $\mathrm{CO}_{2}$ & 307.490 & 307.510 & 315.380 \\
\hline Fuel economy (mpg) & 14.59 & 14.69 & 14.30 \\
\hline \multicolumn{4}{|l|}{ Weighted average } \\
\hline \multicolumn{4}{|l|}{ Emission (g/mi) } \\
\hline HC-FID & 1.666 & 1.108 & 0.9243 \\
\hline $\mathrm{CO}$ & 9.935 & 9.747 & 10.635 \\
\hline $\mathrm{NO}_{\mathrm{x}}$ & 3.474 & 5.464 & 6.890 \\
\hline $\mathrm{HCHO}$ & 0.272 & - & 0.099 \\
\hline $\mathrm{CO}_{2}$ & 352.590 & 362.500 & 342.330 \\
\hline Fuel economy (mpg) & 13.29 & 12.93 & 13.09 \\
\hline
\end{tabular}


TABLE A.12 Converter-out Emissions: FTP with M85

\begin{tabular}{|c|c|c|c|c|c|c|c|c|c|}
\hline Nominal $\mathrm{O}_{2}$ level (\%) & 21 & 21 & 21 & 21 & 23 & 23 & 25 & 25 & 25 \\
\hline Test number & 4335 & 4337 & 4364 & 4366 & 4380 & 4390 & 4369 & 4371 & 4377 \\
\hline Test date & $05 / 02 / 95$ & $05 / 03 / 95$ & $05 / 16 / 95$ & $05 / 17 / 95$ & $05 / 24 / 95$ & $05 / 25 / 95$ & $05 / 18 / 95$ & $05 / 19 / 95$ & $05 / 23 / 95$ \\
\hline Vehicle odometer.(mi)... & 2337 & 2372. & 2469. & 2504 & 2689 & 2723 & .2546. & .2581 & 2647 \\
\hline \multicolumn{10}{|l|}{ Cold transient $(\mathrm{g} / \mathrm{mi})$} \\
\hline HC-FID & 0.855 & 0.880 & 0.860 & 0.784 & 0.738 & 0.742 & 0.706 & 0.539 & 0.706 \\
\hline $\mathrm{HC}^{\mathrm{a}}$ & 0.156 & 0.168 & 0.148 & d & 0.107 & c & 0.056 & 0.041 & d \\
\hline $\mathrm{NMHC}^{\mathrm{b}}$ & 0.119 & 0.130 & 0.115 & d & 0.075 & c & 0.013 & 0.072 & d \\
\hline OMHCE & 0.532 & 0.545 & 0.545 & d & 0.470 & c & 0.464 & 0.374 & $\mathrm{~d}$ \\
\hline OMNMHCE & 0.495 & 0.508 & 0.512 & d & 0.438 & $\mathfrak{c}$ & 0.422 & 0.343 & $\mathrm{~d}$ \\
\hline NMOG & 0.986 & 0.999 & 1.027 & d & 0.910 & c & 0.953 & 0.885 & d \\
\hline $\mathrm{CH}_{3} \mathrm{OH}$ & 0.833 & 0.836 & 0.861 & d & 0.796 & c & 0.896 & 0.926 & d \\
\hline $\mathrm{C}_{2} \mathrm{H}_{5} \mathrm{OH}$ & 0.000 & 0.000 & 0.000 & d & 0.000 & c & 0.000 & 0.000 & $d$ \\
\hline $\mathrm{HCHO}^{d}$ & 0.033 & 0.033 & 0.050 & d & 0.039 & c & 0.043 & 0.031 & d \\
\hline $\mathrm{CH}_{3} \mathrm{CHO}^{\mathrm{d}}$ & 0.001 & 0.001 & 0.001 & d & 0.001 & c & 0.001 & 0.001 & d \\
\hline $\mathrm{CO}$ & 6.898 & 6.427 & 6.285 & 6.018 & 6.250 & 6.221 & 6.848 & 5.612 & 6.516 \\
\hline $\mathrm{NO}_{x}$ & 0.215 & 0.209 & 0.206 & 0.192 & 0.680 & 0.655 & 0.800 & 1.014 & 1.272 \\
\hline $\mathrm{CO}_{2}$ & 383.720 & 373.280 & 388.440 & 388.310 & 387.990 & 384.950 & 395.520 & 386.200 & 399.950 \\
\hline Fuel economy (mpg) & 11.92 & 12.27 & 11.81 & 11.84 & 11.83 & 11.93 & 11.59 & 11.92 & 11.48 \\
\hline \multicolumn{10}{|l|}{ Stabilized (g/mi) } \\
\hline HC-FID & 0.033 & 0.106 & 0.020 & 0.027 & 0.021 & 0.026 & 0.023 & 0.035 & 0.024 \\
\hline $\mathrm{HC}^{\mathrm{a}}$ & 0.017 & 0.055 & 0.010 & d & 0.011 & $\mathrm{c}$ & 0.012 & 0.018 & d \\
\hline $\mathrm{NMHC}^{b}$ & 0.012 & 0.053 & 0.007 & d & 0.008 & c & 0.008 & 0.015 & d \\
\hline OMHCE & 0.018 & 0.056 & 0.011 & d & 0.012 & c & 0.012 & 0.019 & $d$ \\
\hline OMNMHCE & 0.012 & 0.054 & 0.008 & d & 0.009 & $\mathrm{c}$ & 0.008 & 0.016 & d \\
\hline NMOG & 0.012 & 0.054 & 0.008 & d & 0.010 & $\mathrm{c}$ & 0.009 & 0.017 & d \\
\hline $\mathrm{CH}_{3} \mathrm{OH}$ & 0.000 & 0.000 & 0.000 & d & 0.000 & $\mathrm{c}$ & 0.000 & 0.000 & $d$ \\
\hline $\mathrm{C}_{2} \mathrm{H}_{5} \mathrm{OH}$ & 0.000 & 0.000 & 0.000 & d & 0.000 & $\mathrm{c}$ & 0.000 & 0.000 & $\mathrm{~d}$ \\
\hline $\mathrm{HCHO}^{\mathrm{d}}$ & 0.001 & 0.001 & 0.001 & d & 0.002 & c & 0.001 & 0.002 & $d$ \\
\hline $\mathrm{CH}_{3} \mathrm{CHO}^{\mathrm{d}}$ & 0.000 & 0.000 & 0.000 & d & 0.000 & c & 0.000 & 0.000 & d \\
\hline $\mathrm{CO}$ & 0.196 & 0.153 & 0.158 & 0.125 & 0.101 & 0.134 & 0.126 & 0.061 & 0.070 \\
\hline $\mathrm{NO}_{\mathrm{x}}$ & 0.098 & 0.107 & 0.025 & 0.045 & 0.305 & 0.138 & 0.337 & 0.541 & 0.423 \\
\hline $\mathrm{CO}_{2}$ & 358.260 & 335.880 & 366.590 & 362.050 & 367.700 & 368.110 & 376.530 & 363.860 & 375.140 \\
\hline Fuel economy (mpg) & 13.17 & 14.05 & 12.88 & 13.04 & 12.84 & 12.82 & 12.54 & 12.98 & 12.59 \\
\hline \multicolumn{10}{|l|}{ Hot transient (g/mi) } \\
\hline HC-FID & 0.059 & 0.066 & 0.045 & 0.049 & 0.038 & 0.031 & 0.029 & 0.037 & 0.042 \\
\hline $\mathrm{HC}^{\mathrm{a}}$ & 0.029 & 0.033 & 0.024 & d & 0.020 & c & 0.015 & 0.019 & d \\
\hline $\mathrm{NMHC}^{\mathrm{b}}$ & 0.015 & 0.018 & 0.011 & $d$ & 0.007 & c & 0.004 & 0.011 & d \\
\hline OMHCE & 0.031 & 0.035 & 0.024 & $d$ & 0.020 & c & 0.015 & 0.020 & d \\
\hline OMNMHCE & 0.017 & 0.020 & 0.011 & $d$ & 0.007 & c & 0.004 & 0.012 & d \\
\hline NMOG & 0.019 & 0.022 & 0.011 & $d$ & 0.007 & c & 0.004 & 0.012 & d \\
\hline $\mathrm{CH}_{3} \mathrm{OH}$ & 0.003 & 0.003 & 0.000 & d & 0.000 & c & 0.000 & 0.000 & d \\
\hline $\mathrm{C}_{2} \mathrm{H}_{5} \mathrm{OH}$ & 0.000 & 0.000 & 0.000 & d & 0.000 & c & 0.000 & 0.000 & d \\
\hline $\mathrm{HCHO}^{\mathrm{d}}$ & 0.001 & 0.000 & 0.000 & $\mathrm{~d}$ & 0.000 & c & 0.000 & 0.001 & d \\
\hline $\mathrm{CH}_{3} \mathrm{CHO}^{\mathrm{d}}$ & 0.000 & 0.001 & 0.000 & d & 0.000 & c & 0.000 & 0.000 & d \\
\hline $\mathrm{CO}$ & 1.331 & 0.960 & 0.852 & 1.253 & 0.977 & 0.771 & 0.803 & 0.710 & 1.002 \\
\hline $\mathrm{NO}_{\mathrm{x}}$ & 0.023 & 0.017 & 0.013 & 0.021 & 0.208 & 0.186 & 0.261 & 0.293 & 0.455 \\
\hline $\mathrm{CO}_{2}$ & 325.810 & 312.550 & 329.140 & 326.410 & 333.970 & 334.420 & 342.380 & 333.280 & 342.680 \\
\hline Fuel economy (mpg) & 14.40 & 15.04 & 14.29 & 14.38 & 14.08 & 14.07 & 13.74 & 14.12 & 13.72 \\
\hline
\end{tabular}


TABLE A.12 (Cont.)

\begin{tabular}{|c|c|c|c|c|c|c|c|c|c|}
\hline Nominal $\mathrm{O}_{2}$ level $(\%)$ & 21 & 21 & 21 & 21 & 23 & 23 & 25 & 25 & 25 \\
\hline Test number & 4335 & 4337 & 4364 & 4366 & 4380 & 4390 & 4369 & 4371 & 4377 \\
\hline Test date & $05 / 02 / 95$ & $05 / 03 / 95$ & $05 / 16 / 95$ & $05 / 17 / 95$ & $05 / 24 / 95$ & $05 / 25 / 95$ & $05 / 18 / 95$ & $05 / 19 / 95$ & $05 / 23 / 95$ \\
\hline ....Yehicle odometer.(mi). & 2337..... & 2372 & 2469 & 2504 & 2689 & ....2723. & 2546 & ......2581. & ......2647. \\
\hline \multicolumn{10}{|l|}{ Weighted $(\mathrm{g} / \mathrm{mi})$} \\
\hline HC-FID & 0.211 & 0.256 & 0.201 & 0.190 & 0.174 & 0.176 & 0.166 & 0.140 & 0.170 \\
\hline $\mathrm{HC}^{\mathrm{a}}$ & 0.049 & 0.073 & 0.043 & d & 0.033 & c & 0.022 & 0.006 & d \\
\hline $\mathrm{NMHC}^{\mathbf{b}}$ & 0.035 & 0.059 & 0.031 & d & 0.021 & c & 0.008 & -0.004 & d \\
\hline OMHCE & 0.128 & 0.152 & 0.125 & d & 0.109 & c & 0.107 & 0.093 & d \\
\hline OMNMHCE & 0.114 & 0.138 & 0.113 & d & 0.097 & c & 0.093 & 0.083 & d \\
\hline NMOG & 0.216 & 0.241 & 0.220 & d & 0.196 & c & 0.204 & 0.196 & d \\
\hline $\mathrm{CH}_{3} \mathrm{OH}$ & 0.174 & 0.174 & 0.178 & d & 0.165 & c & 0.186 & 0.192 & d \\
\hline $\mathrm{C}_{2} \mathrm{H}_{5} \mathrm{OH}$ & 0.000 & 0.000 & 0.000 & d & 0.000 & $\mathrm{c}$ & 0.000 & 0.000 & d \\
\hline $\mathrm{HCHO}^{\mathrm{d}}$ & 0.007 & 0.007 & 0.011 & $d$ & 0.009 & c & 0.010 & 0.008 & d \\
\hline $\mathrm{CH}_{3} \mathrm{CHO}^{\mathrm{d}}$ & 0.000 & 0.000 & 0.001 & d & 0.000 & c & 0.000 & 0.000 & d \\
\hline $\mathrm{CO}$ & 1.899 & 1.676 & 1.619 & 1.655 & 1.614 & 1.569 & 1.707 & 1.388 & 1.661 \\
\hline $\mathrm{NO}_{x}$ & 0.101 & 0.103 & 0.059 & 0.069 & 0.356 & 0.258 & 0.412 & 0.571 & 0.607 \\
\hline $\mathrm{CO}_{2}$ & 354.620 & 337.220 & 360.830 & 357.710 & 362.640 & 362.350 & 371.090 & 360.090 & 371.360 \\
\hline Fuel economy (mpg) & 13.20 & 13.88 & 12.99 & 13.10 & 12.92 & 12.94 & 12.63 & 13.03 & 12.62 \\
\hline
\end{tabular}

a Corrected for methanol, ethanol, formaldehyde, and acetaldehyde concentrations by using response factors on propane-calibrated FID.

$b$ Corrected for methane concentration in addition to concentrations mentioned in footnote a by using response factors on propane-calibrated FID.

c Not speciated

4 Speciated only the first 125 seconds of the cold transient ernissions. 
TABLE A.13 Averaged Converter-out Emissions: FTP with M85

\begin{tabular}{|c|c|c|c|}
\hline \multirow{2}{*}{$\begin{array}{l}\text { Emissions and } \\
\text { Fuel Economy } \\
\text { per Test Period }\end{array}$} & \multicolumn{3}{|c|}{$\mathrm{O}_{2}$ Level (\%) } \\
\hline & 21 & 23 & 25 \\
\hline \multicolumn{4}{|l|}{ Bag 1} \\
\hline \multicolumn{4}{|l|}{ Emission $(\mathrm{g} / \mathrm{mi})$} \\
\hline HC-FID & 0.845 & 0.740 & 0.706 \\
\hline $\mathrm{CO}$ & 6.407 & 6.236 & 6.682 \\
\hline $\mathrm{NO}_{\mathrm{x}}$ & 0.206 & 0.667 & 1.036 \\
\hline $\mathrm{CO}_{2}$ & 383.440 & 386.470 & 397.740 \\
\hline Fuel economy (mpg) & 11.96 & 11.88 & 11.54 \\
\hline
\end{tabular}

Bag 2

Emission ( $\mathrm{g} / \mathrm{mi})$

$\begin{array}{lrrr}\mathrm{HC}-\text { FID } & 0.027 & 0.024 & 0.023 \\ \mathrm{CO} & 0.160 & 0.118 & 0.099 \\ \mathrm{NO}_{\mathrm{x}} & 0.056 & 0.221 & 0.380 \\ \mathrm{CO}_{2} & 362.30 & 367.910 & 375.830 \\ \text { el economy (mpg) } & 13.03 & 12.83 & 12.56\end{array}$

Bag 3

Emission (g/mi)

$\begin{array}{lrrr}\text { HC-FID } & 0.055 & 0.035 & 0.036 \\ \mathrm{CO} & 1.099 & 0.874 & 0.903 \\ \mathrm{NO}_{\mathrm{x}} & 0.018 & 0.197 & 0.358 \\ \mathrm{CO}_{2} & 323.480 & 334.190 & 342.530 \\ \text { l economy (mpg) } & 14.53 & 14.08 & 13.73\end{array}$

Weighted average

Emission (g/mi)

\begin{tabular}{lrrr}
$\mathrm{HC}-\mathrm{FID}$ & 0.214 & 0.175 & 0.168 \\
$\mathrm{CO}$ & 1.712 & 1.592 & 1.684 \\
$\mathrm{NO}_{\mathrm{x}}$ & 0.083 & 0.307 & 0.510 \\
$\mathrm{CO}_{2}$ & 352.590 & 362.500 & 371.230 \\
fuel economy (mpg) & 13.29 & 12.93 & 12.62 \\
\hline
\end{tabular}


TABLE A.14 Converter-out Emissions: Off-Cycle Test with M85

\begin{tabular}{|c|c|c|c|c|c|c|}
\hline Nominal $\mathrm{O}_{2}$ level $(\%)$ & 21 & 21 & 23 & 23 & 25 & 25 \\
\hline Test number & 4336 & 4338 & 4381 & 4391 & 4370 & 4372 \\
\hline Test date & $05 / 02 / 95$ & $05 / 03 / 95$ & $05 / 24 / 95$ & $05 / 25 / 95$ & $05 / 18 / 95$ & 05/19/95 \\
\hline Vehicle odometer (mi) & 2349. & 2383. & 2700. & 2734 & 2557 & $2581 \ldots$ \\
\hline \multicolumn{7}{|l|}{ Cold transient $(\mathrm{g} / \mathrm{mi})$} \\
\hline HC-FID & 0.050 & 0.060 & 0.104 & 0.137 & 0.027 & 0.197 \\
\hline $\mathrm{HC}^{\mathrm{a}}$ & 0.026 & 0.031 & 0.054 & 0.071 & 0.014 & 0.103 \\
\hline $\mathrm{NMHC}^{\mathrm{b}}$ & 0.026 & 0.031 & 0.054 & 0.071 & 0.014 & 0.103 \\
\hline OMHCE & 0.026 & 0.031 & 0.054 & 0.071 & 0.014 & 0.103 \\
\hline OMNMHCE & 0.026 & 0.031 & 0.054 & 0.071 & 0.014 & 0.103 \\
\hline NMOG & 0.026 & 0.031 & 0.054 & 0.071 & 0.014 & 0.103 \\
\hline $\mathrm{CH}_{3} \mathrm{OH}^{\mathrm{c}}$ & 0.000 & 0.000 & 0.000 & 0.000 & 0.000 & 0.000 \\
\hline $\mathrm{C}_{2} \mathrm{H}_{5} \mathrm{OH}^{\mathrm{c}}$ & 0.000 & 0.000 & 0.000 & 0.000 & 0.000 & 0.000 \\
\hline $\mathrm{HCHO}^{c}$ & 0.000 & 0.000 & 0.000 & 0.000 & 0.000 & 0.000 \\
\hline $\mathrm{CH}_{3} \mathrm{CHO}^{\mathrm{c}}$ & 0.000 & 0.000 & 0.000 & 0.000 & 0.000 & 0.000 \\
\hline $\mathrm{CO}$ & 1.194 & 1.413 & 1.207 & 0.629 & 0.252 & 5.612 \\
\hline $\mathrm{NO}_{\mathrm{x}}$ & 0.080 & 0.037 & 0.148 & 0.051 & 0.593 & 1.014 \\
\hline $\mathrm{CO}_{2}$ & 307.310 & 309.430 & 315.330 & 316.160 & 321.460 & 386.200 \\
\hline Fuel economy (mpg) & 15.27 & 15.15 & 14.88 & 14.88 & 14.68 & 11.95 \\
\hline \multicolumn{7}{|l|}{ Stabilized $(\mathrm{g} / \mathrm{mi})$} \\
\hline HC-FID & 0.082 & 0.074 & 0.106 & 0.116 & 0.059 & 0.035 \\
\hline $\mathrm{HC}^{\mathrm{a}}$ & 0.043 & 0.039 & 0.055 & 0.061 & 0.031 & 0.018 \\
\hline $\mathrm{NMHC}^{\mathrm{b}}$ & 0.043 & 0.039 & 0.055 & 0.061 & 0.031 & 0.018 \\
\hline OMHCE & 0.043 & 0.039 & 0.055 & 0.061 & 0.031 & 0.018 \\
\hline OMNMHCE & 0.043 & 0.039 & 0.055 & 0.061 & 0.031 & 0.018 \\
\hline NMOG & 0.043 & 0.039 & 0.055 & 0.061 & 0.031 & 0.018 \\
\hline $\mathrm{CH}_{3} \mathrm{OH}^{\mathrm{c}}$ & 0.000 & 0.000 & 0.000 & 0.000 & 0.000 & 0.000 \\
\hline $\mathrm{C}_{2} \mathrm{H}_{5} \mathrm{OH}^{\mathrm{c}}$ & 0.000 & 0.000 & 0.000 & 0.000 & 0.000 & 0.000 \\
\hline $\mathrm{HCHO}^{c}$ & 0.000 & 0.000 & 0.000 & 0.000 & 0.000 & 0.000 \\
\hline $\mathrm{CH}_{3} \mathrm{CHO}^{\mathrm{c}}$ & 0.000 & 0.000 & 0.000 & 0.000 & 0.000 & 0.000 \\
\hline $\mathrm{CO}$ & 1.435 & 1.253 & 0.683 & 0.610 & 0.685 & 0.061 \\
\hline $\mathrm{NO}_{\mathrm{x}}$ & 0.010 & 0.010 & 0.032 & 0.113 & 0.159 & 0.541 \\
\hline $\mathrm{CO}_{2}$ & 282.410 & 281.330 & 290.380 & 289.100 & 298.640 & 363.860 \\
\hline Fuel economy (mpg) & 16.59 & 16.67 & 16.20 & 16.28 & 15.76 & 12.98 \\
\hline
\end{tabular}


TABLE A.14 (Cont.)

\begin{tabular}{|c|c|c|c|c|c|c|}
\hline Nominal $\mathrm{O}_{2}$ level (\%) & 21 & 21 & 23 & 23 & 25 & 25 \\
\hline Test number & 4336 & 4338 & 4381 & 4391 & 4370 & 4372 \\
\hline Test date & $05 / 02 / 95$ & $05 / 03 / 95$ & $05 / 24 / 95$ & $05 / 25 / 95$ & $05 / 18 / 95$ & $05 / 19 / 95$ \\
\hline Vehicle odometer (mi). & 2349 & 2383 & 2700 & 2734 & 2557 & 2581 \\
\hline \multicolumn{7}{|l|}{ Hot transient $(\mathrm{g} / \mathrm{mi})$} \\
\hline HC-FID & 0.222 & 0.393 & 0.139 & 0.160 & 0.222 & 0.037 \\
\hline $\mathrm{HC}^{\mathrm{a}}$ & 0.116 & 0.205 & 0.072 & 0.083 & 0.115 & 0.019 \\
\hline $\mathrm{NMHC}^{\mathrm{b}}$ & 0.116 & 0.205 & 0.072 & 0.083 & 0.115 & 0.019 \\
\hline OMHCE & 0.116 & 0.205 & 0.072 & 0.083 & 0.115 & 0.019 \\
\hline OMNMHCE & 0.116 & 0.205 & 0.072 & 0.083 & 0.115 & 0.019 \\
\hline NMOG & 0.116 & 0.205 & 0.072 & 0.083 & 0.115 & 0.019 \\
\hline $\mathrm{CH}_{3} \mathrm{OH}^{\mathrm{c}}$ & 0.000 & 0.000 & 0.000 & 0.000 & 0.000 & 0.000 \\
\hline $\mathrm{C}_{2} \mathrm{H}_{5} \mathrm{OH}^{\mathrm{c}}$ & 0.000 & 0.000 & 0.000 & 0.000 & 0.000 & 0.000 \\
\hline $\mathrm{HCHO}^{\mathrm{c}}$ & 0.000 & 0.000 & 0.000 & 0.000 & 0.000 & 0.000 \\
\hline $\mathrm{CH}_{3} \mathrm{CHO}^{\mathrm{c}}$ & 0.000 & 0.000 & 0.000 & 0.000 & 0.000 & 0.000 \\
\hline $\mathrm{CO}$ & 11.435 & 20.873 & 4.714 & 6.102 & 3.231 & 0.710 \\
\hline $\mathrm{NO}_{\mathrm{x}}$ & 0.346 & 0.082 & 0.844 & 0.786 & 3.304 & 0.293 \\
\hline $\mathrm{CO}_{2}$ & 685.550 & 674.310 & 703.520 & 698.290 & 724.560 & 333.280 \\
\hline Fuel economy (mpg) & 6.71 & 6.67 & 6.64 & 6.67 & 6.47 & 14.12 \\
\hline \multicolumn{7}{|l|}{ Weighted $(\mathrm{g} / \mathrm{mi})^{\mathrm{d}}$} \\
\hline HC-FID & 0.093 & 0.117 & 0.110 & 0.129 & 0.074 & 0.081 \\
\hline $\mathrm{HC}^{\mathrm{a}}$ & 0.049 & 0.061 & 0.058 & 0.067 & 0.038 & 0.042 \\
\hline $\mathrm{NMHC}^{\mathrm{b}}$ & 0.049 & 0.061 & 0.058 & 0.067 & 0.038 & 0.042 \\
\hline OMHCE & 0.049 & 0.061 & 0.058 & 0.067 & 0.038 & 0.042 \\
\hline OMNMHCE & 0.049 & 0.061 & 0.058 & 0.067 & 0.038 & 0.042 \\
\hline NMOG & 0.049 & 0.061 & 0.058 & 0.067 & 0.038 & 0.042 \\
\hline $\mathrm{CH}_{3} \mathrm{OH}^{\mathrm{c}}$ & 0.000 & 0.000 & 0.000 & 0.000 & 0.000 & 0.000 \\
\hline $\mathrm{C}_{2} \mathrm{H}_{5} \mathrm{OH}^{\mathrm{c}}$ & 0.000 & 0.000 & 0.000 & 0.000 & 0.000 & 0.000 \\
\hline $\mathrm{HCHO}^{\mathrm{c}}$ & 0.000 & 0.000 & 0.000 & 0.000 & 0.000 & 0.000 \\
\hline $\mathrm{CH}_{3} \mathrm{CHO}^{\mathrm{c}}$ & 0.000 & 0.000 & 0.000 & 0.000 & 0.000 & 0.000 \\
\hline $\mathrm{CO}$ & 2.831 & 4.170 & 1.420 & 1.419 & 0.936 & 1.714 \\
\hline $\mathrm{NO}_{\mathrm{x}}$ & 0.079 & 0.028 & 0.183 & 0.194 & 0.742 & 0.637 \\
\hline $\mathrm{CO}_{2}$ & 348.420 & 346.750 & 357.870 & 356.600 & 367.400 & 365.650 \\
\hline Fuel economy (mpg) & 14.77 & 14.78 & 14.43 & 14.48 & 14.09 & 12.86 \\
\hline
\end{tabular}

a Corrected for methanol, ethanol, formaldehyde, and acetaldehyde concentrations by using response factors on propane-calibrated FID.

b Corrected for methane concentration in addition to concentrations mentioned in footnote a by using response factors on propane-calibrated FID.

c Based on composite background aldehydes.

d Based on time-weighted-average. 
TABLE A.15 Averaged Converter-out Emissions:

Off-Cycle Test with M85

Emissions and

$\mathrm{O}_{2}$ Level (\%)

Fuel Economy

per Test Period

21

23

25

Bag 1

Emission $(\mathrm{g} / \mathrm{mi})$

$\begin{array}{lrrr}\mathrm{HC} & 0.055 & 0.121 & 0.057 \\ \mathrm{CO} & 1.303 & 0.918 & 0.532 \\ \mathrm{NO}_{\mathrm{x}} & 0.058 & 0.099 & 0.531 \\ \mathrm{CO}_{2} & 308.370 & 315.750 & 353.830 \\ \text { el economy (mpg) } & 15.21 & 14.88 & 13.32\end{array}$

Bag 2

Emission $(\mathrm{g} / \mathrm{mi})$

$\mathrm{HC}$

0.078

0.111

0.095

$\mathrm{CO}$

1.344

0.646

0.624

$\mathrm{NO}_{\mathbf{x}}$

0.010

0.072

0.164

$\mathrm{CO}_{2}$

281.870

289.740

331.250

Fuel economy (mpg)

16.63

16.24

14.37

Bag 3

Emission $(\mathrm{g} / \mathrm{mi})$

$\mathrm{HC}$

0.308

0.149

0.194

$\mathrm{CO}$

16.154

5.408

3.769

$\mathrm{NO}_{\mathrm{x}}$

0.214

0.815

1.726

$\mathrm{CO}_{2}$

679.930

700.910

724.560

Fuel economy (mpg)

6.69

6.66

6.47

Weighted average

Emission (g/mi)

\begin{tabular}{lrrr}
$\mathrm{HC}$ & 0.105 & 0.120 & 0.099 \\
$\mathrm{CO}$ & 3.501 & 1.420 & 1.059 \\
$\mathrm{NO}_{\mathrm{x}}$ & 0.053 & 0.189 & 0.496 \\
$\mathrm{CO}_{2}$ & 347.590 & 357.240 & 366.530 \\
el economy (mpg) & 14.78 & 14.46 & 13.48 \\
\hline
\end{tabular}

